\title{
Cring
}

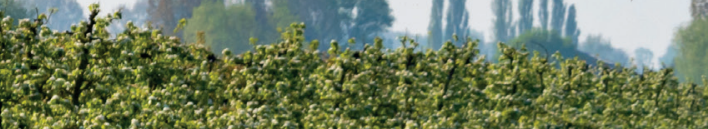

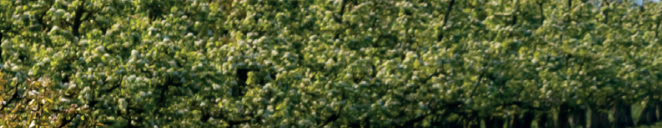

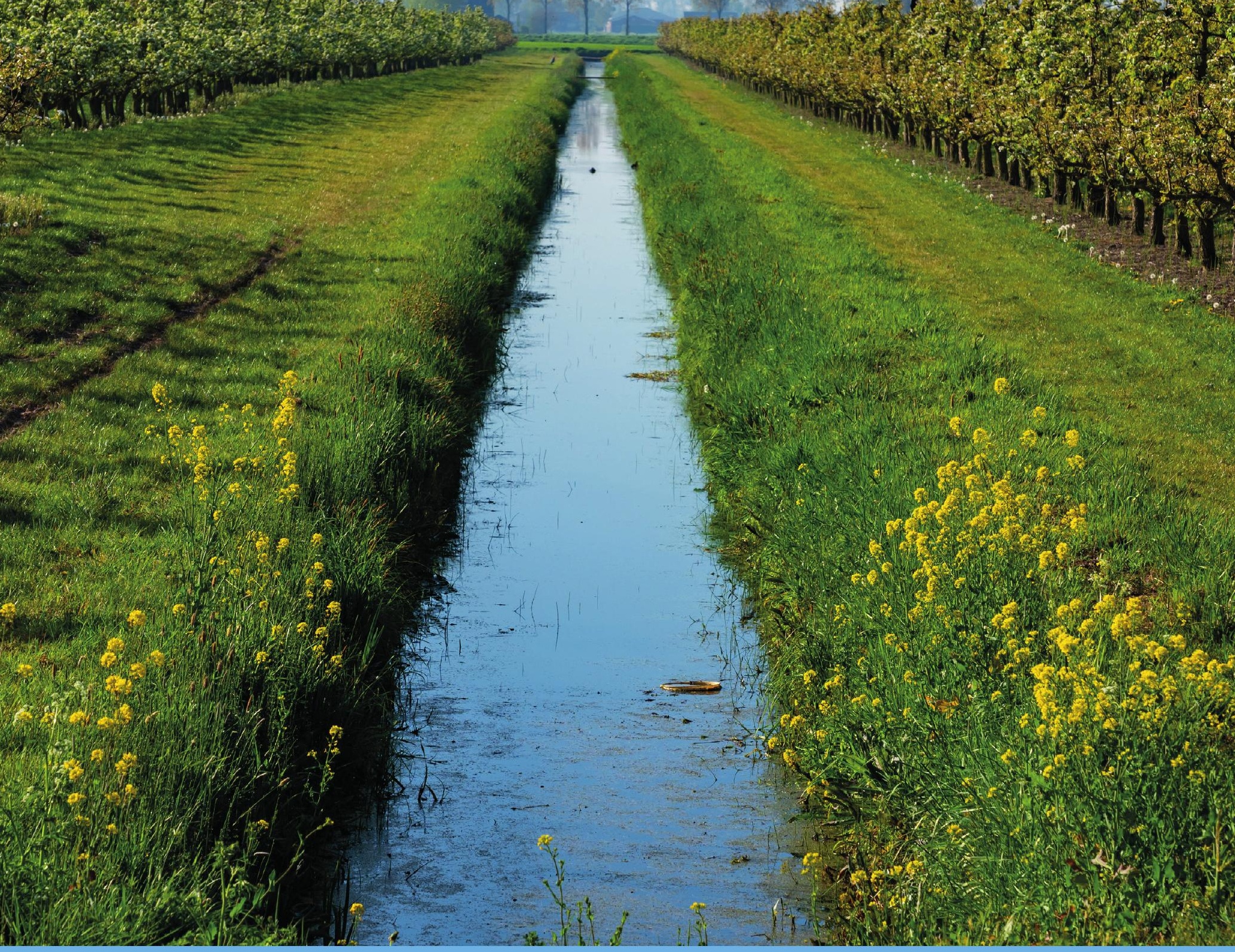

Ditch parameterisation, including the drainage route, for the aquatic exposure assessment of plant protection products in the Netherlands by sideways and upward spraying in fruit orchards

Mechteld ter Horst, Louise Wipfler, Jos Boesten, Harry Massop, Dennis Walvoort 



\section{Ditch parameterisation, including the drainage route, for the aquatic exposure assessment of plant protection products in the Netherlands by sideways and upward spraying in fruit orchards}

Mechteld ter Horst, Louise Wipfler, Jos Boesten, Harry Massop, Dennis Walvoort 
M.M.S. ter Horst, Wipfler, E.L., Boesten, J.J.T.I., H.Th.L. Massop and D.J.J. Walvoort, 2020. Ditch parameterisation, including the drainage route, for the aquatic exposure assessment of plant protection products in the Netherlands by sideways and upward spraying in fruit orchards. Wageningen, Wageningen Environmental Research, Report 3017.152 pp.; 47 fig.; 23 tab.; 43 ref.

Plagen en ziekten in fruitbomen en laanbomen worden regelmatig behandeld met gewasbeschermingsmiddelen. Gezien de hoogte van de bomen wordt er gespoten door middel van zijwaartse en opwaartse bespuitingen. Voor het bepalen van de risico's van deze gewasbeschermingsmiddelen voor aquatische organismen in kavelsloten naast fruitbomen wordt gebruik gemaakt van zogenaamde blootstellingscenario's die onderdeel vormen van een getrapte risicobeoordeling. Deze risicobeoordeling vormt onderdeel van de toelating van gewasbeschermingsmiddelen. Dit rapport beschrijft de hydrologische parameterisatie van het model van de kavelsloot naast fruitboomgaarden, onderdeel van blootstelling-scenario's voor fruitbomen in Nederland. Deze blootstelling-scenario's bevatten naast spray drift, net als in de Europese blootstellingsscenarios voor de risicobeoordeling voor aquatische organismen, ook drainage als aanvoerroute van gewasbeschermingsmiddelen in de kavelsloot Als zodanig kunnen deze scenario's onderdeel gaan vormen van de toelatingsprocedure van gewasbeschermingsmiddelen in Nederland. Dit rapport is een vervolg op WEnR rapport 2850. In aanvulling op de hydrologische parameterisatie beschreven in WEnR rapport 2850, is de drainage aanvoerroute naar de sloot toegevoegd als onderdeel van de hydrologische parameterisatie.

Pests and diseases in fruit-orchards and lane tree-nurseries are frequently treated with pesticides, that are applied by sideways or upward spraying. To assess the risk to aquatic organisms associated with the application of these pesticides, specific scenarios are required as part of a tiered assessment scheme. In these scenarios, next to spray drift, drainage is included as well as entry route of pesticide in the ditch. This report describes the hydrological parameterisation of the edge-of-field ditch model next to fruit-orchards. This parameterised model is part of the Dutch exposure assessment scenarios for fruit-orchards. This report is an update of WEnR report 2850. In addition to the hydrological parameterisation described in WEnR report 2850, the drainage entry route to the ditch is now part of the hydrological parameterisation described.

Keywords: exposure assessment, risk assessment, pesticides, sideways and upward spraying, surfacewater, fruit-orchards, drainage, spray drift

The pdf file is free of charge and can be downloaded at https://doi.org/10.18174/524224 or via the website www.wur.nl/environmental-research (scroll down to Publications - Wageningen Environmental Research reports). Wageningen Environmental Research does not deliver printed versions of the Wageningen Environmental Research reports.

2020 Wageningen Environmental Research (an institute under the auspices of the Stichting Wageningen Research), P.O. Box 47, 6700 AA Wageningen, The Netherlands, $\mathrm{T}+31$ (0)317 4807 00, www.wur.nl/environmental-research. Wageningen Environmental Research is part of Wageningen University \& Research.

- Acquisition, duplication and transmission of this publication is permitted with clear acknowledgement of the source.

- Acquisition, duplication and transmission is not permitted for commercial purposes and/or monetary gain.

- Acquisition, duplication and transmission is not permitted of any parts of this publication for which the copyrights clearly rest with other parties and/or are reserved.

Wageningen Environmental Research assumes no liability for any losses resulting from the use of the research results or recommendations in this report.

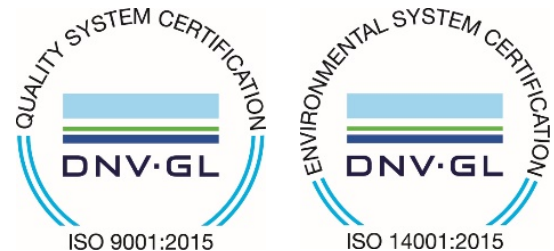

ISO 9001:2015
In 2003 Wageningen Environmental Research implemented the ISO 9001 certified quality management system.

Since 2006 Wageningen Environmental Research has been working with the ISO 14001 certified environmental care system.

By implementing the ISO 26000 guideline, Wageningen Environmental Research can manage and deliver its social responsibility. 


\section{Contents}

$\begin{array}{ll}\text { Preface } & 5\end{array}$

$\begin{array}{ll}\text { Summary } & 7\end{array}$

$\begin{array}{ll}\text { Samenvatting } & 11\end{array}$

1

$\begin{array}{ll}\text { Introduction } & 15\end{array}$

$\begin{array}{lll}1.1 & \text { Background } & 15\end{array}$

1.2 The SPEXUS model and the TOXSWA meta-model 16

1.3 Objectives 18

$\begin{array}{lll}1.4 & \text { Starting points, approach and reading guidance } & 18\end{array}$

2.1 Focus on Rivierenland area $\quad 20$

2.2 Data sources $\quad 21$

2.2.1 Rivierenland: hydrodynamic model SOBEK $\quad 21$

2.2.2 Rivierenland: groundwater model, Moria $2.2 \quad 22$

$\begin{array}{lll}2.3 & \text { Flow velocities by SOBEK and Moria } & 25\end{array}$

$\begin{array}{ll}2.3 .1 \text { SOBEK } & 25\end{array}$

2.3.2 Moria $\quad 25$

2.4 Flow velocity: extension of time-series $\quad 29$

2.4.1 Direct sampling $\quad 29$

2.4.2 Results 31

2.4.3 Residence times $\quad 34$

2.4.4 Discussion $\quad 35$

3 Ditch- and landscape geometry $\quad 37$

$\begin{array}{lll}3.1 & \text { Ditch dimensions } & 37\end{array}$

3.2 Positioning of the ditch in the polder landscape $\quad 37$

3.2.1 Distance between ditches 38

$\begin{array}{ll}3.2 .2 \text { Fruit orchard sizes } & 38\end{array}$

$\begin{array}{ll}3.2 .3 \text { Final configuration } & 39\end{array}$

$\begin{array}{lll}3.3 & \text { Water depths } & 41\end{array}$

4 Drainpipe contribution $\quad 43$

$\begin{array}{lll}4.1 & \text { Introduction } & 43\end{array}$

4.2 Hydrological parameterisation $\quad 43$

4.2.1 Soil type $\quad 44$

4.2.2 Soil physical properties $\quad 44$

4.2.3 Macropore geometry 44

$\begin{array}{ll}4.2 .4 & \text { Drainage } \\ 4.2 .5 & 45\end{array}$

4.2.5 Lower boundary condition $\quad 45$

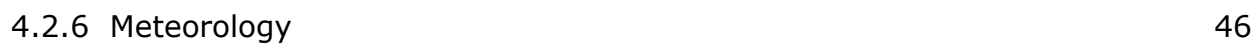

4.3 Crop specific issues in the parameterisation: $\quad 47$

4.3.1 Geometry of the orchard system and impact on the water balance $\quad 47$

4.3.2 Approach for the simulation $\quad 47$

4.3.3 Estimation of crop factors and LAI $\quad 47$

4.3.4 Irrigation $\quad 50$

4.3.5 Further crop parameterisation issues $\quad 51$

4.4 Effect of the new parameterisation on the drainage fluxes $\quad 51$

4.5 Final drain pipe contribution to the ditch $\quad 54$ 
5.1 Schematisation $\quad 59$

$\begin{array}{lll}5.2 & \text { Parameterisation } & 60\end{array}$

$\begin{array}{lll}5.3 & \text { Calibration } & 62\end{array}$

5.4 Result: Hydrology of the parameterised ditch 63

5.4.1 Water depth and discharge $\quad 63$

$\begin{array}{ll}5.4 .2 \text { Water balances } & 67\end{array}$

5.4.3 Effect of drainage on the discharge in the SWQN ditch 69

$\begin{array}{lll}5.5 & \text { Discussion } & 71\end{array}$

$\begin{array}{llr}6 & \text { Sediment characterisation } & 74\end{array}$

$\begin{array}{lll}6.1 & \text { Introduction } & 74\end{array}$

6.2 Sediment properties measured by de Heer (1979) and Adriaanse (2015) 75

6.2.1 Sediment properties measured by de Heer (1979) 75

6.2.2 Sediment properties measured by Adriaanse et al. (2015) 76

$\begin{array}{lll}6.3 & \text { Considerations } & 78\end{array}$

$\begin{array}{ll}\text { 6.3.1 Averaging over time and space } & 78\end{array}$

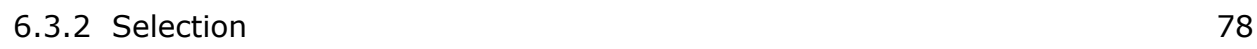

$\begin{array}{ll}\text { 6.3.3 Sediment profile over the depth } & 79\end{array}$

6.4 Ditch properties to be used in the parameterisation 80

$\begin{array}{lll}6.5 & \text { Tortuosity } & 80\end{array}$

$\begin{array}{lll}6.6 & \text { Suspended solids } & 81\end{array}$

$\begin{array}{lll}6.7 & \text { Sediment discretisation } & 81\end{array}$

$\begin{array}{llr}7 & \text { Water temperatures } & \mathbf{8 2}\end{array}$

$8 \quad$ Conclusions and recommendations $\quad 83$

$\begin{array}{ll}\text { List of Abbreviations } & 85\end{array}$

$\begin{array}{ll}\text { References } & 86\end{array}$

Annex $1 \quad$ Tielerwaard: Comparison SOBEK- Moria flow velocities $\quad 89$

$\begin{array}{lll}\text { Annex } 2 & \text { SWAP parameterisation of the Andelst field site } & 92\end{array}$

Annex 3 Template PEARL input files *.prl for the Dutch upwards and sideways spraying in fruit scenario $\quad 95$

$\begin{array}{lll}\text { Annex } 4 & \text { Background information SWQN parameterisation } & 119\end{array}$

Annex 5 Artefacts in discharges and water depths calculated with SWQN

Annex 6 Sediment properties of selected ditches measured by Adriaanse et al.

$\begin{array}{lll}\text { Annex } 7 & \text { Hydrological responses } & 133\end{array}$

Annex 8 Relation between the year numbers of the synthetic velocity time-series and those used the SWAP, PEARL, SWQN and TOXSWA simulations

Annex 9 Meteorological data as input in the TOXSWA model 


\section{Preface}

Pests and diseases in fruit-orchards and lane tree-nurseries are frequently treated by sideways or upward spraying of pesticides. To assess the risk to aquatic organisms associated with the application of these pesticides, specific scenarios are required as part of a tiered assessment scheme. The risk assessment is part of the authorization procedure of plant protection products in the Netherlands.

This report is produced within the framework of a Dutch Working Group appointed to develop exposure scenarios specific for sideways and upward spraying of pesticides by the Dutch Ministry of Agriculture, Nature and Food Quality and the Ministry of Infrastructure and Water Management. These scenarios are intended to be used in the registration procedures of plant protection products in the Netherlands.

The report describes the hydrological parameterisation of the evaluation ditch model, including the entry route drainage. It is an update of Wipfler et al. (2018) in which the hydrological parameterisation of a water course without drainage input is described.

As drift deposition was assumed to be the dominant pathway, in 2015, the Working Group decided not to include drainpipe emissions, with the caveat that this approach required checking with the highest Drift Reduction Technique class (DRT99). This presumption was used as the starting point of the hydrological parameterisation described in Wipfler et al. (2018). However, example calculations have indicated that the contribution from the drainpipe to the exposure in fruit crops cannot be ignored (Boesten et al., 2018). In 2018 it was decided to include the drainage input in the assessments. Therefore the hydrological parameterisation of Wipfler et al. (2018) had to be updated. The new parameterisation of the hydrology (including entries of drainage water in to the ditch) is described in this report. For the sake of completeness large parts of the report of Wipfler et al. (2018) are repeated in this report

The output of the parameterised hydrological model feeds into the evaluation-ditch-model that calculates the Predicted Environmental Concentration for the entry routes spray drift deposition and drainage.

All models will become part of the exposure assessment tool DRAINBOW, which is intended to be used in the environmental risk assessment process of pesticides used in arable crops, as well as in fruit orchards in the Netherlands.

We would like to thank the following (former) members of the Working Group for their input and discussions:

\begin{tabular}{ll}
\hline Henk-Jan Holterman & Wageningen Plant Research \\
\hline Jan van der Zande & Wageningen Plant Research \\
\hline Ton van der Linden & National Institute for Public Health and the Environment \\
\hline Aaldrik Tiktak & Netherlands Environmental Assessment Agency \\
\hline Paulien Adriaanse & Wageningen Environmental Research \\
\hline
\end{tabular}

We are also indebted to Roel Velner and Hella Pomarius of the Rivierenland Water Board for providing the hydrological models and for the lively discussions. 


\section{Summary}

Aquatic risk assessment is part of the Dutch registration procedure of pesticides. Simulation models are used to support the assessment of the exposure concentrations in surface water. In an ideal case, these models could simulate all possible situations in the Netherlands. However, this is currently not feasible and therefore exposure scenarios are used. With the aid of this scenario pesticide exposure concentrations in surface water that are equal or higher than 90 percent of all possible situations in the Netherlands are calculated. Different scenarios are developed for different types of application methods of plant protection products; including a scenario for the application of sideways and upward spraying of plant protection products in fruit-orchards. Several simulations models that are coupled to each other are needed to calculate exposure concentrations in surface water as result of this specific application type. The parameterisation of these different simulation models comprise the exposure scenario for this specific application type. The hydrology in the evaluation ditch is an integral part of the simulated system.

This report describes the hydrological parameterisation of the evaluation ditch as part of the Dutch exposure assessment procedure for sideways and upward spraying of pesticides in fruit-orchards. These scenarios are required as part of a tiered assessment scheme for assessing the risk to aquatic organisms associated with the application of plant protection products in Dutch fruit-orchards. The risk assessment is part of the authorization procedure of plant protection products in the Netherlands.

The hydrological parameterisation is part of and builds further on the general scenario selection procedures which are followed by the Working Group. Hence, the ditch parameterisation is a further elaboration based on initial assumptions by the Working Group, with the final aim of including all (complex) pesticide fate processes in the pesticide fate simulations. The scenario selection procedure (not part of this report) resulted in the selection of (the geometry and water depth of) one edge-offield ditch of the hydrotype, 'Betuwe stroomruggronden', for all scenarios. The selected ditch is of the class 'secondary ditch' according to the classifications used by the TOP10 vector-map. Dutch water boards distinguish between summer- and winter water depths. This was accounted for in the scenario selection procedure. The difference between the winter and summer water depths of the selected ditch was less than $5 \mathrm{~cm}$.

The management area of the Rivierenland Waterboard is the area in the Netherlands with the highest density of fruit-orchards. Ditches in this area were assumed to be representative for the evaluation ditch. For information on the flow velocity, the Rivierenland Water Board was approached. This Water Board has two high-resolution calibrated model types: one hydrodynamic model (SOBEK) and one high-resolution groundwater model (Moria).

The flow velocities derived with the groundwater model Moria were used in the further analysis. One hundred and ten pre-selected time series of flow velocities were used to derive further velocities, based on dominant hydrotype and fruit-orchard density in the correspondent 'peilgebied'. Each time series had a length of nine years. A statistical direct sampling algorithm was used to sample a synthetic signal out of the time series of flow velocities. The constructed time series had a length of 27 years. The flow velocities were not correlated to real weather years and are therefore described here as a 'synthetic time series'.

Median (absolute) flow velocity of the derived synthetic time series is $177 \mathrm{~m} / \mathrm{d}$. In the summer, the median velocity was smaller $(77 \mathrm{~m} / \mathrm{d})$, and in the winter it was higher $(369 \mathrm{~m} / \mathrm{d})$. The median summer- and winter velocities were higher than in the current Dutch evaluation ditch and also higher than in the FOCUS surface water ditches. The velocities are considered in line with those in ditches next to fruit orchards, however, verification of the derived flow velocities with measurements is suggested. 
The evaluation ditch has a length of $300 \mathrm{~m}$, with the evaluated section of the ditch located in the centre (from 100-200 m). Based on GIS analysis of orchard sizes and ditch lengths in the Rivierenland area, the size of the orchard located next to the evaluated section of the ditch was set to 1.4 hectares, with a depth of $140 \mathrm{~m}$ perpendicular to the evaluation ditch. The ditch is discretised into segments of $10 \mathrm{~m}$ each.

The drainage water fluxes were calculated with the agrohydrological model, SWAP (Soil, Water, Atmosphere Plant). SWAP is coupled to the behaviour and emissions of pesticide soil-plant systems model, PEARL and simulates the hydrological fluxes. PEARL simulates pesticide fluxes in the drainage water which are fed in to the pesticide fate and behaviour in surface water and underlying sediment model, TOXSWA (TOXic substances in Surface Waters). TOXSWA simulates the Predicted Environmental Concentration in surface water to be used in the procedure for assessing the risks of pesticide use to aquatic organisms.

The SWAP agrohydrological model was parameterised to calculate the drain water flow. The parameterisation is heavily based on the approach used for the arable crop scenario in which the Andelst experimental site is used. Irrigation, evapotranspiration and hence leaching to the drain pipes differs between the tree strips and the grass strips that lay in between the tree strips. Therefore, the hydrology of the trips were simulated separately and the drain flows were merged to obtain the drain flow from the orchard.

The typical geometry of a Dutch apple orchard consists of tree strips with bare soil beneath the trees with a width of $1 \mathrm{~m}$. Between the tree rows, there are grass strips which are about $2 \mathrm{~m}$ wide. The grass and tree strips are simulated separately by the SWAP-PEARL model and the total drain flow (including pesticides) is added to the evaluation ditch.

The dynamic hydrological model (SWQN) was used to simulate the hydrology of the evaluation ditch and as such to downscale the daily flow velocities to hourly discharge and to obtain water depth in accordance with the flow velocities. The SWQN was calibrated, such that, given the time-series of flow velocities, the simulated water depths were in line with water depths used in the scenario selection procedure, and consistent with Rivierenland water management practices. Drainage water fluxes calculated with the SWAP model were input in to the SWQN model. The simulations with SWQN were carried out over a period of 20 years.

Discharges and water depths per hour and per segment were outputs of the model to be used as input for the TOXSWA model. The TOXSWA model runs for 20 years, with the first five years to establish an initial concentration level in the sediment ('warming up period').

The TOXSWA model simulates pesticide fate and behaviour in water- and in sediment. Sediment bulk density, porosity and organic matter content are important properties that impact the calculated water and sediment concentrations. A literature survey resulted in a limited number of possible sediment property sources. Two Dutch sample locations were selected, covering the range of possible sediments and sediment properties. The impact of the selected two types of sediments should be assessed via example calculations, and one sediment should be selected based on this assessment (not this report).

The temperature in the ditch water and sediment was calculated from weather data. Hourly weather data from the Herwijnen meteorological station, located in the Rivierenland area, were used.

Summarizing, models parameterized as part of the exposure scenario for sideways and upward spraying of plant protection products in Dutch fruit orchards are:

- SWAP, which simulates the drainage (water) fluxes. SWAP is an integral part of the PEARL model;

- SWQN, which simulates the flow velocities and water depths in the evaluation ditch based on i) an at the upper boundary imposed synthetic time series of flow velocities derived from model output of an high resolution groundwater model (Moria) of the Rivierenland Water Board and ii) the by SWAP calculated drainage water fluxes;

- PEARL, which simulates the substance mass in the drainage water;

- TOXSWA, which simulates the behaviour of substance in the evaluation ditch. 
The following parts of this model instrumentation are elaborated in this report: i) the parameterisation of SWAP, ii) the derivation of the synthetic time series of flow velocities via model output of Moria iii) the parameterisation of SWQN and the parameterisation of environmental characteristics (meteorology and sediment) in TOXSWA.

This report serves as a technical report providing the description of the hydrological parameterisation of the Dutch exposure assessment scenarios for sideways and upward spraying of plant protection products in fruit-orchards. 


\section{Samenvatting}

Beoordeling van de risico's van het gebruik van gewasbeschermingsmiddelen voor waterorganismen is een onderdeel van de toelatingsprocedure van deze middelen in Nederland. In de beoordelingsmethodiek wordt gebruik gemaakt van een getrapte benadering. Onderdeel van deze benadering is het gebruik van simulatiemodellen om de blootstellingsconcentraties in het oppervlakte water te berekenen. Daarbij wordt er gebruik gemaakt van een zogenaamd blootstellingscenario. Met behulp van dit scenario wordt de concentratie in het oppervlaktewater berekent dat hoger of gelijk is aan 90 procent van de situaties in Nederland. Verschillende toepassingen van gewasbeschermingsmiddelen hebben elke een eigen scenario; zo ook de toepassing van zijwaartse en opwaartse bespuitingen van gewasbeschermingsmiddelen in boomgaarden. Voor de berekening van bloostellingsconcentraties van gewasbeschermingsmiddelen als gevolg van deze specifieke toepassing zijn verschillende aan elkaar gekoppelde simulatie modellen nodig. De parameterisaties van al deze modellen vormen samen het bloostellingsscenario voor deze specifieke toepassing. De hydrologie in de evaluatie sloot is onderdeel van het systeem dat gesimuleerd wordt. Dit rapport is een technisch achtergronddocument en beschrijft de parameterisatie van de modellen die gebruikt worden voor de simulatie van de hydrologie van de evaluatiesloot. De evaluatiesloot vormt onderdeel van de blootstellingsscenarios ontwikkeld voor de Nederlandse evaluatieprocedure voor zijwaartse en opwaartse bespuitingen van gewasbeschermingsmiddelen in boomgaarden. De scenario's zijn een vereist onderdeel van de getrapte benadering voor de beoordeling van het risico van het gebruik van gewasbeschermingsmiddelen voor waterorganismen. Deze risicobeoordeling is onderdeel van de toelatingsprocedure van gewasbeschermingsmiddelen in Nederland.

De parameterisatie van de hydrologie in de sloot bouwt voort op de scenario-selectieaanpak die is gevolgd door de verantwoordelijke werkgroep. Deze aanpak leidde tot de selectie van één kavelsloot van het hydrotype 'Betuwe stroomruggronden'. De geselecteerde sloot is verder van het type secundaire sloot volgens het classificatiesysteem van de TOP10 vectorkaart. De parameterisatie beschreven in dit rapport is een verder invulling van slooteigenschappen om zo alle relevante (complexe) processen te kunnen simuleren.

In Nederland wordt er door watermanagers onderscheid gemaakt in zomer- en winterpeil. Het verschil in de zomer- en winterpeil van de geselecteerde sloot is kleiner dan $5 \mathrm{~cm}$.

Voor de stroomsnelheden in de evaluatiesloot is gebruik gemaakt van modeluitkomsten van hydrologische modellen van het waterschap Rivierenland. Rivierenland heeft in haar beheergebied het grootste areaal fruit van alle waterschappen. Het waterschap heeft twee typen hoge resolutie hydrologische modellen in gebruik, een hydrodynamisch model (SOBEK) en een grondwatermodel (Moria).

De stroomsnelheden afgeleid van Moria-uitkomsten zijn gebruikt voor verdere bewerking. 110 peilgebieden zijn geselecteerd op basis van hydrotype (Betuwe stroomruggronden) en boomgaarddichtheid. Van elk van deze peilgebieden is een tijdserie van 9 jaar afgeleid met dagelijkse stroomsnelheden. Vervolgens is een 'direct sampling' techniek toegepast om een tijdserie van 27 jaar te construeren. De resulterende tijdserie heeft geen relatie tot echte weerjaren en wordt om deze reden aangeduid als een synthetische tijdserie.

De mediane (absolute) waarde van de resulterende tijdserie is $177 \mathrm{~m} / \mathrm{d}$, waarbij in de zomer de mediane waarde $77 \mathrm{~m} / \mathrm{d}$ is en in de winter $369 \mathrm{~m} / \mathrm{d}$. Deze waarden zijn hoger dan die van het huidige Nederlandse oppervlaktewater scenario en ook hoger dan die van het EU FOCUS oppervlaktewater scenario en sluiten betere aan bij stroomsnelheden die je kunt verwachten in sloten naast fruitboomgaarden in Nederland. We bevelen aan om de afgeleide stroomsnelheden te verifiëren aan de hand van metingen. Daarvoor is het nodig metingen aan stroomsnelheden te verrichten of verschillende locaties in Nederland. 
De evaluatiesloot heeft een lengte van $300 \mathrm{~m}$ en bestaat uit segmenten van $10 \mathrm{~m}$. De grootte van de boomgaard die behandeld wordt met een gewasbeschermingsmiddel is 1.4 ha. Het veld ligt loodrecht op de sloot en heeft een diepte van $140 \mathrm{~m}$. Zowel de grootte van het perceel als de afstand tussen sloten zijn afgeleid van kaarten in het Rivierenland beheergebied.

Drainage (water) fluxen zijn berekend met het agro-hydrologische model, SWAP. Het SWAP model is gekoppeld aan het PEARL model dat de pesticide fluxen in het drainage water simuleert. Deze worden aangeleverd aan het TOXSWA model dat de concentraties van bestrijdingsmiddelen in de sloot simuleert. Voor de parameterisatie van SWAP is een vergelijkbare aanpak gekozen als voor het akkerbouw scenario. Daarbij is gebruik gemaakt van de experimentele site in Andelst. Irrigatie, verdamping, en daarmee de afvoer naar de drains verschilt tussen de bomenrijen en de tussenliggende grasstroken. Daarom is de hydrologie van de bomenrijen en de grasstroken afzonderlijk gesimuleerd. De berekende drainafvoer voor een boomgaard is vervolgens de gewogen som van de afzonderlijke bijdragen. Vanwege een beperkte dataset nodig voor de onderrandvoorwaarde in het model zijn er simulaties gedaan voor een periode van 20 jaar. Hierbij zijn meteorologische data van het weer station Herwijnen gebruikt.

Een typisch Nederlandse appel boomgaard bestaat uit een boomrij met kale grond beneden de bomen ( $1 \mathrm{~m}$ breed). Tussen de bomenrijen liggen grasstroken van ca. $2 \mathrm{~m}$ breed. De grasstroken en de boomstroken worden apart gesimuleerd in het SWAP-PEARL model, waarbij de gezamenlijke drain afvoer geloosd wordt in de evaluatiesloot.

Het dynamische hydrologische model, SWQN is zodanig gekalibreerd dat, gegeven de waterstromentijdserie van 27 jaar, de berekende waterdiepte consistent is met eerdere aannames gedaan in de scenario selectie procedure en met gangbare water management praktijken van Rivierenland. Ook is bij de calibratie van de stuw hoogte in het model rekening gehouden met het verschil in zomer en winter peil.

De verkregen tijdsreeks aan stroomsnelheden en waterdiepten uit SWQN en de door de SWAP-PEARL berekende drainage fluxen (volume water en massa stof) zijn gebruikt als invoer voor het TOXSWA model dat het stofgedrag vervolgens voor de rekening neemt.

Bulkdichtheid, porositeit en organische stofgehalte zijn sedimenteigenschappen die impact kunnen hebben op de berekende concentraties in het slootwater. Uit literatuuronderzoek kwamen een beperkt aantal bruikbare meetlocaties van sedimenteigenschappen naar voren waarvan er twee zijn geselecteerd. Uit voorbeeldberekeningen moet blijken welk van de twee locaties het beste kan worden geselecteerd voor de uiteindelijke evaluatiesloot (niet in dit rapport).

Temperatuur in de sloot wordt berekend met TOXSWA op basis van weercondities. De uurlijkse weergegevens van het meteostation Herwijnen worden gebruikt voor het berekenen van de water- en sedimenttemperatuur.

Het complete blootstellingsscenario voor zijwaartse en opwaartse bespuitingen van gewasbeschermingsmiddelen in boomgaarden bestaat uit parameterisaties van de modellen:

- XSPEXUS, dat de drift percentages die gedeponeerd worden op de evaluatie sloot berekend;

- SWAP, dat de drainage water fluxen berekent. SWAP is een integraal onderdeel van PEARL;

- SWQN, dat de stroomsnelheden and waterdiepten in de evaluatiesloot berekent op basis van i) een aan de bovenrand opgelegde synthetische tijdsreeks van stroomsnelheden verkregen uit modeluitkomsten van een hoge-resolutie grondwater model (Moria) van het waterschap Rivierenland en ii) de door SWAP berekende drainage water fluxen;

- PEARL, dat de massa gewasbeschermingsmiddel in de drainafvoer berekent;

- TOXSWA, dat het gedrag van gewasbeschermingsmiddel in de evaluatiesloot berekent.

Dit rapport beschrijft de volgende onderdelen van het modelinstrumentarium: i) de parameterisatie van SWAP, ii) de totstandkoming van synthetische tijdsreeks van stroomsnelheden via model uitkomsten van Moria, iii) de parameterisatie van SWQN en de parameterisatie van TOXSWA met betrekking tot de omgevingskenmerken (weer, sediment). 
Dit rapport is bedoeld als technisch document en beschrijft de parameterisatie van het hydrologische deel van de Nederlandse blootstellingsscenarios voor zijwaartse en opwaartse bespuitingen van gewasbeschermingsmiddelen in boomgaarden. 


\section{Introduction}

\section{$1.1 \quad$ Background}

Ditches and streams are often found at short distances from crop fields in the Netherlands. Pesticide use and correspondingly high concentrations of pesticides in edge-of-field water bodies is a major concern for water quality managers.

Consequently, the aquatic ecosystem in edge-of-field water bodies is an important protection goal in the Dutch pesticides risk assessment. The Dutch Government initiated improvement of the methodology for the risk assessment of aquatic organisms by establishing a Working Group to develop new procedures for pesticide exposure assessment in edge-of-field ditches. Over the last years, Dutch exposure scenarios were developed as part of a higher tier assessment methodology for upward and sideways sprayed pesticides, which are commonly used techniques in fruit orchards and tree nurseries. The scenarios enable the calculation of a $90^{\text {th }}$ percentile Predicted Environmental Concentration (PEC) for all considered applications and substance-type combinations.

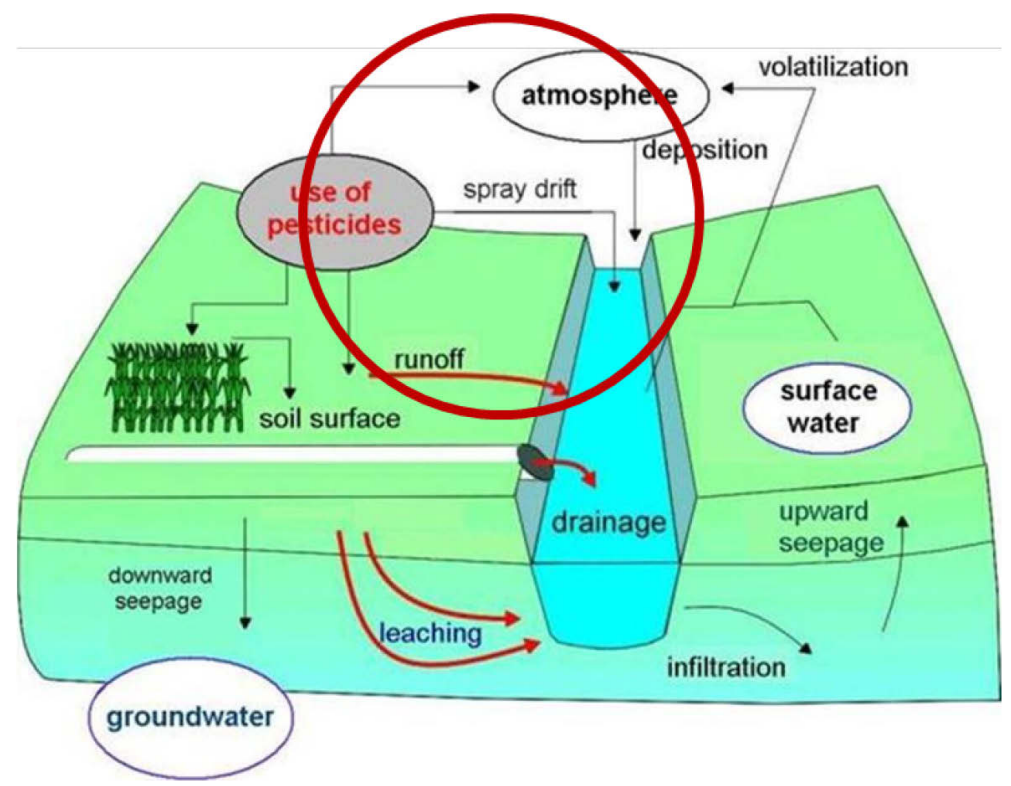

Figure 1.1 Conceptual model of sources and pathways to edge-of-field ditches. Focus of the scenario selection procedure was on spray drift deposition. However, emissions from drainpipes is also part of the scenario.

A modelling approach was followed. The entire area of fruit crops in the Netherlands was considered, and scenarios were selected. The scenario derivation focused on fruit orchards. Predicted Environmental Concentrations (PECs) were calculated for all possible combinations of edge-of-field ditches and fruit orchards, while considering the spatial- and temporal variability of meteorological conditions, crop development stages, water-body types, distance to the water bodies and water depths, as well as orchard orientation. One single location was selected that enabled the calculation of the PEC for one application, for three applications, and for multiple applications; only the temporal percentile for each of these scenarios differed. To cover all application schemes, all other (more complex) application schemes were allocated to one- or combinations of these scenarios. A similar procedure was followed for Drift Reducing Technique (DRT) classes, as well as for crop-free buffer zones, both higher tier options in the risk assessment (for detailed description, see Boesten et al.,2018 and Holterman et al., 2016a). 


\subsection{The SPEXUS model and the TOXSWA meta-model}

To support this approach, a new and sophisticated drift model, SPEXUS, was developed to calculate drift deposition for the entire area of use (Holterman et al., 2016b). Pesticide concentration in surface water was then calculated with a meta-model of TOXSWA that assumes dilution of the incoming drift mass over the wetted cross-section of the water body. For the purpose of the scenario selection, pesticide fate in the receiving watercourse was considered to be sufficiently approximated by this model.

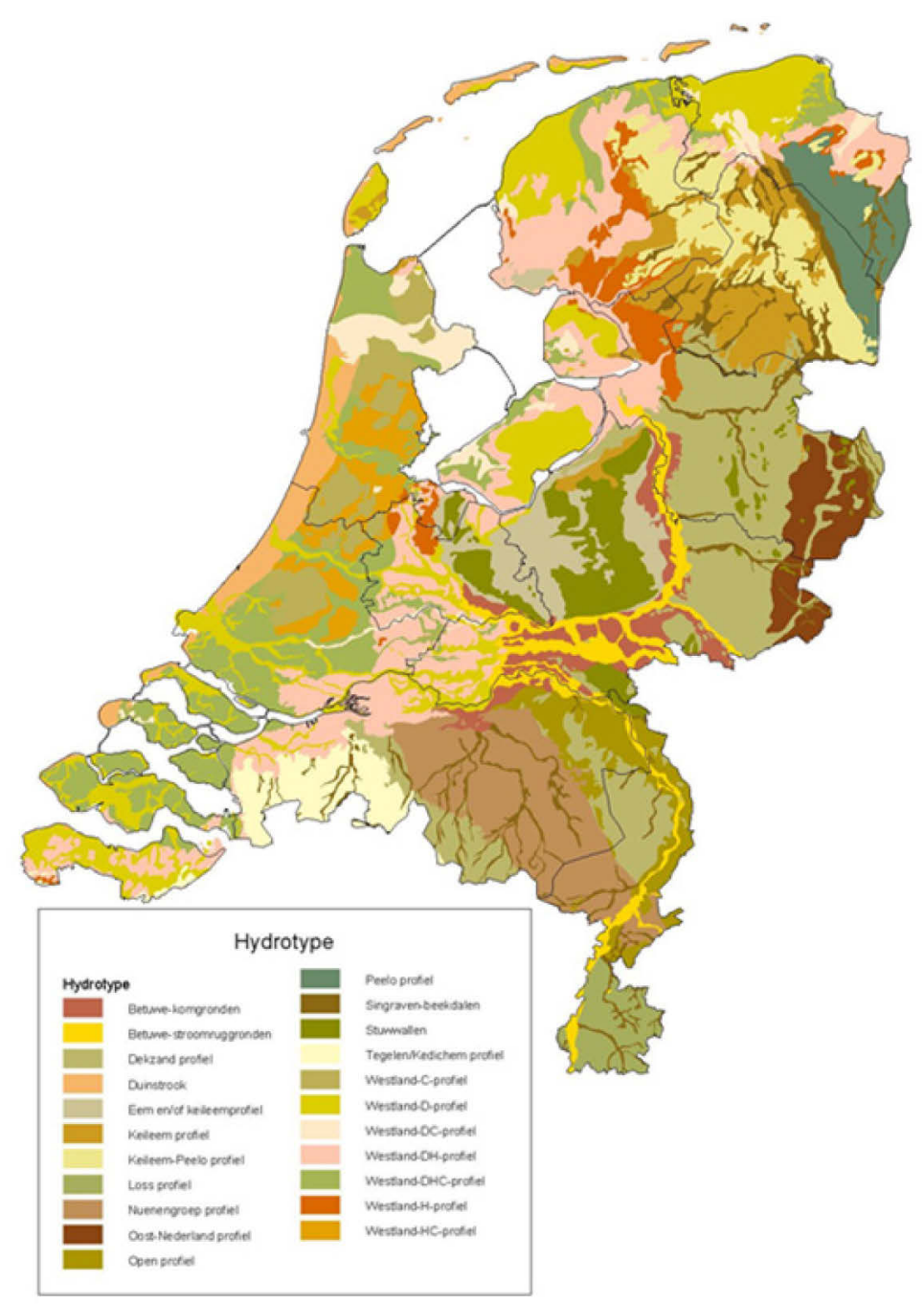

Figure 1.2 Map of hydrotypes in the Netherlands.

Information on the spatial variability of watercourse geometries (specifically water depth, width at the bottom and water table) was obtained through the TOP10 digital vector map of the Netherlands (www.kadaster.nl). The map distinguishes between three ditch classes: i.e. small- or temporarily dry watercourses ('tertiary ditches'); watercourses with a width of less than $3 \mathrm{~m}$ ('secondary ditches'); watercourses with a width of 3-6 m ('primary watercourses'); and watercourses with a width of 6-12 m. Watercourse geometries are known to be correlated with geo-hydrological characteristics of the subsoil (Massop et al. 2006). Based on field inventories, Massop et al. (2006) provided median values and standard deviations of the ditch-geometry characteristics for all combinations of hydrotype and ditch class. The median values were used in the scenario derivation procedure. The map of hydrotypes is shown in Figure 1.2. Table 1.1 shows frequency of occurrence of specific combinations of hydrotypes and region in fruit orchards. The frequency is expressed with the total area of fruit orchards in the Netherlands as $100 \%$. 
Table 1.1 Hydrotype - region combinations as percentage of the total area of fruit orchards. Only the most frequent combinations are shown.

\begin{tabular}{|c|c|c|c|c|c|}
\hline Hydrotype & North Holland & South Holland & Rivierenland & Zeeland & Total \\
\hline Betuwe komruggronden & 0 & 0 & 6.1 & 0 & 6.1 \\
\hline Betuwe stroomruggronden & 0 & 0 & 9.6 & 0 & 9.6 \\
\hline Westland D & 0 & 2.1 & 6.4 & 4.9 & 13.4 \\
\hline Westland DC & 5.7 & 0.5 & 1.1 & 0 & 7.3 \\
\hline Westland DHC & 0.8 & 4.1 & 2.3 & 9.2 & 16.4 \\
\hline Total & 7.6 & 11.1 & 38.1 & 14.9 & 72.4 \\
\hline
\end{tabular}

Most water boards allow for additional water storage in the winter, hence, target water levels are usually lower in summer. Managed water levels, however, differ per water board. In the scenario derivation procedure, water board management was included by using one (winter) water depth for the period; $1^{\text {st }}$ April - $30^{\text {th }}$ September, and one (summer) water depth for the period; $1^{\text {st }}$ October $31^{\text {st }}$ March.

As part of the field inventory, Massop et al. (2006) measured water depth in a wide range of ditches (with a focus on ditches in sandy soils). Measurements were taken in winter times, when the saturation of the soils was highest. In the scenario selection procedure, this value was used for the winter situation and was considered constant over the period; $1^{\text {st }}$ October $-31^{\text {st }}$ March. Hence, the winter water depths in the ditches were based on Massop et al. (2006).

The summer water depths were calculated by adding the difference between the winter and the summer target levels of the water boards to the winter water depths. Winter- and summer water levels were taken from the National Hydrological Instrument (www.nhi.nu). This instrument encompasses data from a target level ('peilvakken') map from the water boards. Only the Western part of the Netherlands has managed surface-water levels ('peilbeheerst'). In the Eastern part, surface water may drain freely and water levels are allowed sink below the target levels. Figure 1.3 shows the frequency distribution of the difference between summer- and winter water depth in areas with fruit orchards for primary- and secondary ditches. Differences may vary between $-20 \mathrm{~cm}$ (target water level in the summer is lower than in the winter) and $+50 \mathrm{~cm}$. The majority of the water level differences lay between $-5 \mathrm{~cm}$ and $+25 \mathrm{~cm}$.

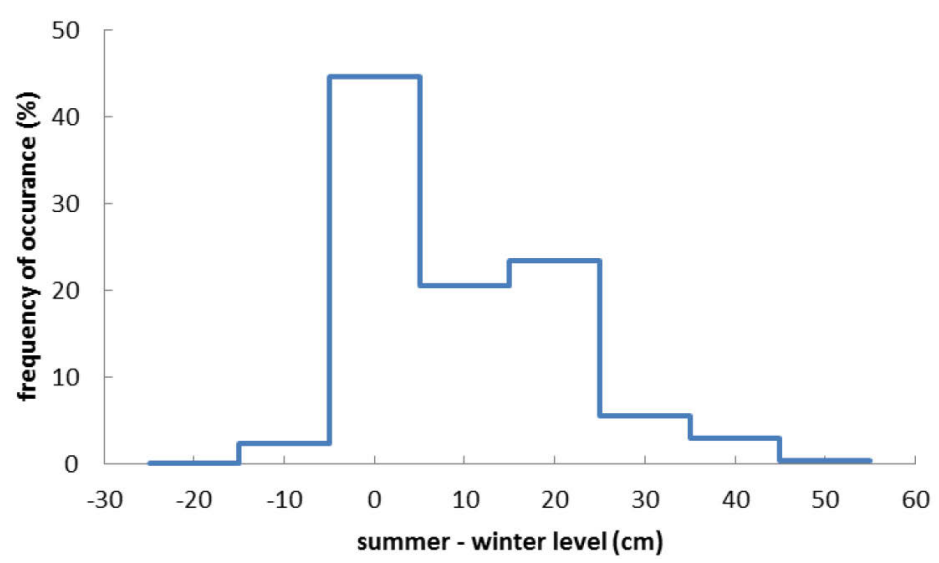

Figure 1.3 Frequency of occurrence of differences in target summer and winter water levels (cm) in Dutch edge-of-field ditches next to fruit orchards for primary-and secondary ditches (source NHI). 


\subsection{Objectives}

In the scenario selection procedure the simplified TOXSWA meta-model was applied to calculate pesticide concentrations in water. The parameterised scenarios should enable the calculation of the Predicted Environmental Concentration (PEC) for complex pesticide application schemes, and for an edge-of-field ditch that is part of the landscape (i.e. connected to other watercourses). The Predicted Environmental Concentration is then the averaged water concentration from $100 \mathrm{~m}$ of evaluation ditch. A more elaborate fate model (i.e. TOXSWA) must be used, that accounts for pesticide fate processes other than dilution only, e.g. transport, sorption and degradation. Additional environmental parameters are needed to parameterise the model.

The objective of the research described in this report is to parameterise the hydrology of the evaluation ditch as part of the scenarios for sideways and upward spraying, while including the drainpipe route and taking the geometric characteristics of the ditch of the scenario that was selected as the starting point. The sediment compartment is also parameterised.

Example calculations with model substances are not included in this report. These will be described in a separate document.

\subsection{Starting points, approach and reading guidance}

Based on the area of use for sideways and upward spraying, one single (scenario) location was selected with different temporal percentiles per application scheme/drift reduction technique. The selected location consists of a fruit orchard with an edge-of-field ditch of the hydrotype, 'Betuwe stroomruggronden'. The ditch is a secondary ditch, according to the classifications used in the TOP10 map. The difference between the summer- and the winter water levels is zero $\pm 5 \mathrm{~cm}$.

As drift deposition was assumed to be the dominant pathway, the Working Group had decided not to include drainpipe emissions, with the caveat that this approach required checking with the highest Drift Reduction Technique class (DRT99). This presumption was used as the starting point of the hydrological parameterisation described in Wipfler et al. (2018). However, example calculations indicated that the contribution from the drainpipe to the exposure in fruit crops cannot be ignored (Boesten et al., 2018). In 2018 it was decided to include the drainage input in the assessments. Therefore, the hydrological parameterisation of Wipfler et al. (2018) needed to be updated. The new parameterisation of the hydrology (including entry of drainage water in to the ditch) is described in this report. For the sake of completeness large parts of the report of Wipfler et al. (2018) are repeated in this report (i.e. Chapters 2, 3, 5 and 6 in Wipfler et al., 2018 are included in this report without any significant changes). Chapter 1 of Wipfler et al. (2018) (also Chapter 1 in this report) is supplemented with information on the drainpipe route. A new chapter (Chapter 4 ) describing the parameterisation of the SWAP model (calculating the drainage water fluxes) is included. Consequently, Chapters 4, 5, 6 and 7 in Wipfler et al. (2018) are renumbered to Chapters 5, 6, 7 and 8. Chapter 4 of Wipfler et al. (2018) (Chapter 5 in this report) is changed significantly; i.e. drainage is part of the hydrological parameterisation of the SWQN model.

Hydrology of the evaluation ditch is simulated with the hydrological model, SWQN (Version 3.03.0; Revision 102). SWQN is a simplified hydraulic model for surface-water systems that simulates water flows and water levels in a schematised network of nodes and sections. Water-flow simulation is based on a simplification of the basic St. Venant Equations. The user can specify a variety of section types, such as open watercourses and weirs, culverts and pumps. Water levels are calculated in the nodes and the differences in water levels between connected nodes are the driving force behind the onedimensional flow (Smit et al., 2009).

Soil water fluxes are simulated with the SWAP model (Kroes et al., 2017). SWAP simulates transport of water and heat in the vadose zone in interaction with vegetation development. The model employs the Richards equation including root water extraction to simulate soil moisture movement in variably 
saturated soils. Also, macroporous flow and water repellence is accounted for. SWAP generates soil water fluxes and in particular drainage water fluxes for the pesticide fate model PEARL (Van den Berg et al., 2016). The PEARL parameterisation is described in a separate report (Boesten et al., in prep.).

Pesticide fate and behaviour in the evaluation ditch is calculated with TOXSWA (TOXic substances in Surface Waters) (Adriaanse, 1996; Adriaanse and Beltman, 2009; Adriaanse et al., 2014). The TOXSWA model has been developed to calculate pesticide concentrations in surface water and sediment. TOXSWA considers transport, degradation, the formation of transformation products, sorption to sediment and suspended solids and volatilisation. Transformation and volatilisation are assumed to be temperature dependent. Sorption to sediment and suspended solids is described by the Freundlich Equation.

The simulation period for the hydrology, the drainage route and the exposure in the evaluation ditch is 20 years. This is different from the simulation period of 26 year for the hydrology in the evaluation ditch as described by Wipfler et al. (2018) i.e. in these simulations the drainage route was not included. Using a simulation period of 20 ( 15 years +5 year warm-up) instead of 26 years is a consequence of using the Andelst parameterisation for calculating the drainage route using the SWAP and PEARL models. The original Andelst dataset was extended to only 15 years (1991 -2005) due to the limited availability on data needed on the lower boundary condition of SWAP (see section 5.2 in Tiktak et al., 2012b).

To simulate a realistic hydrological situation, realistic flow velocities are needed for a period of 20 years. Flow velocities are discussed in Chapter 2.

The ditch geometry and the position in the landscape are discussed in Chapter 3. Water depth is correlated to the water flow velocities and is set by calibration of the model. The conditions used for the calibration of the hydrological model are also discussed in Chapter 3. In Chapter 4 the parameterisation of the SWAP model is described and simulated drainage fluxes are presented. Chapter 5 describes the SWQN hydrological model, including its parameterisation and calibration. Results of the calibration and the final water flow velocities and water depth variability over time are shown and discussed in this chapter. The parameterisation of the sediment is discussed in Chapter 6, and the simulated temperature in Chapter 7. Conclusions and recommendations are discussed in Chapter 8. 


\section{Flow velocities}

\section{$2.1 \quad$ Focus on Rivierenland area}

Flow velocity and water depth are considered key parameters for pesticide concentration in watercourses (e.g. Westein et al., 1998). E.g. high pesticide concentrations are expected to occur in a ditch with low flow velocities, especially in case of repeated application of persistent substances. Good representation of the flow velocity as part of the scenario is, therefore, important, and should be realistic and representative. Water flow velocities vary as a result of variable weather conditions and water-management decisions. The time-series should, therefore, be long enough to reflect the dynamics of fruit-orchard ditches. It was decided to aim for a flow-velocity dataset of at least 20 years plus six years of warming-up period with a higher temporal resolution, e.g. of hours or days.

Forty-three percent of all Dutch fruit orchards are situated in the managed area of the Rivierenland Water Board (see Figure 2.1). The hydrotype, Betuwe stroomruggronden, selected as part of the scenario (see Section 1.3), is mostly located in this area. Therefore, the Rivierenland area was selected as the focal area for the derivation of a representative time-series of flow velocities.

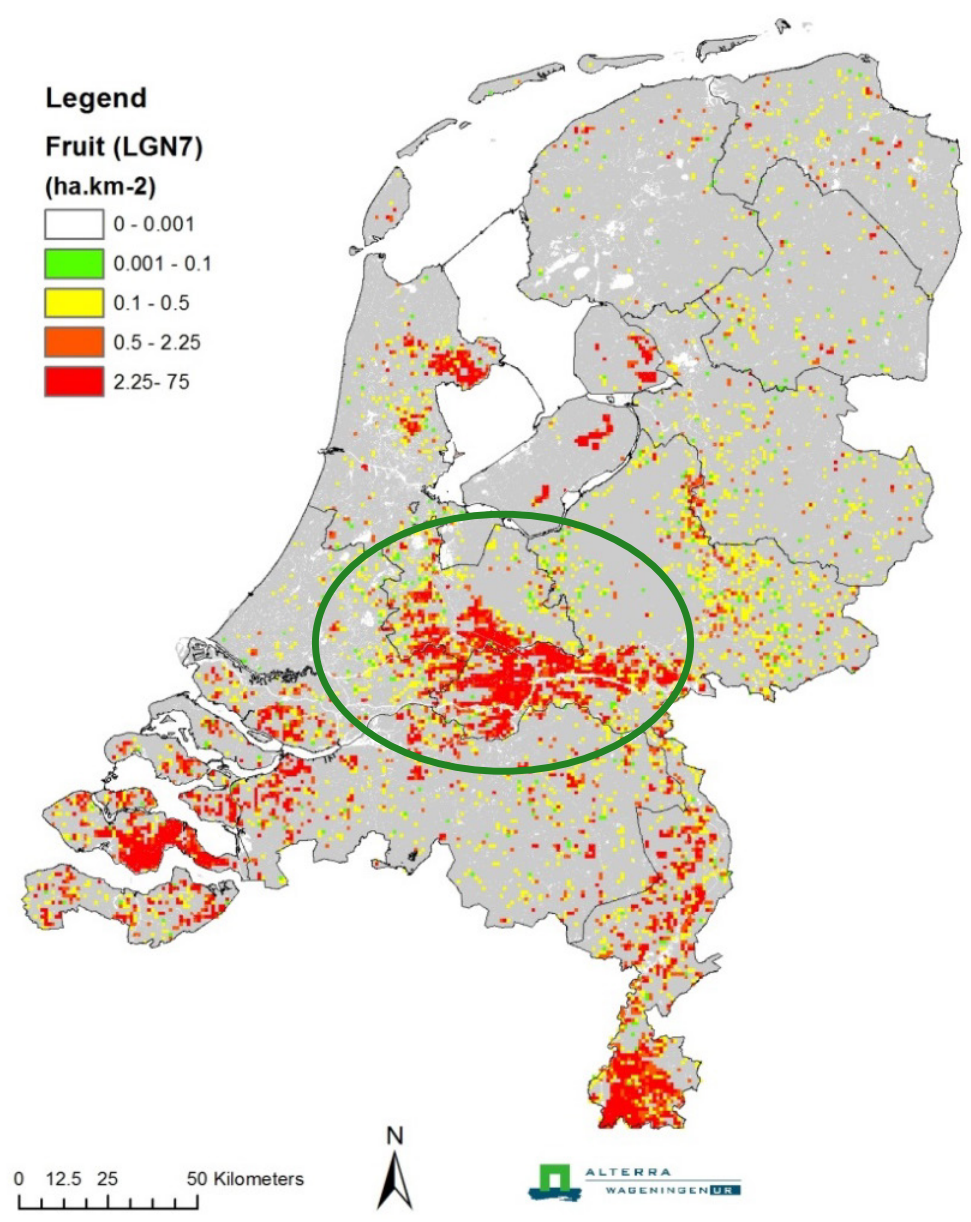

Figure 2.1 Map of density of fruit orchards in the Netherlands based on the LGN7 (Hazeu et al., 2015). The region in the green circle is the Rivierenland area.

As many areas in the Western part of the Netherlands, water levels are managed in the Rivierenland area; individual water-level regimes are applied per 'peilgebied', while differentiating between summer- and winter target levels. These levels are referred to as streefpeilen (target water levels) 
and differ per 'peilgebied'. In Figure 2.2, an example is given of the summer- and winter (target) water levels for one arbitrary chosen location in the Rivierenland area, each colour refers to one 'peilgebied', hereafter referred to as 'target level unit'.

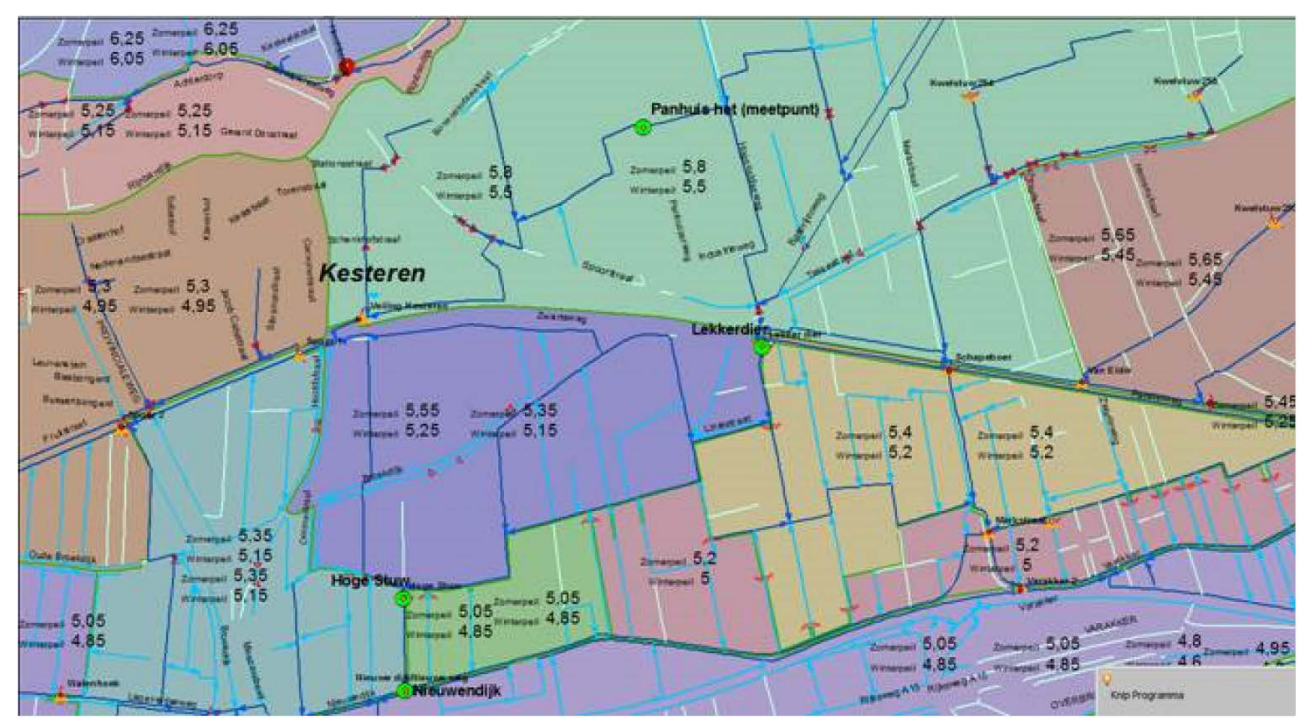

Figure 2.2 Map of an arbitrary example area in the Rivierenland area, indicating the summer-and winter water levels (in $m$ above sea level). Each colour refers to one target level unit (Dutch: peilgebied) with individual target water levels (Dutch: streefpeil).

\subsection{Data sources}

Flow velocities in edge-of-field ditches are not measured systematically, if at all. Water authorities use regional hydrodynamic models to quantify discharges and flow velocities to support decision making associated with storm flow and droughts. The advantage of these models is that they explicitly quantify flow velocities and water depths of the simulated watercourses. The disadvantage of these models is that edge-of-field ditches that only discharge local water from nearby fields, are simulated as a node in a network of larger water bodies; they are considered as of minor importance for regional quantitative water management. Also, the accuracy for low flow of these models is limited. Low-flow conditions are, however, of special interest for water quality simulations.

Water authorities additionally use groundwater models to assess e.g. the impact of groundwater recharges. These models have a high resolution (e.g. $25 \times 25 \mathrm{~m}$ ) and are nested in the Dutch National Hydrological Instrument (www.nhi.nu). They simulate per grid-cell discharges to- and from surface water, as part of the groundwater flow simulation. Drainpipe discharges and run-off overflow discharges to surface water, as well as direct exchange between groundwater and surface water, is simulated and each of these discharges are available as daily output of the model. They can be used to estimate daily surface-water flow velocity dynamics. Auxiliary water in- and outflow across gridcells are not simulated.

Below, the characteristics of the two types of models are described for the Rivierenland area.

\subsubsection{Rivierenland: hydrodynamic model SOBEK}

The Rivierenland Water Board has four hydrological sub-models, which together cover a large part of the managed area, i.e. the sub-models Betuwe \& Linge, Bommelerwaard, Lek \& Linge and Tielerwaard (Figure 2.3). These models are parameterisations of the hydrological model, SOBEK (www.deltares.nl/en/software/sobek). Watercourses are represented by a network of segments, for which the flow velocity is calculated. The SOBEK sub-models simulate hydrological fluxes in larger water bodies only; smaller water bodies are represented by a node in the network of segments. 
Coverage by the model, of ditches next to fruit orchards, was calculated by selecting those ditches that are situated in or next to, a fruit orchard from the TOP10 vector map of the Netherlands, and by making an overlay with SOBEK segments. Table 2.1 gives a summary of the SOBEK sub-models in the Rivierenland area. The last row shows the percentage of coverage, which varies per sub-model between $21 \%$ and $31 \%$ of the total length of water bodies next to fruit orchards in the simulated areas. Hence, more than $70 \%$ of the edge-of-field fruit ditches is not covered by the model, and $69-80 \%$ of the ditches were not considered relevant for the model, probably, because they were too small.

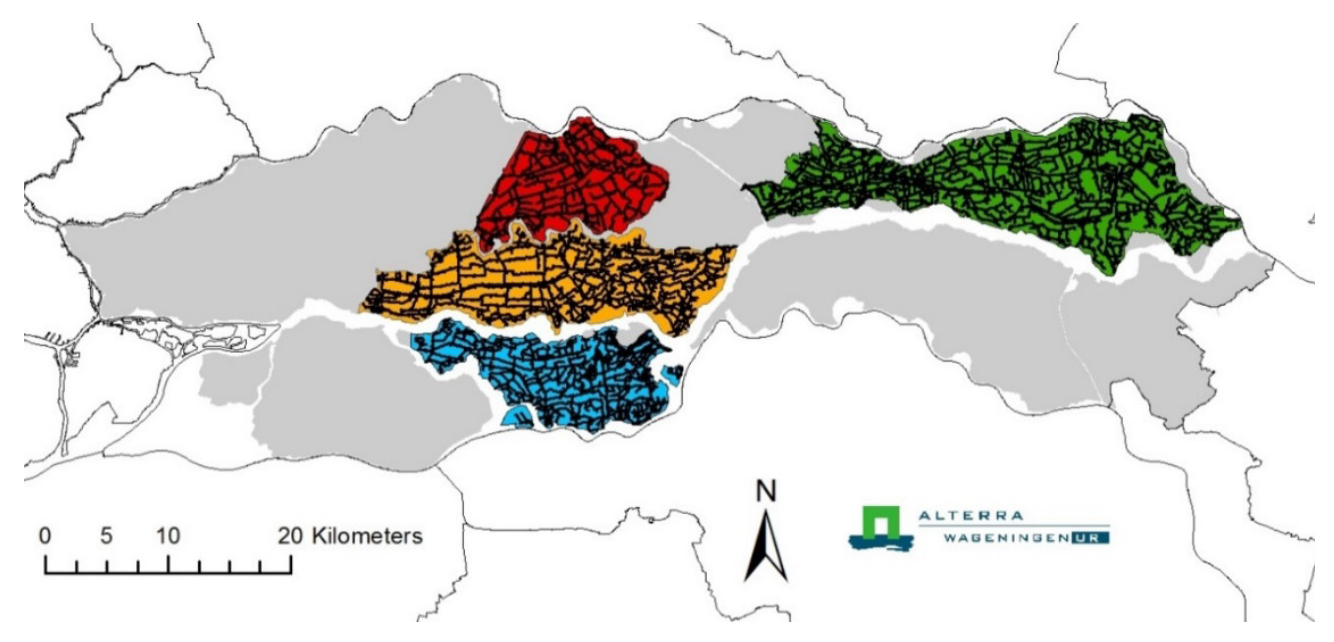

Figure 2.3 Management area of Rivierenland (grey) and the SOBEK sub-models (Betuwe \& Linge (green), Bommelerwaard (blue), Lek \& Linge (red) en Tielerwaard (orange).

Table 2.1 Characteristics of the SOBEK sub-models in the Rivierenland area.

\begin{tabular}{|c|c|c|c|c|}
\hline & Betuwe en Linge & Bommelerwaard & Lek en Linge & Tielerwaard \\
\hline Available simulation period & $1-3--^{\prime} 06-1-4-07$ & $1-1--^{\prime} 05-1-4-{ }^{\prime} 06$ & $1-3--^{\prime} 04-1-4-{ }^{\prime} 05$ & $1-3--^{\prime} 04-1-4-{ }^{\prime} 05$ \\
\hline Output frequency & $0.25 \mathrm{~d}$ & $1 \mathrm{~d}$ & $1 \mathrm{~d}$ & $1 \mathrm{~d}$ \\
\hline Overlap with fruit ditches & $75.9 \mathrm{~km}$ & $34.1 \mathrm{~km}$ & $15.3 \mathrm{~km}$ & $79.2 \mathrm{~km}$ \\
\hline $\begin{array}{l}\text { Segments next to fruit orchards } \\
\text { (\% of ditch lengths next to fruit } \\
\text { orchards simulated by SOBEK) }\end{array}$ & $28 \%$ & $31 \%$ & $20 \%$ & $30 \%$ \\
\hline
\end{tabular}

\subsubsection{Rivierenland: groundwater model, Moria 2.2}

The Moria 2.2 model (Borren and Hoogewoud, 2014) is a high resolution groundwater model, specially developed and calibrated for the Rivierenland management area. The model has a resolution of $25 \mathrm{x}$ $25 \mathrm{~m}$ and solves the water balance per grid cell based on exchange groundwater fluxes with adjacent grid cells, incoming precipitation and outgoing (evapo-) transpiration and also the exchange discharges with surface-water bodies such as ditches or ponds. Note that vertical exchange with surface water is only accounted for and that, hence, surface water that crosses the borders of grid cells horizontally is not considered by the model.

The model has been calibrated for the period 01-04-2002 to 01-04-2011; over this period, daily groundwater-surface water exchange discharges are available for five areas within Rivierenland, i.e. the Betuwe-Linge area (BL), the Bommelerwaard (BW), the Lek and Linge area ( $L L)$, the Maurikse wetering area (MW) and the Tielerwaard (TW). In Figure 2.4, the modelled areas are indicated. The grey lines in the figure indicate the borders of the individually managed target-level units ('peilgebieden'). Each sub-model contains a number of these units, with a total of 1925 . The dominant hydrotypes per unit are shown in Figure 2.5. In the Maurikse Wetering, the Bommelerwaard, the Lekand Linge area, and the Tiererwaard, the dominant hydrotype is the Westland DH profile. In the Betuwe-Linge area, the dominant hydrotype is Betuwe stroomruggronden. 


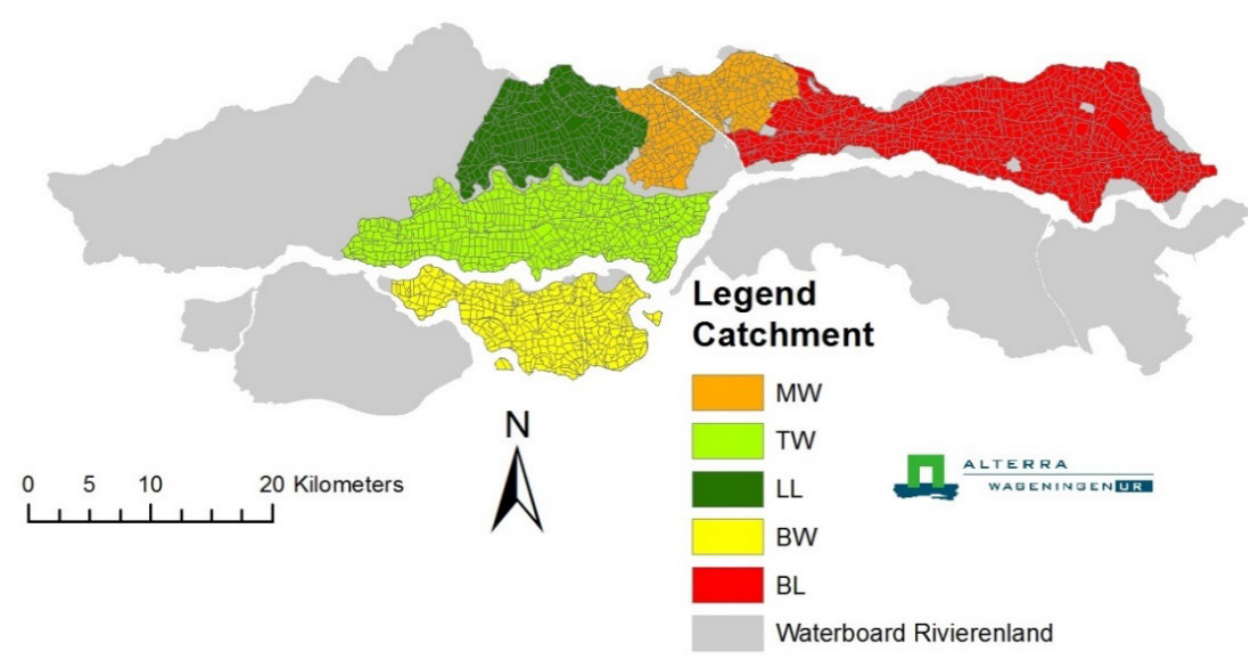

Figure 2.4 Moria sub-models of the Rivierenland Water Board. BL=Betuwe Linge; $B W=$ Bommelerwaard; $L L=L$ ek and Linge; $M W=$ Maurikse Wetering; $T W=$ Tielerwaard .

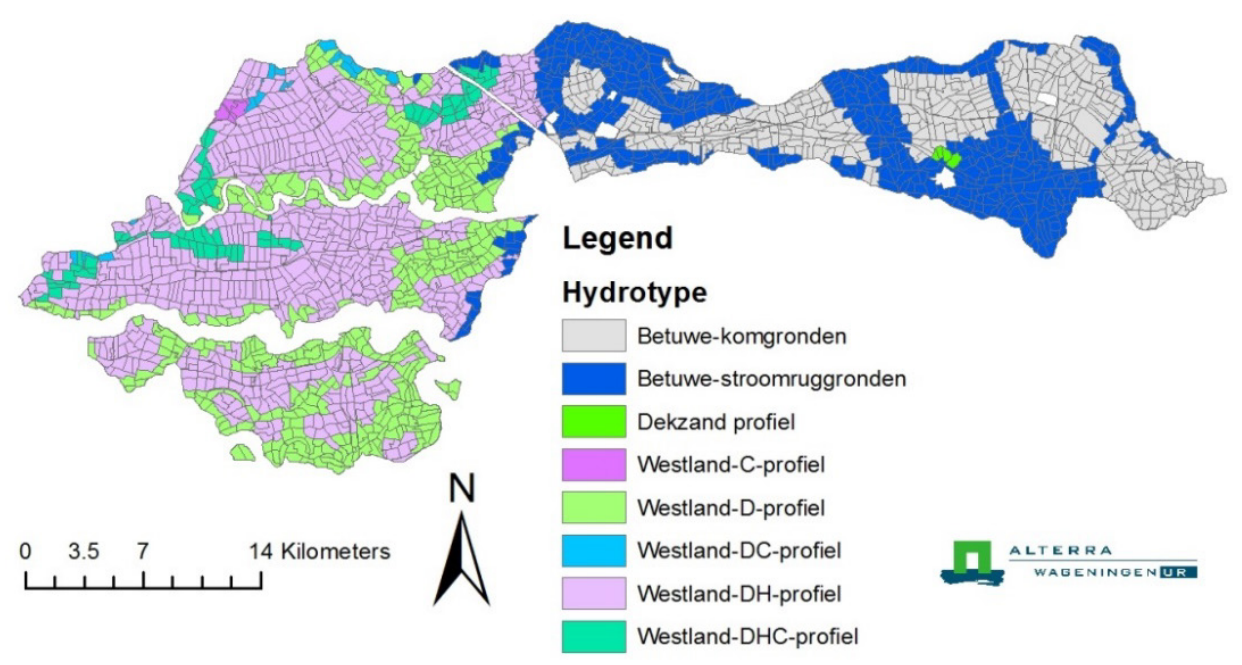

Figure 2.5 Dominant hydrotype in the target level units of the modelled Moria area of Rivierenland.

Figure 2.6 shows the surface water- groundwater exchange discharges of one example unit for the summer period of 2004 . All water that flows towards surface water, e.g. drainpipe discharge or groundwater discharge is represented by negative discharges in the figure. Groundwater recharge (from surface water to groundwater) is considered as positive.

Daily flow velocities averaged per unit can be approximated by:

$$
v_{t}=Q_{t} / \bar{A}
$$

with $v_{t}$ is the average velocity in the unit at time $t(\mathrm{~m} / \mathrm{d}), Q_{t}$ is the total discharge to the surface water at time $t\left(\mathrm{~m}^{3} / \mathrm{d}\right)$, and $\bar{A}$ is the weighted averaged wetted cross section of the ditches in the unit $\left(\mathrm{m}^{2}\right)$. $Q_{t}$ is the sum of all exchange discharges $\left(\mathrm{m}^{3} / \mathrm{d}\right)$ at time $t$ :

$Q_{t}=Q_{t, \text { drpipe }}+Q_{t, \text { runoff }}+Q_{t, \text { disch } \arg e}+Q_{t, \text { rech } \arg e}$

where $Q_{t, \text { drpipe }}$ is the discharge from the drainpipes and dry falling ditches to surface water $\left(\mathrm{m}^{3} / \mathrm{d}\right)$, $Q_{t, \text { runoff }}$ is the discharge to surface water from run-off overflow $\left(\mathrm{m}^{3} / \mathrm{d}\right), Q_{t, \text { discharge }}$ is the discharge from groundwater to surface water $\left(\mathrm{m}^{3} / \mathrm{d}\right)$ and $Q_{t, \text { recharge }}$ is the recharge from surface water to groundwater $\left(\mathrm{m}^{3} / \mathrm{d}\right)$. $Q_{t, \text { drpipe, }} Q_{t, \text { runoff }}$ and $Q_{t, \text { discharge }}$ have negative values and $Q_{t, \text { recharge }}$ has positive values in Moria. 
$\bar{A}$ is calculated by:

$$
\bar{A}=\frac{\sum_{i=1}^{n} L_{i} A_{i}}{\sum_{i=1}^{n} L_{i}}
$$

Where $L_{i}(m)$ is the length of the ditches according to the TOP10 vector map for the ditches of primary-, secondary- and tertiary classes, and for the considered hydrotypes, and $A_{i}\left(\mathrm{~m}^{2}\right)$ is the corresponding wetted cross section for each hydrotype-ditch class combination. Drying out of the shallow trenches in summer was accounted for by taking the wetted cross-section equal to zero in the summer. For larger water bodies, such as large ponds or rivers, a special approach was followed. For these water bodies, the total area covered by the water body was derived directly from the TOP10 vector map.

Note, that the method described above does not distinguish between ditch classes, the velocities derived are average velocities over one unit. Within this unit, ditches of various hydrotypes and of various classes may occur. The finally derived velocity is the weighted averaged velocity over the unit. This derived velocity does not consider (horizontal) exchanged (surface) water volumes between separate units. Also, the discharges $Q_{t, d r p i p e}, Q_{t, \text { runoff }}$ and $Q_{t, \text { discharge }}$ and $Q_{t, \text { recharge }}$ are added, i.e. when both groundwater discharge and groundwater discharge occurs in one day, they will cancel each other out.

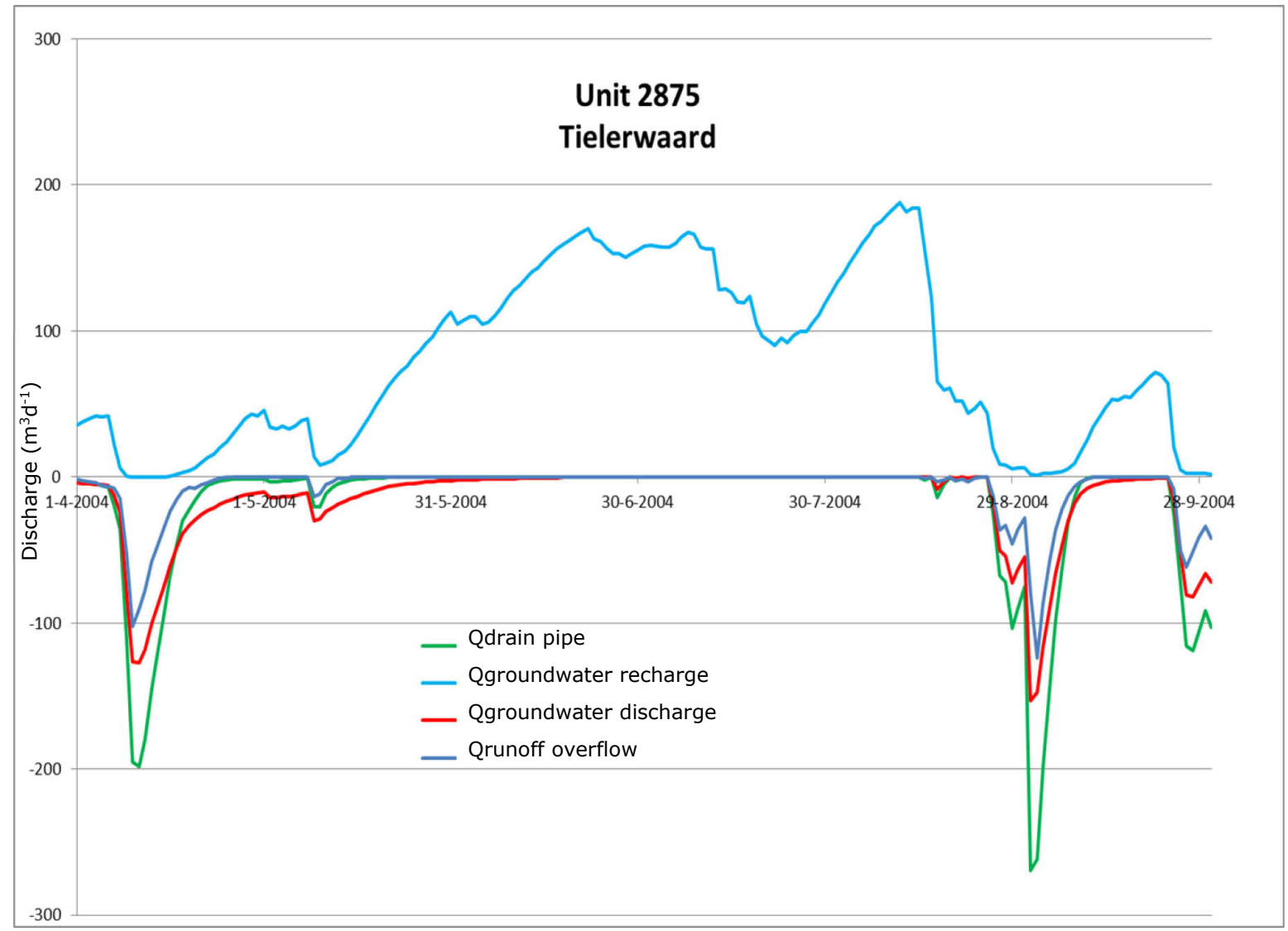

Figure 2.6 Example of exchange discharges for the summer of 2004. The discharges towards surface water are considered negative in Moria and recharge to groundwater as negative. Qdrainpipe is the discharge from the drainpipes and dry falling ditches to surface water $\left(\mathrm{m}^{3} / d\right)$, Q discharge to surface water from run-off overflow $\left(\mathrm{m}^{3} / d\right)$, $\mathrm{Q}_{\text {discharge }}$ is the discharge from groundwater to surface water $\left(\mathrm{m}^{3} / \mathrm{d}\right)$ and $\mathrm{Q}_{\mathrm{recharge}}$ is the recharge from surface water to groundwater $\left(\mathrm{m}^{3} / \mathrm{d}\right)$. Only recharge occurs in June and July. 


\subsection{Flow velocities by SOBEK and Moria}

\subsubsection{SOBEK}

Flow velocities were analysed over a simulation period of approximately one year, and the output of the different sub-models was compared. In Table 2.2, the mean values of the flow velocities in summer- and winter. Only secondary ditches were considered, as this ditch type corresponds to the ditch class of the selected ditch. The mean model velocities vary between 1200 and $6250 \mathrm{~m} / \mathrm{d}$. For Tielerwaard and Betuwe-Linge the mean summer velocity is lower than the mean winter velocity. For the Bommelerwaard and the Lek and Linge sub-models, it is the other way around. We did not investigate the cause of this difference in dynamics between the sub-models, but one might think of the effect of water management practices and differences in local hydrology. In the analyses, summer was defined as the period from $1^{\text {st }}$ April- $30^{\text {th }}$ September and winter was defined as the period from $1^{\text {st }}$ October $-31^{\text {st }}$ March.

The calculated flow velocities are relatively high, as compared to what would be expected based on discharge from nearby fields only. A simple back-of-the-envelope calculation of the velocity due to discharge from nearby fields $v$ is (Beltman and Adriaanse, 1999):

$$
v=(\gamma P L) /(2 A)
$$

where $y$ is the distance between ditches $(m), P$ is the net precipitation $(m / d), A$ is the cross-sectional area $\left(\mathrm{m}^{2}\right)$ and $L$ is ditch length $(\mathrm{m})$. For a ditch distance $y$ of $500 \mathrm{~m}$ (which is quite large for the Netherlands), a net precipitation $P$ of $0.001 \mathrm{~m} / \mathrm{d}$, a cross-sectional area $A$ of $0.5 \mathrm{~m}^{2}$ and a ditch length $L$ of $100 \mathrm{~m}$, the flow velocity would be $50 \mathrm{~m} / \mathrm{d}$. This estimated velocity is between a factor of 25 to 50 lower than the simulated mean velocities by the SOBEK sub-models. A plausible explanation for this difference is that the flow velocities calculated with the SOBEK model include auxiliary water from upstream polder areas; next to a local discharge, the simulated watercourses also discharge regional water, and the local (field) discharge is only a small part of the total water budget.

Table 2.2 Mean flow velocities in summer and winter for all segments next to fruit orchards, which are classified as secondary ditches according to the TOP10 vector map (the flow velocities were calculated as the median of velocities per segment in time; then, the mean was taken over all segments).

\begin{tabular}{lllll} 
& Betuwe and Linge & Bommelerwaard & Lek and Linge & Tlelerwaard \\
Simulation period & $1 / 3 / 2006-1 / 4 / 2007$ & $1 / 1 / 2005-1 / 4 / 2006$ & $1 / 3 / 2004-1 / 4 / 2005$ & $1 / 3 / 2004-1 / 4 / 2005$ \\
\hline Number of segments & 1323 & 205 & 101 & 626 \\
\hline Summer velocity (mean) & $1202 \mathrm{~m} / \mathrm{d}$ & $6234 \mathrm{~m} / \mathrm{d}$ & $2464 \mathrm{~m} / \mathrm{d}$ & $1602 \mathrm{~m} / \mathrm{d}$ \\
\hline Winter velocity (mean) & $2514 \mathrm{~m} / \mathrm{d}$ & $5968 \mathrm{~m} / \mathrm{d}$ & $1500 \mathrm{~m} / \mathrm{d}$ & $2034 \mathrm{~m} / \mathrm{d}$ \\
\hline
\end{tabular}

\subsubsection{Moria}

A pre-selection of the units was made by considering only units with an fraction of area coverage of fruit orchards larger than 0.15 , a fraction of water-course lengths of Class 2 ( $<3 \mathrm{~m}$ width), larger than $50 \%$, and with 'Betuwe stroomruggronden' as the dominant hydrotype,. The location of the fruit orchards was derived from the LGN map (Hazeu et al., 2014). Next, an additional refinement of the selection was made by ranking the units according to ditch class and select the 110 units with the highest fraction of ditches of Class 3 (smaller ditches) with the rationale that smaller water bodies are considered as more vulnerable. The final set contained 110 flow velocity time series. The selected units are depicted in Figure 2.8. Most of them are located in the Eastern part of the district, predominantly featuring watercourses of hydrotype, Betuwe stroomruggronden. The size of one unit is approximately 40 ha, i.e. 640 gridcells. 


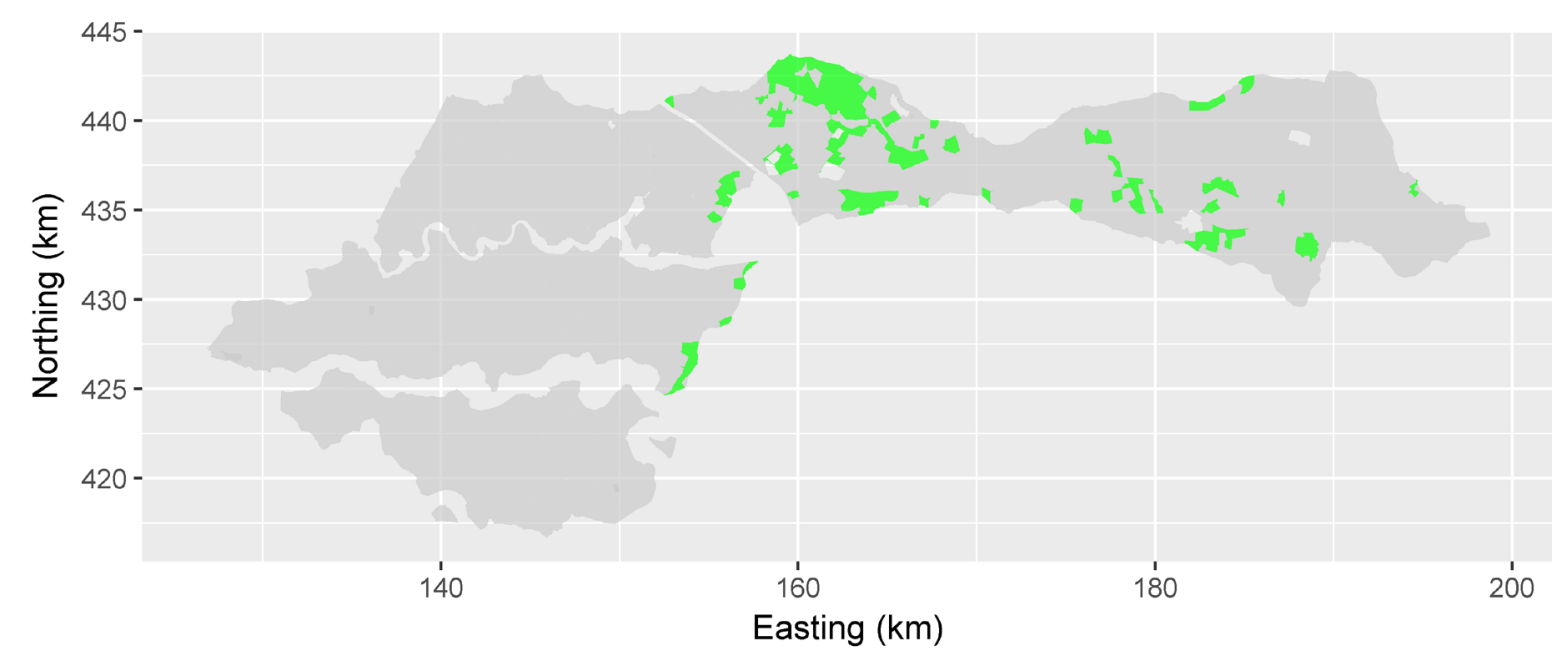

Figure 2.7 Selected units are indicated in green. The selected units have a fraction of area coverage of fruit orchards larger than 0.15, a fraction of watercourses smaller than $3 \mathrm{~m}$ of 0.5 , and a dominant hydrotype of 'Betuwe stroomruggronden'.

An example of velocity time-series resulting from the methodology described in Section 2.2.2 is shown in Figure 2.8. The figure shows daily averaged flow velocities with flow in one direction due to discharge in the winter caused by excess precipitation water, whereas, in the summer, the water flows in the opposite direction, as it is let in to support plant uptake and transpiration. In the winter time, the velocities are larger, up to $2.5 \mathrm{~km} / \mathrm{d}$.

Figures 2.9, 2.10 and 2.11 illustrate the frequency distribution of these time-series, ranked according to their median daily flow velocity. The median velocity is negative for most of the time-series, which indicates that water is mostly discharged to the watercourses through drainpipes or overland flow (excess of water). Also, most of the time-series show positive, as well as negative water velocities, i.e. the direction of the water flow alternates over the seasons. The median summer- and winter flow velocities, derived with the Moria model are shown in Table 2.3. These flow velocities are much lower than those of the SOBEK model, and more in line with indicative calculations (e.g. Equation 2.4).

An additional comparison between flow velocities of SOBEK and Moria is given in Annex 1 for the area Tielerwaard area. Also, this comparison shows that the velocities derived with Moria are lower. 


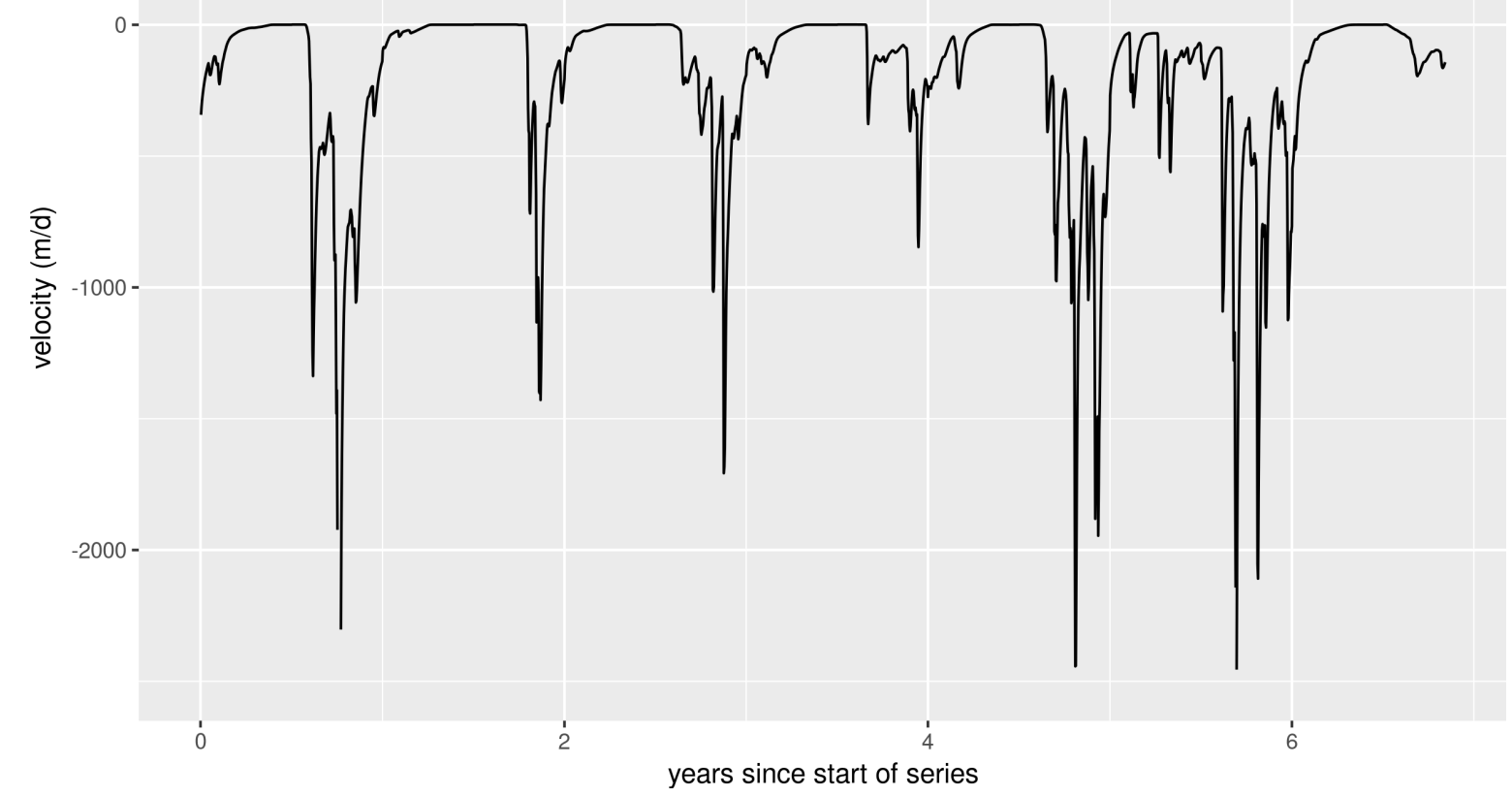

Figure 2.8 Example of the flow velocity time-series over seven years (m/d), i.e. from $1^{\text {st }}$ April 2002 to $1^{\text {st }}$ April 2011, as derived from the Moria model. Velocities show a seasonal trend. Negative flow velocities refer to discharge of excess water in the winter season, positive to inlet of water to support crop irrigation.

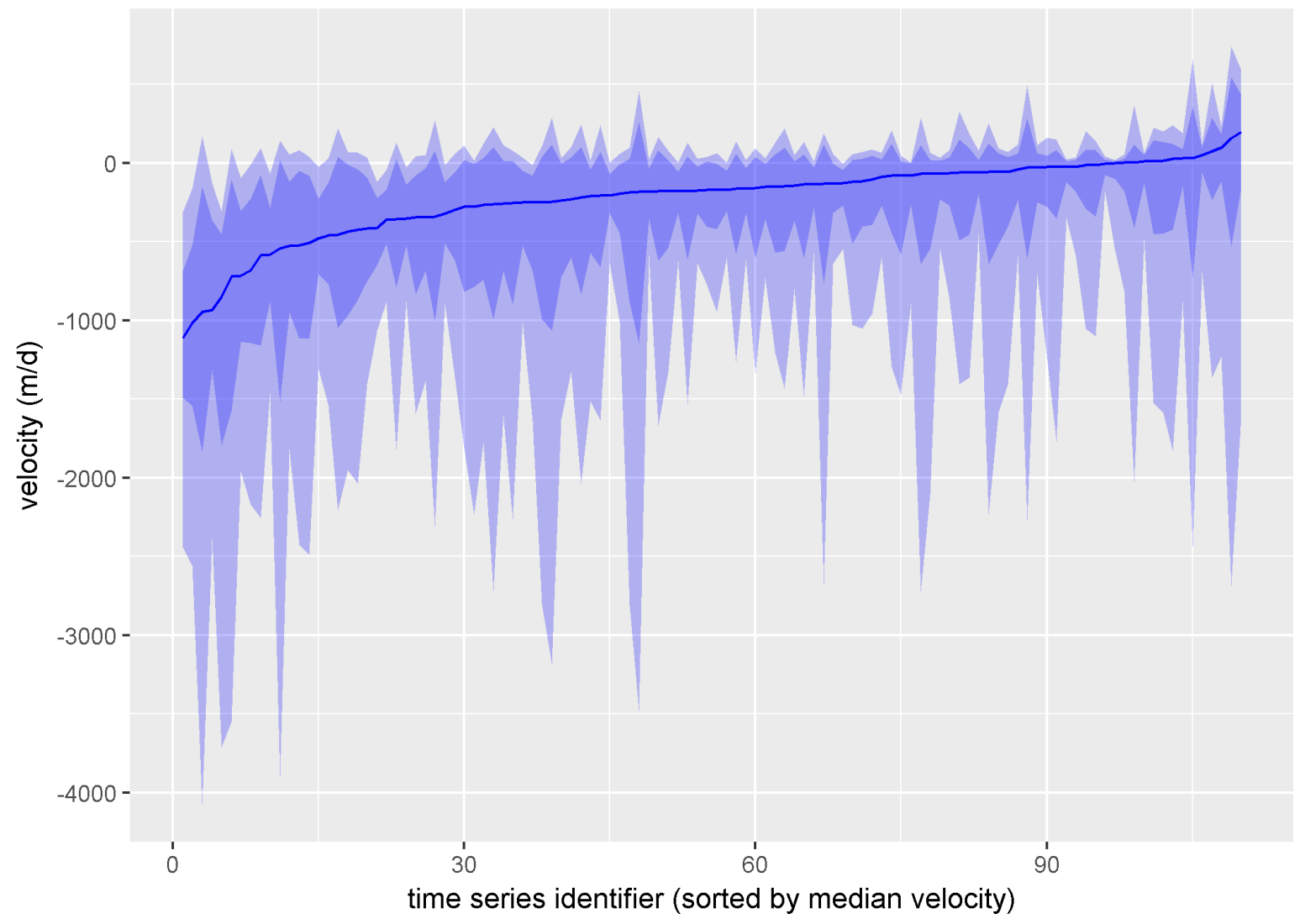

Figure 2.9 Sorted time series of flow velocities $(\mathrm{m} / \mathrm{d})$. The time-series ranges from $1-110$ on the $x$-axis according to ranking. Dark blue line: median velocity, the dark blue colour indicates the $25-75^{\text {th }}$ percentiles of the time-series and light blue colour indicates the $10-25^{\text {th }}$ and $75-90^{\text {th }}$ percentiles. Negative flow velocities refer to discharge of excess water in the winter season, positive to inlet of water to support crop irrigation. 


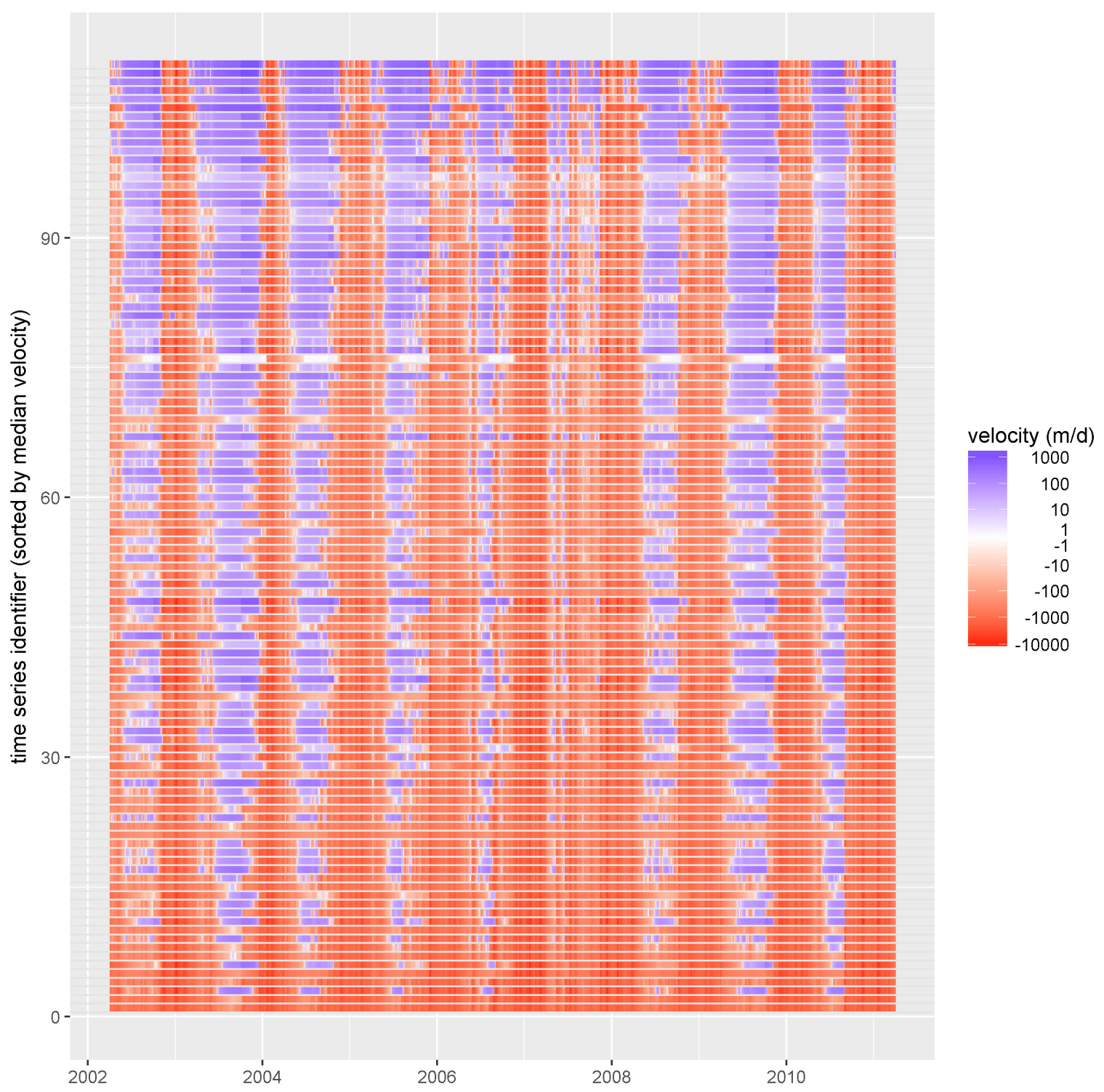

Figure 2.10 Sorted time-series of flow velocities $(\mathrm{m} / \mathrm{d})$. The time-series counts from 1-110 on the $y$-axis according to the median flow velocities. The red colour refers to negative flow velocities and discharge of excess water. The blue colour refers to positive velocities and to the inlet of water to support crop irrigation.

Table 2.3 Characteristic flow velocities in summer and winter for selected units (based on the Moria model).

\begin{tabular}{ll}
\hline Simulation period & $1 / 4 / 2002-1 / 4 / 2011$ \\
\hline Number of units & 110 \\
\hline Median of the absolute values - 1-Jan to 31-Dec & $209 \mathrm{~m} / \mathrm{d}$ \\
\hline Median of the absolute values - 1-Apr to 30-Sept (summer) & $89 \mathrm{~m} / \mathrm{d}$ \\
\hline Median of the absolute values - 1 Oct to 31-Mar (winter) & $515 \mathrm{~m} / \mathrm{d}$ \\
\hline
\end{tabular}




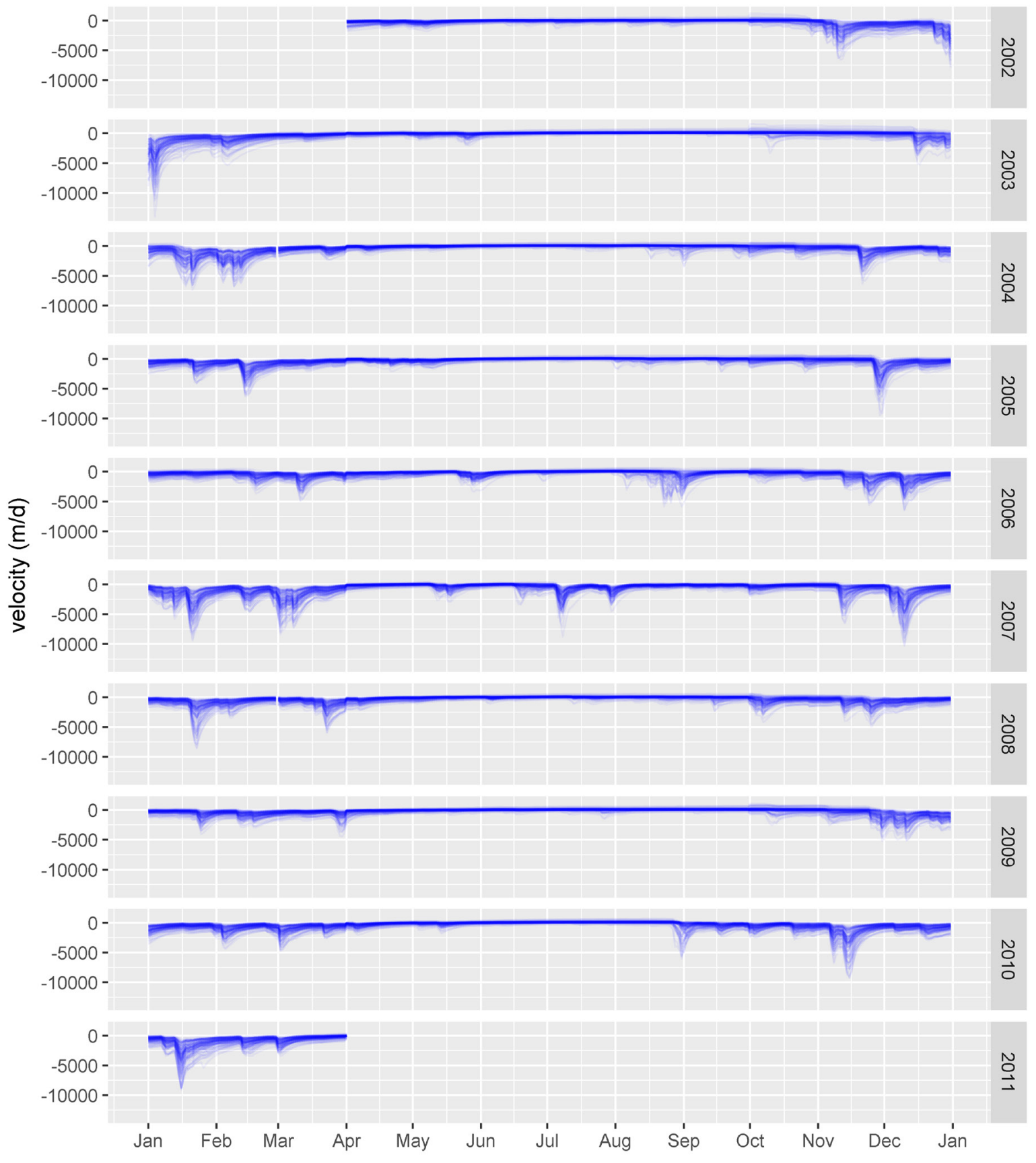

Figure 2.11 flow velocities $(\mathrm{m} / \mathrm{d})$ of all selected time-series plotted per year.

\subsection{Flow velocity: extension of time-series}

\subsubsection{Direct sampling}

The Working Group decided to proceed with the pre-selected flow velocities derived from Moria. These velocities are expected to be closer to flow velocities of ditches with a local discharge function only. This option is also expected to be more conservative, as a low flow velocity will lead to higher concentrations in the ditch.

The individual time-series derived from Moria have a length of nine hydrological years of daily values (April 2002 - March 2011). This was considered too short for a proper derivation of the target percentiles; it is common in the EU to assess pesticide exposure with at least a simulation run over 20 years with six years of warming-up period. 
To generate at least a 26-year-long time series of daily flow velocities, a direct sampling (DS) method was applied. Oriani et al. (2014) recently geared DS to the simulation of synthetic time-series. Their work builds on earlier work carried out in the field of multiple-point geostatistics (Mariethoz et al. 2010, and references therein) during the last decades.

Direct sampling simulates synthetic time series (the so called simulation grid, SG) by iteratively searching for temporal patterns in an existing long time series (the so-called 'training image', TI). Oriani et al. (2014) simulated synthetic time series of rainfall. For a random time $T$ in the SG, for which rainfall needs to be simulated, they search for a time $t$ in the TI that has approximately the same temporal pattern as time $T$ in the SG. That is, the temporal distribution of rainfall in a time window around time $T$ in the SG, is similar to that around $\mathrm{t}$ in the TI. The value at time, $t$, in the TI is then assigned to time, $T$, in the SG.

Unlike Oriani et al. (2014), we didn't have one long TI (otherwise, we wouldn't have been required to simulate one in the first place). Instead, we had 110 relatively short time series of daily flow velocities. Instead of one long time series, we used these shorter time series as a distributed TI. The time series were offered to the SG as one large time series. We ensured that patterns searched for in the TI only belonged to a single time series to prevent boundary effects.

DS is a relatively simple method that honours higher order statistics in the TI, such as e.g. the shape parameters of skewness or kurtosis. The SG reproduces variation at different temporal scales also found in the TI. The performance of DS can be further improved by adding constraints. As Oriani et al. (2014), we added seasonality constraints. Direct sampling does not rely on an explicit parametric model, like an autocorrelation function. Instead, temporal structure is directly taken from the TI. See Oriani et al. (2014) and Mariethoz et al., (2010) for details.

Figure 2.12 gives a small part of the training image (TI) scaled between 0 and 1 . The training image is a concatenation of the 110 smaller time series, each of nine years in length. We sampled this time series (of $9 \times 110=990$ years) to simulate a new time series of 27 years in length. The first panel gives the time series of the flow velocity $(\mathrm{m} / \mathrm{d})$. This is the quantity of interest. The 'target' panel gives a binary time series that is either zero or one. A one means that the value of the flow velocity at this specific date is a candidate for sampling, a zero means that the date is excluded from sampling. The reason for taking this 'target'- timeseries into account, is to prevent edge-effects on the transition between the smaller time series. Indeed, we do not want to compare flow patterns that are part of two different time series. The triangular functions 'tri1' and 'tri1' are required to guarantee that seasonality is taken into account. The simulation grid (SG) has the same triangular functions. Samples are only accepted if the values of the triangle wave functions of the training image and simulation grid are approximately equal (see Oriani et al. (2014) for details).

The original time series was transformed, first to a normal distribution using the normal score transformation ${ }^{1}$. After applying the algorithm, the derived time-series was transformed back again. The derived velocities cover 27 years of daily velocities $(\mathrm{m} / \mathrm{d})$, and do not refer to a real (weather) year.

\footnotetext{
${ }^{1}$ For detailed explanation see e.g.: http://pro.arcgis.com/en/pro-app/help/analysis/geostatistical-analyst/normal-scoretransformation.htm
} 
Flow velocity $(\mathrm{m} / \mathrm{d})$
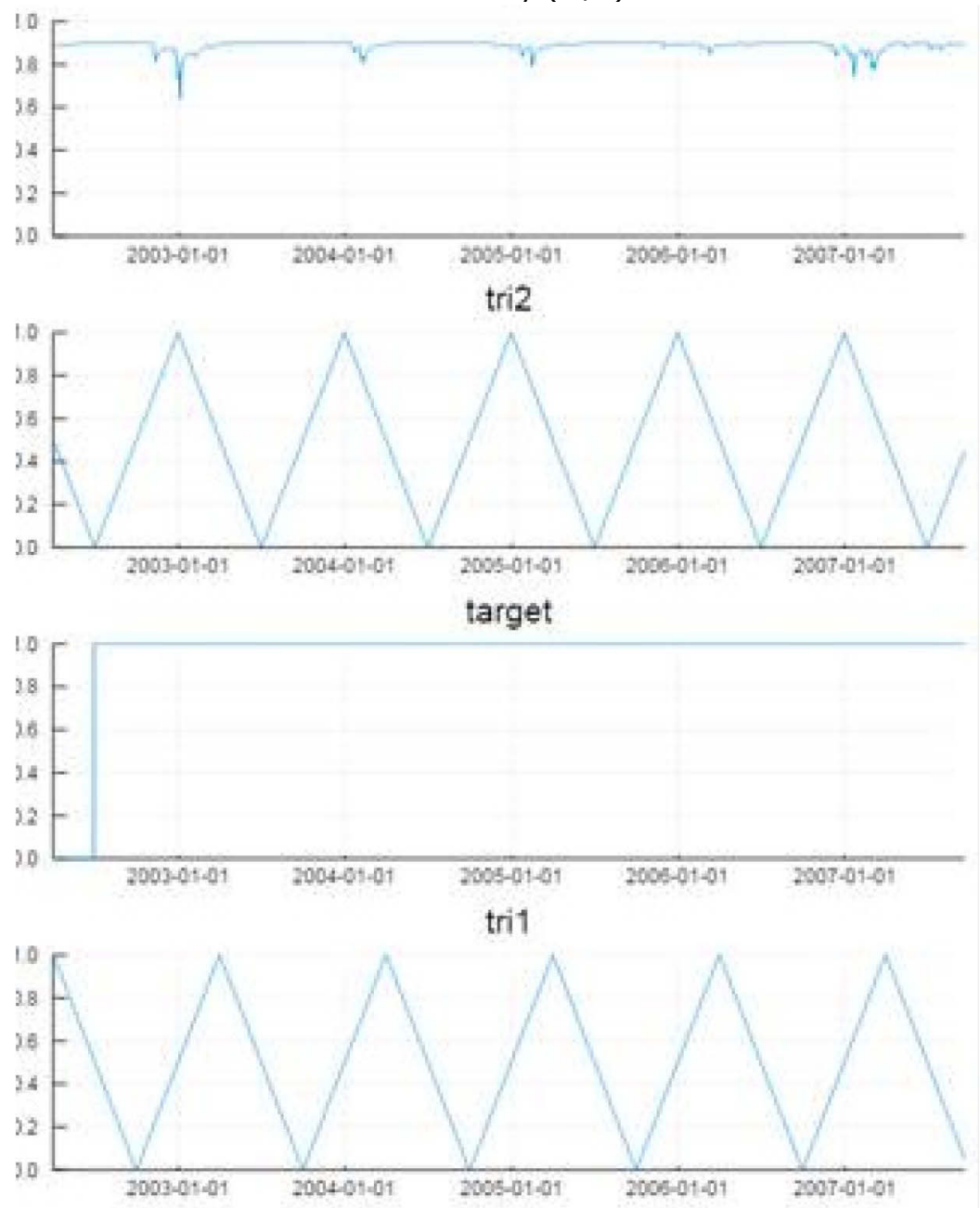

Figure 2.12 Training image and constraints used to sample the so-called 'simulation grid', being a 27-year-long time series of daily flow velocities. The upper panel shows a part of the concatenated time-series of flow velocities from the groundwater model, Moria. Tri1 and tri2 are used as constraints to guarantee the seasonality of the signal. The target 'signal' shown in the target panel is used to overcome the transitions between the nine-year time series. The dates below the panels refer to the dates from the nine-year time series of the training image. The simulation grid has no reference to any real (weather) year.

\subsubsection{Results}

The direct sampling resulted in the synthetic velocity time series can be found below (Figure 2.13). Note, that an infinite number of synthetic time series may be derived from one training image. 


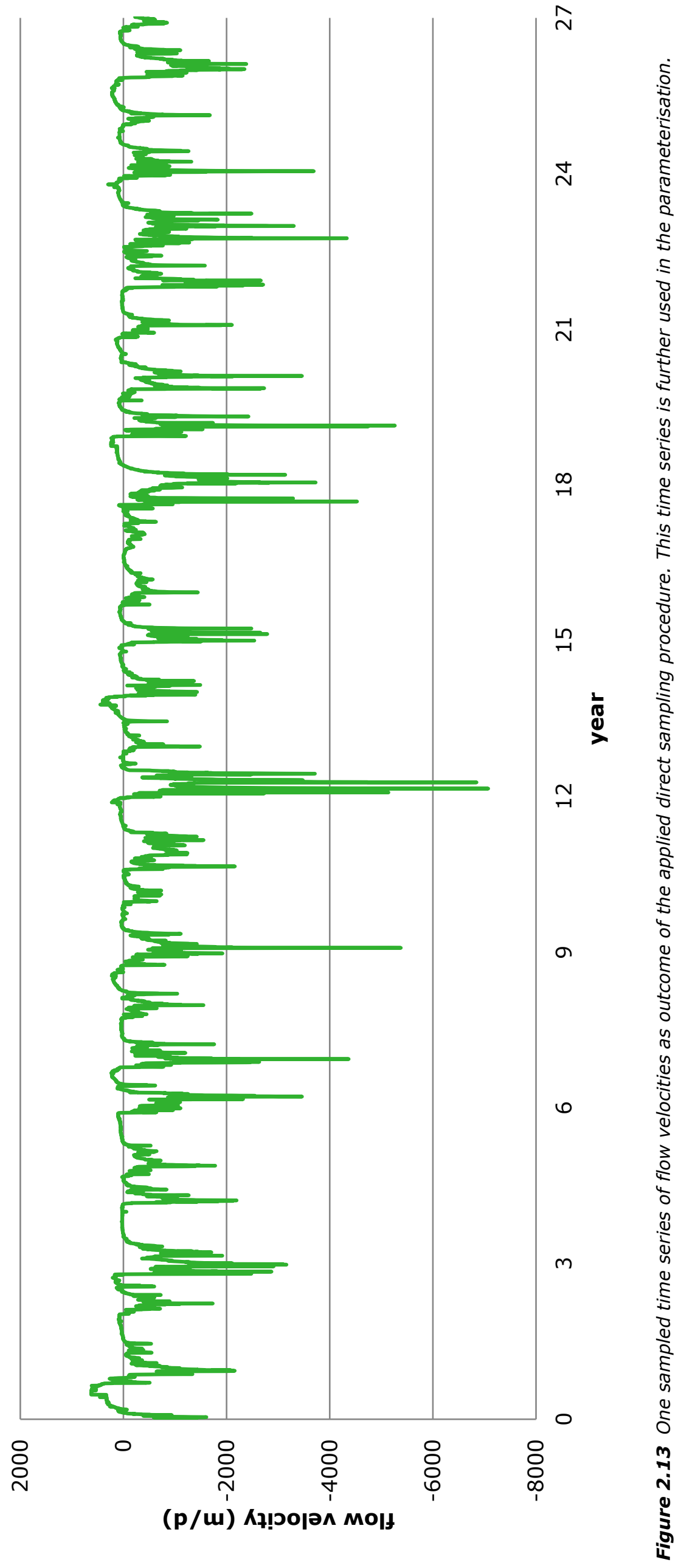


To assess the differences in statistical properties of the TI and the SG, we plotted the cumulative probability density functions for both the TI and one or more SGs (Figure 2.14), as well as the autocorrelation functions (Figure 2.15).

Figure 2.14 shows the cumulative probability density functions of the training image in red, and ten separate synthetic time series in blue. The TI function and the synthetic time series functions are very close, but not the same. The applied sampling method lessens the extremes in the dataset, i.e. highest- and the lowest values occur less frequently in the SG as compared to the TI. Also, the median of the synthetic time series is lower than then the training image. E.g. the median of the dataset as presented in Figure 2.13 is $-112 \mathrm{~m} / \mathrm{d}$, whereas that of the training image is $-173 \mathrm{~m} / \mathrm{d}$. In the continuation of this report, we use the time-series as presented in Figure 2.13. We expect that the impact of which dataset is finally used in the fate calculations is very limited. This should be verified with example calculations.

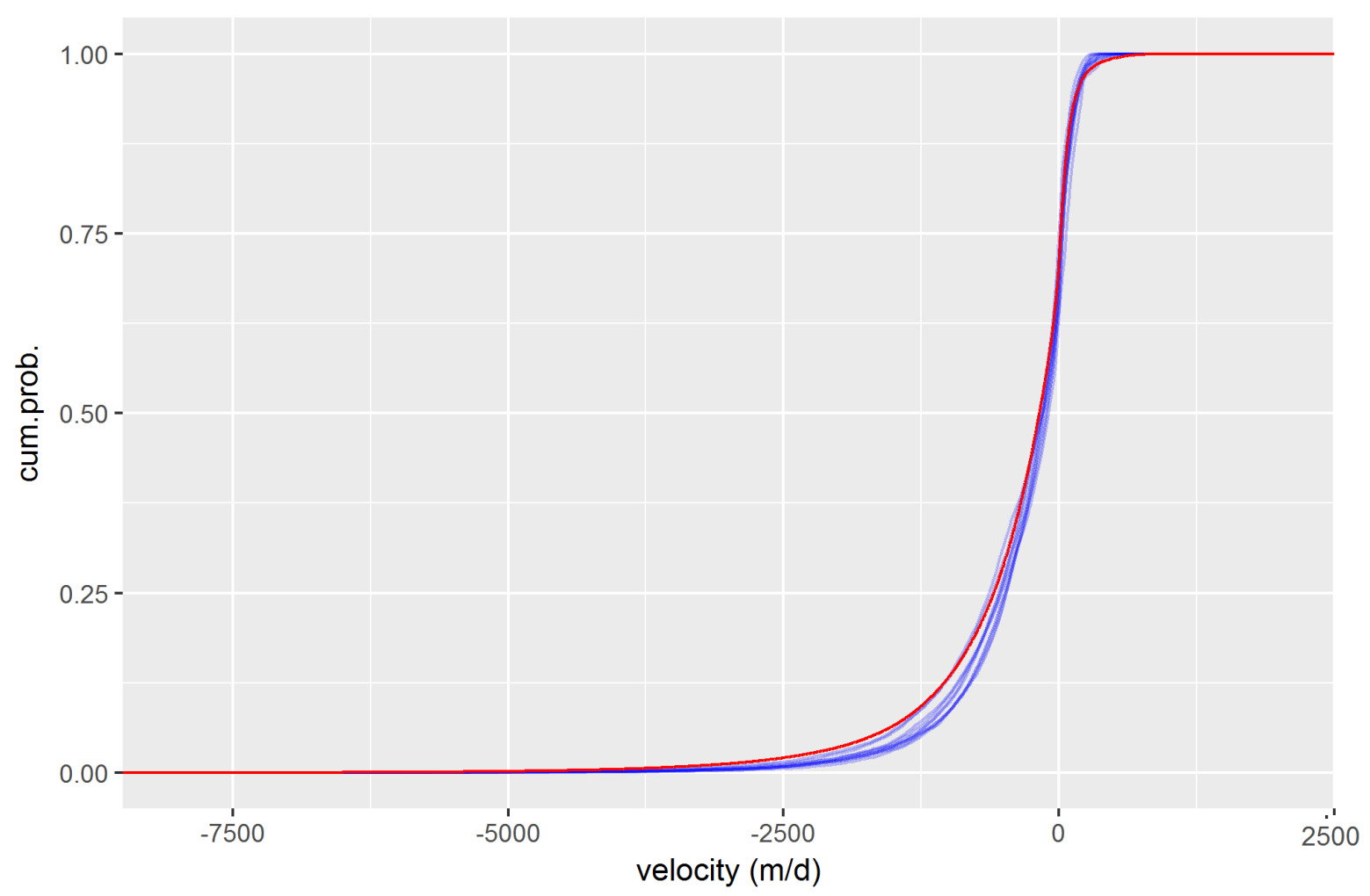

Figure 2.14 Cumulative probability density function of the training image (IT) in red, and ten synthetic time series sampled from the IT in blue (also referred to as simulation grid, SG). Note, that the negative velocities refer to discharge in the winter and the positive to the summer. 
Figure 2.15 shows the autocorrelation function of both the training image and the sampled time series of Figure 2.13. The autocorrelation is the correlation of a signal with a delayed copy of itself as a function of delay. In other words; it is the similarity between observations as a function of the time lag between them. Up until 20 days, both functions have the same autocorrelation. The functions only start to deviate after 20 days, which implies that the method is able to conserve the autocorrelation rather well, up until 20 days.

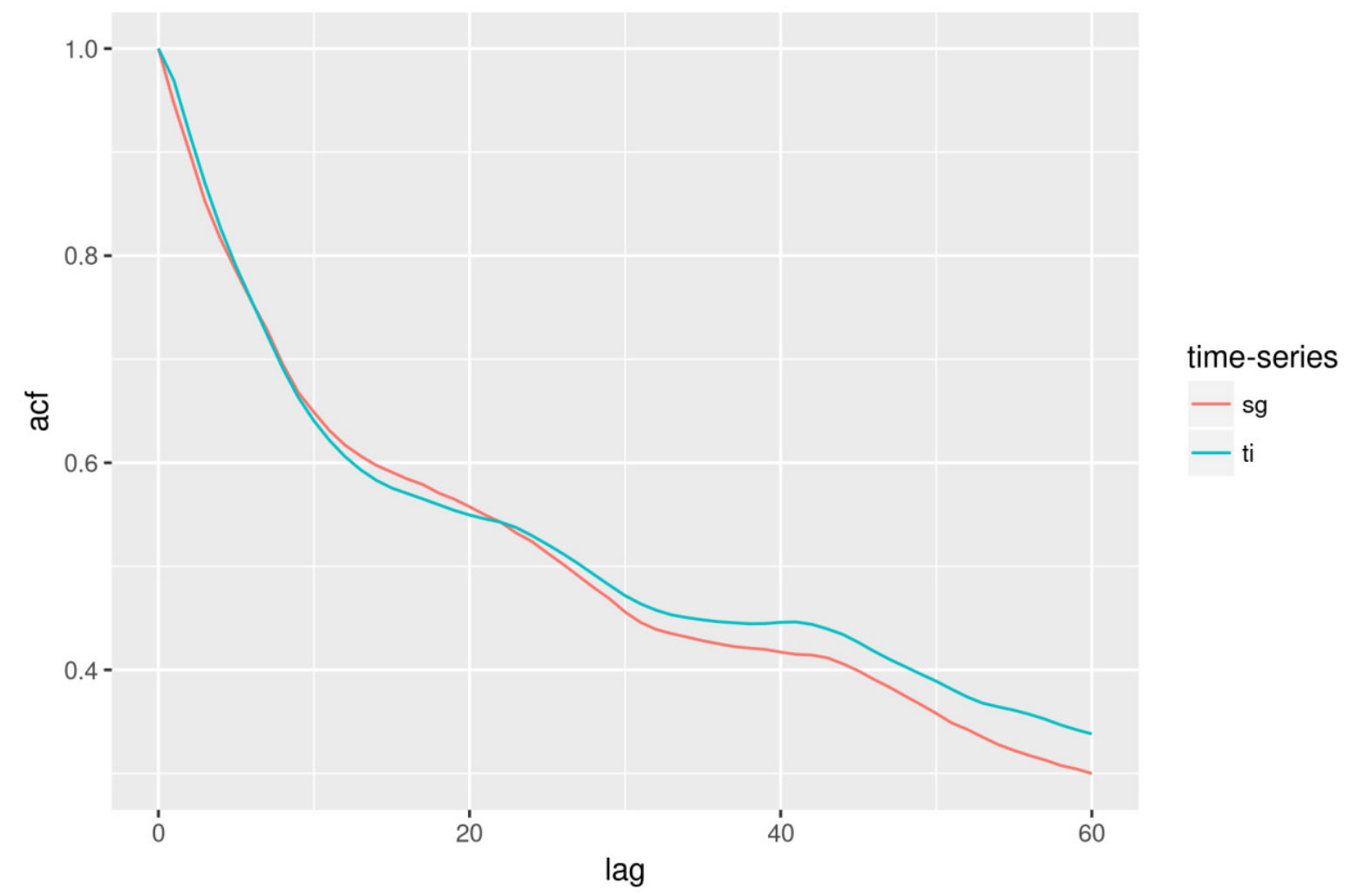

Figure 2.15 Autocorrelation function of the training image (IT) and the synthetic time series (also referred to as simulation grid, SG). The lag is given in days.

\subsubsection{Residence times}

Given a standard evaluation ditch of $100 \mathrm{~m}$, instantaneous residence times can be calculated. Instantaneous residence times refer to residence times corresponding to each of the (daily) flow velocities in the time-series, in contrast to e.g. monthly (averaged) residence times or seasonal residence times.

Residence times of the derived synthetic time series are summarised in Table 2.4. Typically, the minimum instantaneous residence time is $\mathbf{2 0}$ minutes for the summer and the winter, whereas maximum instantaneous residence times are higher in the summer, i.e. 6,377 days, than in winter, i.e. 1,681 days.

Median instantaneous residence time is $13.5 \mathrm{~h}$, which corresponds to a median velocity of $177 \mathrm{~m} / \mathrm{d}$ for a $100 \mathrm{~m}$ ditch. In the summer the median instantaneous residence time is longer, $31 \mathrm{hr}$ and in the winter it is shorter, $6.5 \mathrm{hr}$, corresponding to respectively a flow velocity of $77 \mathrm{~m} / \mathrm{d}$ and $369 \mathrm{~m} / \mathrm{d}$.

For reference: the mean velocities of the FOCUS surface water scenarios vary between $9.6-84 \mathrm{~m} / \mathrm{d}$ and the currently used Dutch evaluation ditch has a velocity of $9.6 \mathrm{~m} / \mathrm{d}$ (summer) and $101 \mathrm{~m} / \mathrm{d}$ (winter), which is considerably lower. Hence, for these scenarios the residence time would be 1-10 d.

The chance of accumulation of pesticides in the simulation ditch will be smaller than the FOCUS scenarios or the Dutch scenario. This will, of course, depend upon the timing of the application, as well as on the substance characteristics. The impact of the residence time on the accumulation of pesticides in the evaluation ditch is not part of this report. 
Table 2.4 Statistical parameters of the time series of the instantaneous residence time corresponding to the final constructed flow velocity time series from Section 2.4.3.

\begin{tabular}{llll} 
& & \multicolumn{2}{c}{ Residence time } \\
\cline { 2 - 3 } Minimum & 1 -Jan to 31 -Dec & 1 -Apr to 30-Sept (Summer) & 1 -Oct to 31-Mar (Winter) \\
\hline $10^{\text {th }}$ percentile & $20 \mathrm{~min}$ & $20 \mathrm{~min}$ & $20 \mathrm{~min}$ \\
\hline $50^{\text {th }}$ percentile & $2.5 \mathrm{hr}$ & $5 \mathrm{~h}$ & $2 \mathrm{~h}$ \\
\hline $90^{\text {th }}$ percentile & $13.5 \mathrm{hr}$ & $31 \mathrm{~h}$ & $49 \mathrm{~h}$ \\
\hline $99^{\text {th }}$ percentile & $114 \mathrm{hr}$ & $180 \mathrm{~h}$ & $16.5 \mathrm{~d}$ \\
\hline Maximum & $41.8 \mathrm{~d}$ & $73.6 \mathrm{~d}$ & $1681 \mathrm{~d}$ \\
\hline
\end{tabular}

\subsubsection{Discussion}

Ideally, flow velocities are based on experimental data or alternatively modelled data covering a wide range of edge-of-field ditches. These measured or modelled flow velocities in addition cover a longer time period and have a temporal resolution of at least hours or minutes. However, this data is not available. Calibrated high resolution hydrological models can be used to derive flow velocity dynamics. These are widely available in the Netherlands. Hydrodynamic models, though, have the drawback that only larger water bodies are explicitly simulated by the model, which makes the output of these models less useful. Groundwater models can be used to estimate flow velocities, as well. As a best approximation, we decided to derive flow velocities from the Moria groundwater model.

The method discussed in this chapter aims to derive flow velocities that conserve the dynamic effects of (time-variable) precipitation, farmers' practices (irrigation), as well as water-management practices. A number of interpretation and post-processing steps were taken to come to a dataset of the requested length- and temporal resolution. In how far the applied post-processing steps affect the final data set, and if they can be justified, is not easy to answer. Each of these steps has an effect on the lower- and higher order statistics of the dataset.

In Figure 2.16, an overview is given of the original output by the Moria model and how it was translated into the final dataset of flow velocities, which is used in the further parameterisation described in this report. The first column contains the process steps taken, the last column contains the characteristics of the datasets and the column in the middle contains the interpretation or postprocessing steps applied. Also the expected effect is described, qualitatively.

In order to justify all of these steps taken, it should be assessed if the statistics of the final dataset of flow velocities are in line with flow velocities in real ditches next to fruit orchards. To this end, it is recommended to start a survey to measure flow velocities in Dutch edge-of-field ditches. The measures flow velocities will be the basis to justifying the followed approach, but also, to better underpin model parameterisation in general of smaller edge-of-field watercourses used in the exposure assessment of agrochemicals.

In the near future computer power will increase further and high resolution models will be improved. The output of these future models will, therefore, e.g. cover a longer simulation period and have a higher spatial- and temporal resolution. The survey mentioned above may also serve to support calibration and validation of future hydrological models that provide edge-of-field hydrological information used in scenario derivation. 


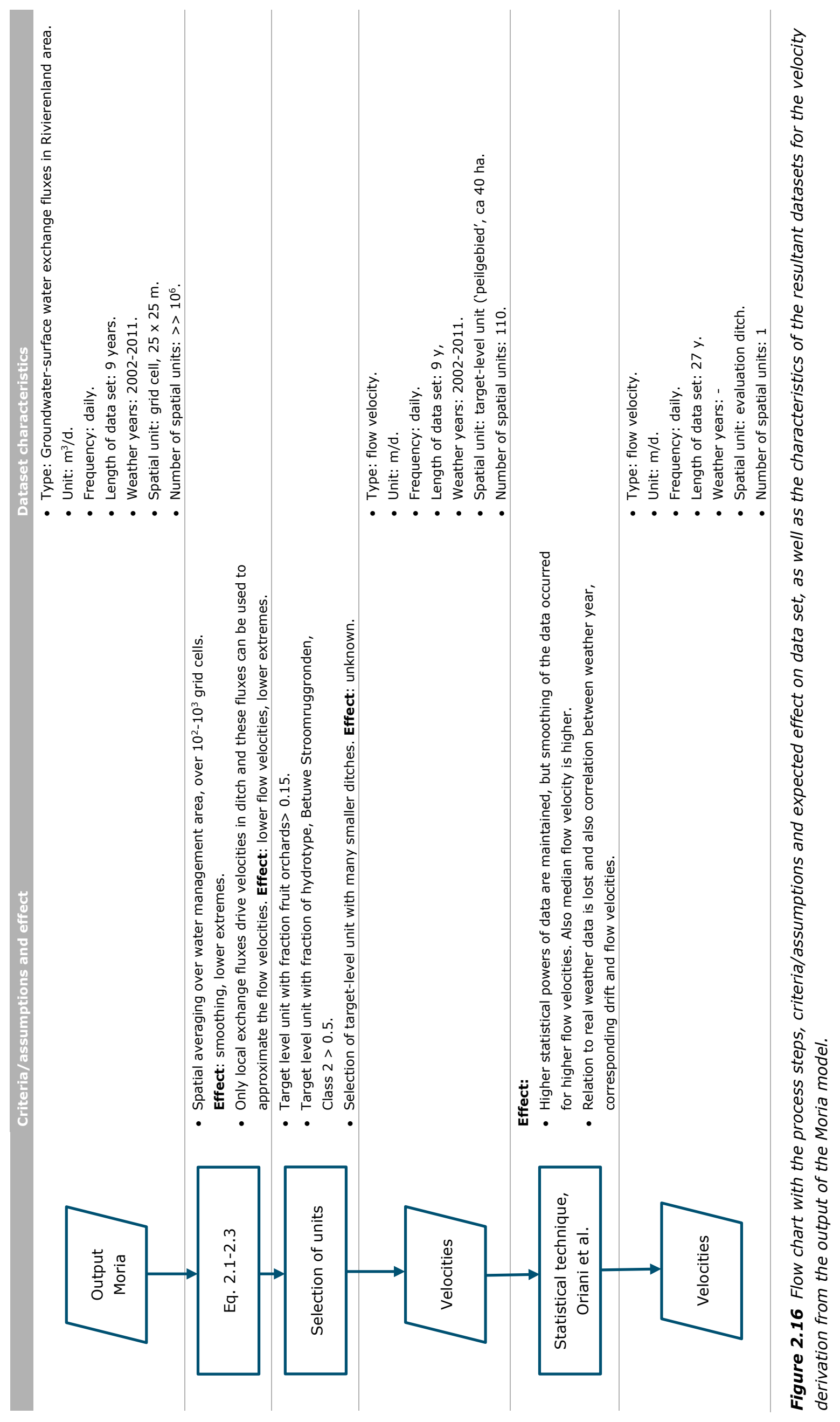




\section{Ditch- and landscape geometry}

\subsection{Ditch dimensions}

One scenario was selected with an edge-of-field ditch of the hydrotype, Betuwe stroomruggronden, secondary ditch. The corresponding mean ditch geometry was taken from Massop et al. (2006), as listed in Table 3.1 and as depicted in Figure 3.1.

Table 3.1 Dimensions of the selected ditch for the upwards and sideways directed spraying scenario.

\begin{tabular}{ll} 
Hydrotype & Ditch properties \\
\hline Ditch type & Betuwe stroomruggronden \\
\hline Width top ditch $(\mathrm{m})$ & secondary ditch \\
\hline Width bottom ditch $(\mathrm{m})$ & 3.90 \\
\hline Width water $(\mathrm{m})$ & 1.74 \\
\hline Water depth $(\mathrm{m})$ & 2.34 \\
\hline Lineic volume $\left(\mathrm{m}^{3} \mathrm{~m}^{-1}\right)$ & 0.30 \\
\hline Slope (horizontal:vertical) & 0.612 \\
\hline
\end{tabular}

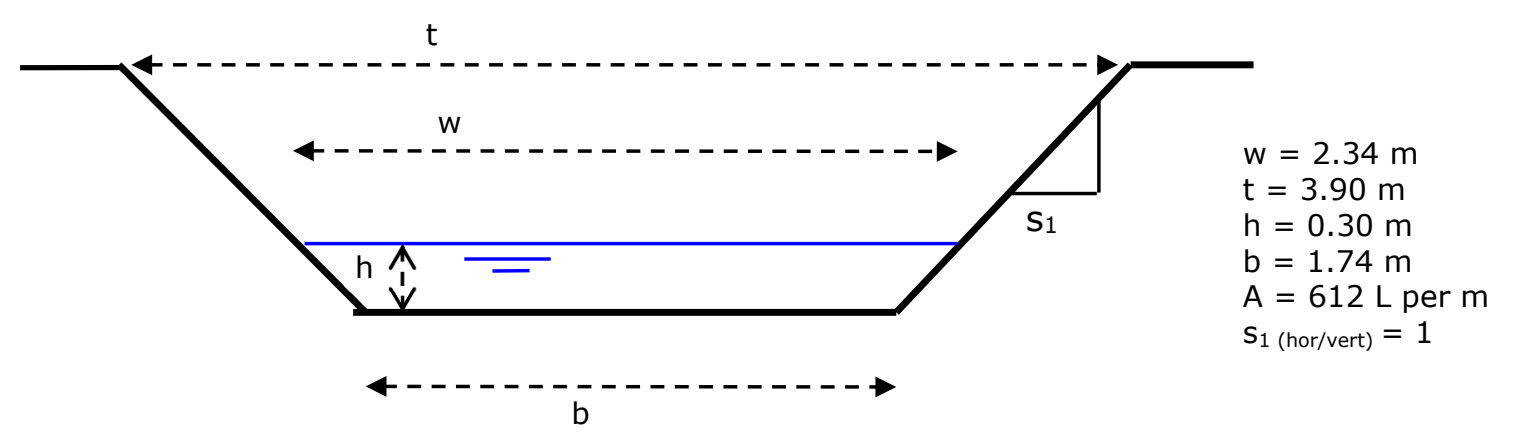

Figure 3.1 Dimensions of the ditch for the selected scenario, where $w$ is the width of the water surface, $h$ is the water depth, $b$ is the width of the bottom of the ditch, $t$ is the width of the top of the ditch, s1 is the side slope (horizontal/vertical), and $A$ is the lineic volume of the water in the ditch.

In line with preceding exposure assessment methodologies, the length of the evaluation ditch is $100 \mathrm{~m}$, i.e. the calculated Predicted Environmental Concentration (PEC) is the concentration averaged over $100 \mathrm{~m}$ of ditch (e.g. Tiktak et al., 2012a).

\subsection{Positioning of the ditch in the polder landscape}

Up until now, the water flow velocity in evaluation ditches used for the risk assessment of pesticides in the Netherlands and the EU was in one direction only (FOCUS, 2001). Flow in two directions is typical for polder regions, such as in the Netherlands, as excess water is discharged in the winter and water is let in during the summer to support irrigation and crop growth. The water-flow-velocity time series, as derived in Chapter 2 has two flow directions. 
Pesticides entering the ditch may, therefore, be transported over one of the boundaries of the evaluation ditch and then return, due to the alteration of flow direction. Hence, model simulations should be done over the length of a ditch, which is longer than $100 \mathrm{~m}$. In the following, we distinguish between the 'evaluation ditch', i.e. the part of the ditch, for which the PEC is calculated, and the 'simulated ditch', i.e. the length of the ditch, over which the pesticide fate is simulated.

It was decided to simulate the pesticide fate over a length of $300 \mathrm{~m}$, i.e. the simulated ditch is $300 \mathrm{~m}$. The rationale behind the extension of no more than $100 \mathrm{~m}$ is that the ditch will not be any longer as it is connected to other water bodies downstream and upstream, as part of a network of watercourses, in which the concentrations are yet unknown, but probably lower than in the evaluation ditch.

\subsubsection{Distance between ditches}

The depth of the orchard has little to no effect on the drift deposition on the evaluation ditch. However, when the drainpipe is included in the scenario, the depth may become important.

If we assume that a fruit orchard is in-between two ditches, then the median distance between ditches may be considered as a proxy for the depth of the fruit orchard situated perpendicular to the ditch. The median distance between ditches was approximated by dividing the total area of one target level unit (peilvak) by the total length of all water bodies. This was done for the selected units in the Rivierenland area (see also Figure 2.8, which shows the selected units). The lengths of the ditches were derived from the TOP10 vector map. Some (tertiary) ditches become dry in the summer. In that case, they were only accounted for in the winter.

In Table 3.2, mean- and median distances are given for the selected units (110 units), as well as minimum and maximum values in summer and winter times. The median distance was $137 \mathrm{~m}$ in summer and $103 \mathrm{~m}$ in winter. The Working Group decided to use the rounded summer value in the parameterisation, i.e. $140 \mathrm{~m}$ between the ditches. Tertiary ditches are not part of the exposure assessment goal, therefore, the summer value was considered appropriate.

Table 3.2 Distances between ditches in summer and winter in the Rivierenland, calculated by dividing the total area of a unit by the ditch lengths.

\begin{tabular}{|c|c|c|}
\hline Distance between ditches ( $\mathrm{m}$ ) & Summer & Winter \\
\hline Median & 137 & 103 \\
\hline Maximum & 1218 & 320 \\
\hline
\end{tabular}

\subsubsection{Fruit orchard sizes}

The LGN6 map and the BRP map 2012 (Dutch registration of land plots) both contain geographical information of arable and horticultural crops. LGN6 is a grid-map with a resolution of $25 \mathrm{~m} \times 25 \mathrm{~m}$. The BRP map is based on field inventories, for which the grower has indicated the crops per field. In Figure 3.2, an example of an overlay is shown of both maps. The figure shows that orchard sizes and dimensions differ per map. Some fruit orchards that are on the LGN6 map are not on the BRP map and vice versa. Also, the orchards of LGN6 appear to be merged sometimes. Table 3.2 summarises the mean- and median fruit-orchard sizes for both maps. The BRP map, which is based on an annual survey among farmers was considered to be the best source (pers. Comm. Massop). The Working Group decided that the simulated fruit orchard should have a median size derived from the BRP map for the selected units, of 1.39 ha, rounded to 1.4 ha. 


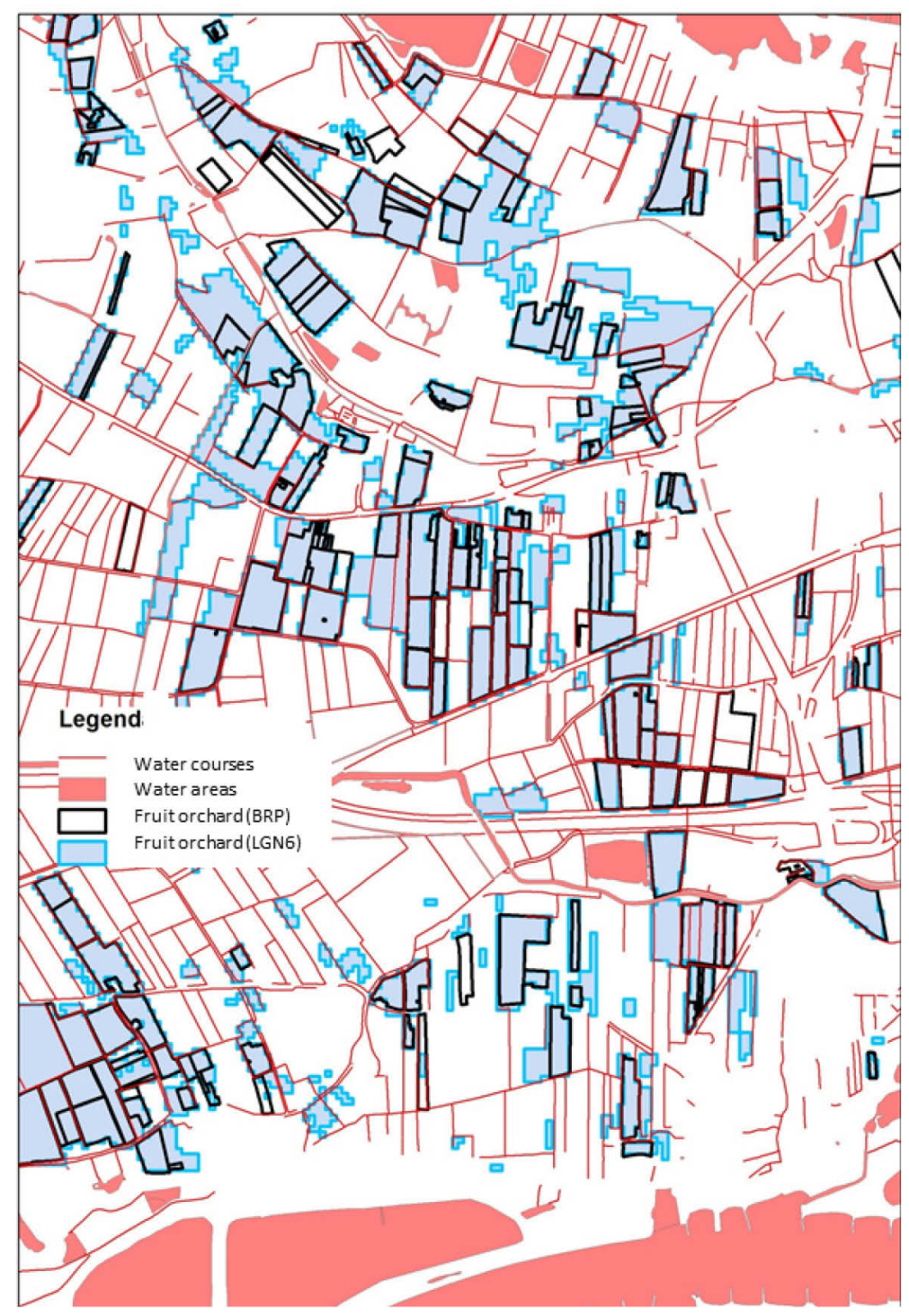

Figure 3.2 Example of an area with fruit orchards as defined by the BRP map (black lines) and the LGN6 map (blue lines). Water area and water courses are indicated in red.

Table 3.3 Fruit orchard surface areas as derived from the BRP map and the LGN6 map. 'All units' refers to the target level units that were simulated by the groundwater model, Moria, in the Rivierenland area. 'Selected units' refers to the target level units in the Rivierenland area that were selected for the flow velocity derivation.

\begin{tabular}{l|l|llll} 
& BRP map & \multicolumn{3}{c}{ LGN6 map } \\
& Netherlands & All units & Selected units & All units & Selected units \\
\hline $\begin{array}{l}\text { Number of fruit- } \\
\text { orchards }\end{array}$ & 9870 & 2330 & 544 & 2476 & 567 \\
\hline Mean (ha) & 1.98 & 1.78 & 2.00 & 2.41 & 2.46 \\
\hline Median (ha) & 1.31 & 1.28 & 1.39 & 0.44 & 0.27
\end{tabular}

\subsubsection{Final configuration}

Figure 3.3 shows the final configuration of the simulated ditch. For pesticide fate calculations, a ditch length of $300 \mathrm{~m}$ was simulated, with the evaluation part of the ditch in the centre (from 100-200 m). This ditch is situated parallel to the tree rows. The size of the fruit orchard is 1.4 ha with a depth perpendicular to the evaluation ditch of $140 \mathrm{~m}$. 


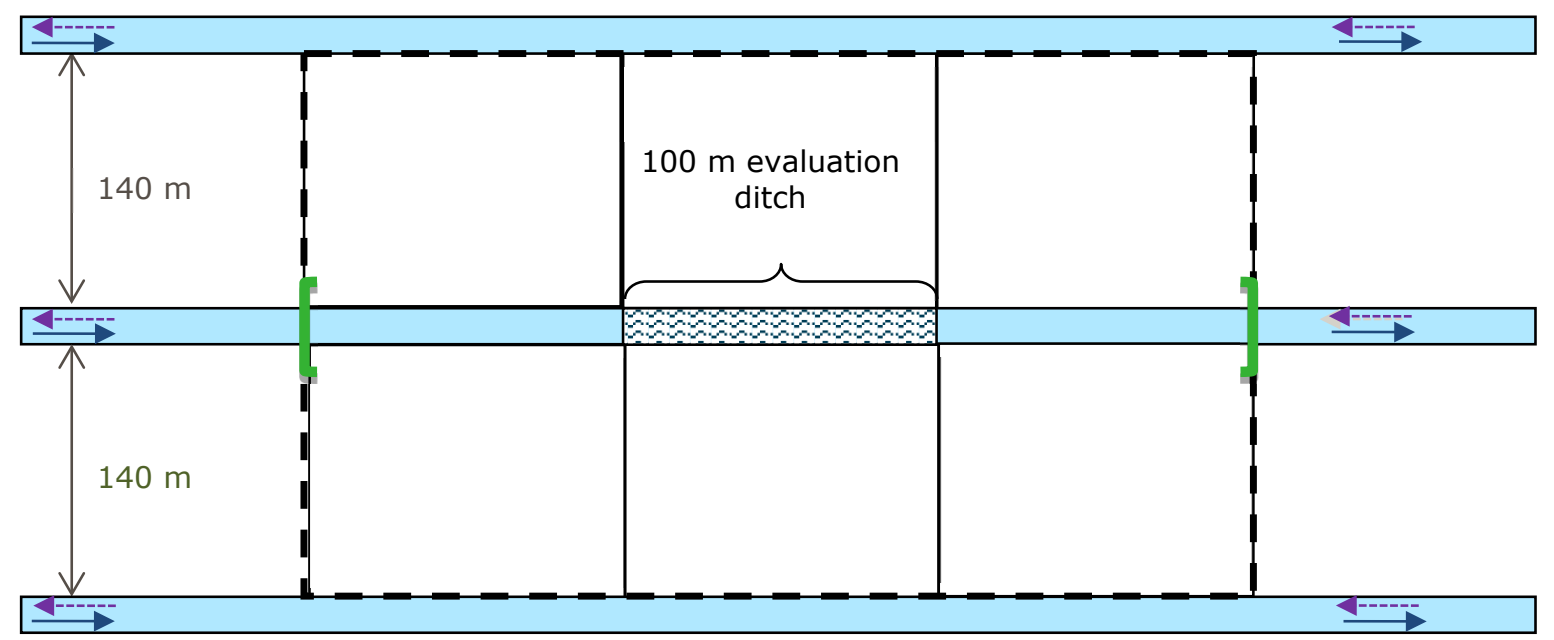

$4----$ Direction of water flow at (river) water-inlet situation (summer).

Direction of water flow at water-outlet situation (winter)

- 7 Part of the ditch in which the

_ _ hydrology is simulated with SWQN Weir

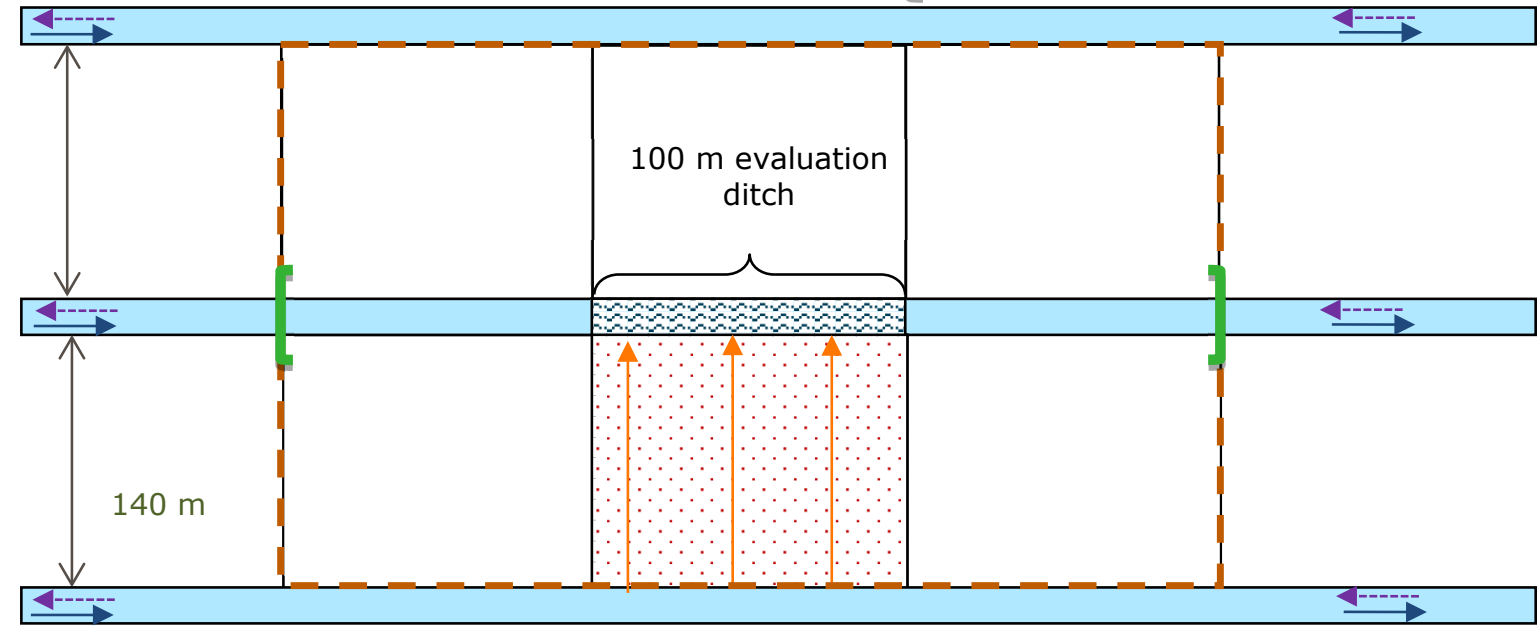

Spray drift and drainage from treated field
Field, $100 \%$ treated with pesticides

Field, untreated

$1-1$

Part of the ditch in which the pesticide fate is simulated with TOXSWA

Figure 3.3 Schematic layout of the $100 \mathrm{~m}$ evaluation ditch with adjacent field. Upper part: position of the evaluation ditch in landscape and the hydrological situation simulated with SWQN. Lower part: Pesticide entries from the field adjacent in the evaluation ditch simulated with TOXSWA. The model will be extended with drainpipe emission. How this will be described in a separate document.

Boesten et al. (2018) showed that the contribution from the drainpipe emission is a relevant entry route, especially when drift reduction measures are taken of classes higher than $95 \%$. The contribution from the drainpipe is therefore explicitly included in the scenario. 


\subsection{Water depths}

The water depth of the evaluation ditch, as given in Table 3.1 refers to an average water depth measured in a wet winter situation. In real-life the water-depth fluctuates driven by excess precipitation and correlates with flow-velocity dynamics; the larger the velocity the higher the water depth in the ditches and vice versa. The hydrodynamic model SWQN is used to derive a consistent and realistic correlation between the time variable water-flow velocities and the water depth. The model is calibrated, such that the simulated water depths are consistent with those assumed in the scenario selection procedure:

i. The winter water depth had to be equal to the Betuwe Stroomruggronden ditch, i.e. $30 \mathrm{~cm}$.

ii. Water depths had to be the same in the summer and in the winter, i.e. the maximum summer water depth should be no more than $5 \mathrm{~cm}$, plus or minus the winter water depth.

These two requirements were considered not very specific. Is the winter water depth the median value, the mean value or a 90th percentile in time? And how are the water levels defined?

Ad (i) Winter water depth. The water depth for the winter period is based on Massop et al. (2006). Massop et al. (2006) measured water depth in a wide range of ditches. Measurements were taken in winter times, when the saturation of the soils was highest. The corresponding temporal percentile of these water depths is unknown. The definition of a wet winter period may apply, which is 'exceeding the mean highest groundwater level 30 days a year'. In Tiktak et al. (2012a), this definition was used and translated to 'exceeding the mean highest water level 30 days a year'.

Ad (ii). Summer- and winter levels. Water managers of the water boards apply different target polder water levels in summer and winter. The target polder water level in summer is usually higher than the target polder water level in winter. Definitions for summer- and winter target levels are not well established. The target levels refer, however, to fixed levels that are imposed officially over a certain period $^{2}$.

The water managers aim to maintain the target polder water levels in the centre of the drainage level area (polder). The Rivierenland Water Board estimates that levels are met for 80 percent of the time. Deviations from the target level may occur mainly due to intensive rain events or intensive waterspraying events to prevent frost damage in fruit orchards (pers. comm. Rivierenland Water Board). These deviations are accepted by the Water Board. Ranges are accepted between $-25 \mathrm{~cm}$ and $+25 \mathrm{~cm}$ in the summer and $-30 \mathrm{~cm}$ and $+20 \mathrm{~cm}$ in the winter of the target level. Also water depths reaching the soil surface are anticipated to occur once in ten years.

The everyday practice shows that the polder water level is regulated by weirs. Regulation occurs mostly manually, but the most important weirs are controlled automatically. A rule of thumb is that the target level of the weir is about $5 \mathrm{~cm}$ lower than the target polder water level in summer and the target level of the weir is about $5-10 \mathrm{~cm}$ lower than the target polder water level in winter. In vulnerable areas, the weir height is adapted more frequently than other areas (pers.comm Rivierenland Water Board).

Given the definitions as applied by the Water Board and the definition of the wet winter water depth, and that the parameterisation of the evaluation ditch should be conservative in the sense that underestimation of the water depth gives less dilution and, hence, higher concentrations, the two conditions for the water depths was interpreted, as follows:

i. The winter water depth, as provided by Massop et al. (2006), is assumed to 'exceed the mean highest water level 30 days a year'. This excess belongs to the winter situation only (six months). Hence, the percentile corresponding to the water depth of $30 \mathrm{~cm}$ will be: $100-(100 * 30 / 180)=$ $83.33^{\text {th }}$ percentile.

\footnotetext{
2 The website of the 'Hollandse Delta' Water Board uses the following definitions (in Dutch):

- Winterpeil: Een vast peil dat in de winterperiode (meestal september tot april) wordt gehanteerd. De periode wordt in het peilbes/uit vastgelegd en mag ook afhangen van de weersgesteldheid.

- Zomerpeil: Een vast peil dat in de zomerperiode (meestal april tot september) wordt gehanteerd. De periode wordt in het peilbes/uit vastgelegd en mag ook afhangen van de weersgesteldheid.
} 
ii. Water levels should be the same in the summer and in the winter is interpreted as: the $50^{\text {th }}$ percentile of the summer level and the $50^{\text {th }}$ percentile of the summer level are equal.

Furthermore, management of the weirs aims to achieve a difference of ca. $5 \mathrm{~cm}$ between summerand winter weir levels. The calibration of the hydrological model based on these conditions is described in Chapter 5. 


\section{Drainpipe contribution}

\subsection{Introduction}

This section describes the hydrological parameterisation of the drainpipe contribution to the fruit orchard scenario. The approach is based on the Andelst field dataset, which was also used in Tiktak et al. (2012b) for the arable crop scenario. The Andelst dataset is currently the only dataset available that includes preferential flow, which is simulated by SWAP and PEARL ${ }^{3}$. At the Andelst field site preferential transport through cracks and macropores was measured for several test compounds (Smelt et al., 2003). Both shrinkage cracks and permanent macropores (worm holes and perished roots) were observed. At the Andelst test location winter wheat was grown. The Andelst soil type is considered as comparable to Dutch orchard soil types.

In this chapter only the hydrological parameterisation is discussed. We refer to Boesten et al. (in prep), for the description of the fruit orchard exposure scenario and on how the drainpipe impacts the Predicted Environmental Concentration and the corresponding selection of the temporal percentile.

\subsection{Hydrological parameterisation}

The Andelst dataset covers one year which was extended to a 15-year dataset by Tiktak et al. (2012b) while using weather information from De Bilt weather station and a nearby groundwater bore hole. For the parameterisation of the fruit orchard scenario we used this 15-year dataset and the corresponding hydrological parameterisation of SWAP as a starting point. Soil parameterisation, parameterisation of the lower boundary condition and drain characteristics are the same.

A summary of the aspects of the parameterisation described in Tiktak et al. (2012b) which were included in the parameterisation of the SWAP model for the drainage orchard scenario are described in the sections below. Deviations from Tiktak et al. (2012b) are addressed explicitly. Soil and drain parameterisation are discussed in Section 4.2.1-4.2.5.

No ploughing was simulated (ploughing is not common for fruit orchards). Tiktak et al. (2012b) assumed an annual ploughing event on 15 October for the drainage scenario for arable crops. Note that ploughing has no effect on the simulated water fluxes. The used version of the SWAP model (Swap 3.2.37t) does not include concepts for altering of the geometry of the macropore structure by ploughing and/or tilling (Kroes et al., 2017).

The meteorological data from meteorological station De Bilt used for the arable crop scenario was replaced by data from meteorological station Herwijnen (Section 4.2.6).

Crop characteristics were initially parameterised based on the FOCUS apple parameterisation, assuming a uniform system without irrigation. This parameterisation was also used to derive the temporal percentile for the drainage route (see Boesten et al., in prep.). Comparison of water balances of this uniform system with water balances resulting from simulations with the arable crop scenario showed high unrealistic seepage fluxes. Therefore, the parameterisation of SWAP was reconsidered, which led to further refinement. In Section 4.3 considerations are discussed based on additional details on typical orchard configuration and water management.

\footnotetext{
3 The PEARL model (Pesticide Emission Assessment at Regional and Local scales) describes the fate of pesticides in the plant-soil system and it is coupled to the hydrological model SWAP (Soil Water Atmosphere Plant). SWAP simulates vertical transport of water and heat in unsaturated/saturated soils. SWAP and PEARL use a common input file, the *.prl file.
} 
The final and selected parameterisation of SWAP of the Andelst scenario to be used as part of the risk assessment for orchard crops is provided in Annex 3 (with the extension .prl, i.e. the common extension for input files of PEARL).

\subsubsection{Soil type}

The soil of the Andelst field site is characterized as a young Holocene river bank deposit of the River Rhine. The clay profile, which reaches to about $3 \mathrm{~m}$ depth, is underlain by a thick layer of coarse sand which is in direct contact with the nearby river Waal and therefore acts as a natural drain (Smelt et al., 2003). The arable layer $(0-26 \mathrm{~cm})$ contains on average $28 \%$ clay.

Some general soil properties are given in the Table 4.1 below:

Table 4.1 Soil properties at the experimental site in Andelst (Tiktak et al., 2012b).

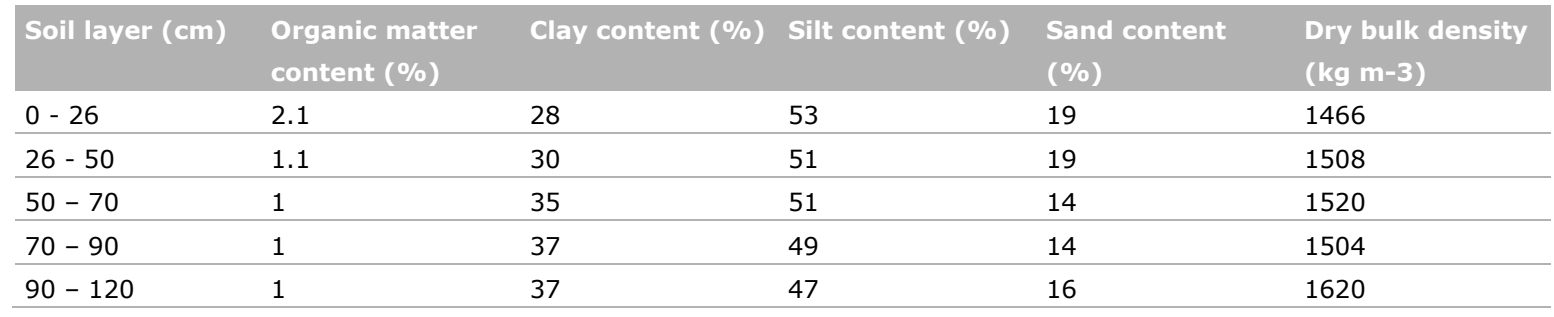

Segmentation and corresponding soil properties as used in the SWAP parameterisation of the fruit orchard exposure scenario is given in Annex 2, Table A2.1.

\subsubsection{Soil physical properties}

Soil water retention characteristics and unsaturated hydraulic conductivity are represented in SWAP by Mualem Van Genuchten functions. Parameter values for these functions were fitted to the Andelst dataset and described in Annex 2, Table A2.2.

\subsubsection{Macropore geometry}

The macropore parameterisation is the same as for the arable crop scenario. The following information, providing a description of the macropore geometry in SWAP on the basis of three properties (i.e. continuity, persistency, macropore shape), is taken from Tiktak et al. (2012b).

\section{Continuity}

In SWAP, macropores are divided into two domains: 1) the bypass domain and 2) the internal catchment domain:

1. The bypass domain represents the main system of continuous structural and shrinkage cracks as well as root and worm holes. It is a network of continuous, horizontally interconnected macropores. These macropores penetrate deep into the soil profile and are assumed to be horizontally interconnected. In the main bypass domain, water is transported fast and deep into the soil profile, bypassing the soil matrix. This may lead to rapid drainage towards drainpipes and short-circuiting between the soil surface and the groundwater.

2. The internal catchment domain consists of discontinuous, non-interconnected macropores ending at different depths in the profile. In this domain, water is captured at the bottom of individual macropores, resulting in forced infiltration of macropore water into the soil matrix.

\section{Persistency}

The macropore volume of the two domains is further subdivided into a static macropore volume and a dynamic macropore volume. The static macropore volume consists of structural shrinkage cracks, biopores and macropores that originate from tillage operations. Dynamic macropores originate from the shrinking of the soil matrix due to soil moisture loss. Shrinking is generally restricted to soils that 
contain a substantial amount of interlayered clay minerals (particularly smectites and vermiculites) and/or organic matter (peats).

\section{Macropore shape}

Macropore shape is described by an effective soil matrix polygon diameter $\left(d_{p o l}\right)$. Macropore shape affects the exchange of water between the soil matrix and the macropores: in soils with a large effective matrix polygon diameter, exchange will be relatively slow because of the relatively small vertical area of macropore walls per unit of horizontal area. The effective matrix polygon diameter is also related to crack width, which affects rapid drainage to drainpipes. It is assumed that the effective soil matrix polygon diameter is a function of depth with its minimum value at the soil surface where macropore density is maximal, and consequently distances between macropores are relatively small.

Tiktak et al. (2012b) and Kroes et al. (2017) provide an elaborated description of the mathematical model of the macropore geometry in SWAP.

\subsubsection{Table A2.3 in Annex 2 provides the parameterisation in SWAP of the macropore geometry for the fruit orchard exposure scenario. Drainage}

SWAP was parameterised for a single drainage system. Flow toward the drains happens from a network of horizontally interconnected macropores (i.e. the bypass domain), the so-called rapid drainage flux, and from the soil matrix.

The rapid drainage flux is calculated from the hydraulic head difference between the simulated groundwater level in the bypass domain and the drainage level and using a rapid drainage resistance:

$q_{r d}=\frac{z_{g w l, b y p}-z_{d r a}}{\gamma_{r d, a c t}}$

where $q_{r d}\left(\mathrm{~m}^{3} \mathrm{~m}^{-2} \mathrm{~d}^{-1}\right)$ is the rapid drainage flux, $Z_{g w l, b y p}(\mathrm{~m})$ is the water level in the bypass domain, $z_{d r a}(m)$ is the depth of the pipe drainage system, and $Y_{r d, a c t}(d)$ is the actual rapid drainage resistance.

The drainage flux from the soil matrix is calculated from the head difference between the groundwater level in the soil matrix and the drainage level and using a drainage resistance:

$q_{m d}=\frac{z_{g w l, m a t}-z_{d r a}}{\gamma_{r d, a c t}}$

where $q_{m d}\left(\mathrm{~m}^{3} \mathrm{~m}^{-2} \mathrm{~d}^{-1}\right)$ is the drainage flux from the soil matrix, $Z_{g w l, m a t}(\mathrm{~m})$ is the water level in the soil matrix, and $Y_{m d}(\mathrm{~d})$ is the drainage resistance.

Table A2.4 in Annex 2 provides the parameterisation in SWAP of the drainage system for the fruit orchard exposure scenario.

\subsubsection{Lower boundary condition}

The Cauchy boundary condition was used, in which the bottom boundary flux is calculated using the hydraulic head difference between the phreatic groundwater level and the underlying (semi-confined) aquifer and a resistance of the in-between aquitard:

$$
q_{b o t}=\frac{\Phi_{a q f}-\Phi_{g w l}}{\gamma_{a q t}}
$$

where $\Phi_{\text {aqf }}(\mathrm{m})$ is the hydraulic head of the semi-confined aquifer, $\Phi_{\text {avg }}(\mathrm{m})$ is the phreatic head and $Y_{a q t}(\mathrm{~d})$ is the vertical resistance of the aquitard. 
Hydraulic heads were available from continuous measurements (Tiktak et al., 2012b). The measurements showed that the head gradient was generally small, so the resistance of the semiconfining layer was set by Tiktak et al. (2012b) to a small value of 5 days. Observations of the hydraulic heads of the semi-confined aquifer from DINO database (www.dinoloket.nl) were used to calibrate the model. Note that the latter data was only available for the period $1991-2005$, confining the extension of the Andelst data set and thus the evaluation period to 15 years (1991 -2005).

\subsubsection{Meteorology}

Daily data from the KNMI Meteostation Herwijnen of the period 1991 - 2005 were used (https://www.knmi.nl/nederland-nu/klimatologie/daggegevens) for the simulation of drainage water fluxes with the SWAP model. Tiktak et al. (2012b) use weather data from De Bilt station for the arable crop scenario. It was decided to use the Herwijnen data because Herwijnen is one of the Dutch meteorological stations used for the drift calculations as part of the scenario derivation procedure (Boesten et al., 2018) and the selected scenario ditch is of the hydrotype 'Betuwe stroomruggrond', these types of ditches are typically located in the meteorological district Herwijnen (Boesten et al., 2018). The average annual precipitation is about $75 \mathrm{~mm}$ lower at station Herwijnen (orchard scenario) than at station De Bilt (arable crops).

The KNMI data provides reference evapotranspiration according Makkink. Initially, SWAP was parameterised for a uniform system (i.e. the orchard with its tree strips and grass strips is represented by an one-dimensional soil column). Therefore, the crop factors of the FOCUS Groundwater Hamburg apples scenario were used. These factors are related to evapotranspiration according Penman-Monteith ${ }^{4}$ (further abbreviated to P-M). Hence it was considered more appropriate the use reference evapotranspiration according P-M. Therefore, meteorological data from the Herwijnen meteostation was used to calculate reference evapotranspiration according P-M following the method described in Allen et al. (1998).

Herwijnen precipitation data is not lacking in the period $1^{\text {st }}$ January $1991-4^{\text {th }}$ May 1993 and data on vapour pressure (needed for the calculation of reference evapotranspiration according $\mathrm{P}-\mathrm{M}$ ) is missing for the period $1^{\text {st }}$ January $1991-23^{\text {rd }}$ April 2009. Data of nearby meteorological station De Bilt were used to fill these gaps. The expected effect of filling the missing data from that of a nearby meteorological station is considered to be small.

Furthermore, data from the period 2001-2005 was copied to the warm-up period 1986 - 1990 (after correction for leap years) ${ }^{5}$.

For simulating preferential flow information on precipitation events (i.e. start and end time of a precipitation event and amount of precipitation) is needed. Only daily rainfall duration is provided by the KNMI for the Herwijnen meteorological station. Similar to Tiktak et al. (2012b; section 5.2 on p. 51) a simplifying assumption that all rain fell in the first hours of the day, with the number of hours being equal to the rainfall duration was made.

\footnotetext{
4 The crop factor is defined as the ratio of evapotranspiration observed for the crop studied over that observed for the well calibrated reference crop under the same conditions. For a given set of weather data, different methods to calculate the reference evapotranspiration will give different answers. Hence, the crop factors using different definitions of the reference evapotranspiration will be different. Crop factors are thus linked to a specific definition of the evapotranspiration.

5 The correction for leap years for the warm-up period was done as follows. Data of the year 2004 was attributed to the year 1989. The year 2004 is a leap year, but the year 1989 is not. Therefore, the data of 29 February 2004 was removed from the dataset. Data from the year 2003 was attributed to the year 1988 . The year 2003 is not a leap year, but the year 1988 is a leap year. Therefore, data of 28 February 2003 was attributed to 29 February 1988.
} 


\subsection{Crop specific issues in the parameterisation:}

\subsubsection{Geometry of the orchard system and impact on the water balance}

The fruit orchard scenario is based on Dutch apple orchards. Apple trees are commonly grown in rows at a distance of $3 \mathrm{~m}$ with $1 \mathrm{~m}$ distance between the trees in a row (this gives 3333 trees per ha). Below the trees there is a strip of about $1 \mathrm{~m}$ that is kept bare and the remaining $2 \mathrm{~m}$ between the rows is grown with grass (Figure 4.1 ).

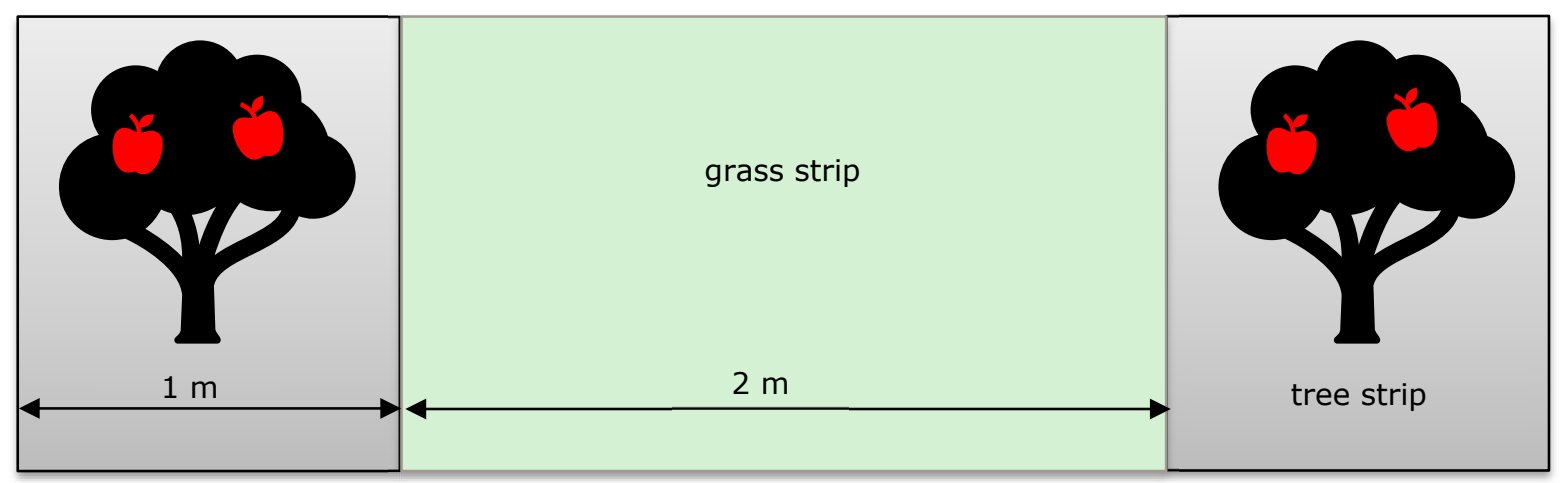

Figure 4.1 Geometry of a typical Dutch apple orchard.

About $75 \%$ of Dutch fruit growers have irrigation systems which they use for drip irrigation. Irrigation is applied daily if needed. Bal and Verhage (2011) indicate that the variation in annual water need between dry and wet years is between $36-147 \mathrm{~mm}$ (based on the total surface area of the orchard). In an average year the annual irrigation is typically $110 \mathrm{~mm}$ (personal communication

M.P. van der Maas, 2019). The irrigation is applied only to the 1-m tree strip which receives an annual irrigation of $330 \mathrm{~mm}$ whereas the 2-m grass strip is not irrigated. This difference in irrigation between the grass strip and the tree strip is expected to lead to considerable differences between the water balances in the soil below the two strips.

\subsubsection{Approach for the simulation}

The SWAP soil hydrological model is a 1-D model, simulating the hydrological processes of the plant atmosphere, and in the soil. It was decided to parameterise the tree and the grass strips separately and merge the drain flows hereafter. The effect of this separate approach was assessed by comparison with calculations done for a uniform system.

\subsubsection{Estimation of crop factors and LAI}

\section{Role of crop factors and LAI in the hydrological model}

For the Andelst parameterisation SWAP follows a two-step approach for calculating actual transpiration and soil evaporation. First potential evapotranspiration is calculated by multiplying crop factors with reference evapotranspiration (reference was based on P-M), then the potential evapotranspiration is divided into potential evaporation and potential transpiration based on the LAI. Next, actual evapotranspiration is calculated taking into account reduction of root water uptake due to water stress and reduction of soil evaporation due to drying of the top soil. So, the estimation of crop factors and LAI is an important aspect of the parameterisation.

In the following we estimate crop factors and LAI for the tree strip, the grass strip and the uniform system. SWAP requires the course of time of the crop factor and the LAI as input. We used the timing of the different development stages as described in Table 4.2; these were based on expert judgement from Jan van de Zande (Wageningen Plant Research). 
Table 4.2 Course of time of the development stages of Dutch apple trees.

\begin{tabular}{lll} 
Date & Time (relative) & Description \\
\hline 01/Jan & 0.0 & bare \\
\hline 01/Apr & 0.2493 & start of leaf growth \\
\hline $30 /$ Jun & 0.4959 & end of leaf growth (max. evapotranspiration) \\
\hline 31 Oct & 0.8329 & start of late season (start of defoliation) \\
\hline 31 Dec & 1.0 & end of defoliation \\
\hline
\end{tabular}

\section{Crop factor and LAI for the tree strip}

Kodde \& Kipp (1990) reported a water use of $2.5 \mathrm{~L}$ per apple tree in full leaf per $1 \mathrm{~mm}$ Makkink reference evaporation based on Dutch studies and assumed 3000 trees per ha, which gives 7500 L/ha, corresponding with $0.75 \mathrm{~mm}$, which gives a Makkink crop factor of $0.75^{6}$. Maas \& Op 't Hof (2006) reported that Dutch apple trees transpire $0.28 \mathrm{~L} \mathrm{per} \mathrm{m}^{2}$ of leaf and per $\mathrm{mm}$ of Makkink reference evaporation. They assume $7 \mathrm{~m}^{2}$ of leaf for a full-grown tree and 3333 trees per ha which gives $7 \times$ $3333=23331 \mathrm{~m}^{2}$ of leaves per ha (so an LAI of 2.3) and a potential transpiration of $0.28 \times 23331=$ $6533 \mathrm{~L} / \mathrm{ha}=0.65 \mathrm{~mm}$ per $\mathrm{mm}$ of Makkink reference evaporation (calculated back to the total surface area). This corresponds with a crop factor of 0.65 for Makkink (which gives a P-M crop factor of 0.53 for the period July-August ${ }^{7}$; Feddes, 1987). This 0.65 is somewhat lower than the 0.75 found by Kodde \& Kipp (1990) but Kodde \& Kipp indicate that their data was based on ongoing research so the 0.65 of Maas \& Op 't Hof (2006) is considered more reliable.

Because the total area included the grass strip, the numbers have to be calculated back to the 1-m tree strip. This gives a Makking crop factor of $3 \times 0.65=1.95$ and a P-M crop factor of $3 \times 0.53=$ 1.59 .

These numbers include only transpiration so we have to add still the contribution of the potential evaporation from the bare soil. SWAP assumes that the potential soil evaporation is a fraction equal to $\exp (-f \mathrm{LAI})$ of the potential evapotranspiration with $f=0.39$. This is based on measurements of extinction of radiation in canopies by Ritchie et al. (1972). In this equation we need to use the LAI based on the tree strip because the extinction of radiation is caused by the leaves concentrated in the tree strip.

Maas \& Op 't Hof (2006) measured an LAI of 2.3. The LAI of the tree strip is then $3 \times 2.3=6.9$. For an LAI of 6.9 the fraction $\exp (-0.39 \mathrm{LAI}$ ) becomes as low as 0.07 (so $7 \%$ ). If we require that the contribution of the evaporation to the overall crop factor is $7 \%$, subsequently the contribution of the transpiration to the overall crop factor is $93 \%$, which means that the P-M crop factor of 1.59 is $93 \%$ of the total. Consequently, we obtain an overall crop factor of $1.59 / 0.93=1.71$, which gives a contribution of evaporation from the bare soil to the overall crop factor of $0.07 \times 1.71=0.12$. However, FOCUS (2009) uses a P-M 'crop factor' for bare soil of 1.0. So, SWAP should calculate a contribution of the bare soil to the crop factor of $0.07 \times 1=0.07$ and not of 0.12 . To overcome this problem, we used a crop factor for trees in full leaf of $1.59+0.07=1.66$ and modified the $f$ value such that $1.66 \exp (-f \times 6.9)$ equals 0.07 , so $f=0.46$. In autumn and winter, the tree strip is more or less a bare-soil system so its P-M crop factor is estimated at 1.0 (see Table 4.3).

\footnotetext{
6 Not considering evaporation of the bare soil below the trees and evapotranspiration of the grass strip

7 Analogous to the theory in Feddes, 1987, the P-M crop factor $\mathrm{f}_{\mathrm{P}-\mathrm{M}}$ can be derived from the Makkink crop factor, $\mathrm{f}_{\mathrm{M}}$ according:$$
f_{P-M} E T_{P-M}=f_{M} E T_{M}
$$

ETP-M is evapotranspiration according to Penman_Monteith and $\mathrm{ET}_{M}$ is evapotranspiration according to Makkink The multiplication factor ETP-M / ET is given by Feddes (1987) for 10-day period averages. For the period July-August the average multiplication factor $E T_{P-M} / E T_{M}$ is 1.23 , resulting in a $f_{P-M}$ of 0.53 .
} 
Table 4.3 Leaf Area Index (LAI) and Penman-Monteith crop factor as function of the day in the year for the crop fruit trees in the Netherlands as used in the simulations for the tree strip. SWAP interpolates linearly between the dates.

\begin{tabular}{|c|c|c|c|c|}
\hline Date & Time (relative) & LAI & Crop factor & Description \\
\hline 01/Jan & 0.0 & 0 & 1 & No leaves \\
\hline 01/Apr & 0.249 & 0 & 1 & Start growth of leaves \\
\hline $31 /$ Oct & 0.833 & 6.9 & 1.66 & Start of defoliation \\
\hline 31/Dec & 1.0 & 0 & 1 & End of defoliation \\
\hline
\end{tabular}

\section{Crop factor and LAI for the grass strip}

FOCUS (2009) uses a crop factor of 1.0 for grassland. As described before, the potential evapotranspiration of the grass strip is likely to be less than that of grassland when the trees are in full leaf (some shadow of trees, reduced wind speed). Let us assume a grass crop factor of $75 \%$ of the potential value so 0.75 . In autumn and winter, the effect of the trees on the evapotranspiration of the grass strip is likely to be minimal, which leads to a P-M crop factor of 1.0 for this strip, i.e. the same value as estimated for the tree strip. So the crop factor was set at 0.75 between 30 June and 31 October, 1.0 between 31 December and 1 April and interpolated between these values in April-June and November-December (see Table 4.4).

FOCUS (2009) uses a maximum LAI of 4-5 for grass grown for production. The grassed strips are likely to have a lower LAI because they are not grown for production. So it seems reasonable to assume about half the value of FOCUS (LAI of 2.5) for the grass strip for the full year.

Here the correction of $f=0.39$ is not needed because the crop factor is 1 from 1 January to 1 April, so equal to the value for bare soil; contributions of both evaporation and transpiration are reflected in this value. The lower crop factor for the remainder of the year is due to the shadow of the trees and the reduced wind speed and thus applies to both the grass and the bare soil, this value also includes contributions of both evaporation and transpiration and therefore a correction of $f$ as needed for the tree strip is not necessary.

Table 4.4 Leaf Area Index (LAI) and Penman-Monteith crop factor as function of the day in the year for the crop fruit trees in the Netherlands as used in the simulations for the grass strip. SWAP interpolates linearly between the dates.

\begin{tabular}{|c|c|c|c|c|}
\hline Date & Time (relative) & LAI & Crop factor & Description \\
\hline 01/Jan & 0.0 & 2.5 & 1 & No leaves \\
\hline 01/Apr & 0.249 & 2.5 & 1 & Start growth of leaves \\
\hline $31 /$ Oct & 0.833 & 2.5 & 0.75 & Start of defoliation \\
\hline 31/Dec & 1.0 & 2.5 & 1 & End of defoliation \\
\hline
\end{tabular}

\section{Crop factor and LAI for the Uniform system}

The crop factors and LAI were area-weighted averages of the numbers for the tree and grass strips in Tables 3.5 and 3.6: e.g. the crop factor for the full-grown system was calculated as: $1 / 3 \times 1.66+2 / 3$ $\times 0.75=1.05$ (see Table 4.5).

Here the correction of $f=0.39$ is not needed as well because the crop factor is close to 1.0 (i.e. the value for bare soil; contributions of both evaporation and transpiration are reflected in this value). 
Table 4.5 Leaf Area Index (LAI) and Penman-Monteith crop factor as function of the day in the year for the crop fruit trees in the Netherlands used in the simulations for the uniform system. SWAP

interpolates linearly between the dates. Timing of the development stages was based on Table 4.2.

\begin{tabular}{|c|c|c|c|c|}
\hline Date & Time (relative) & LAI & Crop factor & Description \\
\hline 01/Jan & 0.0 & 1.7 & 1 & No leaves \\
\hline 01/Apr & 0.249 & 1.7 & 1 & Start growth of leaves \\
\hline $31 /$ Oct & 0.833 & 4 & 1.05 & Start of defoliation \\
\hline 31/Dec & 1.0 & 1.7 & 1 & End of defoliation \\
\hline
\end{tabular}

\subsubsection{Irrigation}

Van der Maas (1998) reported that optimal yield of apples and pears is obtained at moisture suctions of -300 to $-700 \mathrm{~cm}$ for low numbers of fruits per tree; for high numbers of fruits per tree $-300 \mathrm{~cm}$ is optimal in the period from May to October except for June when $-500 \mathrm{~cm}$ is optimal. These suctions apply to the depth in soil that has the highest root density. Van der Maas \& Op 't Hof (2002) state that a suction of $-450 \mathrm{~cm}$ is optimal for apples from 1 May to 1 August (thereafter $-150 \mathrm{~cm}$ is optimal to obtain the maximum fruit yield). Background of these recommendations is that some moisture stress is desirable to avoid too strong vegetative growth (i.e. leaf development) because this leads to lower fruit production. Thus we included surface irrigation (drip irrigation) that is triggered if the suction at $30 \mathrm{~cm}$ depth becomes lower than $-300 \mathrm{~cm}$ in the period May-October (a more or less worst-case assumption). The amount of irrigation equals then the difference between the actual moisture profile and that corresponding with a suction of $-100 \mathrm{~cm}$ ('field capacity') over the root zone depth.

Dutch farmers supply water by sprinkler irrigation to apples and pears in case of night frost during the blooming period. According to van der Maas (personal communication, 2020) this happens in $50 \%$ of the years with an average of three irrigations in the years that night frost occurs and they use about $20 \mathrm{~mm}$ per night. So for our 15-y simulation period, we should have about 22 events occurring in 7-8 years. Van de Zande et al. (2019) measured the blooming period of apples over an 11-year period and found that it starts between Julian day numbers of 104 to 125 (average 114) and ends between the day numbers 121 and to 142 (average 134). The SWAP input file of the meteo time series of weather station Herwijnen contains the minimum air temperature. Assuming a blooming period based on the averages (day 114 to day 134) and a night frost criterion of a minimum air temperature below $0^{\circ} \mathrm{C}$ resulted for the years 1991-2005 in far too few night frost events. So we increased the blooming period in steps of 2 days and found the best result for a blooming period of 110 to 138 days (i.e. 21 events in 9 years; see Table 4.6). We implemented 21 irrigation events of $20 \mathrm{~mm}$ each both for the tree strip, the grass strip and the uniform system (see Table 4.7). The irrigation intensity was assumed to be $3 \mathrm{~mm} / \mathrm{h}$ which is realistic according to van der Maas. The irrigation events had to be implemented by changing the meteorological input files because SWAP already simulates suctiondriven drip irrigation (see previous paragraph). For irrigation days which had already some rainfall, the duration of the irrigation ( $20 / 3 \mathrm{~h}=6.68 \mathrm{~h}=0.2778 \mathrm{~d}$ ) was added to the duration of the rainfall.

Table 4.6 Number of night frost events and number of years in which these events occur as a function of the length of the blooming period of apples for the 1991-2005 simulation period based on meteo data of station Herwijnen. The selected blooming period and corresponding night frost events is marked in orange.

\begin{tabular}{|c|c|c|c|}
\hline \multicolumn{2}{|c|}{ Blooming period (Julian day numbers) } & \multicolumn{2}{|c|}{ Night frost events } \\
\hline 114 & 134 & 8 & 4 \\
\hline 112 & 136 & 12 & 5 \\
\hline 111 & 137 & 16 & 7 \\
\hline 109 & 139 & 31 & 11 \\
\hline
\end{tabular}


Table 4.7 Dates of the 21 night frost events in the 1991-2005 simulation period that triggered $20 \mathrm{~mm}$ extra irrigation.

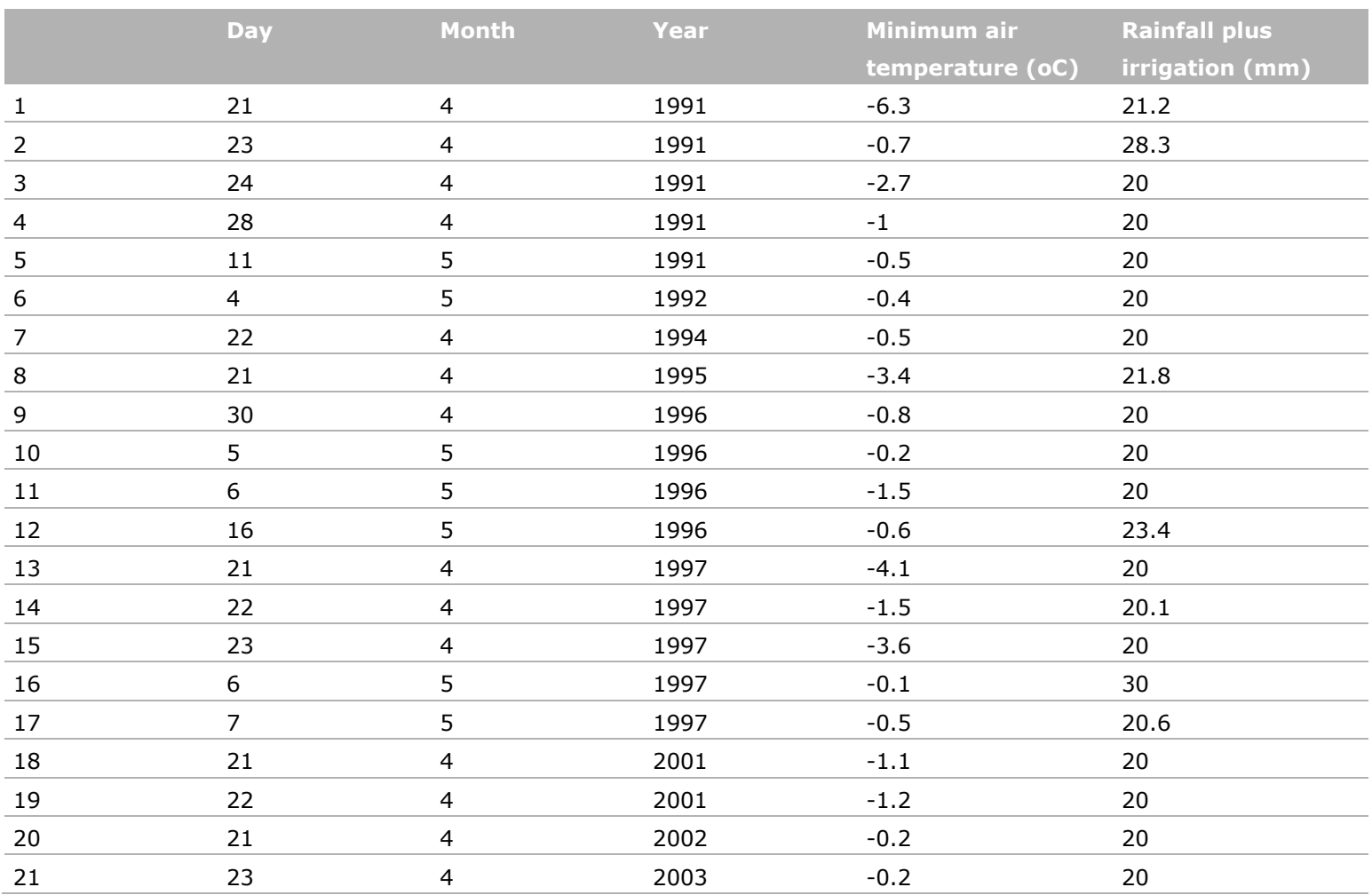

\subsubsection{Further crop parameterisation issues}

In SWAP water stress is described by the function proposed by Feddes et al. (1978). Conform the parameterisation of the FOCUS Groundwater scenario for Hamburg-apples, no root water uptake was assumed for apples at values where the soil pressure head was above $-10 \mathrm{~cm}$ or below $-16000 \mathrm{~cm}$. A linear increase in root water uptake was assumed in case the soil pressure head was between $-25 \mathrm{~cm}$ to $-10 \mathrm{~cm}$, optimal root water uptake was assumed for soil pressure heads between $-500 \mathrm{~cm}$ to $-25 \mathrm{~cm}$ and decrease in root water uptake was assumed in case the soil pressure head was between $-16000 \mathrm{~cm}$ to $-500 \mathrm{~cm}$. For the grass strip and the uniform system the same values were used.

In the FOCUS groundwater scenarios interception of water by the crop was ignored. We considered this not realistic and included interception using the same precipitation interception parameter in the equation of Braden as Tiktak et al. (2012b), i.e. $0.25 \mathrm{~mm} \mathrm{~d}^{-1}$ for all three systems. It is assumed that roots are present in that part of the soil profile that is water unsaturated for most of the year. Therefore, the rooting depth of both the trees and the grass was set equal to the drain depth $(80 \mathrm{~cm})^{8}$. The root density was assumed to be equal over this depth (FOCUS, 2000).

\subsection{Effect of the new parameterisation on the drainage fluxes}

To assess the effect of the different parameterisation options on the simulated water fluxes, a comparison was made between the arable crop parameterisation by Tiktak et al. (2012b), the parameterisation of the two strips, i.e. the grass strip and the tree strip and the uniform system. An overview is shown in Table 4.8.

\footnotetext{
8 In the FOCUS Groundwater scenarios (FOCUS, 2000), the rooting depth of grass varies between 45 and $90 \mathrm{~cm}$.
} 


\section{Comparison between arable crop parameterisation and uniform system (run 1 to 5)}

We compare first the results of uniform apple/grass system without irrigation (run 4) with the results obtained for arable crops (runs 1-3) by Tiktak et al. (2012b). The average annual precipitation is about $75 \mathrm{~mm}$ lower at station Herwijnen (orchard scenario) than at station De Bilt (arable crops). Actual evapotranspiration plus evaporation from intercepted water in run 4 was $512.3 \mathrm{~mm}$ compared with $470-490 \mathrm{~mm}$ in runs $1-3$. So one would expect some $100 \mathrm{~mm}$ less drainage in run 4 . However, the opposite is the case which is caused by the $177 \mathrm{~mm}$ upward seepage in run 4 compared with 30$40 \mathrm{~mm}$ downward seepage in runs $1-3$. We were not able to reproduce the results of runs $1-3$. The difference with respect to the seepage remains unexplained.

Evaporation of intercepted water of run 4 is about three times higher than that of winter wheat and sugar beets. This is probably caused by the fact that apples have leaves during a larger period of the year than winter wheat and sugar beets.

Adding irrigation for the uniform apple/grass system (run 5) resulted in an average annual irrigation of about $200 \mathrm{~mm}$ which seems too high compared with the average of about $110 \mathrm{~mm}$ used in practice.

\section{Water fluxes in the tree strip}

Results for the tree strip (run 6) without irrigation give a potential transpiration of $666 \mathrm{~mm}$ which corresponds with a water layer of $666 / 3=222 \mathrm{~mm}$ considering the whole surface area of the orchard.

Van der Maas \& Op 't Hof (2006) report that a full-grown apple tree well supplied with water transpires about $700 \mathrm{~L}$ per year. This corresponds with a potential transpiration of $230 \mathrm{~mm}$ per year $\left(0.7 \mathrm{~m}^{3} \times 3333\right.$ trees per ha). So the simulated potential transpiration corresponds well with these $700 \mathrm{~L}$ per year. The $405 \mathrm{~mm}$ actual transpiration in this run indicates considerable moisture stress. Adding irrigation (run 7) resulted in an annual irrigation of $368 \mathrm{~mm}$ for the tree strip which equals $123 \mathrm{~mm}$ when calculated back to the total surface area. This corresponds well with the about $110 \mathrm{~mm}$ used in practice to avoid too much reduction of the transpiration (note that on average $28 \mathrm{~mm}$ is irrigated because of night frost protection; 21 events of $20 \mathrm{~mm}$ in 15 years as follows from Table 4.6). Figure 4.2 shows that the suction of the soil moisture at $30 \mathrm{~cm}$ depth was reasonably close to the target value of $-300 \mathrm{~cm}$ in the growing season for two more or less representative years of the 15-year simulation period. The actual simulated transpiration in run 7 was $575 \mathrm{~mm}$ versus $665 \mathrm{~mm}$ potential transpiration. This indicates that there was some but no extreme moisture stress. This seems consistent with the recommendation to have some moisture stress to avoid too strong vegetative growth. 


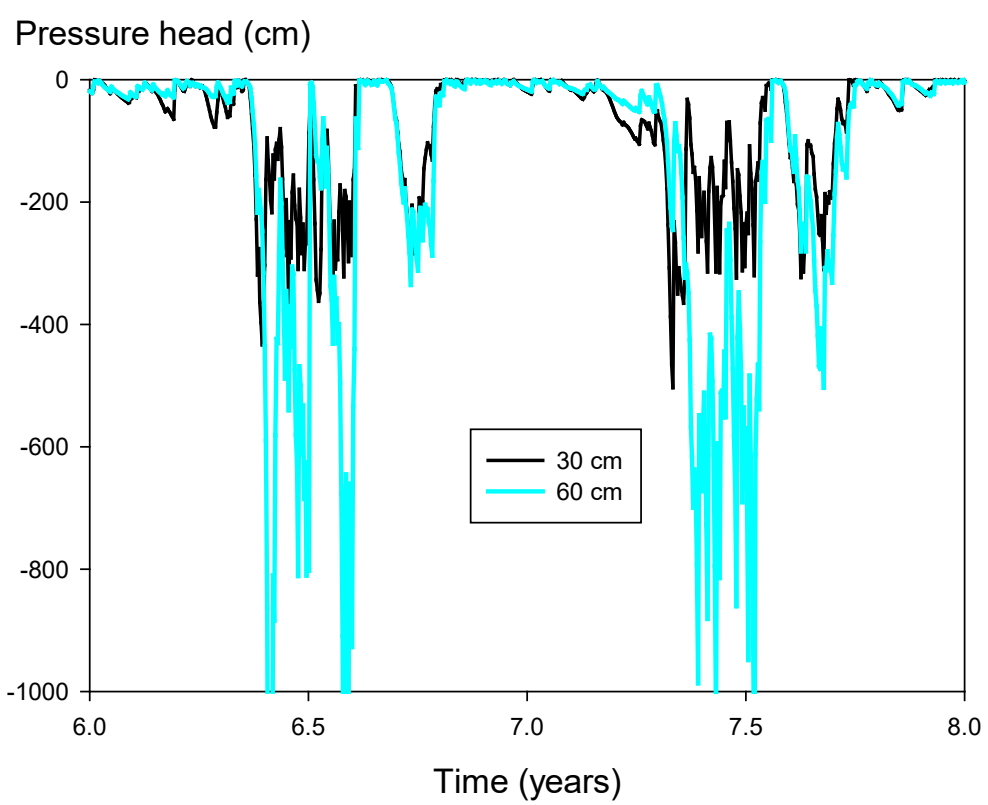

Figure 4.2 The pressure head at 30 and $60 \mathrm{~cm}$ depth as a function of time as simulated for the tree strip assuming irrigation (run 7 of Table 4.8).

\section{Water fluxes in the grass strip}

Results for the grass strip (run 8) with sprinkler irrigation in times of frost, show that calculated actual transpiration is some $400 \mathrm{~mm}$ less than that of the irrigated tree strip. Somewhat surprisingly the average downward flow (i.e. precipitation plus irrigation minus interception evaporation and minus actual evapotranspiration) of the grass strip is even somewhat larger than that of the irrigated tree strip. This is caused by the much lower evapotranspiration plus evaporation of intercepted water from the grass strip $(72+159+184=415 \mathrm{~mm})$ than from the irrigated tree strip $(93+124+575=792 \mathrm{~mm})$ which is only partly compensated by the higher irrigation for the irrigated tree strip ( $368 \mathrm{vs} 26 \mathrm{~mm}$ ).

\section{Conclusion for the parameterisation}

The most realistic approach seems to be to run PEARL both for the grass strip and the irrigated tree strip and to sum on a 1-h basis the drainage fluxes (both water and substance), so by combining the e2t-files of the two runs into one e2t-file.

However, SWAP will simulate different groundwater levels for the grass and the tree strips whereas differences between these levels for the two strips are likely to be very small in reality for this soil because of its macropores. To assess this hypothesis, we compared simulated daily groundwater levels for the two systems. The average absolute difference between the groundwater levels was no more than $0.9 \mathrm{~cm}$.

We decided to simulate the drain fluxes for the grass and tree strips separately followed by summing up the fluxes on an hourly basis, whereby the weight of tree strip was 1 and that of the grass strip was 2. In Table 4.8 this is indicated as run 9.

With respect to drainage, evapotranspiration and seepage differences between run 9 and run 5 (uniform system, irrigated) are not very large. The approach of run 9 is however preferred for the fruit orchard scenario as it mimics best the actual situation in fruit orchards. 
Table 4.8 Average annual water layers $(\mathrm{mm})$ simulated using the Andelst parameterisation for arable crops (winter cereals and sugar beets) and the Andelst parameterisation for fruit (apples) for the period 1991 -2005; 'adapted' indicates use of crop parameters based on Dutch data and 'FOCUS' indicates crop parameters based on the FOCUS Hamburg scenario. 'Uniform', 'grass strip' and 'tree strip' are the three systems considered; 'spr' indicates sprinkler irrigation. Met gives the meteo station ( $d B=$ de Bilt, $\mathrm{He}=$ Herwijnen), $P$ is precipitation, $I$ is irrigation, $Q_{b o t}$ is the bottom boundary flux (positive downward and at $1 \mathrm{~m}$ depth), $E_{\text {int }}$ is evaporation of intercepted water, $E_{\text {sol }}$ is soil evaporation, $E_{t r p}$ is transpiration, $D_{f}$ is downward flow $\left(P+I-E_{i n t}-E_{s o l, a c t}-E_{t r p, a c t}\right), D_{r m}$ is drainage from the soil matrix, $D_{r b}$ is drainage from the bypass domain (i.e. the macropores) and $D_{\text {rtot }}$ is the sum of the two drainages; act. = actual and pot. = potential.

\begin{tabular}{|c|c|c|c|c|c|c|c|c|c|c|c|c|c|c|}
\hline \multirow[t]{2}{*}{$\mathrm{Nr}$} & \multirow[t]{2}{*}{ Crop parameterisation } & \multirow[t]{2}{*}{ Met } & \multirow[t]{2}{*}{$\mathbf{P}$} & \multirow[t]{2}{*}{ I } & \multirow[t]{2}{*}{ Qbot } & \multirow[t]{2}{*}{ Eint } & \multicolumn{2}{|l|}{ Esol } & \multicolumn{2}{|l|}{$E_{\text {trp }}$} & \multirow[t]{2}{*}{$D_{f}$} & \multirow[t]{2}{*}{ Drm } & \multirow[t]{2}{*}{ Drb } & \multirow[t]{2}{*}{ Drtot } \\
\hline & & & & & & & act. & pot. & act. & pot. & & & & \\
\hline 1 & winter cereals adapted* & $\mathrm{dB}$ & 860 & & 42 & 27 & 270 & & 170 & & 393 & 67 & 283 & 350 \\
\hline 2 & winter cereals FOCUS* & $\mathrm{dB}$ & 860 & & 35 & 23 & 284 & & 164 & & 389 & 68 & 268 & 336 \\
\hline 3 & sugar beets FOCUS* & $\mathrm{dB}$ & 860 & & 28 & 34 & 255 & & 196 & & 375 & 70 & 277 & 347 \\
\hline 4 & uniform no irrigation & $\mathrm{He}$ & 785 & & -177 & 81 & 154 & 190 & 277 & 371 & 273 & 64 & 397 & 460 \\
\hline 5 & uniform spr.+drip irrigated & $\mathrm{He}$ & 785 & 198 & -26 & 82 & 176 & 192 & 302 & 369 & 423 & 67 & 383 & 449 \\
\hline 6 & tree strip no irrigation & $\mathrm{He}$ & 785 & & -274 & 93 & 120 & 143 & 405 & 666 & 167 & 60 & 381 & 441 \\
\hline 7 & tree strip spr.+drip irrigated & $\mathrm{He}$ & 785 & 368 & -97 & 93 & 124 & 144 & 575 & 665 & 360 & 64 & 378 & 457 \\
\hline 8 & grass strip sprinkler irrigated & $\mathrm{He}$ & 785 & 28 & -60 & 72 & 159 & 203 & 184 & 240 & 399 & 67 & 392 & 458 \\
\hline 9 & weighted average of $7+8 \#$ & $\mathrm{He}$ & 785 & 141 & -72 & 79 & 147 & 183 & 314 & 382 & 386 & 66 & 392 & 458 \\
\hline
\end{tabular}

* taken from Table 7 in Tiktak et al. (2012b); \#weight of tree strip was 1 and that of the grass strip was 2 because the tree strip was $1 \mathrm{~m}$ wide and the grass strip was $2 \mathrm{~m}$ wide.

\subsection{Final drain pipe contribution to the ditch}

Detailed graphs of run 9 of rainfall and drainage events as a function of time are given in Figures 4.3 4.6. The drainage events feed into the ditch. Parametrisation of the hydrology of the ditch is discussed in the next chapter. 


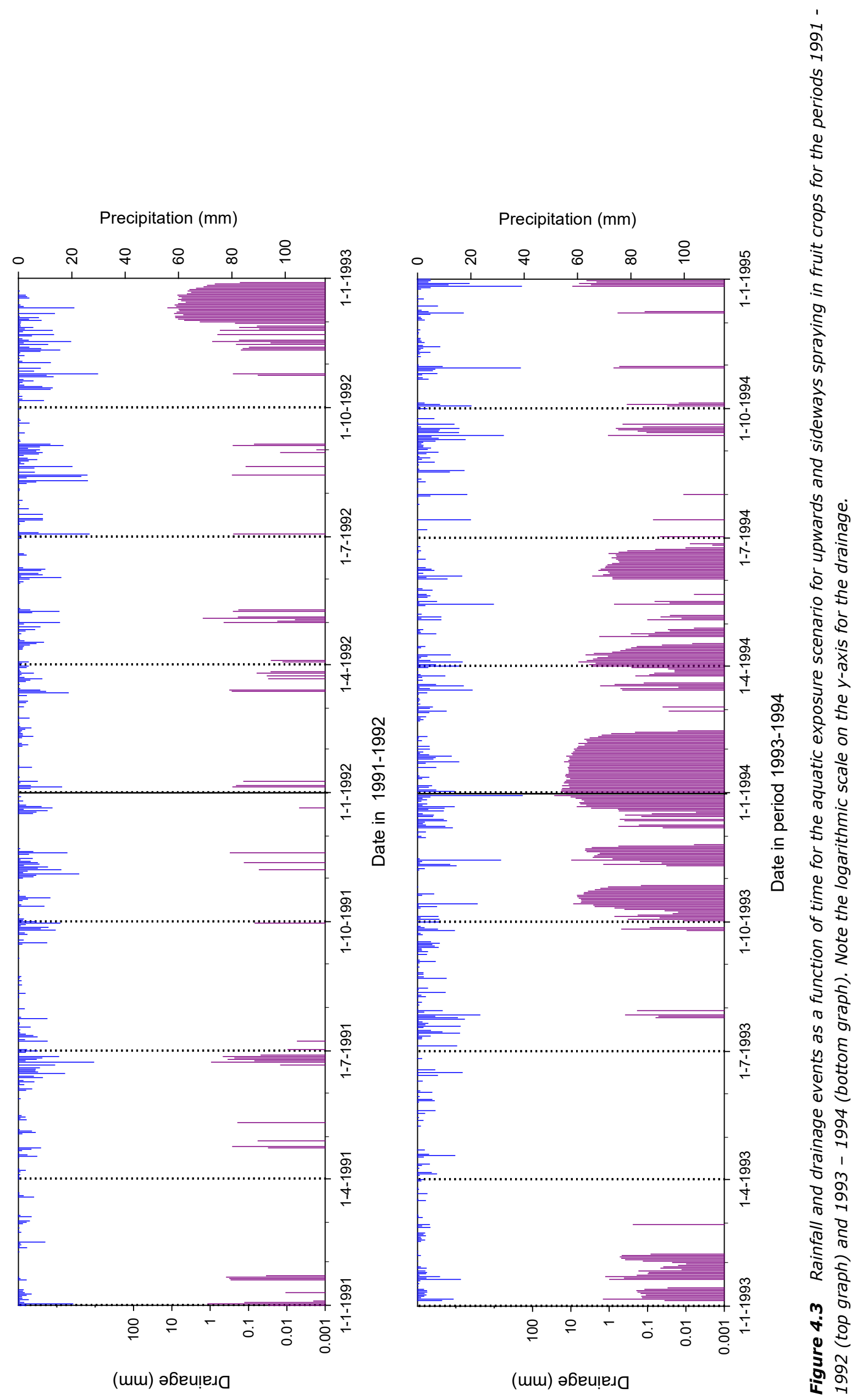




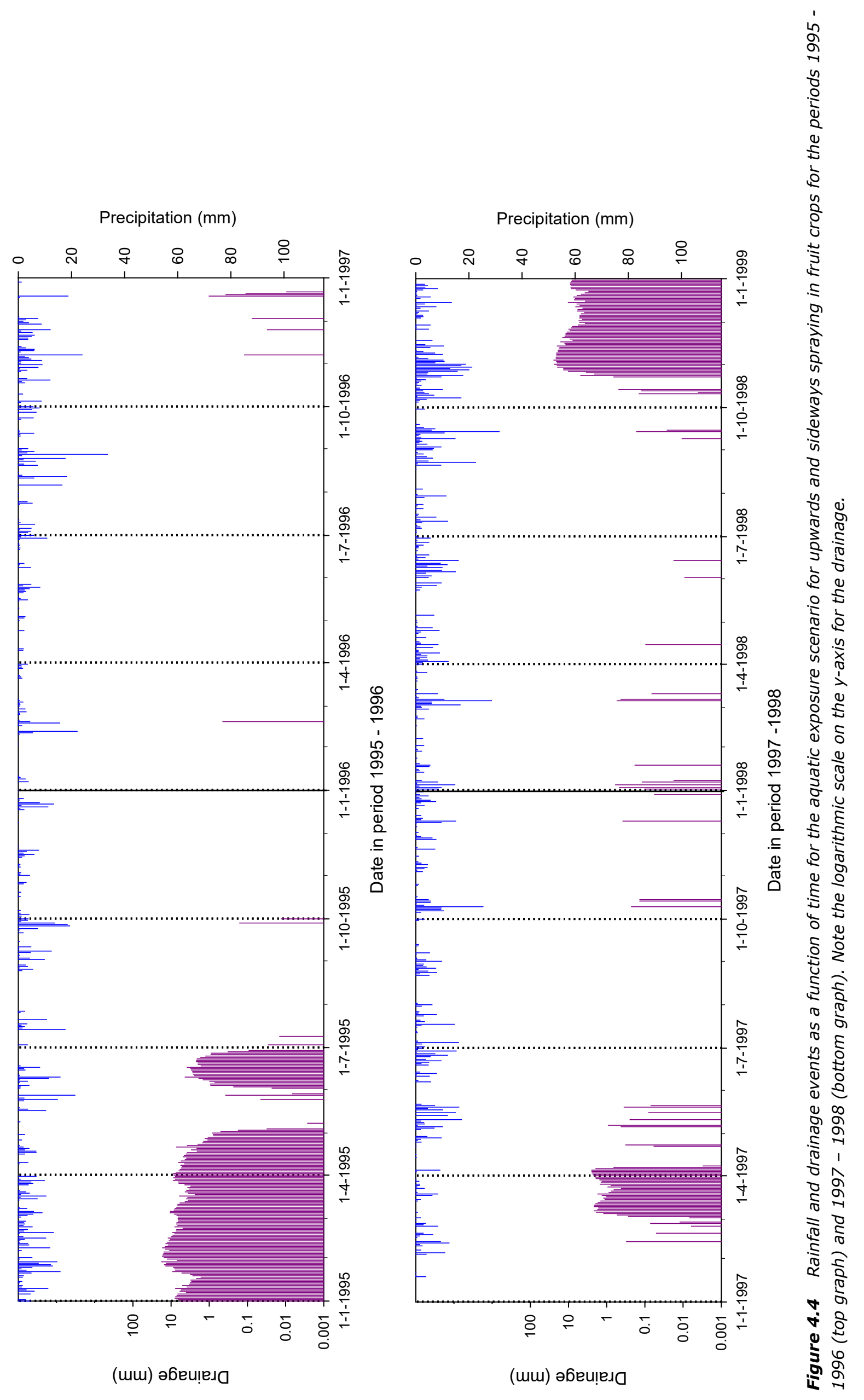




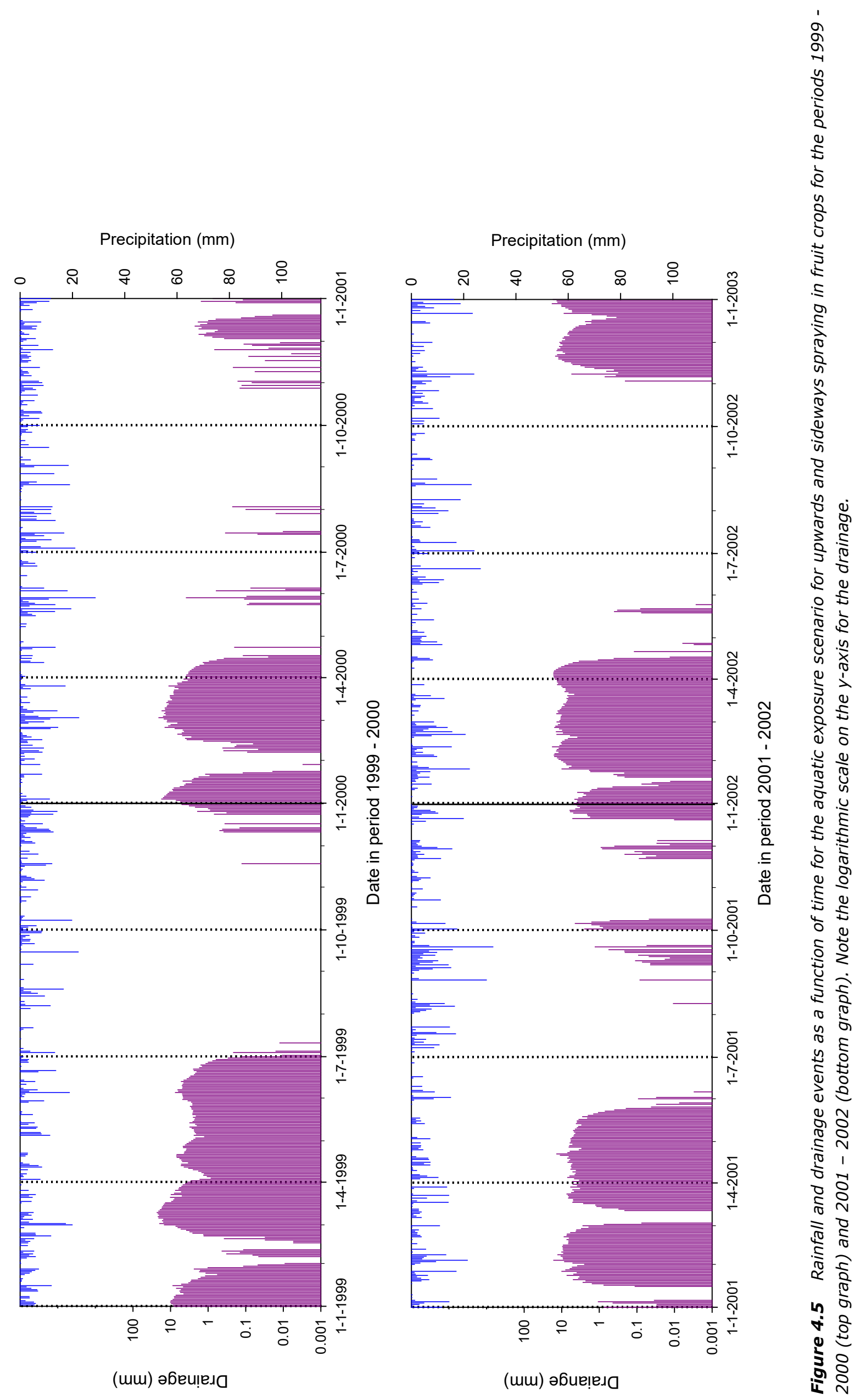




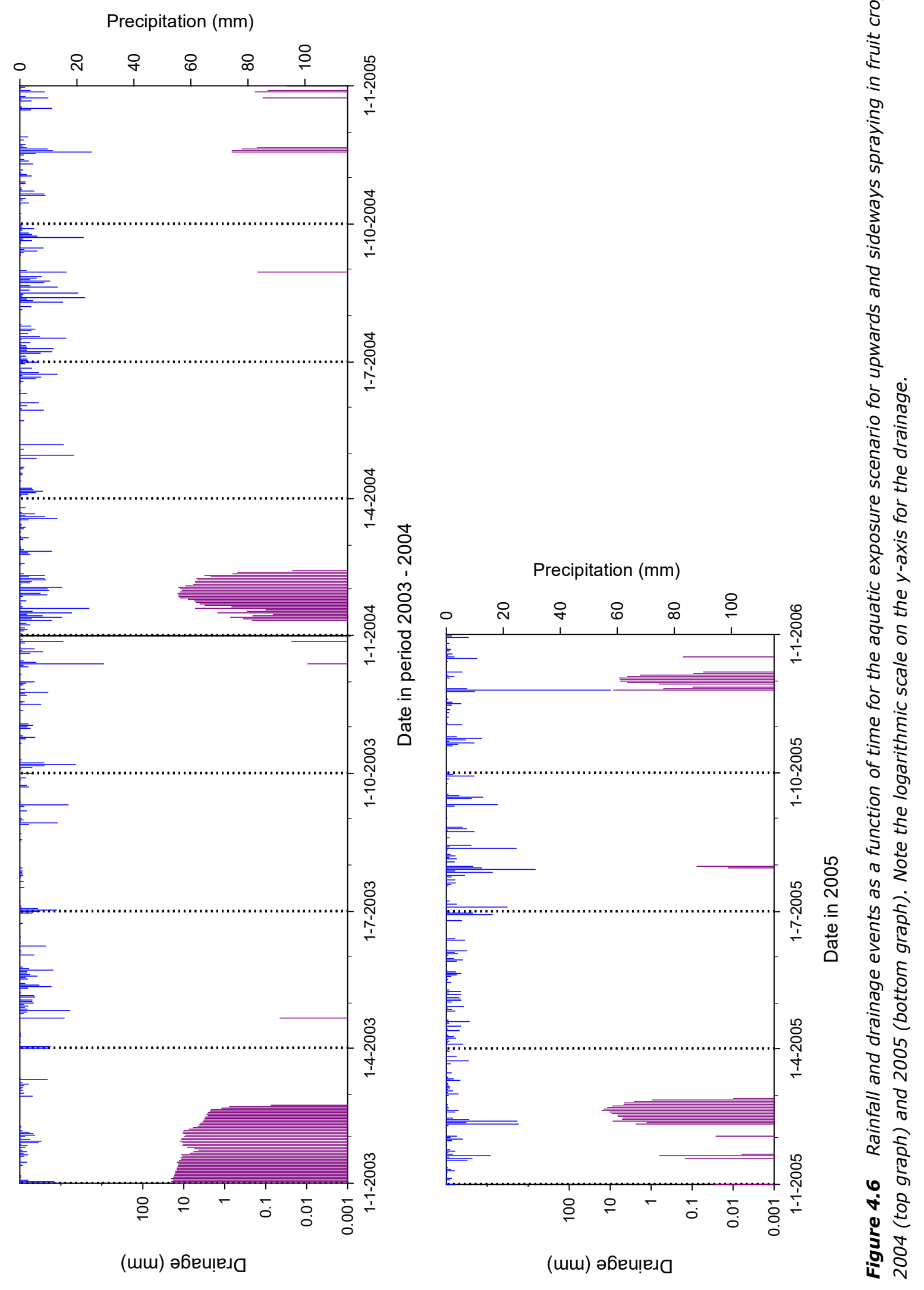

58 | Wageningen Environmental Research report 3017 


\section{Parameterisation of the hydrological model}

\subsection{Schematisation}

SWQN is a dynamic model that simulates water flows and water levels in a schematised network of nodes and sections. Water levels are calculated in the nodes, and the differences in water levels between connected nodes are the driving force behind the (one-dimensional) flow (Smit et al., 2009). The water levels depend upon the storage capacity, and are driven by incoming and outgoing flows imposed on the sections and a number of different boundary conditions. A section can represent an open water course, but also a structure, like a weir or a pump. The SWQN model was adapted to enable hourly output of water levels and discharges per section (instead of daily output). Hourly hydrological data are required for TOXSWA.

The simulated ditch comprises of a length of $300 \mathrm{~m}$. The direction of the water flow alternates between incoming and outgoing. SWQN allows for a number of boundary conditions, including; a fixed water level, a fixed sink/source or a fixed discharge-water level ( $Q-h$ ) relationship. The model does not allow for types of boundary conditions that alternate within one simulation. Also, a section can only be specified as a weir, when it is not connected to a boundary node. To simulate alternating water-flow directions, and to simultaneously maintain a certain minimum water level, these constraints had to be dealt with. The approach followed is explained below.

Firstly, to maintain a certain minimum water level, the parameterised ditch has two weirs located at both sides of the ditch (Figures 5.1 and 5.2). Next, to generate the water flow, a water flux is imposed at the node located at the 'inner-ditch' side of the weir section (i.e. nodes 4 and 34 in Figure 5.2). In case of discharge of water (the blue, solid arrow in Figure 5.1), water is let in on the left-hand side of the ditch, and in case of inlet of water (the purple, dashed arrow in Figure 5.1), this water is let in on the right-hand side of the ditch. Only the downstream weir has a realistic height, i.e. when the water direction is from the weir towards the ditch, the height of the weir is increased, such that it functions as an artificial flow barrier.
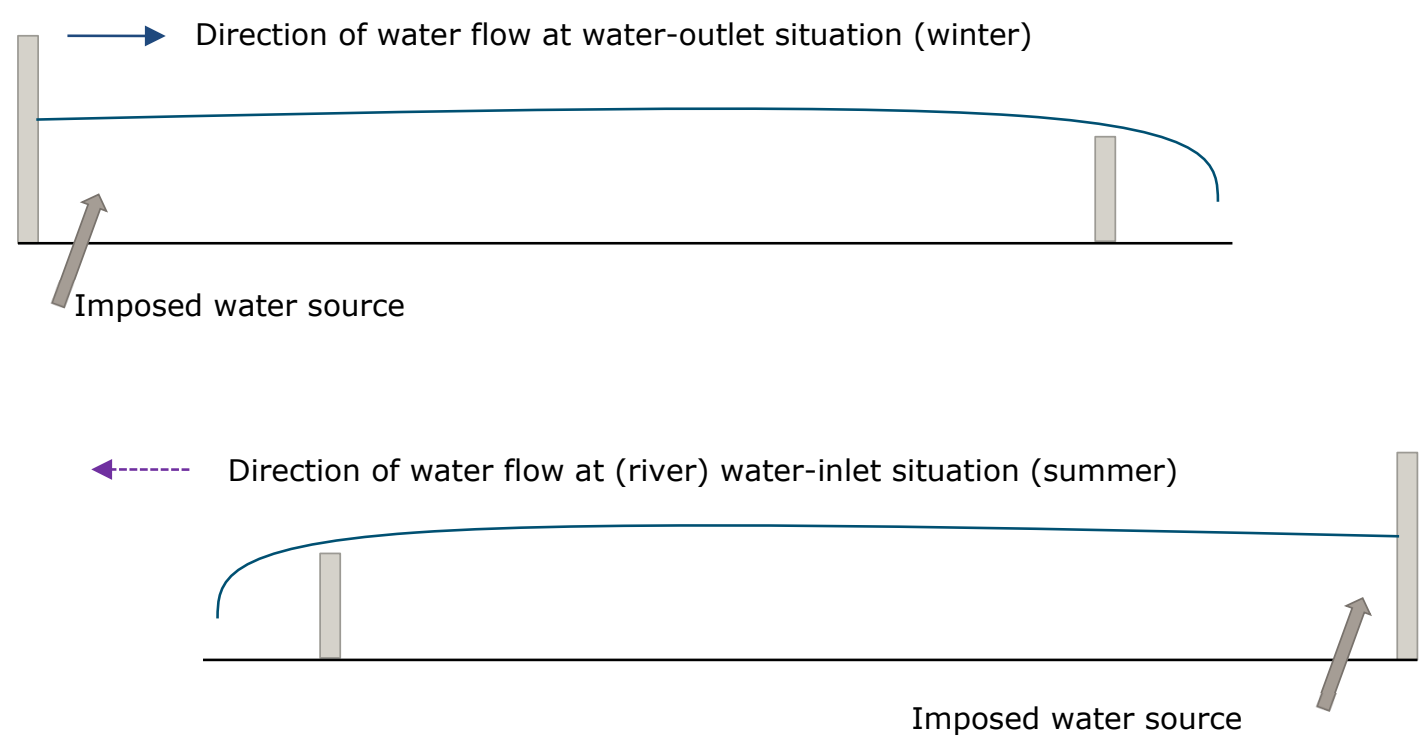

Figure 5.1 Visualisation of the configuration of the weirs in the ditch, as applied in the SWQN parameterisation for simulating alternating water flows in two directions. Only the downstream weir has a realistic height, the upstream weir is used to avoid water flowing in the wrong direction. 
In addition to the imposed water fluxes, at either node 4 or 34 , lateral water fluxes (i.e. drainage) are imposed at the intervening nodes. These water fluxes, which vary in time are calculated with the SWAP model.

\subsection{Parameterisation}

A 360 m long ditch with 36 sections, each of $10 \mathrm{~m}$, was schematised in SWQN (Figure 4.2). The sections connect all 37 nodes, which are defined by a node ID, an $x$ - and $y$-coordinate, a bottom level and a minimum- and maximum water level. The SWQN-simulated discharges and water depths for the 10-m-sections from section number 4 upwards to, and including, section number 33, are to be provided as input to TOXSWA model for the pesticide fate calculations, i.e. discharges and water depths over $300 \mathrm{~m}$ of ditch (with the $100 \mathrm{~m}$ evaluation ditch in the centre) are provided as input to TOXSWA. As TOXSWA needs discharges at the boundaries of the segments and the heads in the centre, a conversion is required. Annex 4.2 describes the method for converting the output of SWQN to input for TOXSWA.

The ditch geometry (bottom width etc.) was parameterised, as shown in Figure 3.1. Starting at Node 1 on the left-side and ending at Node 37 and the right-side, incoming water fluxes were imposed via either Node 4 or Node 34, depending on the flow direction. A discharging situation was defined as water flowing from Node 4 to Node 37. A water-inlet situation was defined as water flowing from Node 34 to Node 1 . The imposed incoming discharges were calculated by multiplying the derived flow velocities from Section 2.4 with the wetted cross-sectional area corresponding to a water depth of $30 \mathrm{~cm}$ (i.e. $0.612 \mathrm{~m}^{2}$; see Figure 3.1). Hence, a constant water depth was assumed.

Lateral water fluxes as a function of time and calculated with the SWAP model (see Chapter 4) were imposed as follows: i) in case of a discharging situation lateral water fluxes were imposed to node 4 up to and including node $33, \mathrm{ii}$ ) in case of a water-inlet situation lateral water fluxes were imposed to node 5 up to and including node 34. For each node, the imposed lateral discharges were calculated by multiplying the drainage water flux from SWAP with the length of the section $(10 \mathrm{~m})$ and the depth of the field (i.e. depth perpendicular to the evaluation ditch: $140 \mathrm{~m}$ ).

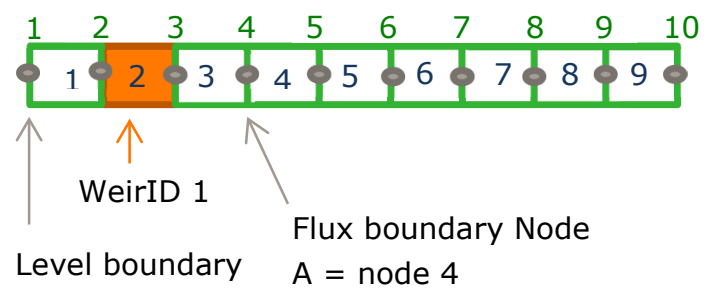

Node 1

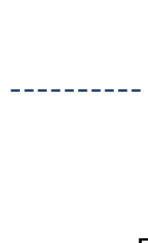

Flux boundary Node B $=$ node 34

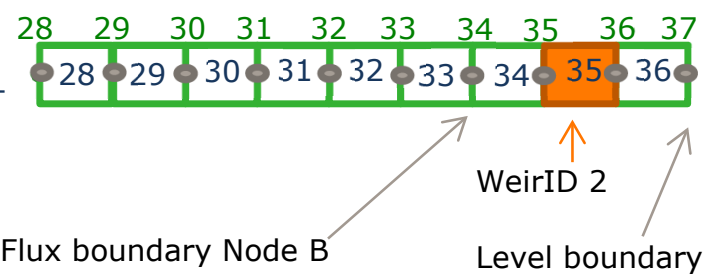

Node 37

Figure 5.2 Schematisation of the ditch in nodes and sections. The dots represent the nodes (starting with Node ID 1 on the left-hand side and ending with Node ID 37 on the right-hand side). The green boxes represent the sections (starting with Node ID 1 on the left-hand side and ending with Node ID 36 on the right-hand side). The size of one section is $10 \mathrm{~m}$. 'Level boundary node' refers to fixed-level boundary conditions. WeirID 1 and 2 refer to a specific control that corresponds to Figure 5.1 and Eq. 5.1.

Figure 5.3 shows the daily (imposed) discharge at the 'inner-ditch' side of the weir as function of time for the 20-year simulation period. Discharges during an inlet situation (mainly in summer) have a negative sign and discharges during an outlet situation have a positive sign. Note, that the pattern is similar to the velocities shown in Figure 2.13. The velocities have been multiplied by minus the crosssectional area (i.e. $-0.612 \mathrm{~m}^{2}$ ). 


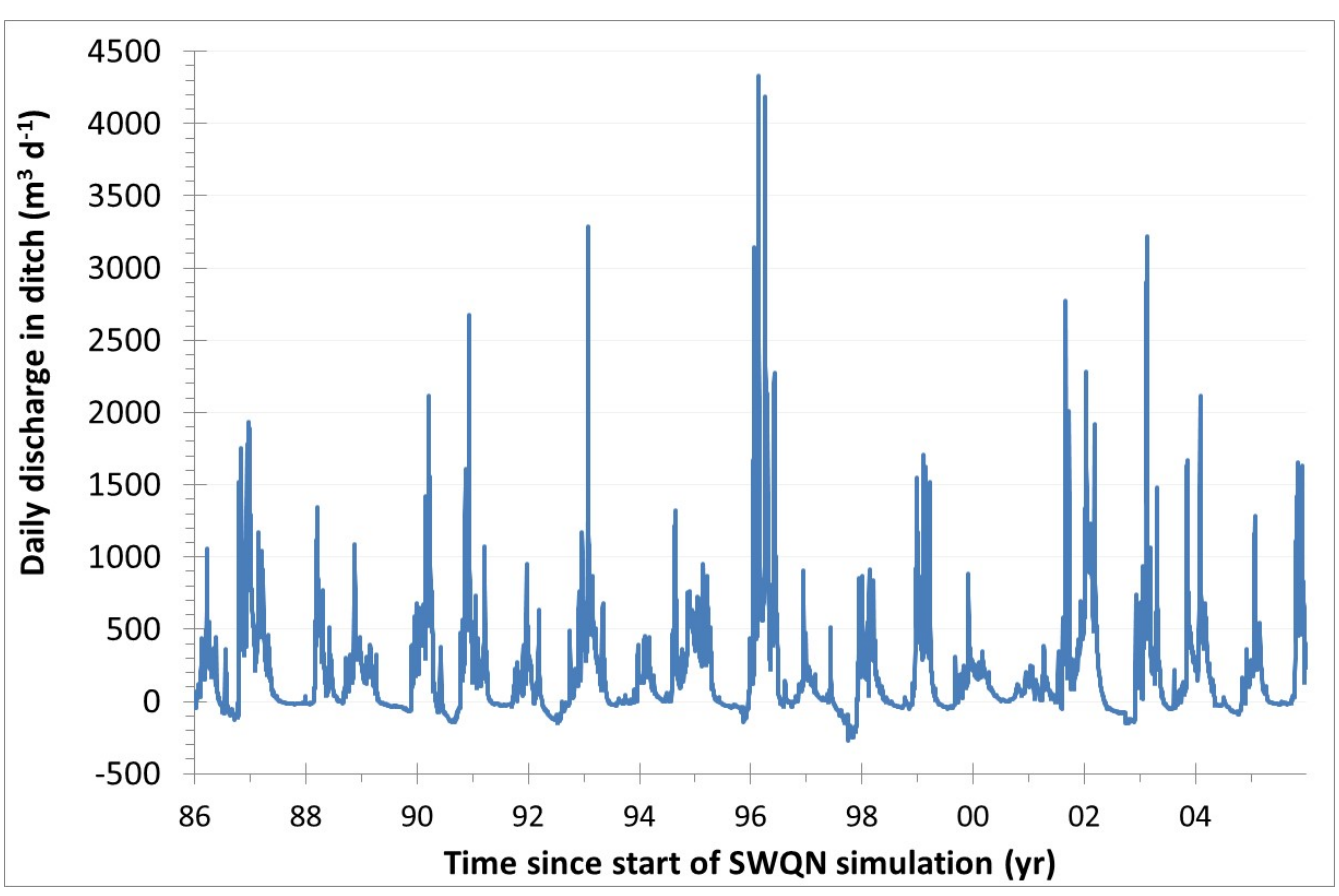

Figure 5.3 Daily (imposed) discharge in the SWQN ditch as a function of time for a period of 20 years $^{9}$. The daily discharges are imposed to the boundaries of the model, and derived by multiplying the flow velocities of Chapter 2 by minus the cross-sectional area of $0.612 \mathrm{~m}^{2}$.

Sections 2 and 35 were specified as weirs to control the water depth. The discharge over the weirs was simulated by:

$Q_{w e i r, t}=\mu_{\text {weir }} W_{\text {crest }}\left(h_{u p, t}-h_{\text {crest }, t}\right)^{1.5}$

Where $Q_{\text {weir, }}$ is the weir discharge at time $t\left(\mathrm{~m}^{3} \mathrm{~s}^{-1}\right), \mu_{\text {weir }}$ is the weir coefficient $\left(\mathrm{m}^{0.5} \mathrm{~s}^{-1}\right), W_{\text {crest }}$ is the width of the crest of the weir $(\mathrm{m}), \mathrm{h}_{\mathrm{up}, \mathrm{t}}$ is the upstream water level $(\mathrm{m})$ and, $\mathrm{h}_{\text {crest,t }}$ is the crest level $(\mathrm{m})$.

The main characteristics of the weirs are:

- Weir width: $50 \mathrm{~cm}$

- Weir coefficient $\left(\mu_{\text {weir }}\right)=1.5 \mathrm{~m}^{0.5} \mathrm{~s}^{-1}$

The value for the weir coefficient is experimentally determined for broad-crested weirs and taken from the Cultuur Technisch Vademecum (Cultuurtechnisch Vademecum, 1988). The weir heights in summer and winter were calibrated, such that the management of the Water Board, as well as the preassumptions done in the drift scenario derivation procedure were fulfilled (see Section 3.3).

In case a weir functions as a flow barrier, the height of the weir crest in section 2 is set equal to the soil surface to simulate a flow barrier. The boundary sections 1 and 36 have fixed-level boundaries which were set to $5 \mathrm{~cm}$ above the bottom of the ditch. The fixed-level boundaries are needed to allow the water to leave the ditch at either side, depending on the flow direction. The parameterisation of the weirs in SWQN is described in more detail in Annex 4.1

The simplified St. Venant Equations solved by SWQN (Smit et al., 2009) require either the Manning- or Chézy friction coefficient as input. We decided to use the Manning coefficient with the same value as for the ditch of the EU FOCUS Surface Water scenarios: $25 \mathrm{~m}^{1 / 3} \mathrm{~s}^{-1}$ (FOCUS, 2001).

The simulations with SWQN were done over a period of 20 years: 1986 - 2005. This corresponds to the simulation period in SWAP using the extended Andelst dataset and the same simulation will be

9 Data of the years shown in this figure correspond to the flow velocity data of years 2 up to and including 22 of Figure 2.13. See also Annex 8 for the relation between the year numbers of the velocity time-series used and those used for the simulations with SWAP/PEARL, SWQN and TOXSWA. 
used later on in TOXSWA for calculating PECs in water. The original Andelst dataset was extended to only 15 years (1991 -2005) due to the limited availability on data needed on the lower boundary condition of SWAP (see section 5.2 in Tiktak et al., 2012b). Note that for the simulations with both SWAP, PEARL and TOXSWA a warm-up period of five years was added to the dataset. Therefore, the data for the period 2001 - 2005 was copied to the period 1986 - 1990 (after correction of leap years), resulting in a total dataset of 20 years. The approach differs from that of the FOCUS groundwater scenarios (FOCUS, 2000), where 20 unique years were used and the first six years are identical to the last six years.

Note, that the velocity time-series used to calculate the imposed discharges do not refer to real weather years and cover a period of 27 years. The velocity time-series were coupled the simulation years of SWQN in such a way that leap years would coincide; i.e. the first two years and the last 5 years of the 27-year velocity time-series were not used.

Annex 8 shows the relation between the year numbers of the velocity time-series used and those used for the simulations with SWAP, PEARL, SWQN and TOXSWA.

\subsection{Calibration}

In an ideal situation, data of measured water depths would be available and by tweaking the height of the weir crest, the SWQN model could have been calibrated, such that a good fit between the simulated and the measured water depths would be attained. For our case, measurements of water depths were not available, but several related system properties are known, based on previous assumptions made during the scenario derivation or water-management practices of the Rivierenland Water Board. A set of preconditions for the water depth was drafted and discussed in Section 3.3. The SWQN model was calibrated, such that these preconditions were met:

1. The winter water depth, as provided by Massop et al. (2006), is assumed to be equal to the wet winter water level of the type Betuwe stroomruggronden, secondary ditch, which is $30 \mathrm{~cm}$. The level is defined as: 'exceeding the mean highest water level for at least 30 days a year'. The operational definition here is that the $83.3^{\text {rd }}$ percentile of the water depth in a winter situation should be equal to $30 \mathrm{~cm}$.

2. The weir heights will be calibrated such that the $50^{\text {th }}$ percentile of the winter level (1 October $31 \mathrm{March}$ ) and the $50^{\text {th }}$ percentile of the summer level (1 April- 30 September) are equal.

The height of the weir crest in winter and summer were used as calibration parameters. In addition, the management of the weirs was followed, which implied that the height of the weir crest in summer was taken between 0-5 cm higher than in winter.

The calibration was done manually as follows. SWQN simulations were performed over 20 years using different combinations of height of the weir crest in summer and winter. All other parameters remained constant. Cumulative frequency distributions of the water depth at the centre of the $300 \mathrm{~m}$ ditch (i.e. that is also the centre of the $100 \mathrm{~m}$ evaluation ditch) were made for each simulation. Background for selecting the water depth in the centre of the evaluation ditch was that this value also represents the average water depth in the evaluation ditch.

Table 5.1 83. $3^{\text {rd }}$ and $50^{\text {th }}$ percentile water depths as calculated for two combinations of weir crest height in summer and winter. The calculations were performed as part of the manual calibration of SWQN.

\begin{tabular}{|c|c|c|c|c|c|}
\hline Case & $\begin{array}{l}\text { Height of the } \\
\text { weir crest in } \\
\text { winter }(\mathrm{cm})\end{array}$ & $\begin{array}{l}\text { Height of the weir } \\
\text { crest in summer } \\
(\mathrm{cm})\end{array}$ & $\begin{array}{l}83.3 \text { rd percentile } \\
\text { water depth in } \\
\text { winter }(\mathrm{cm})\end{array}$ & $\begin{array}{l}50 \text { th percentile } \\
\text { water depth in } \\
\text { winter }(\mathrm{cm})\end{array}$ & $\begin{array}{l}\text { 50th percentile } \\
\text { water depth in } \\
\text { summer }(\mathrm{cm})\end{array}$ \\
\hline 2 & 26 & 27.5 & 30.0 & 27.8 & 27.8 \\
\hline
\end{tabular}




\section{Result calibration}

Table 5.1 shows two combinations of winter and summer crest heights for which criteria were assessed. The optimal combination was achieved in Case 2, i.e. using a height of the weir crest in winter of $26 \mathrm{~cm}$ and a height of the weir crest in summer of $27.5 \mathrm{~cm}$, hence, the difference between weir height in summer and winter was $1.5 \mathrm{~cm}$. Frequency distributions for the summer and winter period based on hourly simulated values are shown in Figure 5.4. The water depths range from $26 \mathrm{~cm}$ to $43 \mathrm{~cm}$.

Note that in Figure 5.4, several hourly water depths are below the height of the weir crest of $27.5 \mathrm{~cm}$ in summer (red dots). This is, because after raising the weir from 26 to $27.5 \mathrm{~cm}$ on April $1^{\text {st }}$, it takes a few hours before the water depth at the centre of the ditch reaches $27.5 \mathrm{~cm}$.

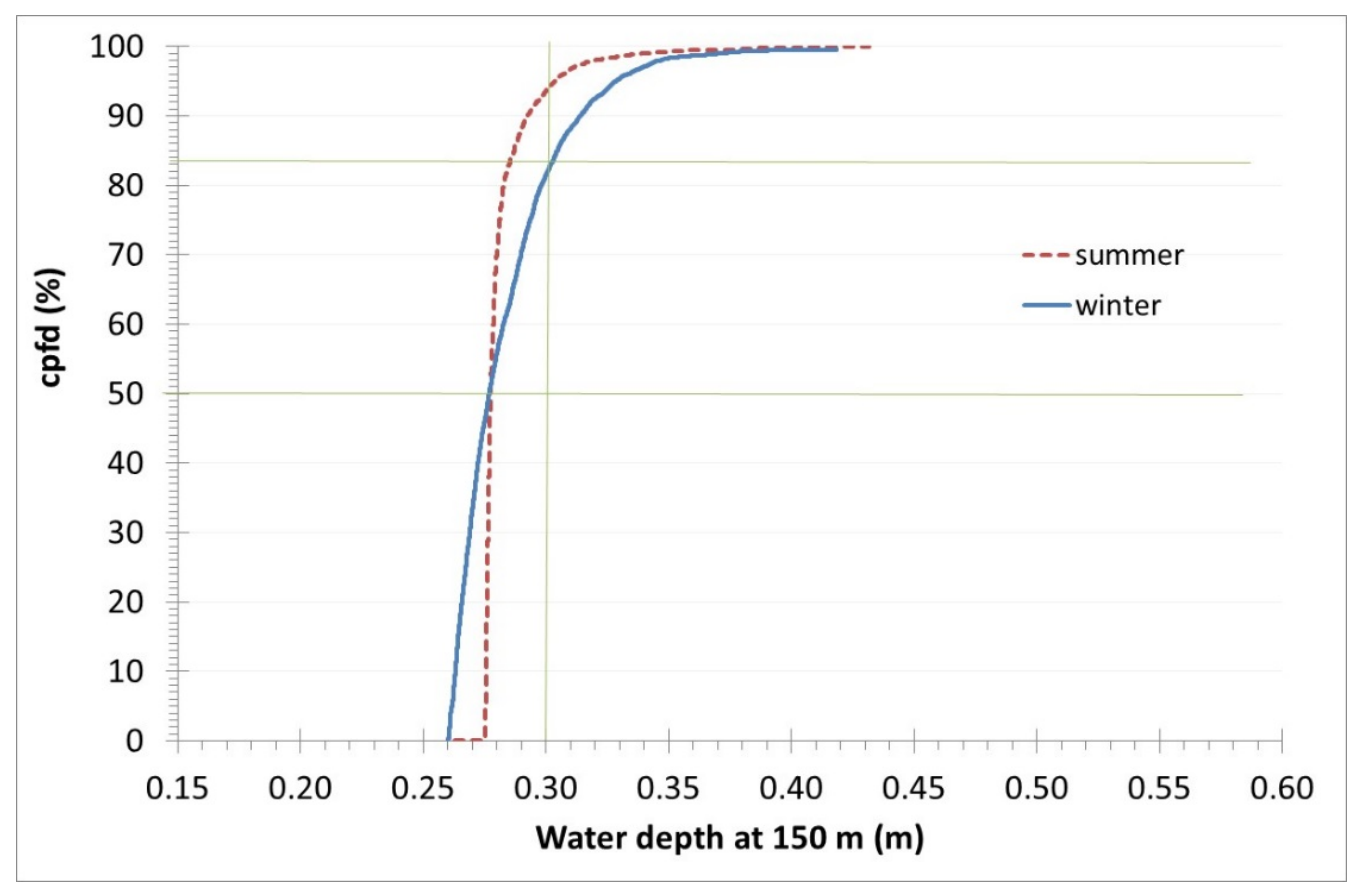

Figure 5.4 Cumulative frequency distribution function (cpdf) of the water depth in the centre of the $100 \mathrm{~m}$ evaluation ditch of 20 years of simulations with SWQN for the summer and the winter period for the optimal combination of weir crest heights (Case 2). The horizontal lines indicate the $50^{\text {th }}$ and 83. $3^{\text {rd }}$ temporal percentiles and the vertical line indicates the $30 \mathrm{~cm}$ water depth.

\subsection{Result: Hydrology of the parameterised ditch}

\subsubsection{Water depth and discharge}

Figures 5.5 - 5.10 show time courses of the water depth and discharge in the segment in the centre of the evaluation ditch for the optimal case (Case 2 of Table 5.1). Water depth and discharges may slightly differ between segments due to the dynamics of the system. Figure 5.5 gives the water depth for the optimal case. Figure 5.6 shows further that the maximum water depth is $\mathrm{ca} .43 \mathrm{~cm}$, which is less than half of the total depth of the evaluation ditch, i.e. $1.08 \mathrm{~m}$. The figure shows that the variability of the water depth is limited.

To demonstrate the effect of weather conditions on the system dynamics, a relatively wet year and a relatively dry year were selected and highlighted. Figure 5.6 shows an example of the water depths of a wet year (year 1996) with a median instantaneous residence time of 5.8 hours, and Figure 5.8 shows an example of the water depths of a dry year (year 2000) with a median instantaneous residence time of 17.4 hours. The figures show that the water depth may rise and fall within a few days, however, lowering of the water depth usually occurs more gradually. In year 1996, the water 
depth fluctuates between 26-43 cm, and in year 2000, the water depth fluctuates between 26 and $32 \mathrm{~cm}$ (note the difference in scale between the vertical axes of Figures 5.6 and 5.7). Figure 5.7 clearly shows the effect of the changes in weir depths from summer to winter and vice versa.

Figure 5.8 shows the discharge for the optimal case. This figure is for many periods almost equal to Figure 5.3. Figure 5.8 shows the model output of SWQN (i.e. including the effect of incoming drainage fluxes), and Figure 5.3 shows the discharges as imposed at the boundaries. Largest differences between the time-series in the two figures are found at periods were incoming drainage fluxes occur (e.g. November 1987 - February 1998). Figures 5.9 and 5.10 show the discharge dynamics for the selected wet- and dry years, respectively. Both Figures 5.9 and 5.10 show that discharges can be very low for several months. Figure 5.10 shows two remarkable fluctuations in the discharge (around the beginning of April and the beginning of October). These discharge peaks coincide with rising of the weir on April $1^{\text {st }}$ and the lowering of the weir on October $1^{\text {st }}$. In the first case, the discharge sharply decreases, as additional storage is created in the ditch. In the latter case, the discharge sharply increases, because there is suddenly less storage capacity in the ditch due to lowering of the weir. Occasionally, sudden increases or decreases in both the water depth and discharge are found on the day of a switch in the flow direction of the water, or for a few days after this switch. These sudden increases and decreases prolong for one to a few hours. They often occur on the day of a switch in the flow direction of the water or a few days after this switch. We suspect that they are the result of artefacts of the numerical solution. However, analysis showed that they do not provoke water balance errors (Annex 5). Given the limited number of these sudden increases or decreases, their short duration (one to several hours), and limited size (around one order of magnitude for the discharge and several millimetres for the water depth), we expect that the sudden increases or decreases in both the water depth and discharge will have a limited effect on the Predicted Environmental Concentration in the ditch. This should be assessed with example calculations (which do not form part of this report).

For a detailed overview per simulated year, we refer to Annex 7, in which hourly water depth, discharge, flow velocity and residence times per year are given.

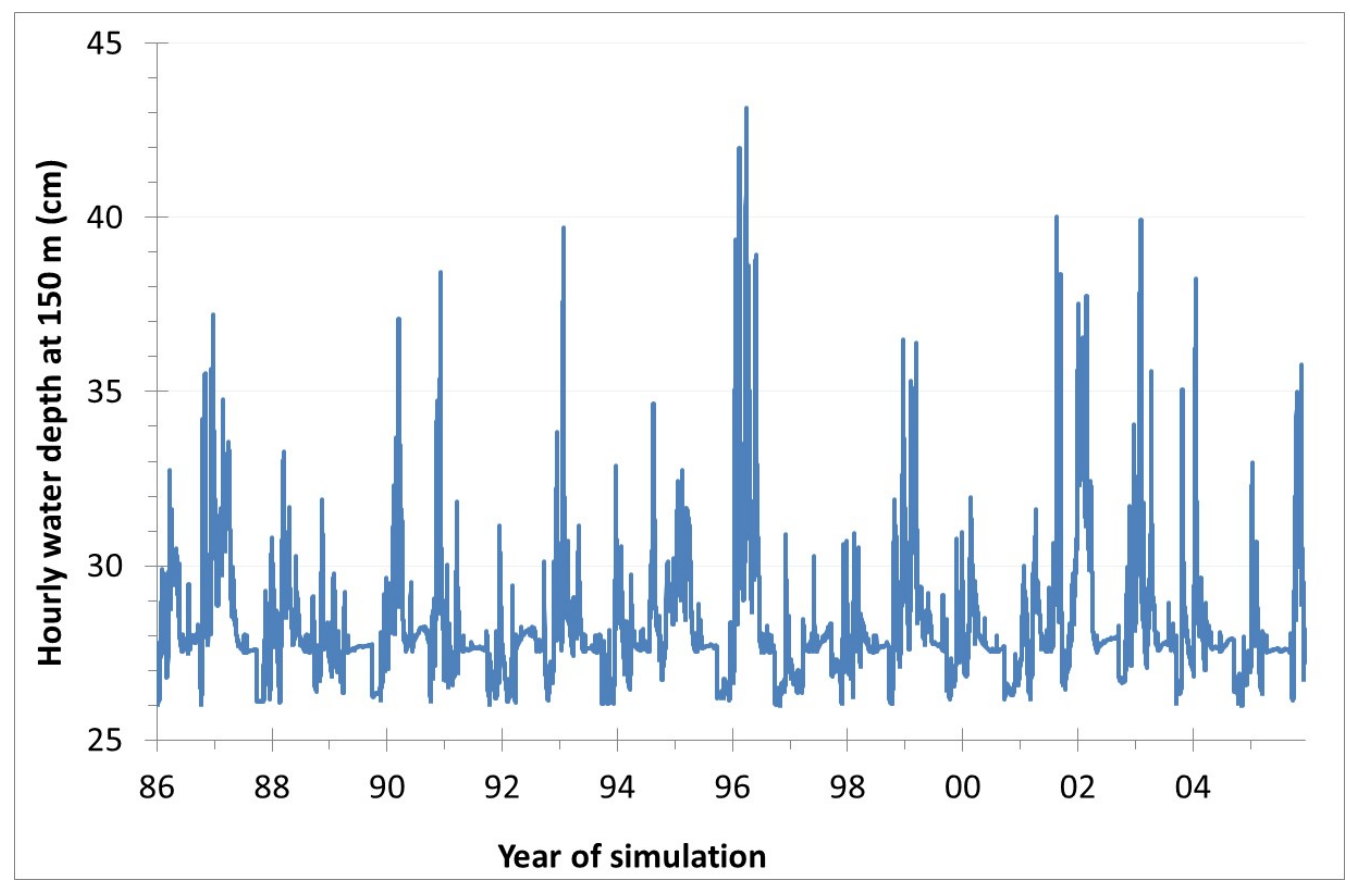

Figure 5.5 Hourly values of water depth in the centre of the $100 \mathrm{~m}$ evaluation ditch as function of time for a period of 20 years (1986 - 2005) and as a result of the calibration of the model for the selected case (Case 2 in Table 5.1). 


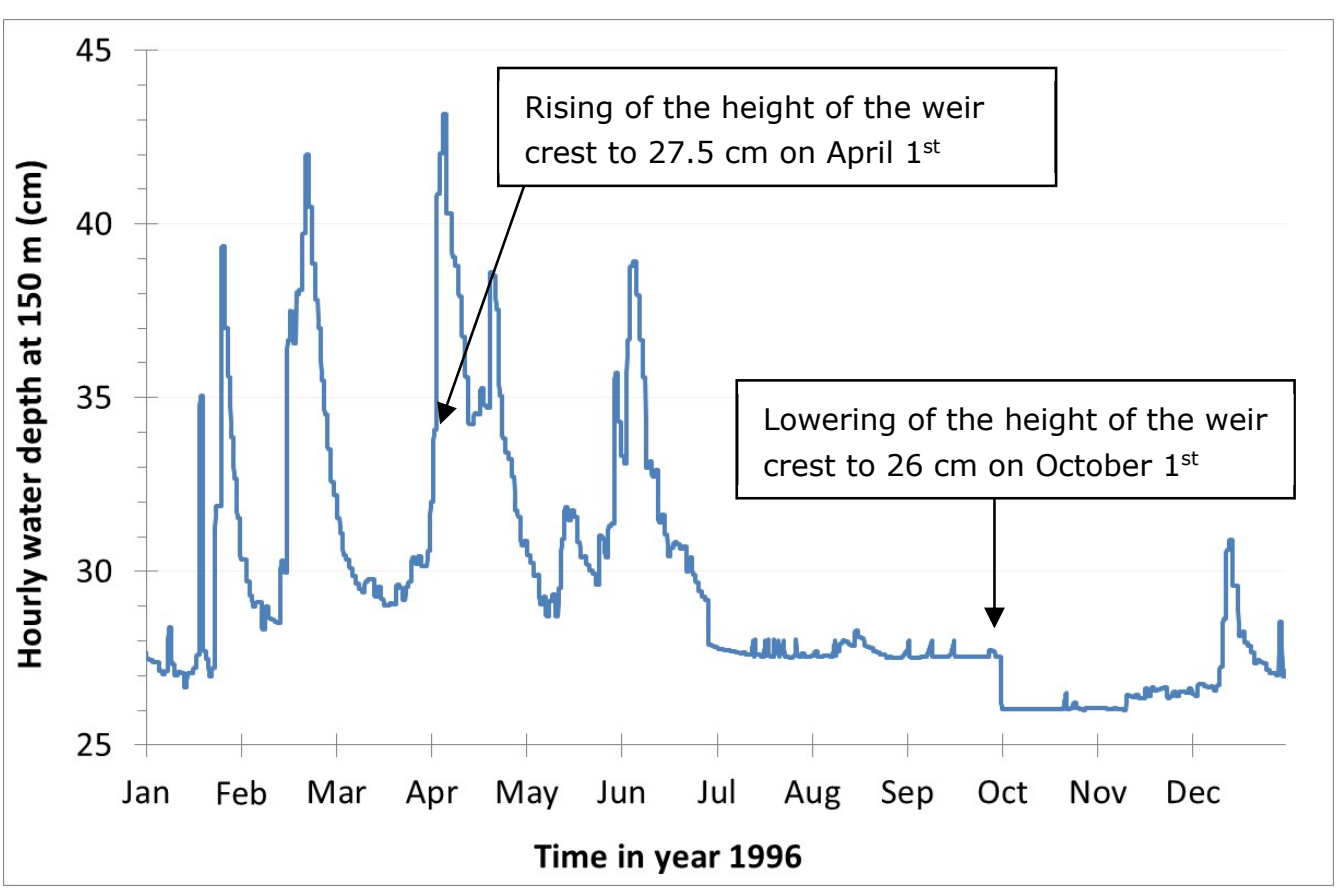

Figure 5.6 Hourly values of water depth in the centre of the $100 \mathrm{~m}$ evaluation ditch as function of time for year 1996 (the year with the highest discharge in the period of 20 years) and as a result of the calibration of the model for the selected case (Case 2 in Table 5.1).

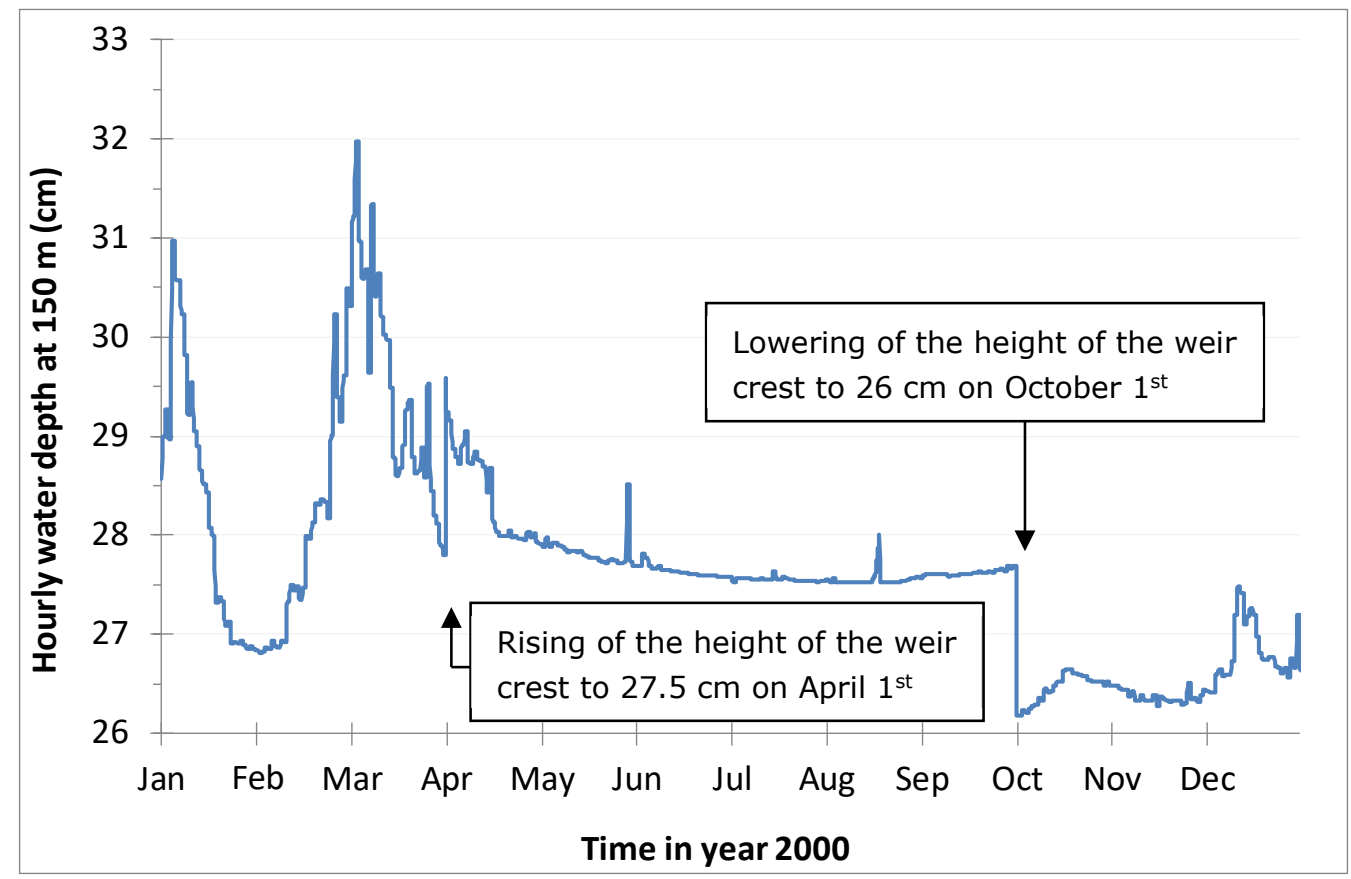

Figure 5.7 Hourly values of water depth in the centre of the $100 \mathrm{~m}$ evaluation ditch as function of time for the year 2000 (a year within the 20-year period with relatively low discharges) and as a result of the calibration of the model for the selected case (Case 2 in Table 5.1). 


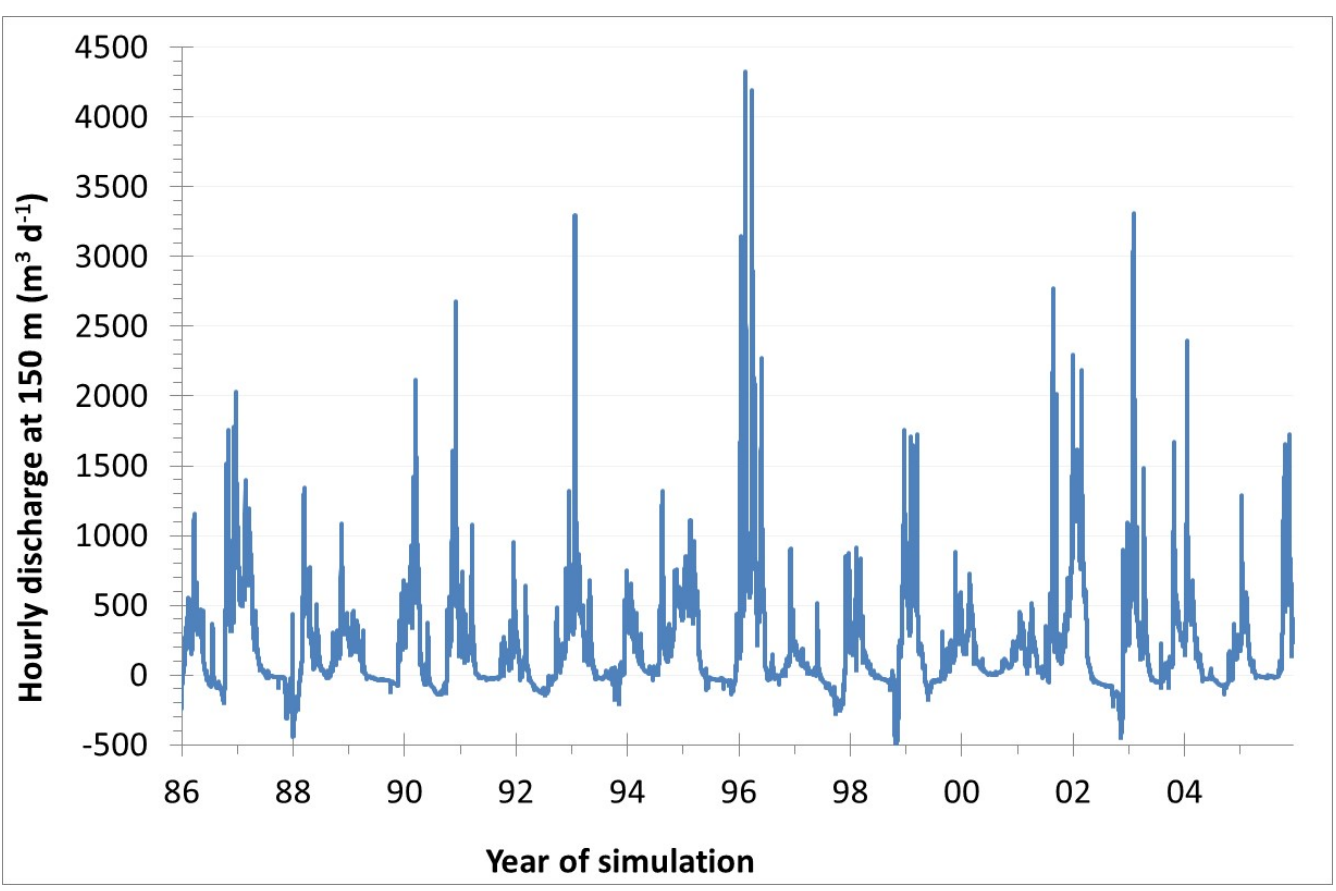

Figure 5.8 Hourly values of discharge in the centre of the $100 \mathrm{~m}$ evaluation ditch as function of time for a period of 20-years and for Case 2. This figure is almost equal to Figure 5.3. The difference is only that this is the model output of SWQN, and Figure 5.3 shows the discharges, as imposed at the boundaries.

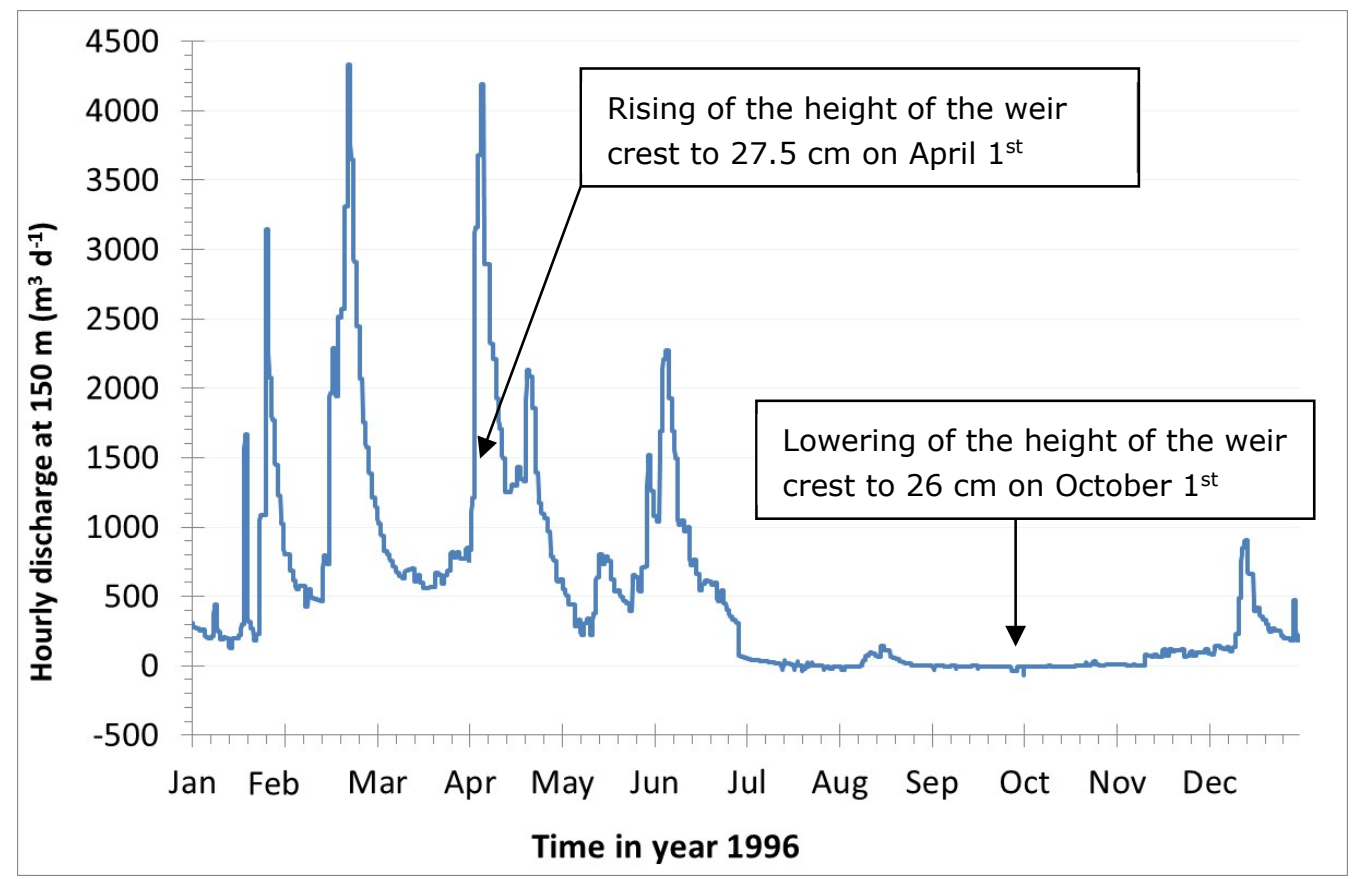

Figure 5.9 Hourly values of discharge in the centre of the $100 \mathrm{~m}$ evaluation ditch as function of time for year 1996 (the year with the highest discharge in the period of 20-years) and as a result of the calibration of the model for the selected case (Case 2 in Table 5.1). 


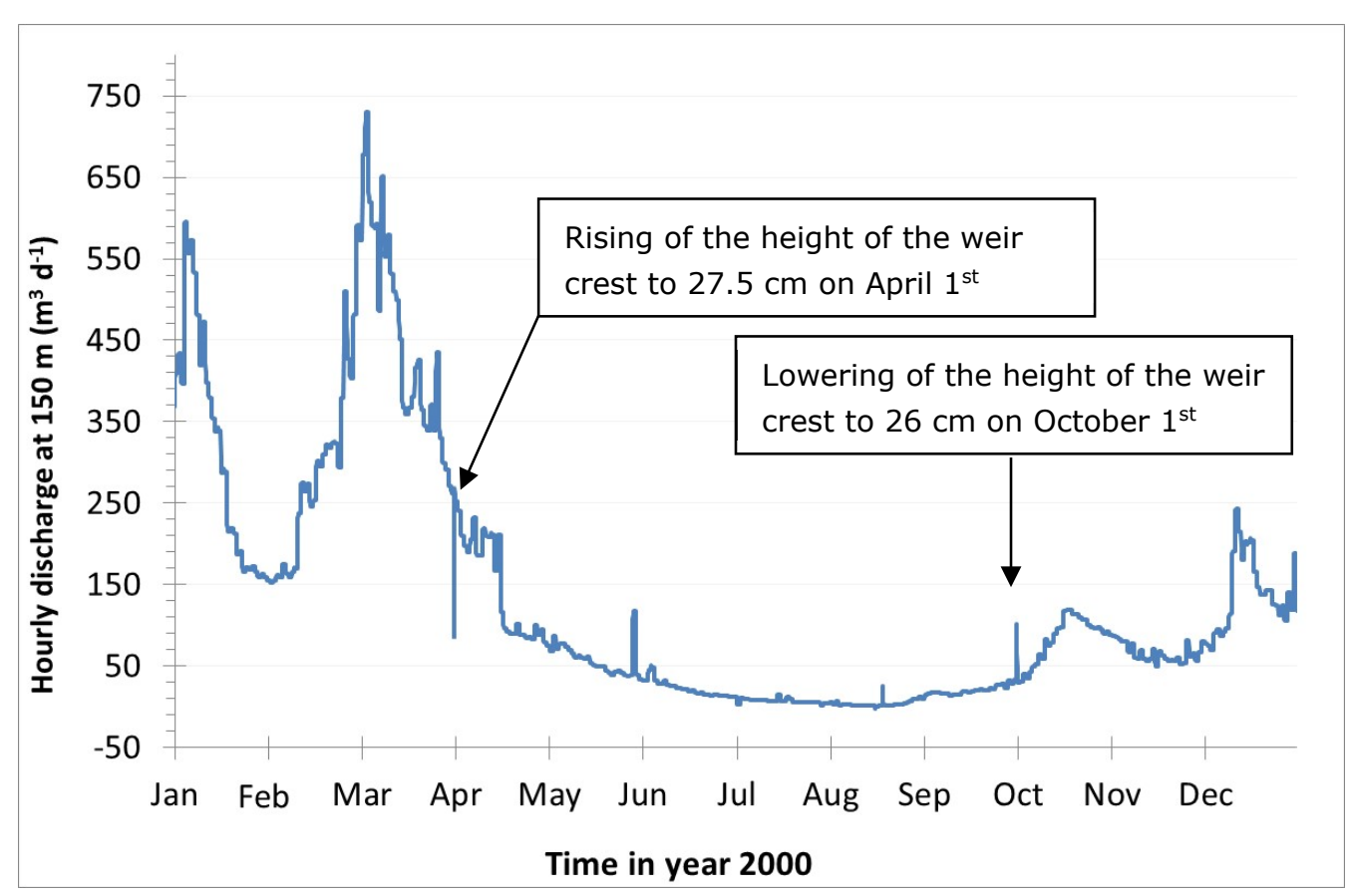

Figure 5.10 Hourly values of discharge in the centre of the $100 \mathrm{~m}$ evaluation ditch as a function of time for year 2000 (a year with relatively low discharges in the 20-year period), and as a result of the calibration of the model for the selected case (Case 2 in Table 5.1).

\subsubsection{Water balances}

Figure 5.11 gives the annual water balances over the simulated period. The imposed discharges entering the ditch and the outflow of the ditch are the main components of the water balance. The imposed discharges and the outflow are almost equal, which implies that the change in water storage in the ditch is small. The water balance error is calculated as the difference in the annual change in storage minus the sum of the annual inflow (flow boundary discharge) and annual outflow (level boundary discharge). This error is max. $1.210^{-5} \mathrm{~m}^{3} \mathrm{yr}^{-1}$ (i.e. $0.12 \mathrm{~mL} \mathrm{yr}^{-1}$ ), and is considered acceptable for an annual discharge of between $4.6 \cdot 10^{4}$ and $2 \cdot 10^{5} \mathrm{~m}^{3} \mathrm{yr}^{-1}$. Note that year 1996 was the selected wet year and year 2000 was the selected dry year.

Figure 5.12 shows the cumulative probability frequency distribution of the hourly water balance errors. A balance error of zero corresponds to the $50^{\text {th }}$ percentile. The errors are more or less evenly distributed around the $50^{\text {th }}$ percentile, indicating there was no bias found in the data. The errors are in the same order of magnitude as the annual water balance error. However, to judge if the errors are low enough, they need to be compared to the total volume in the $300 \mathrm{~m}$ ditch, which varies from $156 \mathrm{~m}^{3}$ at the minimum water depth of $26 \mathrm{~cm}$ and $280 \mathrm{~m}^{3}$ at the maximum water depth of $43 \mathrm{~cm}$. Figure 5.13 shows that the water balance error relative to the average water volume in the ditch is $6 \cdot 10^{-5} \%$ at most, which is considered low enough. 


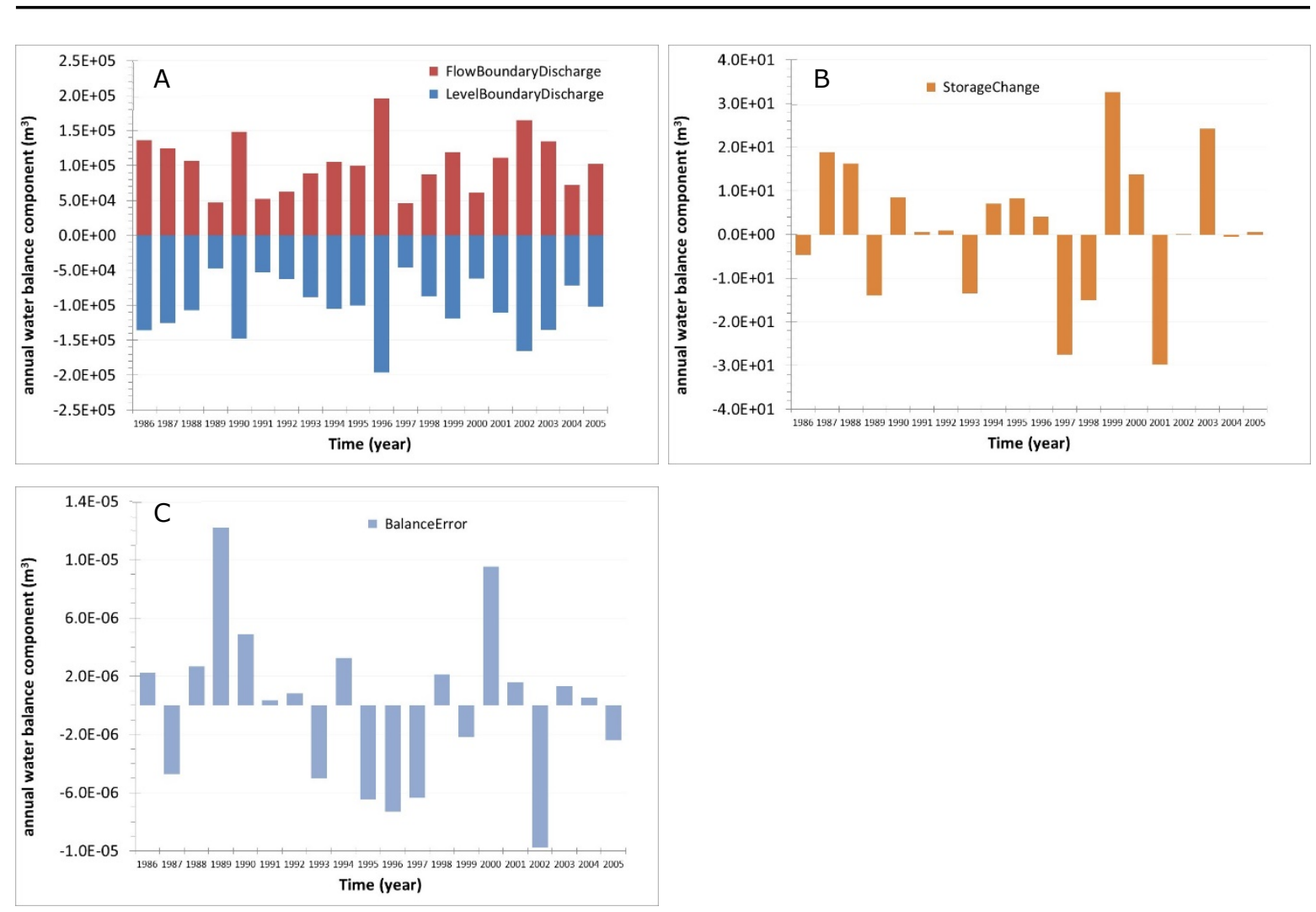

Figure 5.11 Annual water balance for the 20-year simulation period in SWQN. A. Major water balance components: Flow boundary discharge refers to the imposed and incoming discharges. Level boundary discharge refers to discharges leaving the ditch. $B$. Change in storage in the ditch, as calculated by the model; a positive value indicates an increase in water storage, a negative value indicates a decrease in storage. C. Annual water balance error. Note the different scales at the $y$-axis.

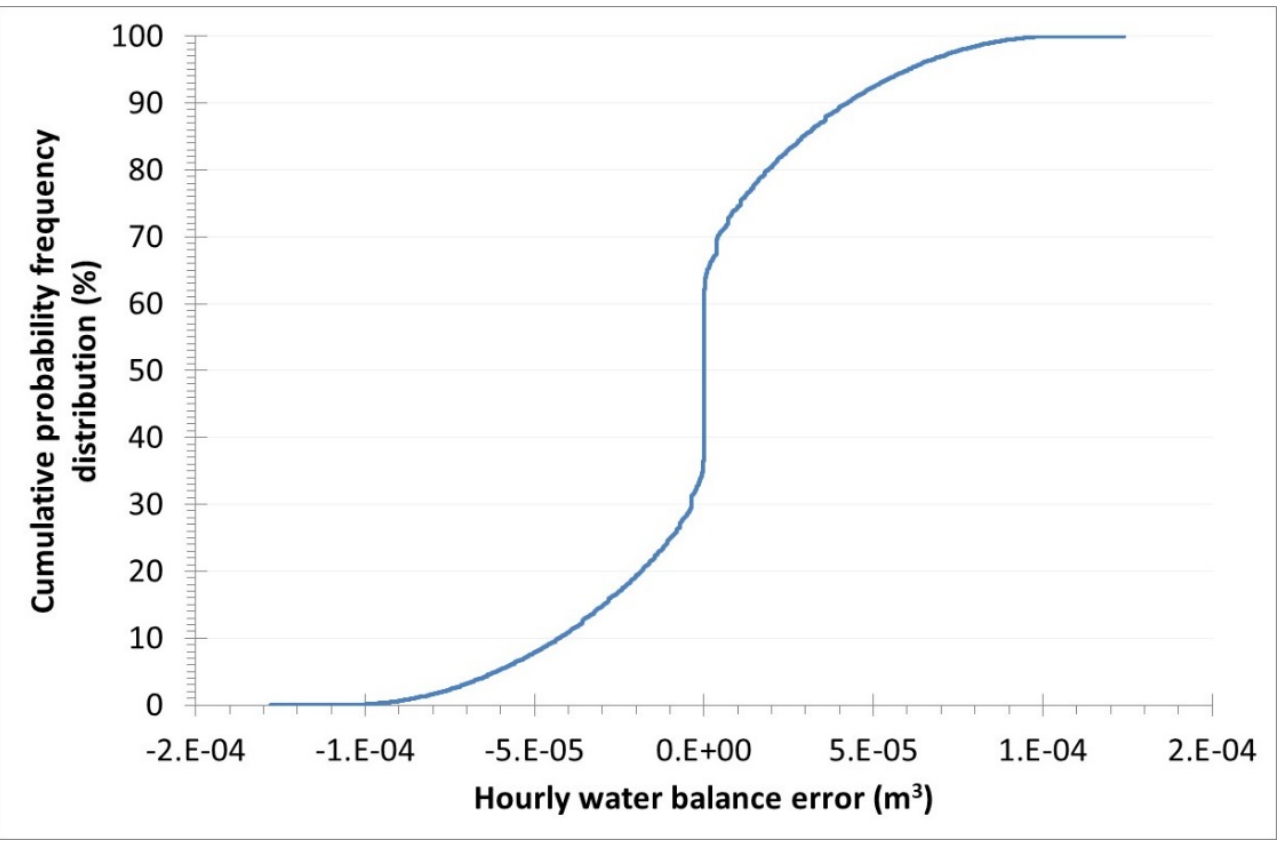

Figure 5.12 Cumulative probability frequency distribution of the hourly water balance errors of 20-years of simulations with SWQN. 


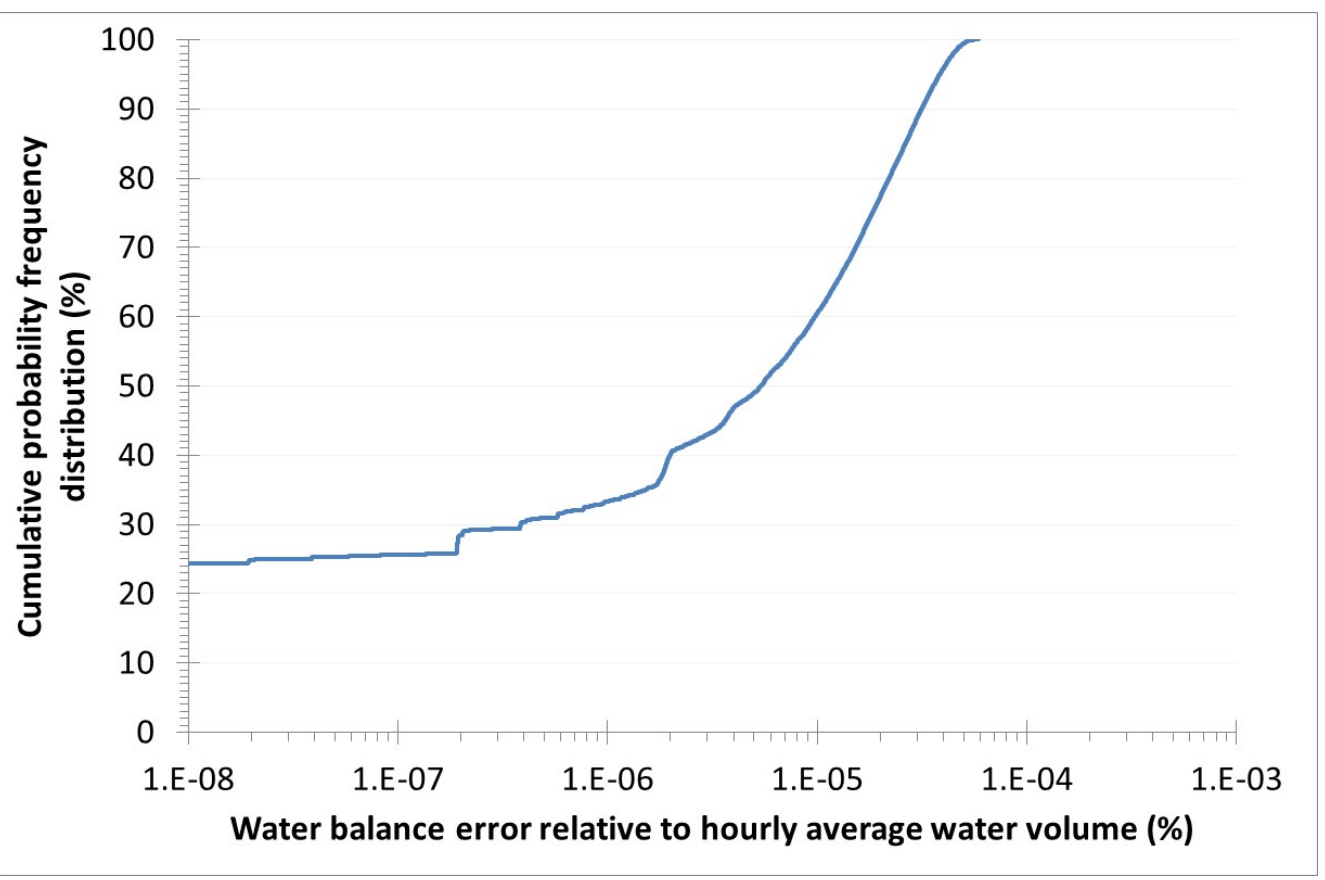

Figure 5.13 Cumulative probability frequency distribution of the water balance error as percentage of the hourly average water volume in the $300 \mathrm{~m}$ long ditch. The median relative error is $7.510^{-6 \%}$ of the volume of water in the ditch.

\subsubsection{Effect of drainage on the discharge in the SWQN ditch}

Wipfler et al. (2018) presented the hydrological responses based upon imposed discharge (calculated from synthetic velocity time-series) at the upper boundary of the ditch only, so without contribution of the drainage route. The hydrological responses presented in this report are based upon both the imposed discharge at the upper boundary of the ditch calculated from synthetic velocity time-series and lateral discharges from drainage events calculated with SWAP-PEARL using real weather data.

The synthetic velocity time-series are based upon pre-selected flow velocities derived from discharges calculated by the Moria model. Discharge from drainage contributes to the total discharge to the surface water that are used to calculate the pre-selected flow velocities (Figure 2.6). However, for several reasons the extremes over the day are smoothed (see Chapter 2.4.4.). To incorporate variability in water depth and flow velocity due to drainage it was decided to explicitly add this route to the SWQN parameterisation.

This was considered justified as the imposed discharges are based on pre-selected flow velocities calculated from target-level units of approximately 40 ha, whereas in the SWQN parameterisation lateral drainage of 4.2 ha $(140 \times 300 \mathrm{~m})$ is used. This implies that the drainage route will not dominate (Figure 5.14). Compared to the imposed discharge, drainage calculated with SWAP-PEARL is about a factor 10 lower. 


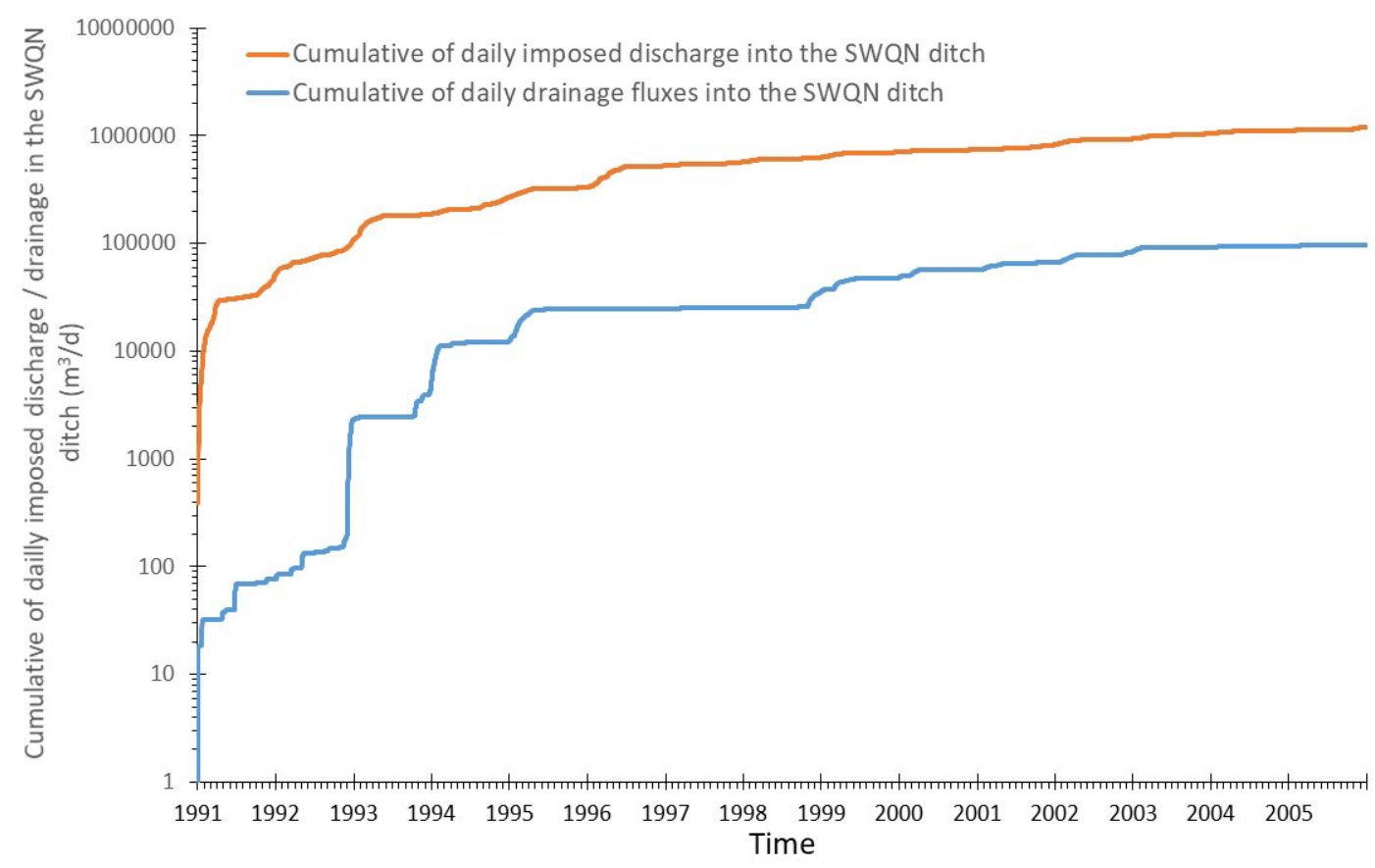

Figure 5.14 Cumulative of the daily (imposed) discharge in the SWQN ditch (absolute values used) and the cumulative of the daily (lateral) drainage fluxes in to the SWQN ditch as function of time for the period 1991 - 2005. The daily discharges are imposed to the boundaries of the model, and derived by multiplying the flow velocities of Chapter 2 by minus the cross-sectional area of $0.612 \mathrm{~m}^{2}$. The orange line is the $1: 1$ line.

The imposed discharge is based upon synthetic data (i.e. not referring to real weather years) but the drainage is calculated using real weather data. Consequently, discharges might not be in line; i.e. high imposed discharges do not necessarily go hand in hand with high lateral discharges. This is illustrated by Figure 5.15. The orange line in Figure 5.15 represents the $1: 1$ line. All dots between this $1: 1$ line and the $x$-axis indicate cases where the discharge from drainage events exceed the imposed discharge at the boundaries. In $5 \%$ of the days (278 out of 5979 days) in the period $1991-2005$ lateral discharge exceeds the imposed discharge. This means that the hydrology of the ditch is predominantly determined by the imposed discharge. 


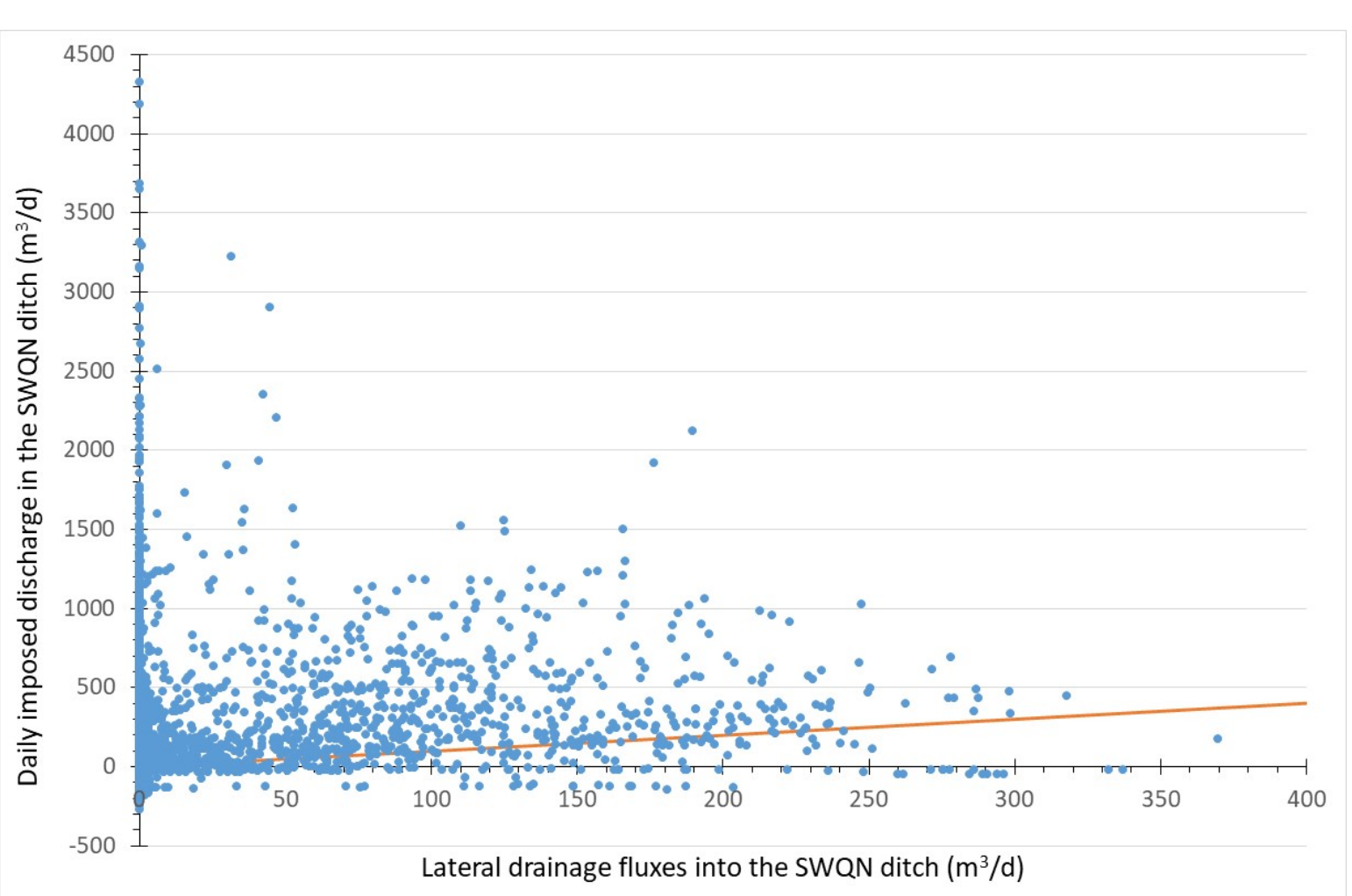

Figure 5.15 Daily (imposed) discharge in the SWQN ditch plotted against the daily lateral drainage fluxes in to the SWQN ditch. The daily discharges on the $y$-axis are imposed to the boundaries of the model, and derived by multiplying the flow velocities of Chapter 2 by minus the cross-sectional area of $0.612 \mathrm{~m}^{2}$. The orange line is the $1: 1$ line.

Note that a large drainage event does not automatically lead to pesticide exposure in the ditch. Exposure in the ditch as result of drainage also depends on the timing of the pesticide application and the substance properties of the pesticide (i.e. very fast degrading substances and or strongly sorbing substances will less likely enter the ditch via drainage). On the other hand, pesticide exposure in the ditch might also be caused by a very small drainage event. One drop of drainage water with a very high pesticide concentration might also cause a peak concentration in the ditch.

\subsection{Discussion}

In this Chapter, the hydrological SWQN model is parameterised. The output of the model, hourly water discharges per segment, as well as hourly water depths is used as input for the TOXSWA model. Flow velocities, as derived in Chapter 2, are used as input for the SWQN model. Lateral drainage water input in to the ditch was calculated with the SWAP model (i.e. the soil-hydrological model underlying the pesticide fate model PEARL) and fed into the SWQN model. The flow velocities and lateral water fluxes are subject to a number of process steps before final hourly data for TOXSWA can be derived. In the figure below, these additional process steps are summarised, as well as the corresponding assumptions. In the last column, the characteristics of the datasets are given.

What is the effect of the individual processing steps? And can they be justified? Each of the steps are discussed below following the steps in the Figure 5.16. 

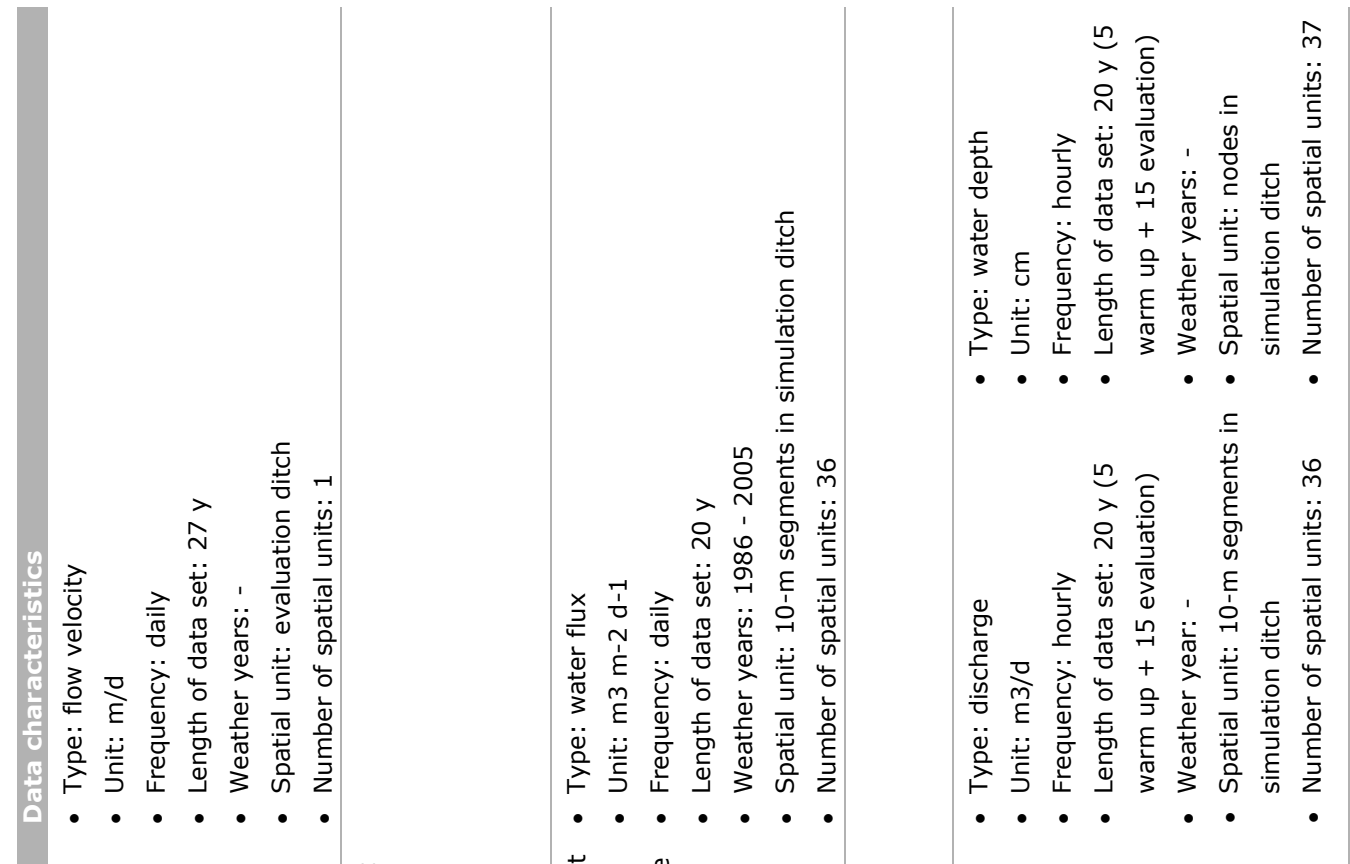

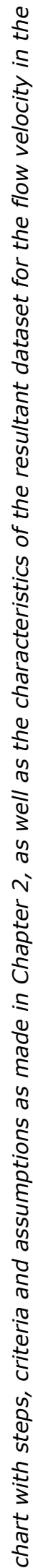

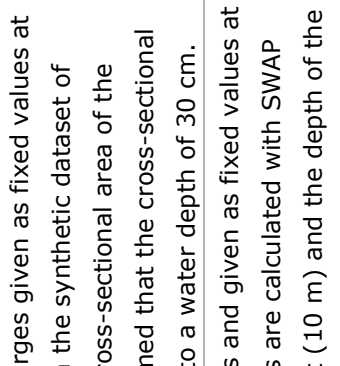

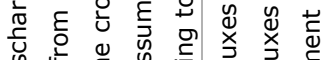

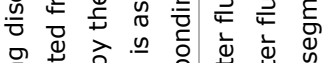

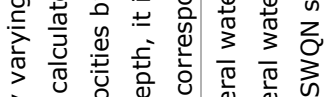

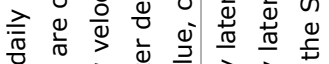

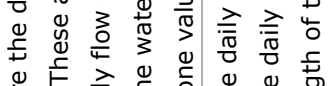

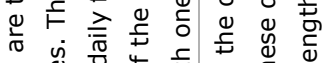

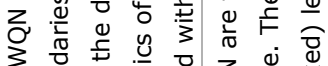

管

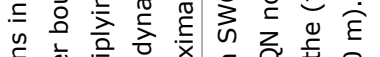

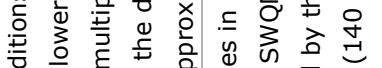

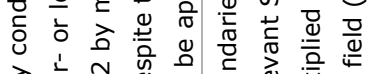

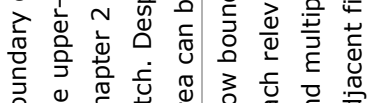

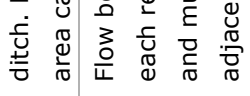

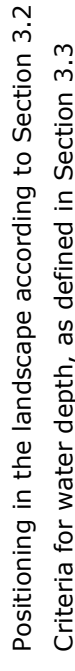
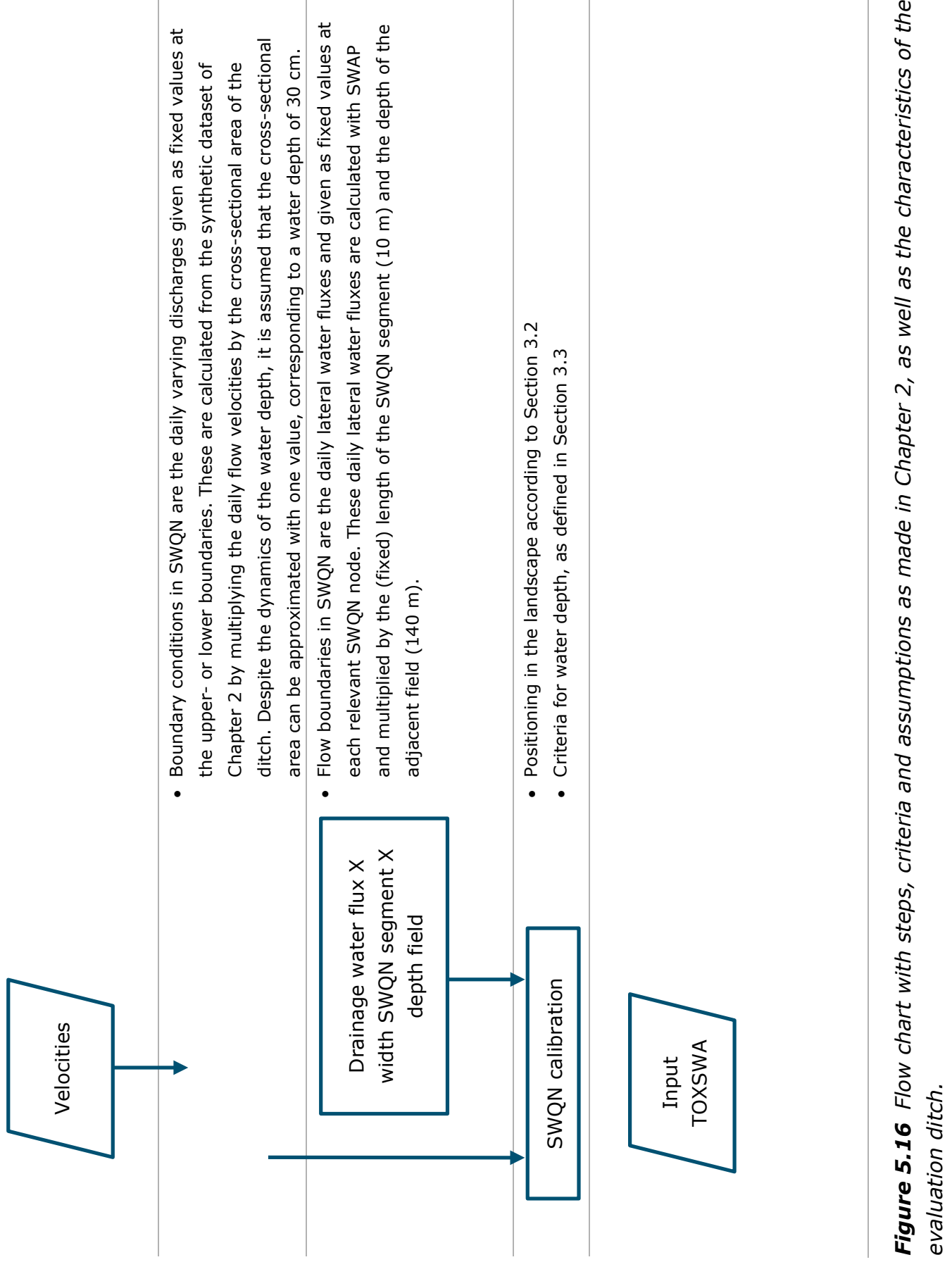

言器 
Table 5.2 Comparison of the statistical parameters of the residence times calculated from the dataset, as discussed in Chapter 2 and used as input for the SWQN simulations and the resulting residence times in the ditch, calculated from the velocities in the centre of the ditch.

\begin{tabular}{lll} 
& Residence time calculated from & $\begin{array}{l}\text { Residence time calculated from } \\
\text { SwoN output }\end{array}$ \\
minimum & flow velocities of Chapter $\mathbf{2}^{10}$ & 30 min \\
\hline $10^{\text {th }}$ percentile & $20 \mathrm{~min}$ & $2.3 \mathrm{~h}$ \\
\hline $50^{\text {th }}$ percentile & $2 \mathrm{~h}$ & $12.15 \mathrm{~h}$ \\
\hline $90^{\text {th }}$ percentile & $13.5 \mathrm{~h}$ & $105 \mathrm{~h}$ \\
\hline maximum & $114 \mathrm{~h}$ & $5422 \mathrm{~d}$ \\
\hline
\end{tabular}

1. The first interpretation step assumed a fixed water depth and cross-sectional area in the ditch to derive the water discharges in the ditch from the time series of flow velocities. As the water depth and flow velocity are correlated, this may result in lowering the variability of the water discharges and hence a lower variability in the residence times associated with the synthetic dataset and the output of SWQN. A comparison of residence times of both datasets is given in Table 5.2. The median residence time remains more or less the same, although the SWQN calculated residence time is slightly lower, and the variability decreases, i.e. the lower percentiles become a bit higher and the higher percentile, a bit lower. The approach taken is considered to be solid, as the difference is limited, and in view of all other assumptions that have been made.

2. The effect of adding daily lateral drainage fluxes is limited. Residence times calculated from SWQN are comparable as those given in Wipfler et al. (2018) who reports the results of the SWQN parametrisation for the Dutch orchard ditch without lateral drainage fluxes ${ }^{12}$.

3. The effect on the positioning in the landscape according to Section 3.2 cannot be quantified, there are many options to position the ditch in a catchment.

4. Also the effect of the criteria for water depth used for the calibration of SWQN is unknown. The criteria applied to the weir management are in line with the management practices of the Rivierenland Water Board, though. Adjustment twice a year is normal for smaller watercourses. Adjusting a weir only $1.5 \mathrm{~cm}$ in summer and winter is not expected to be common practice for water managers, but it is within the bandwidth indicated by Rivierenland. Furthermore, experts from the Water Board indicated that they expected the water level to reach to the soil surface approximately once in ten years. The evaluation ditch has a ditch depth of $1.08 \mathrm{~m}$. The water depth corresponding to a 1:10 year event of the SWQN output would be the 99.97 percentile $^{13}$, which is approximately $42 \mathrm{~cm}$ (see Figure 5.4). So, the evaluation ditch will not have a water depth above soil surface once every ten years. This can be explained as daily flow velocities are used: hourly data would have shown higher extremes.

Again, it is recommended to assess the realism of this final dataset against water flow and water depth measurements in ditches next to fruit orchards over a considerable length of time.

\footnotetext{
${ }^{10}$ Based on daily values of the flow velocities derived in Chapter 2 of the 27 year period. Hydraulic residence times as calculated by Wipfler et al. (2018): the daily residence time is $100 \mathrm{~m}$ divided by the daily flow velocity.

${ }^{11}$ Based on hourly values of the 15 year evaluation period: $1991-2005$ and calculated according Eq. A5.1

${ }^{12}$ Next to the addition of lateral drainage fluxes, any differences with the values presented in Table 4.2 in Wipfler et al. (2018) are also due to i) different period (20 years in Wipfler et al. (2018), 15 years in this report) and ii) a different method for calculating the residence time.

${ }^{13} 1 /(365 * 10) * 100 \%$
} 


\section{Sediment characterisation}

\subsection{Introduction}

The sediment properties porosity, bulk density and organic matter content play a role in the distribution of pesticides between the pore water and the solid matter (adsorption), as:

$$
c_{b}=\varepsilon c_{l b}+\rho_{b} X_{b}
$$

where (for linear sorption):

$$
X_{b}=m_{o m} K_{o m} c_{l b}
$$

With:

$c_{\mathrm{b}}=$ mass concentration of substance in sediment $\left(\mathrm{M} \mathrm{L}^{-3}\right)$

$c_{l b}=$ mass concentration of substance in the liquid phase of the sediment $\left(\mathrm{M} \mathrm{L}^{-3}\right)$

$X_{b}=\quad$ content of sorbed substance related to the mass of dry sediment material $\left(\mathrm{M} \mathrm{M}^{-1}\right)$

$\varepsilon \quad=\quad$ porosity of the sediment $(-)$

$\rho_{\mathrm{b}} \quad=\quad$ bulk density of dry sediment material $\left(\mathrm{M} \mathrm{L}^{-3}\right)$

$m_{\mathrm{om}}=$ mass fraction of organic matter of the sediment material $\left(\mathrm{M} \mathrm{M}^{-1}\right)$

$K_{\mathrm{om}}=\quad$ sorption coefficient $\left(\mathrm{L}^{3} \mathrm{M}^{-1}\right)$

Also, the diffusion flux of the sediment pore water and the diffusion flux that controls the exchange between the water layer and the sediment layer depends upon one of the sediment properties, i.e. the porosity.

As all volume fractions within the sediment add up to one, a relationship between sediment properties can be defined as:

$$
\varepsilon+\frac{\rho_{\mathrm{b}}}{\rho_{\mathrm{om}}} m_{\mathrm{om}}+\frac{\left(1-m_{\mathrm{om}}\right) \rho_{\mathrm{b}}}{\rho_{\text {min }}}=1
$$

With:

$\rho_{\mathrm{om}}=\quad$ bulk density of the organic matter $\left(\mathrm{M} / \mathrm{L}^{-3}\right)$, approx. with $1.4 \mathrm{~g} / \mathrm{mL}$

$\rho_{\min }=\quad$ bulk density of the mineral fraction $\left(\mathrm{M} \mathrm{L}^{-3}\right)$, approx. with $2.65 \mathrm{~g} / \mathrm{mLf}$

Ideally, sediment properties should be based on spatially distributed data, measured over a range of ditches. This set would enable the derivation of cumulative probability distribution functions of these properties and corresponding target percentiles. Such an extensive dataset is not available.

A literature survey provided a limited number of field studies. In 1979, de Heer measured sediment properties in ditches nearby fruit orchards at six locations in the management area of the Stichtse Rijnlanden Water Board (de Heer, 1979). Also Arts and Smolders, (2008a \& 2008b) measured sediment properties in different types of waters, which were selected on the basis of nature conservation criteria. Evaluation ditches used in the EU and the Netherlands exposure assessments use sediment properties that are largely based on those of the experimental ditches of the experimental site of Wageningen Environmental Research in Renkum, in the Netherlands (FOCUS, 2001). And finally, Adriaanse et al. (2015) measured sediment properties in five ditches alongside Dutch arable crop fields. 
The Working Group considered the data obtained by de Heer (1979) and Adriaanse et al. (2015) as the most appropriate and qualified for use in further analyses. The experimental ditches of the experimental site of Alterra were artificially dug in a sandy soil, and are considered less appropriate, as the measured properties are possibly far away from natural ditches situated next to fruit orchards or tree nurseries. Also the properties measured by Arts and Smolders were considered to be less suitable for the selected ditch population, as the ditches were mostly in peaty and sandy areas. Fruit trees grow mostly in well-drained soils with a sandy/loamy texture. The dominant soil texture in the management area of Rivierenland is silty clay and clay and silty loam and loam (see Figure 6.1).

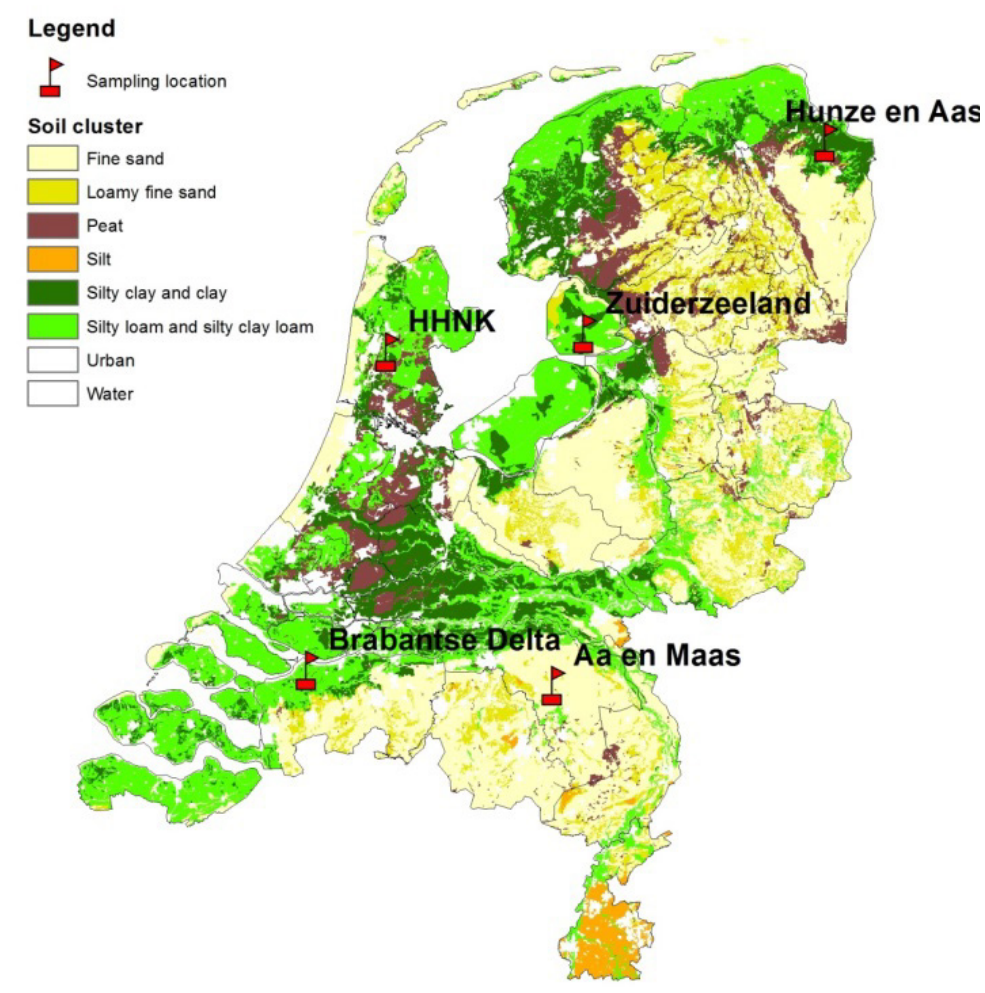

Figure 6.1 Soil texture classes and sample locations of Adriaanse et al. (2015). (source: Adriaanse et al., 2015).

\subsection{Sediment properties measured by de Heer (1979) and Adriaanse (2015)}

\subsubsection{Sediment properties measured by de Heer (1979)}

De Heer (1979) sampled sediment in the Lopikerwaard Polder at two locations (two ditches in Benschop and one ditch in Jaarsveld), where fruit trees grew just alongside the ditches. The ditches in Benschop had $50-64 \%$ clay in the sediment, and the ditch in Jaarsveld had $28-38 \%$ clay. The Lopikerwaard is an area with relatively high groundwater levels and with mainly grassland farming.

Mud cores were extracted and frozen to measure the volume fraction of liquid (porosity) and the bulk density and elementary carbon. Cores were taken in triplicate from six sampling sites in three ditches during April 1977: in each ditch, samples were extracted from two sites. Samples were taken from the upper $0-30 \mathrm{~cm}$ of the sediment layer with a slice thickness of $2 \mathrm{~cm}$. The organic matter content was measured by 'loss on ignition' corrected for clay and $\mathrm{CaCl}_{2}$ and also by total elementary carbon analysis.

Elementary carbon was translated to organic matter by multiplying by a factor of 1.724 . 
Figure 6.2 shows that in the first $10 \mathrm{~cm}$ of the samples, the volume fraction of liquid varies between 0.8 and 0.95 , the bulk density varies between 100 and $450 \mathrm{~kg} \mathrm{~m}^{-3}$ and the elementary carbon percentage varies between 6-16\%, which corresponds with a \% OM content of $10-28 \%$. The bulk density tends to increase with depth and the porosity tends to decrease with depth.
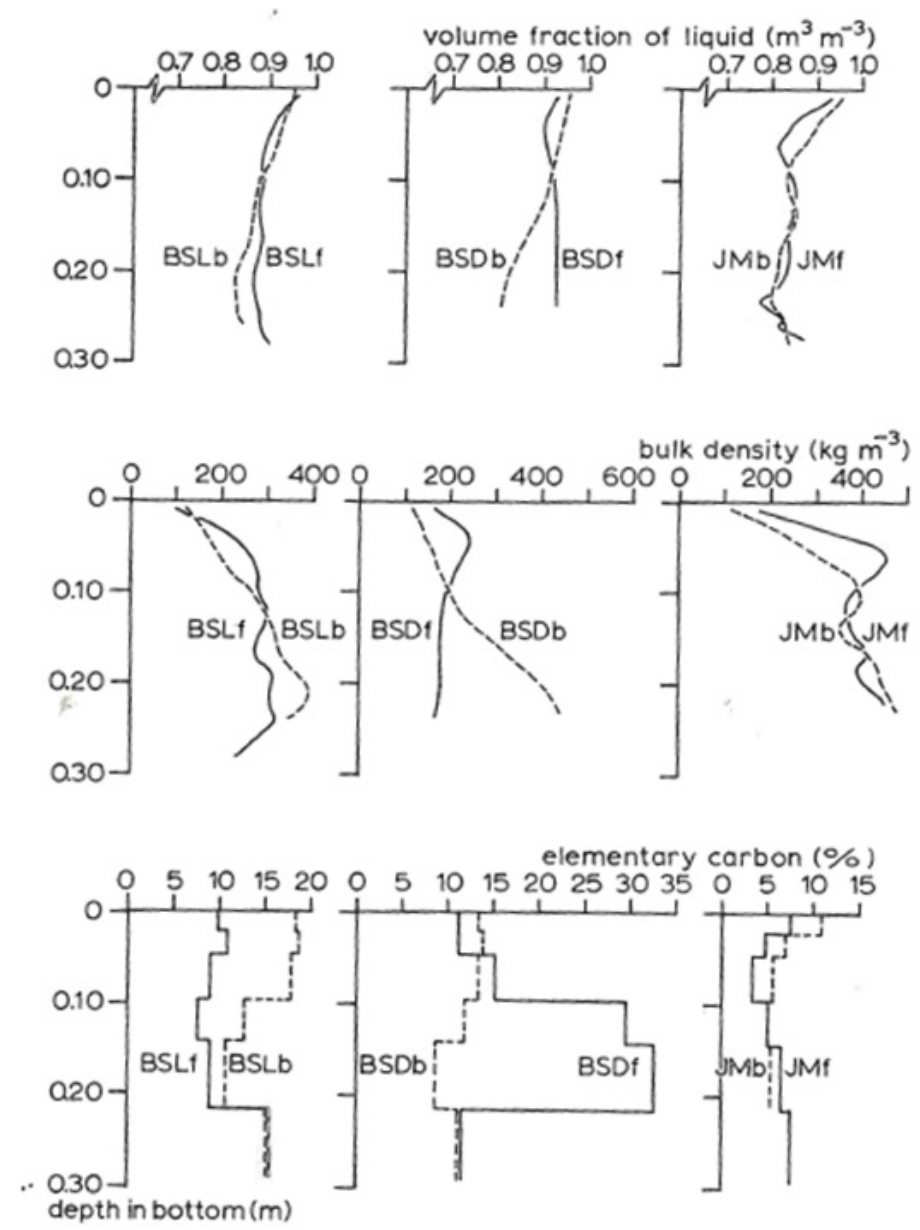

Figure 6.2 The sediment properties of ditch bottoms for six sampling sites in the Lopikerwaard Polder plotted as a function of depth (the lines are averaged values of three samples). Volume fractions of liquid (i.e. porosities), bulk densities and elementary carbon contents. Abbreviations for sampling site: $B=$ Benschop, $J=$ Jaarsveld, $S L=$ siphon-linked ditch, $S D=$ supplementary drained ditch, $M=$ middle ditch, $b=$ back of ditch, $f=$ front of ditch (source: De Heer (1979)).

\subsubsection{Sediment properties measured by Adriaanse et al. (2015)}

\section{Sampling strategy and techniques}

Four watercourses were selected that satisfied a set of predefined criteria for sample site selection. The selected watercourses were geographically spread over the Netherlands and corresponded to one of the soil types typical for arable crop farming/horticulture.

Additional criteria for the site selection were:

- The watercourse should be located adjacent to a field with arable farming or horticulture.

- The watercourse should not fall dry during the summer season.

- The total set of the selected watercourse should be in line with the watercourses considered by Tiktak et al. (2012a), who describes the Dutch scenario for downwards spraying in field crops.

Five samples were taken per selected site over a $100 \mathrm{~m}$ length of ditch. The samples were taken in June/July 2013, as well as in September 2013. A new sampling technique was applied with relatively wide sampling cores. The sediment cores were frozen without formation of an ice cone on top, and 
were divided into segments with a belt saw. The measured sample volumes were corrected for expansion due to water freezing. Measurements were taken from the upper $0-10 \mathrm{~cm}$ of the sediment layer with a slice thickness of 1 to $5 \mathrm{~cm}$. Sediment properties of the five samples taken from one ditch were averaged per sediment layer. See Adriaanse et al. (2015) for a more detailed description of the sampling strategies and techniques used. The properties of all four selected ditches are provided in Annex 6 for June/July and September 2013 over the entire measured sediment profile $(10 \mathrm{~cm})$.

Table 6.1 Main characteristics of the sampling sites (after Table 3.2 of Adriaanse et al., 2015).

\begin{tabular}{|c|c|c|c|c|c|c|}
\hline Municipality & Water Board & $\begin{array}{l}\text { Soil type } \\
\text { (LGN6) }\end{array}$ & $\begin{array}{l}\text { Watercourse } \\
\text { type }\end{array}$ & $\begin{array}{l}\text { Width at water } \\
\text { level ( } \mathrm{m} \text { ) } \\
\text { (June/July) }\end{array}$ & $\begin{array}{l}\text { Water depth } \\
\text { (m) } \\
\text { (June/July) }\end{array}$ & Crop observed \\
\hline Emmeloord & Zuider-Zeeland & $\begin{array}{l}\text { Silty loam and } \\
\text { silty clay loam }\end{array}$ & Primary & 5.5 & 0.8 & $\begin{array}{l}\text { Winter wheat, } \\
\text { sugar beets }\end{array}$ \\
\hline Nieuwolda & Hunze en $\mathrm{Aa}$ & $\begin{array}{l}\text { Silty clay and } \\
\text { clay }\end{array}$ & primary & 4.2 & 0.55 & $\begin{array}{l}\text { Winter wheat, } \\
\text { rape }\end{array}$ \\
\hline
\end{tabular}

\section{General characteristics}

To get a flavour of the values measured, in Table 6.2, the bulk density, the porosity and the OM content measured in June/ July 2013 in the first $\mathrm{cm}$ of the sediment are given for the four selected locations. The data suggest a trend from sandy soils with high organic matter content and low bulk densities towards clayey soils, with low organic matter content and high bulk densities.

In Figure 6.2, the profiles over depth are given for the sampling locations, Emmeloord and Willemstad. Both locations are associated with a soil type that corresponds to the dominant soil type for fruit orchards, silty loam and silty clay loam. Sediment properties vary very little in depth, with the exception that the first $\mathrm{cm}$ has a lower density and a higher porosity than the deeper layers for all measured profiles in Figure 6.3. Differences between measurements in June and September are small. There is a slight decrease in bulk density in the upper $\mathrm{cm}$ of the sediment from June to September and a slight increase of organic matter content. Standard deviations are small between samples in the same ditch.

Table 6.2 Averaged sediment properties in the first upper $\mathrm{cm}$ of the sediment layer. Measurements were taken in June/July 2013 in the four sampling locations.

\begin{tabular}{llll} 
& Bulk density $(\mathrm{g} / \mathrm{mL})$ & Porosity $(-)$ & OM content $(\%$ mass $)$ \\
\hline Uden & 0.19 & 0.93 & 22.2 \\
\hline Emmeloord & 0.23 & 0.91 & 17.4 \\
\hline Willemstad & 0.31 & 0.81 & 12.4 \\
\hline
\end{tabular}



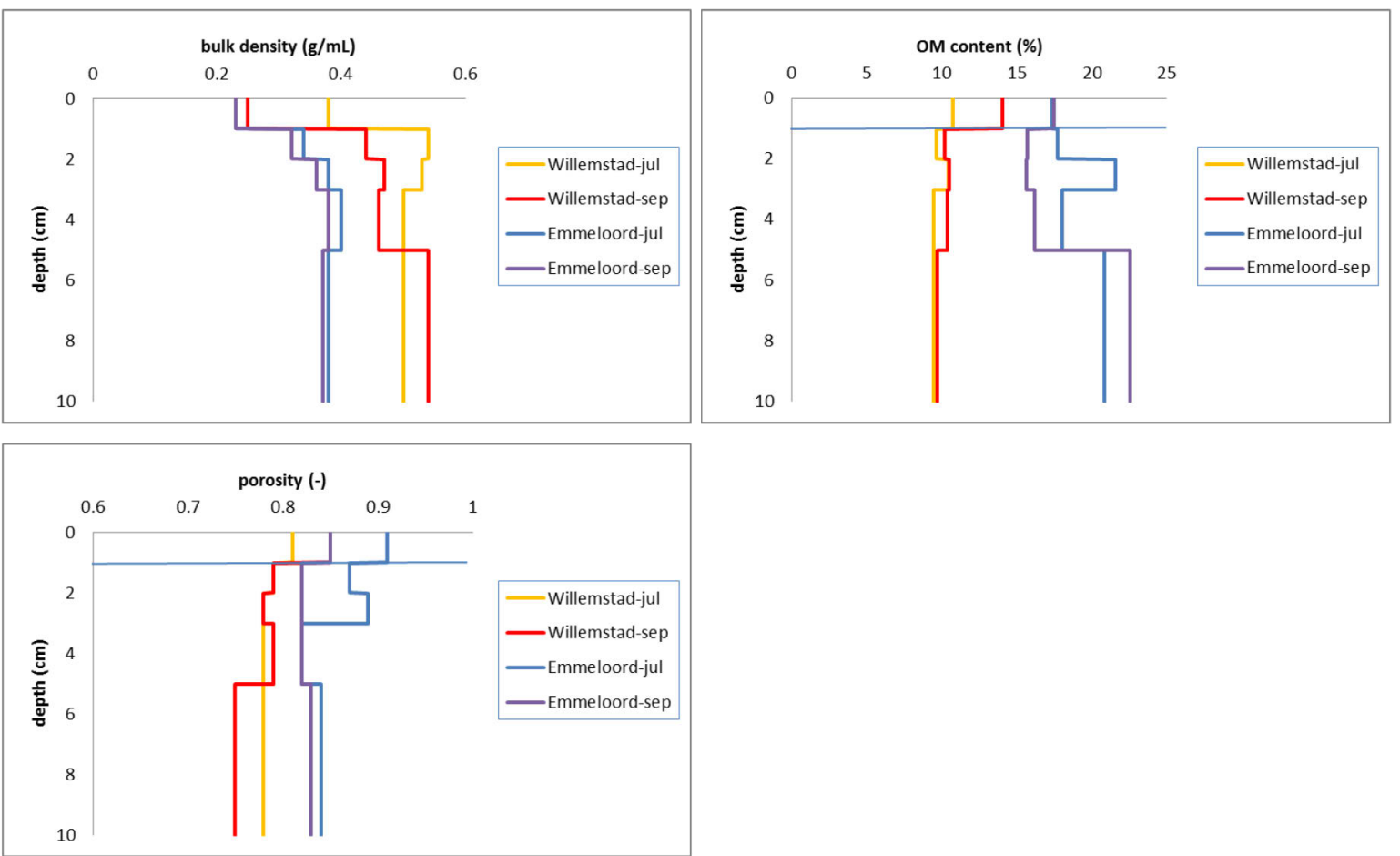

Figure 6.3 Porosity (-), Bulk density $(\mathrm{g} / \mathrm{mL})$, and OM content (\%) in over depth for the sample locations Willemstad and Emmeloord.

\subsection{Considerations}

\subsubsection{Averaging over time and space}

Organic matter content, porosity and bulk density are correlated properties; they belong to one sediment profile. Therefore, it is considered most appropriate to select one of the sampling locations and its properties as being representative for fruit-orchard and tree-nursery ditches instead of e.g. averaging over the measurements.

Adriaanse et al. (2015) differentiated between sediment properties in June/July and September, as properties may vary due to e.g. decay of water plants and algae. A closer view on the data, however, showed little variability between both datasets. Also TOXSWA does not allow for variation of sediment properties over time. Therefore, it is considered appropriate to take the average of the sediment properties measured in June/July and September, for each separate location.

The Benschop sampling location contains four sampling sites distributed over two ditches. As the samples were taken in the close surroundings of one fruit orchard, the average value of all samples were considered appropriate for Benschop.

\subsubsection{Selection}

Based on the description, the crop type, soil type and sampling strategies, the sediment properties measured near a fruit orchard (Benschop and Jaarsveld) or in silty loam and silty clay loam (Willemstad and Emmeloord) were preferred above those measured in sandy soil or clayey soil (Uden and Nieuwolda).

In Table 6.3, sediment properties of the first $\mathrm{cm}$ of the sediment layer are shown for Benschop, Jaarveld, Willemstad and Emmeloord. For Benschop and Jaarveld, an estimated average of all measurements is given, because the data behind the figures (Figure 6.2) were not available. The values used in FOCUS (2006) have been added for reference. 
The measured sediment properties of de Heer (1979) show a higher porosity, a lower bulk density and a higher organic matter content than the properties measured by Adriaanse et al. (2015). Both are very different from FOCUS (2006), with its much higher bulk density and much lower porosity, as compared to the sampling locations properties.

Table 6.3 Averaged sediment properties in the upper first $\mathrm{cm}$ of the sediment layer, including their source.

\begin{tabular}{lllll} 
Source & Sampling location & Bulk density $(\mathrm{g} / \mathrm{mL})$ & Porosity $(-)$ & OM content $(\%$ mass $)$ \\
De Heer (1979) & Benschop & $\sim 0.12$ & $\sim 0.94$ & $17-31$ \\
\hline De Heer (1979) & Jaarsveld & $\sim 0.18$ & $\sim 0.94$ & $12-17$ \\
\hline Adriaanse et al. (2015) & Emmeloord & 0.23 & 0.88 & 17.4 \\
\hline Adriaanse et al. (2015) & Willemstad & 0.32 & 0.83 & 12.4 \\
\hline FOCuS (2006) & Renkum & 0.80 & 0.68 & 9.0 \\
\hline
\end{tabular}

\section{Further selection}

All measured sediment properties from the sampling locations; Benschop, Jaarsveld, Emmeloord and Willemstad, were considered to be of similar quality. Therefore, it was decided to consider the entire range of properties provided by the four locations. In a next step, the sensitivity of the Predicted Environmental Concentration to the sediment properties must be analysed before selecting one of the sampling locations. As Benschop (high organic matter content and low bulk density) and Willemstad (lower organic matter content and relatively higher bulk density) are the two extremes, with respect to sediment properties, it was decided to use the data of these two locations to assess the impact of the sediment properties on pesticide fate.

\subsubsection{Sediment profile over the depth}

Both Willemstad and Benschop show little variation of properties in depth. The porosity for Willemstad fluctuates around 0.78 , whereby the upper $1 \mathrm{~cm}$ seems to have a slightly higher porosity than the sediment between $1-10 \mathrm{~cm}$ depth. Also the organic matter content in the first $\mathrm{cm}$ appears to be higher (10.7-14\%) than in the lower layers (9.5-10.5\%), especially in September. Although a closer look at the data showed that one sample with a high organic matter content (22\%) caused this high value. The bulk density instead is lower in the first $1 \mathrm{~cm}$ of the sediment $(0.25-0.38 \mathrm{~g} / \mathrm{ml})$, as compared to the lower sediment layers $(0.44-0.54 \mathrm{~g} / \mathrm{ml})$.

A similar pattern can be observed for Benschop (averaged values over two ditches), for which the porosity fluctuates around 0.92 . Also in Benschop, the porosity is slightly higher in the upper first $1 \mathrm{~cm}$ of the sediment. The bulk density of the sample locations is ca. $0.18 \mathrm{~g} / \mathrm{ml}$ in the first $\mathrm{cm}$ of the sediment layer, which is lower than the $0.38 \mathrm{~g} / \mathrm{ml}$ in the lower part of the sediment cores: this trend is again similar to Willemstad.

Considering the six available profiles (four from Benschop and two from Willemstad), for five out of six profiles, the upper $1 \mathrm{~cm}$ has a lower bulk density and higher porosity than the remainder of the profile. Given these observations, and the sensitivity of the calculated water concentrations to the sediment properties in the upper $\mathrm{cm}$ of the sediment (pers. comm. P. Adriaanse), the Working Group decided to differentiate between sediment properties of the first $\mathrm{cm}$ of the sediment and then (weighted) average over the sediment between $1-10 \mathrm{~cm}$ or deeper, if the data is available. 


\subsection{Ditch properties to be used in the parameterisation}

The final list of ditch properties consists of two sets; one based on data from Willemstad and one based on data from Benschop. The final selection will be based on example calculations with the TOXSWA model.

Table 6.4 Proposed sediment properties based on Willemstad sample location.

\begin{tabular}{llll} 
& Bulk density $(\mathrm{g} / \mathrm{mL})$ & Porosity $(-)$ & OM content $(\%$ mass $)$ \\
$0-1 \mathrm{~cm}$ & 0.32 & 0.83 & 12.4 \\
\hline $1-10 \mathrm{~cm}$ & 0.49 & 0.78 & 10.1 \\
\hline
\end{tabular}

Table 6.5 Proposed sediment properties based on Benschop sample location.

\begin{tabular}{llll} 
& Bulk density $(\mathrm{g} / \mathrm{mL})$ & Porosity $(-)$ & OM content (\% mass) \\
\hline $0-1 \mathrm{~cm}$ & 0.12 & 0.94 & 22 \\
\hline $1-10 \mathrm{~cm}$ & 0.2 & 0.92 & 24 \\
\hline
\end{tabular}

The consistency of the data was checked by summing the volume fractions for both locations, using equation 6.3 , with the values for bulk density of the organic matter, $\rho_{\text {om }}$ and bulk density of the mineral fraction, $\rho_{\min }$ of $1.4 \mathrm{~g} / \mathrm{mL}$ and $2.65 \mathrm{~g} / \mathrm{mL}$, respectively. The volume fractions varied between 0.96 and 1.01, which was considered appropriate for use in TOXSWA calculations:

\subsection{Tortuosity}

The tortuosity factor, $\lambda(-)$, controls the diffusion of chemicals into the sediment, and is estimated according to Boudrau (1996):

$$
\lambda=\frac{1}{1-\ln \left(\varepsilon^{2}\right)}
$$

Consequently the tortuosity (-) will be:

\begin{tabular}{ll} 
Willemstad: & Benschop: \\
$0-1 \mathrm{~cm}: 0.73$ & $0-1 \mathrm{~cm}: 0.89$ \\
\hline $1-10 \mathrm{~cm}: 0.67$ & $1-10 \mathrm{~cm}: 0,86$ \\
\hline
\end{tabular}




\subsection{Suspended solids}

Conform FOCUS (2001); the water layer contains suspended solids, but no macrophytes. In the absence of special data on suspended solid characteristics, values for suspended solids from the Dutch downward spraying scenario were used (Tiktak et al., 2012a), i.e.: the concentration of suspended solids in the water layer at $11 \mathrm{~g} \mathrm{~m}^{-3}$. For the mass fraction of organic matter in suspended solids the Working Group advised to use the value of the mass fraction of organic matter in the top $1 \mathrm{~cm}$ of the selected sediment. This is the most rational assumption to make as the top layer of the sediment is the most likely source of suspended solids in the water layer of the ditch.

\subsection{Sediment discretisation}

The sediment layer is discretised into a number of layers for substances with a low sorption coefficient as follows:

\begin{tabular}{ll} 
Soil depth below surface $(\mathrm{mm})$ & Thickness layers $(\mathrm{mm})$ \\
\hline $0-4$ & 1 \\
\hline $4-10$ & 2 \\
\hline $10-20$ & 5 \\
\hline $20-50$ & 10 \\
\hline $50-70$ & 20 \\
\hline $70-100$ & 30 \\
\hline
\end{tabular}

And for substances with a high sorption coefficient:

\begin{tabular}{ll} 
Soil depth below surface $(\mathrm{mm})$ & Thickness layers $(\mathrm{mm})$ \\
\hline $0-0.24$ & 0.03 \\
\hline $0.24-0.36$ & 0.06 \\
\hline $0.36-0.46$ & 0.05 \\
\hline $0.46-0.7$ & 0.12 \\
\hline $0.7-1.0$ & 0.3 \\
\hline $1.0-2.5$ & 0.75 \\
\hline $2.5-6.5$ & 2 \\
\hline $6.5-10$ & 3.5 \\
\hline $10-20$ & 5 \\
\hline $20-50$ & 10 \\
\hline $50-70$ & 20 \\
\hline $70-100$ & 30 \\
\hline
\end{tabular}

The value of the sorption coefficient that marks the transition between both discretisation types has yet to be established. This will be done based on the accepted numerical error for the Predicted Environmental Concentration. 


\section{$7 \quad$ Water temperatures}

The temperature of the water in of the water body is simulated on an hourly basis using the TOXSWA model. The TOXSWA model has recently been extended with the functionality to simulate water temperature using hourly meteorological data added (Beltman et al., 2017). The new functionality is based on a 1D-bulk approach, which assumes a well-mixed water layer. Contributions to the energy budget from shortwave radiation, longwave radiation, sensible- and latent heat-exchange between air and water, precipitation, potential heat-exchange between water and sediment and possible external sources, such as incoming drainage water, are taken into account. The temperature of sediment is assumed equal to the water temperature. The main effect of the temperature to the behaviour of pesticide in the water body involves the degradation rate.

To simulate the water temperatures, hourly data from the KNMI Meteostation Herwijnen were used (https://www.knmi.nl/nederland-nu/klimatologie/uurgegevens), Herwijnen is one of the Dutch meteostations used for the drift calculations as part of the scenario derivation procedure (Boesten et al., 2018). The eventual scenario selected calculates drift deposition based on the weather measured at the meteostation Herwijnen over the period 1991-2005. Meteo data of the Herwijnen station were used for the same period. Precipitation data is not available for the period $1^{\text {st }}$ January $1991-4^{\text {th }}$ May 1993 and data on vapour pressure is missing for the period $1^{\text {st }}$ January $1991-23^{\text {rd }}$ April 2009 . Both types of data are needed for the temperature simulations, but not for the drift simulations. Data of nearby meteostation De Bilt were used to fill these gaps. The expected effect of filling the missing data from that of a nearby meteostation is small. Furthermore, data from the period 2001-2005 was copied to the warm-up period 1986 - 1990 (after correction for leap years).

To simulate the temperature in water and in sediment from weather data, TOXSWA requires an input file that specifies hourly meteo data (the so-called *. meth file). Details of the meteorological data needed are given in Annex 8.

In TOXSWA inflow of energy via drainage water has been included. Contribution of drainage to the energy budget was calculated using the temperature in the drainage water (Beltman et al., 2017). These temperatures are calculated by SWAP and provided by the PEARL model as part of the *.e2t file. The meteorological data used for the SWAP/PEARL parameterisation is taken as well from the Herwijnen meteorological station.

\section{Practical considerations}

The dynamic discharge and the water depths resulting from the SWQN simulation must be coupled to the meteorological data from meteostation Herwijnen (which are used by both TOXSWA and SWAP/PEARL). The SWQN simulation covered a period of 27 years. This period does not refer to real weather years because the flow velocities resulted from the statistical direct sampling technique (Section 2.4.2). The meteorological data of meteostation Herwijnen do refer to real weather years and were available for the period 1991-2010. A pragmatic approach was applied of coupling the two different periods, such that leap years coincide. Also, part of the meterological data set is used twice, as the dataset of Herwijnen does not cover the 26 year period needed for the pesticide fate simulations.

This resulted in the following solution:

1. For the period 1986-1990, meteorological data of station Herwijnen from the period 2001-2005 was used.

2. For the period 1991-2005, meteorological data of station Herwijnen from the period 1991-2005 was used.

3. The meteorological data set for the period 1986-2005 constructed in Step 1 and Step 2 was coupled to the SWQN time-series of the period 2022-2041. 


\section{$8 \quad$ Conclusions and recommendations}

In this report, the hydrological parameterisation of the evaluation ditch as part of the Dutch exposure assessment procedure for sideways and upward spraying in fruit orchards is described. The parameterised model, which is coupled to corresponding parameterised drift and drainage models, enables the calculation of Predicted Environmental Concentrations (PECs) in surface water for complex application schemes. The concentration in water averaged over $100 \mathrm{~m}$ of ditch is the Predicted Environmental Concentration. This PEC is calculated with the pesticide fate model TOXSWA. Hydrology of the evaluation ditch was simulated with the SWQN model of which the simulated water discharges and water depths were input to the TOXSWA model. One of the initial assumptions was that drift is the dominant pathway in case of sideways and upward application of plant protection products. Recent example calculations, however, indicated that the contribution from drainpipes is more dominant. The contribution from drainpipes, simulated with the SWAP-PEARL model, is therefore added to the evaluation ditch and described in this report.

The parameterisation is part of, and builds further upon, the scenario selection procedure, which is described in a separate report. The ditch parameterisation is a further elaboration of initial assumptions by the Working Group, with the final aim to allow for all (complex) pesticide fate processes in the pesticide fate simulations.

Four aspects were of specific interest for the parameterisation of TOXSWA: the dynamics of the flow velocity in the ditch, the corresponding water-depth dynamics, the drainpipe parameterisation and sediment characteristics. Conclusions and recommendations considering these four aspects are described below.

\section{Flow velocities}

- High resolution groundwater models are useful to derive flow velocities in edge-of-field ditches in polder areas, with a large impact of water management practices. In this report output from a high resolution groundwater model was obtained from the Rivierenland Water Board and used to derive flow velocities. The advantage of the approach followed was that the obtained flow velocities pretty much conserve the dynamic effects of (time-variable) precipitation, farmers' practices (irrigation), as well as water management practices.

- The statistical direct sampling method maintains the higher order statistics of the original dataset. Due to the applied method, the link to real weather data was lost, though. Also, some smoothing of extremes occurred. This was considered acceptable.

- Flow directions alternate, which is consistent with water management practices. Typical for the flow velocities of this constructed time-series is that water flows in two directions. This is in line with hydrological practice in Dutch polders, i.e. in the winter excess precipitation water is discharged, and in the summer water is let in to support crop water demand, and consistent with water management practices in the management area of the Rivierenland Water Board.

- Flow velocities of the dataset are higher and residence times corresponding to the flow velocities are shorter than currently used in the Dutch aquatic risk assessment for plant protection products.

- The Working Group thinks that the flow velocities derived are in line with what can be expected in the Rivierenland area. As pesticide concentrations in a water course are sensitive to the water flow velocity in the water course, the developed hydrological scenario would benefit from further underpinning of the flow velocity dataset used. A survey in Dutch edge-of-field ditches in which water flow velocities are measured continuously in e.g. 10-20 edge-of-field ditches over 2-3 years will help to assess the level of realism of the dataset used. 


\section{Water depths}

- The variability in the water depth, resulting from the calibration process, was lower than experienced by the Rivierenland Water Board; the Water Board expects the water level to be at soil surface once in every ten years. For the evaluation ditch, the probability is much lower than in every ten years. This can be explained (at least partly) by the averaging of the flow velocities over one 'target level unit', which diminishes the extremes in individual water courses. Also, the velocity values used were daily averaged values, which smooths the extremes over the day. This is considered as acceptable for the use in the scenario context.

- As pesticide concentrations in a water course are sensitive to the water depths in the water course, the developed hydrological scenario would benefit from further underpinning of the water depth dynamics of the ditch. Extension of the survey as mentioned above with water depths would help to assess the level of realism of the hydrological parameterisation of the fruit orchard scenario.

\section{Drainpipe discharges}

- Analysis showed that differentiation between a grass strip and a tree strip is needed in the SWAP model for a good simulation of the soil hydrological system in typical Dutch orchards and hence for a proper simulation of drain flows to nearby ditches. The differentiation between a grass strip and a tree strip is now part of the parameterisation of the SWAP model.

\section{Sediment characteristics}

- A survey resulted in two selected beneficial sediment property sources. Both sources are considered as useful in this report. To make a final selection we recommend assessing the impact of the selected two types of sediments on the calculated pesticide concentrations with example calculations while using the full scenario. Based on this assessment, one sediment property source can be selected to be used in the evaluation ditch. 


\section{List of Abbreviations}

\begin{tabular}{ll}
\hline CBS & Statistics Netherlands \\
\hline BRP & 'Basis Registratie Percelen' (Registration of land plots in the Netherlands) \\
\hline FOCUS & Direct Sampling \\
\hline ID & Forum for Co-ordination of pesticide fate models and their use \\
\hline LGN & Identification number \\
\hline KNMI & Land Use Database of the Netherlands \\
\hline NHI & The Royal Netherlands Meteorological Institute \\
\hline PEARL & Dutch Hydrological Instrument \\
& $\begin{array}{l}\text { Pesticide Emission Assessment at Regional and Local scales. One-dimensional, } \\
\text { dynamic, multi-layer model, which describes the fate of a pesticide and relevant } \\
\text { transformation products in the soil-plant system }\end{array}$ \\
\hline PEC & Predicted Environmental Concentration \\
\hline P-M & Penman-Monteith \\
\hline SOBEK & Model suite for hydrological quantitative modelling \\
\hline SWAP & $\begin{array}{l}\text { Soil, Water, Atmosphere and Plant. Agrohydrological model simulating transport } \\
\text { of water and heat in unsaturated/saturated soils }\end{array}$ \\
\hline SWQN & $\begin{array}{l}\text { Surface Water QuaNtity tool for calculation of water flows in a network of } \\
\text { watercourses }\end{array}$ \\
\hline TI & Training Image \\
\hline TOP10 vector & Digital topographic map of the Netherlands 1:10,000 \\
\hline TOXSWA & Toxic Substances in Water. Model that simulates pesticide fate in surface water \\
\hline
\end{tabular}




\section{References}

Adriaanse, P.I., 1996. Fate of pesticides in field ditches: the TOXSWA simulation model. Report 90, DLO Winand Staring Centre for Integrated Land, Soil and Water Research, Wageningen, the Netherlands.

Adriaanse, P.I. and W.H.J. Beltman, 2009. Transient water flow in the TOXSWA model (FOCUS versions): concepts and mathematical description. Wageningen, Statutory Research Tasks Unit for Nature and the Environment. WOt-report No. 101, 78pp.

Adriaanse, P.I., W.H.J. Beltman, F. Van den Berg, 2014. Metabolite formation in water and in sediment in the TOXSWA model. Theory and procedure for the upstream catchment of FOCUS streams. Alterra report 2587.

Adriaanse, P.I., S.J.H. Crum, J.A. Elbers, H.Th.L. Massop and W.H.J. Beltman, 2015. Sediment properties in five Dutch watercourses. Indicative measurements for registration procedure of plant protection products in The Netherlands. Alterra report 2574, Alterra, Wageningen, The Netherlands.

Allen, R.G., Pereira, L.S., Raes, D., and Smith, M., 1998. Crop evapotranspiration. Guidelines for computing crop water requirements. Irrigation and Drainage Paper 56, FAO, Rome, Italy, $300 \mathrm{p}$. Available from: http://www.fao.org/docrep/X0490E/x0490e07.htm (last entered 26 February 2019).

Arts, G.P.H. and A.J.P. Smolders, 2008a. Selectie van referentiepunten voor aquatische vegetatietypen voor het Staatsbosbeheer-project terreincondities. Fase 1 aquatisch: resultaten inventarisatie 2005. Alterra rapport 1802, Alterra, Wageningen, The Netherlands.

Arts, G.P.H. and A.J.P. Smolders, 2008b. Selectie van referentiepunten voor aquatische vegetatietypen voor het Staatsbosbeheer-project terreincondities. Fase 2 aquatisch: resultaten inventarisatie 2006. Alterra rapport 1803, Alterra, Wageningen, The Netherlands.

Bal JJM, Verhage, AB, 2011. Water optimalisatie plan fruitteelt. ZLTO Advies 27-03-2012 - Kenmerk: ZJBA.2011.0888. Website: https://edepot.wur.nl/333091 (last entered 7 February 2020).

Beltman, W.H.J., P.I. Adriaanse, C.M.J. Jacobs and H.M. Mulder, 2017. Temperature in water and sediment in the pesticide model TOXSWA; Implementation report. Wageningen, Alterra Wageningen University \& Research, Wageningen Environmental Research report 2794, Wageningen, the Netherlands.

Beltman and Adriaanse, 1999. Proposed standard scenarios for a surface water model in the Dutch authorization procedure of pesticides. Method to define standard scenarios determining exposure concentrations simulated by the TOXSWA model. DLO Staring Centre report 161, Wageningen, The Netherlands

Boesten, J.J.T.I., H.J. Holterman, Wipfler L., M.M.S. ter Horst, J.C. van de Zande, P.I. Adriaanse, 2018. Scenarios for exposure of aquatic organisms to plant protection products in the Netherlands. Part 2: Sideways and upward spraying in Dutch fruit crops (interim report). Wageningen, Wageningen Environmental Research, Report 2861.

Boesten, J.J.T.I., Adriaanse P.I., Holterman H.J., ter Horst M.M.S., A. Tiktak, van de Zande J.C., Wipfler E.L. (in prep.) Scenarios for exposure of aquatic organisms to plant protection products in the Netherlands. Part 2: Sideways and upward spraying in Dutch fruit crops (final report)

Borren, W. and J. Hoogewoud, 2014. Hercalibratie MORIA (in Dutch). Deltares report 1208395.

Cultuurtechnisch Vademecum. 1988. Handboek inrichting en beheer landelijk gebied. Werkgroep Herziening Cultuurtechnisch Vademecum. Cultuurtechnische Vereniging. Utrecht.

Boudrau, P.B., 1996. The diffusive tortuosity of fine-grained unlithified sediments. Geochimica et Cosmochimica Acta (60):3139-3142.

De Heer, 1979. Measurements and computations on the behaviour of the insecticides azinphos-methyl and dimethoate in ditches

Dik, P.E., Jeuken, M.H.J.L., Van Gerven, L.P.A., 2009. SWQN, Manual version 3.0. Alterra Report 1226.3, Wageningen, Alterra.

Feddes, R.A., P.J. Kowalik and H. Zaradny, 1978. Simulation of field water use and crop yield. Simulation Monographs. Pudoc. Wageningen. 189 pp. 
Feddes, R.A., 1987. Crop factors in relation to Makking reference crop evapotranspiration. In 'Evaporation and weather', TNO Committee on Hydrological Research, Proceedings and information no 39, p. 33-46.

FOCUS (2000) 'FOCUS groundwater scenarios in the EU review of active substances' Report of the FOCUS Groundwater Scenarios Workgroup, EC Document Reference Sanco/321/2000 rev.2, 202pp.

FOCUS surface water scenarios in the EU evaluation process under 91/414/EEC. 2001. Report of the FOCUS working group on surface water scenarios, EC document reference SANCO/4802/2001rev.2.

Holterman, H.J., Van de Zande, J.C., Massop, H.T.L., Boesten, J.J.T.I., Huijsmans, J.F.M., $2016 a$. Modelling the exposure of water bodies to spray drift for fruit growing in the Netherlands. International Advances in Pesticide Application, Barcelona, Spain, 13-15 January 2016.

Holterman, H.J, J.C. van de Zande, J.F.M. Huijsmans and M. Wenneker, 2016b. An empirical model based on phenological growth stage for predicting pesticide spray drift in pome fruit orchards. Biosystems Engineering; Available online 16 September 2016 (http://www.sciencedirect.com/science/article/pii/S1537511016305074)

Kodde, K., Kipp, J., 1990. Watergift beter afstemmen op behoefte. Fruitteelt 80(28): 12-13.

Kroes, J.G., J.C. van Dam, R.P. Bartholomeus, P. Groenendijk, M. Heinen, R.F.A. Hendriks, H.M. Mulder, I. Supit, P.E.V. van Walsum, 2017. SWAP version 4; Theory description and user manual. Wageningen, Wageningen Environmental Research, Report 2780.

LGN6 map. http://www.wur.nl/nl/Expertises-Dienstverlening/Onderzoeksinstituten/EnvironmentalResearch/Faciliteiten-Producten/Kaarten-en-GIS-bestanden/Landelijk-GrondgebruikNederland/LGN6.htm

Hazeu, G.W., C. Schuiling, G.J. Dorland, G.J. Roerink, H.S.D. Naeff en R.A. Smidt, 2014. Landelijk Grondgebruiksbestand Nederland versie 7 (LGN7). Alterra-rapport 2548 (in Dutch)

Massop, H.Th.L., Van Der Gaast, J.W.J., Hermans, A.G.M., 2006 Kenmerken van het ontwaterinsstelsel in Nederland. Alterra report 1397, Wageningen.

Mariethoz, G., P. Renard, and J. Straubhaar, 2010. The Direct Sampling method to perform multiplepoint geostatistical simulations, Water Resour. Res., 46, W11536, doi:10.1029/2008WR007621.

Oriani, F., Straubhaar, J., Renard, P., and Mariethoz, G. Simulation of rainfall time-series from different climatic regions using the direct sampling technique, Hydrol. Earth Syst. Sci., 18, 30153031, doi:10.5194/hess-18-3015-2014, 2014.

Ritchie, J.T., 1972. Model for predicting evaporation from a row crop with incomplete cover. Water Resources Research 8: 1204-1213.

Smelt, J.H., R.F.A. Hendriks, L.J.T. van der Pas, A.M. Matser, A. van den Toorn, K. Oostindie, O.M. van Dijk-Hooijer, J.J.T.I. Boesten and R.P. Scorza Jr. 2003. Transport of water, bromide ion, nutrients and the pesticides bentazone and imidacloprid in a cracking, tile drained clay soil at Andelst, The Netherlands. Wageningen, Alterra-rapport 289.

Smit, A.A.M.F.R., Siderius, C., Van Gerven, L.P.A., 2009. Process description of SWQN, A simplified hydraulic model. Alterra Report 1226.1, Wageningen, Alterra.

Ter Horst, M.M.S, R.A.F. Hendriks, J.J.T.I. Boesten, 2006. Addendum to Alterra report 289 'Transport of water, bromide ion, nutrients and the pesticides bentazone and imidacloprid in a cracking, tile drained clay soil at Andelst, the Netherlands'. Wageningen,

Tiktak, A., P.I. Adriaanse, J.J.T.I. Boesten, C. van Griethuysen, M.M.S. ter Horst, J.B.H.J. Linders, A.M.A. van der Linden, J.C. van der Zande, 2012a. Scenarios for exposure of aquatic organisms to plant protection products in the Netherlands. Part 1: Field crops and downward spraying. RIVM Report 607407002/2012, Bilthoven, The Netherlands, 129 pp.

Tiktak A, J.J.T.I. Boesten, R.F.A. Hendriks, A.M.A. van der Linden, 2012b. Leaching of plant protection products to field ditches in the Netherlands. Development of a drain pipe scenario for arable land. RIVM Report 607407003/2012, RIVM, Bilthoven, The Netherlands, 106 pp.

Tiktak A, R.F.A. Hendriks, J.J.T.I. Boesten, 2012c. Simulation of movement of pesticides towards drains with a preferential flow version of PEARL. Pest Manag. Sci. (68):290-302

Van den Berg, F., A. Tiktak, J.J.T.I. Boesten and A.M.A. van der Linden, 2016. PEARL model for pesticide behaviour and emissions in soil-plant systems; Description of processes. The Statutory Research Tasks Unit for Nature \& the Environment (WOT Natuur \& Milieu). WOt-technical report 61.

Van der Maas, M., 1998. Watergeven doe je niet op gevoel. Fruitteelt 88(2): 12-13. 
Van der Maas, M., Op 't Hof, M., 2002. Iedere boom krijgt zijn eigen hoeveelheid water. Fruitteelt 92(2): 12-13.

Van der Maas, M.P., Op 't Hof, M.C.J., 2006. Extra vochttekorten na grondwaterstanddaling als gevolg van grondwateronttrekking bij een fruitteelt- en een boomteeltgewas in de Overbetuwe in worstcase-situaties. Unpublished report, PPO-Fruit, Wageningen, $32 \mathrm{pp}$.

Westein, E., Jansen, M.J.W., Adriaanse, P.I., Beltman, W.H.J., 1998. Sensitivity analysis of the TOXSWA model simulating fate of pesticides in surface waters. SC-DLO, Wageningen, Report 154. Wipfler, E.L., M.M.S. ter Horst, H.Th.L. Massop and D.J.J. Walvoort, 2018. Ditch parameterisation for the aquatic exposure assessment of plant protection products in the Netherlands by sideways and upward spraying in fruit orchards. Wageningen, Wageningen Environmental Research, Report 2850. 


\section{Annex 1 Tielerwaard: Comparison SOBEK- Moria flow velocities}

The hydrodynamic model, SOBEK, and the groundwater model Moria 2.2. both simulate flow velocities in the Rivierenland area. In this Annex, simulated velocities are compared for the sub-region Tielerwaard, which is part of the management area of Rivierenland.

The Rivierenland Water Board provided SOBEK daily flow velocities of the Tielerwaard for the period $1 / 3 / 2004$ to $1 / 4 / 2005$. Velocities could be positive or negative. The value depends upon the predefined positive direction in the model. Figure A1.1 shows the map of the Tielerwaard, with mean absolute velocities in the simulated watercourses over the period 1 April to 1 October 2004 (summer). For the same region, and the same period, flow velocities were derived with the Moria model, according to the procedure as described in Section 2.2. Absolute mean values are shown in Figure A1.2.

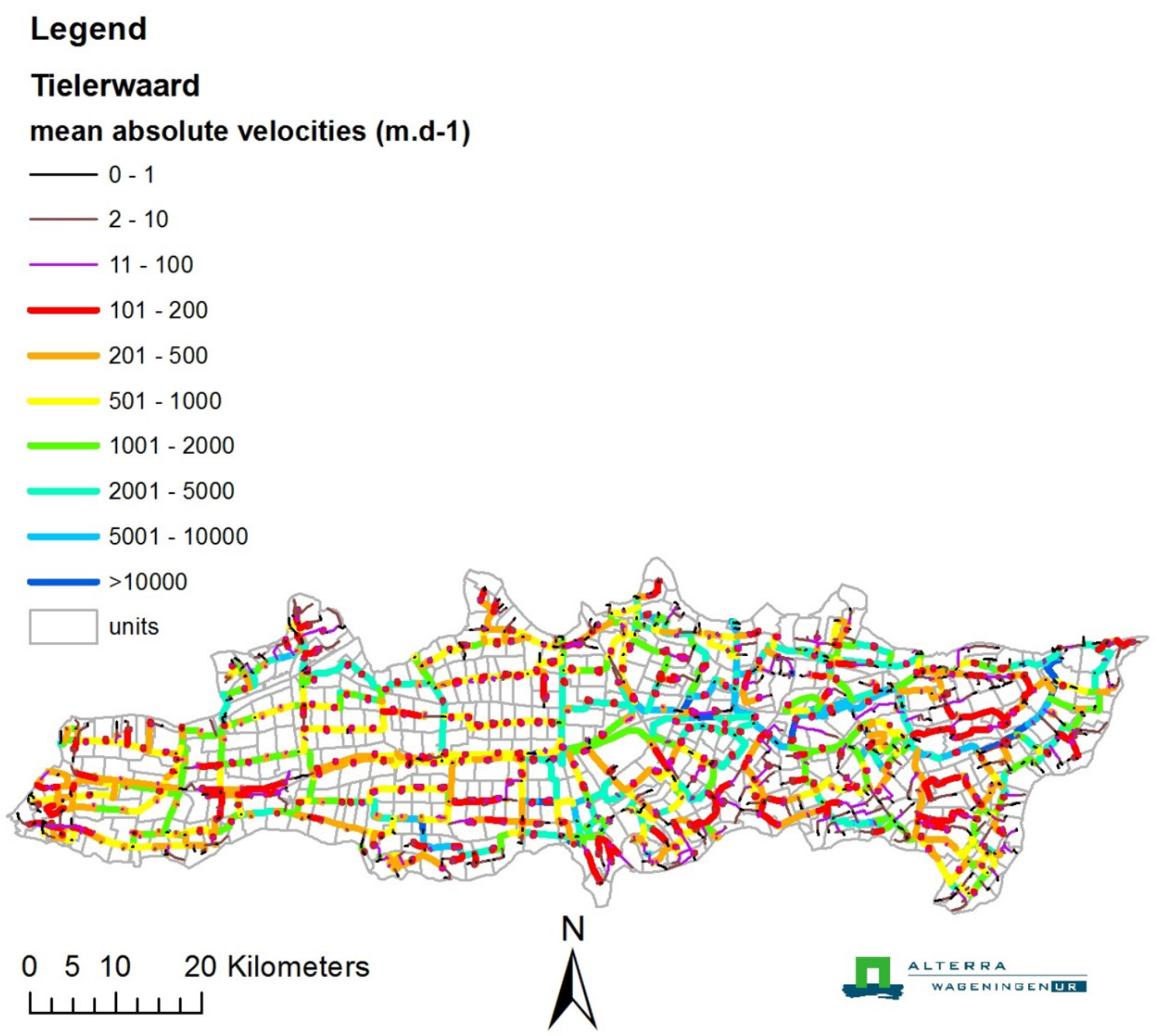

Figure A1.1 Absolute mean summer velocities in the watercourses of the SOBEK model of Tielerwaard. 


\section{Legend}

\section{Units Tielerwaard}

mean absolute velocities (m.d-1)

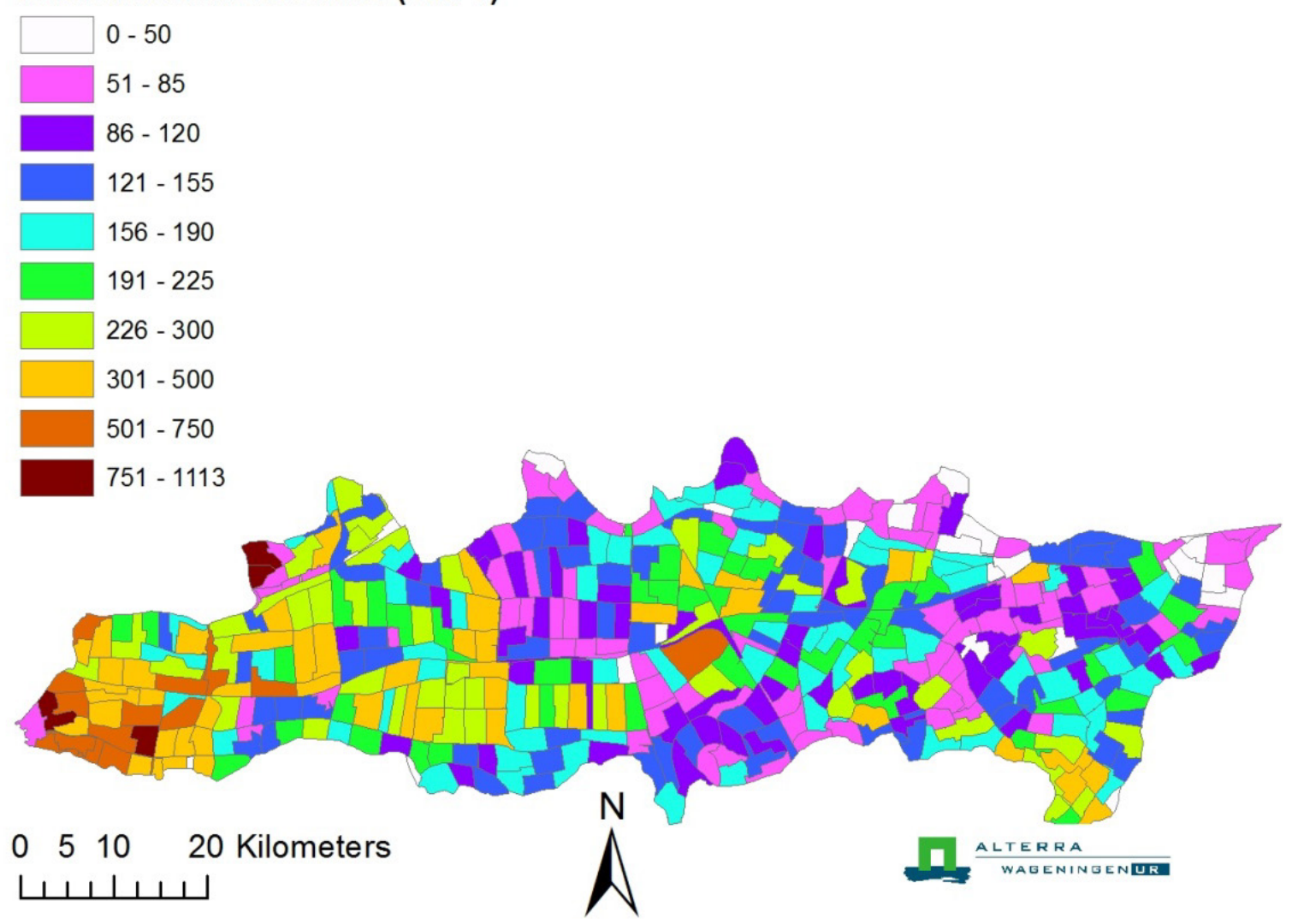

Figure A1.2 Absolute mean summer velocities in the units of the MORIA model simulation of Tielerwaard.

To enable the comparison of both methods, individual ditch flow velocities from SOBEK were attributed to the units as used by Moria. For each unit, the velocities were averaged (weighted per ditch length). The frequency distributions of both models are provided in Figure A1.3. An overview of the main statistics of both sets over flow velocities is given in Table A1.1. In Figure A1.4, the ratio of velocities calculated by SOBEK and MORIA per unit is plotted.

In general, it may be concluded that SOBEK calculates higher velocities than MORIA. There are some exceptions though, as 89 of the 441 units had lower velocities than MORIA (red-and orange units in Figure A1.4). Also the variability in the velocities calculated by SOBEK is larger than that of MORIA.

The higher velocities of the SOBEK model and the larger variability may be explained by the additional discharge of regional water. The cause of the lower velocities calculated by SOBEK is not known.

Table A1.1 Mean, median and standard deviation of the flow velocities in summer and winter for the Tielerwaard.

\begin{tabular}{lll} 
Statistics of velocities & SOBEK & MORTA \\
Mean & $1382 \mathrm{~m} / \mathrm{d}$ & $173 \mathrm{~m} / \mathrm{d}$ \\
\hline Median & $708 \mathrm{~m} / \mathrm{d}$ & $147 \mathrm{~m} / \mathrm{d}$ \\
\hline Standard deviation & $2022 \mathrm{~m} / \mathrm{d}$ & $146 \mathrm{~m} / \mathrm{d}$ \\
\hline
\end{tabular}




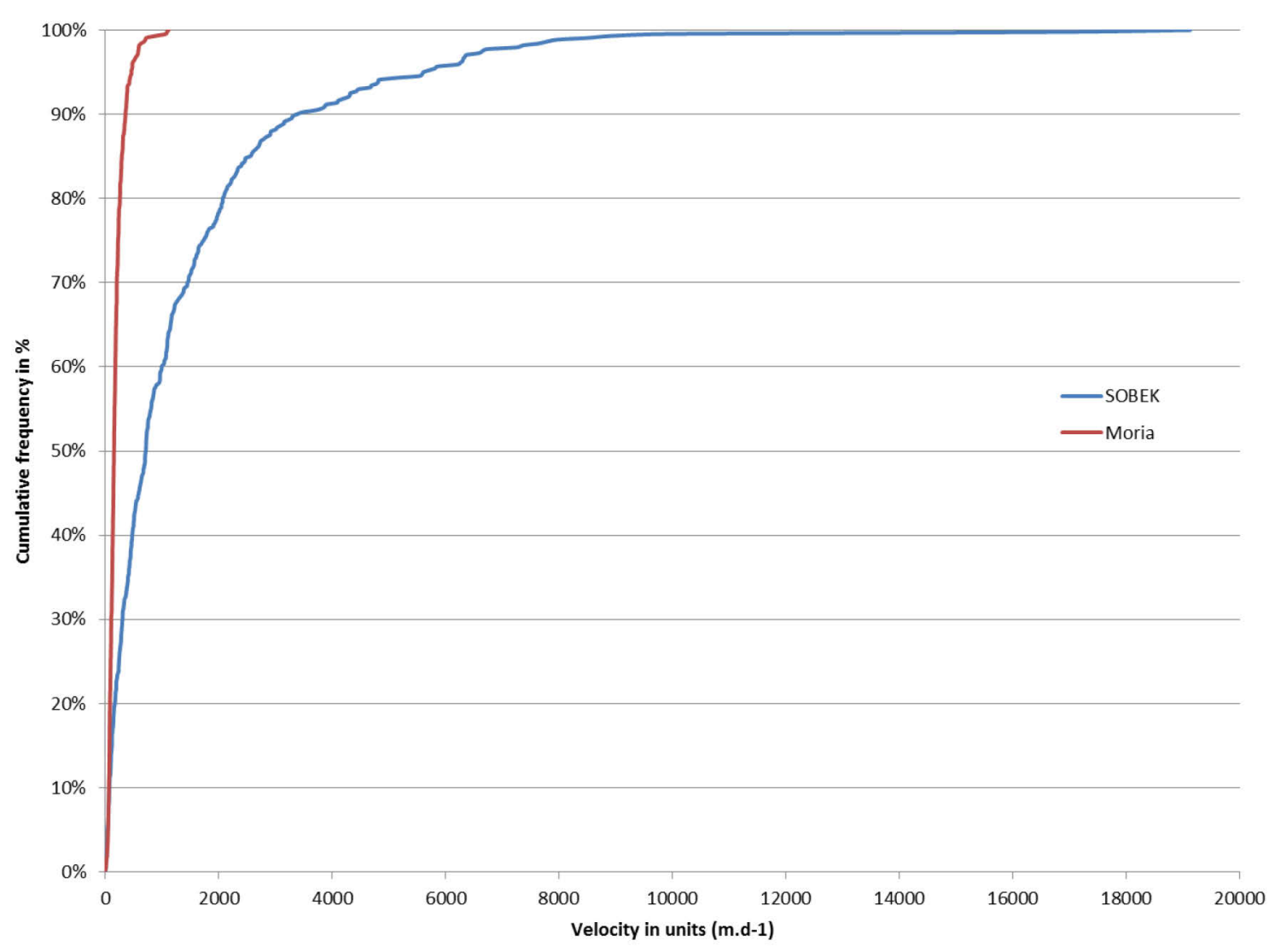

Figure A1.3 Frequency distribution of the simulated velocities per unit for SOBEK and Moria.

\section{Legend}

\section{Ratio SOBEK/MORIA}

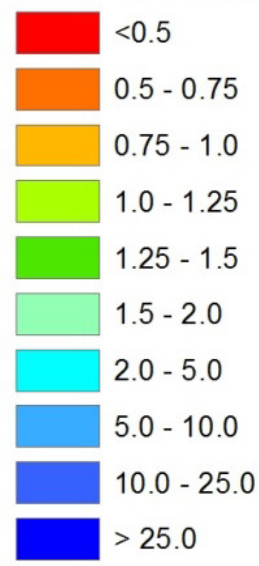

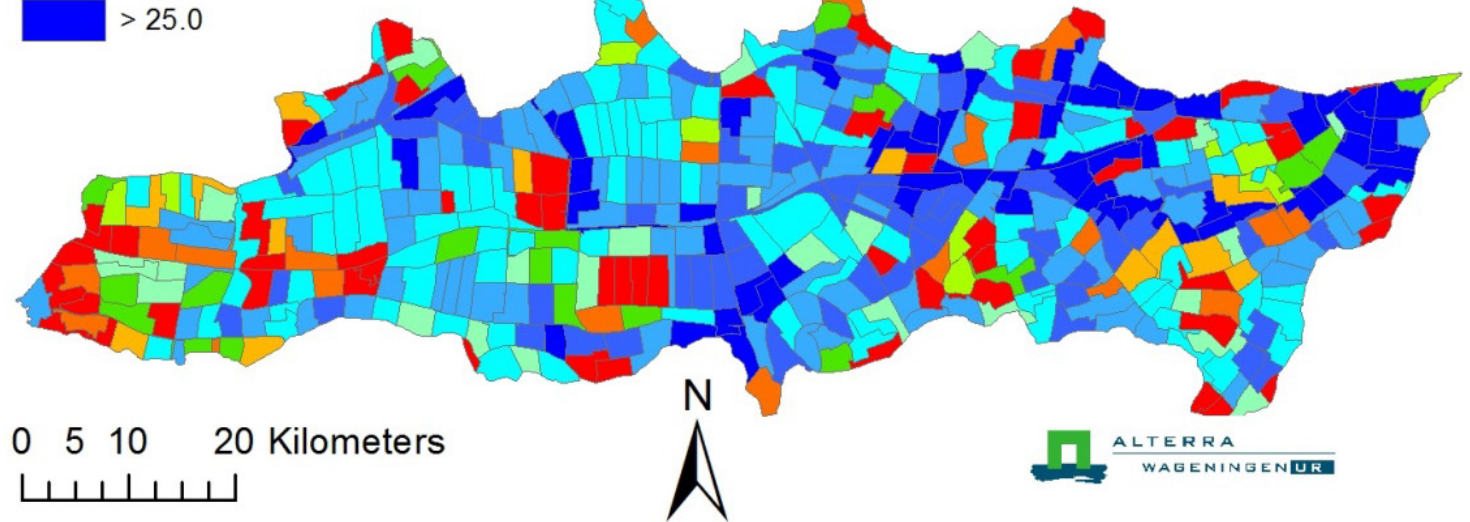

Figure A1.4 Ratio SOBEK / MORIA for the absolute averaged summer velocities in the units (Tielerwaard). 


\section{Annex 2 SWAP parameterisation of the Andelst field site}

The parameterisation by Tiktak et al. (2012b) of the Andelst field site was the starting point of the parameterisation of the SWAP model for the drainage contribution to the exposure in surface water scenario. In the table below the exact pages, tables and sections are listed for each of the aspects that are relevant to the parameterisation of the SWAP model for the fruit orchard scenario. The SWAP model is incorporated in the PEARL model. Input files of SWAP are generated via PEARL. Hence, for several parameters the parameter name in the *.prl file of PEARL is provided.

Table A2.1 Sources of information on the parameterisation of the SWAP model for the fruit orchard scenario.

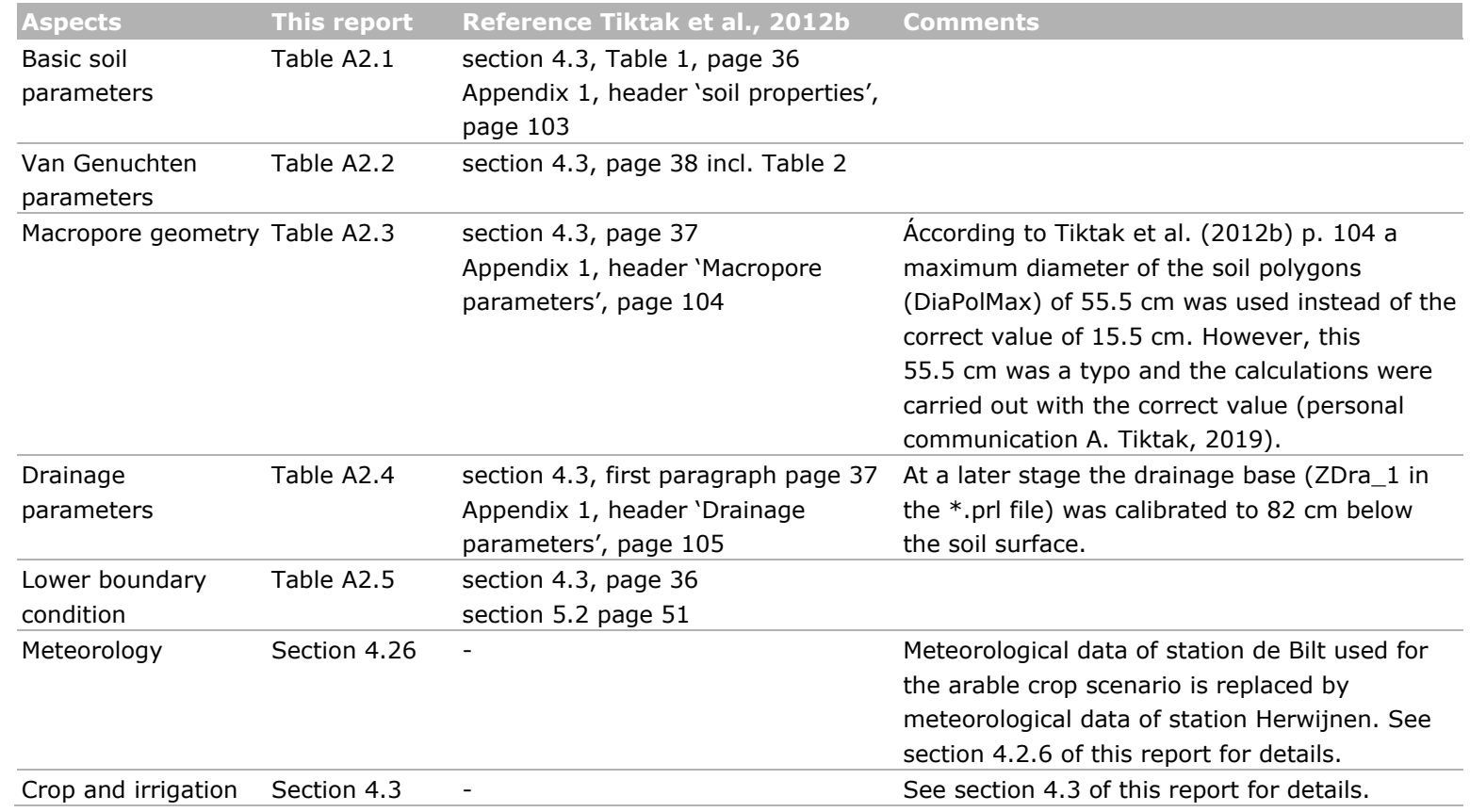

The mathematical description of the macropore geometry in SWAP and a short overview of the hydrological concepts regarded in the SWAP parameterisation of the Andelst field site is provided in Tiktak et al. (2012b) as well.

\section{Soil}

Table A2.2 provides the parameterisation in SWAP of the soil for the fruit orchard scenario. Data is taken from Table 4.1 however, a deeper profile and therefore a somewhat different segmentation than described in Tiktak et al. (2012b) was used.

Table A2.2 Segmentation and corresponding soil properties as used in the SWAP parameterisation of the Andelst field site.

\begin{tabular}{lllllll} 
Soil layer $(\mathrm{cm})$ & $\begin{array}{l}\text { Number of } \\
\text { numerical } \\
\text { layers }\end{array}$ & $\begin{array}{l}\text { Organic matter } \\
\text { content }(-)\end{array}$ & & & & $\begin{array}{l}\text { Clay content }(-) \\
(-)\end{array}$ \\
\hline $0-1$ & 1 & 0.021 & 0.277 & 0.529 & 0.194 & 1466 \\
\hline $1-26$ & 25 & 0.021 & 0.277 & 0.529 & 0.194 & 1508 \\
\hline $26-34$ & 8 & 0.021 & 0.289 & 0.52 & 0.191 & 1520 \\
\hline $34-50$ & 8 & 0.011 & 0.3 & 0.512 & 0.188 & 1520 \\
\hline $50-70$ & 10 & 0.01 & 0.348 & 0.509 & 0.143 & 1504 \\
\hline $70-120$ & 20 & 0.005 & 0.373 & 0.48 & 0.147 & 1620 \\
\hline $120-220$ & 20 & 0.005 & 0.372 & 0.471 & 0.157 & 1620 \\
\hline $220-320$ & 20 & 0.005 & 0.372 & 0.471 & 0.157 & 1620 \\
\hline
\end{tabular}




\section{Physical properties}

Table A2.3 provides the parameterisation in SWAP of the soil physical properties for the fruit orchard scenario.

Table A2.3 Parameters of the Mualem van Genuchten function to describe the soil physical properties.

\begin{tabular}{|c|c|c|c|c|c|c|c|}
\hline $\begin{array}{l}\text { Soil layer } \\
(\mathrm{cm})\end{array}$ & $\begin{array}{l}\text { Saturated } \\
\text { water } \\
\text { content } \\
\text { (m3 m-3) }\end{array}$ & $\begin{array}{l}\text { Residual } \\
\text { water } \\
\text { content } \\
\text { (m3 m-3) }\end{array}$ & $\begin{array}{l}\text { AlphaDry } \\
(\mathrm{cm}-1)\end{array}$ & $\begin{array}{l}\text { AlphaWet } \\
(\mathrm{cm}-1)\end{array}$ & $\begin{array}{l}n \\
(-)\end{array}$ & $\begin{array}{l}\text { Saturated } \\
\text { conductivity } \\
(\mathrm{m} \mathrm{d-1)}\end{array}$ & $\begin{array}{l}\text { lambda } \\
(-)\end{array}$ \\
\hline $0-1$ & 0.405 & 0.05 & 0.0063 & 0.0063 & 1.1712 & 0.01 & -4.8 \\
\hline $1-26$ & 0.405 & 0.055 & 0.0278 & 0.0278 & 1.114 & 0.0287 & -9.5 \\
\hline $26-34$ & 0.393 & 0.1 & 0.0075 & 0.0075 & 1.108 & 0.0017 & -14.45 \\
\hline $50-70$ & 0.444 & 0 & 0.0117 & 0.0117 & 1.0735 & 0.0251 & -0.25 \\
\hline $70-120$ & 0.442 & 0.05 & 0.0078 & 0.0078 & 1.087 & 0.0125 & -7.7 \\
\hline $120-220$ & 0.46 & 0.01 & 0.018 & 0.018 & 1.05 & 0.71 & -11 \\
\hline $220-320$ & 0.46 & 0.01 & 0.018 & 0.018 & 1.05 & 0.71 & -11 \\
\hline
\end{tabular}

The entry pressure head is set to $0 \mathrm{~cm}$ for all soil layers and the anisotropy coefficient is set to 1 for all soil layers

\section{Macropore geometry}

Table A2.4 provides the parameterisation in SWAP of the macropore geometry for the fruit orchard scenario.

Table A2.4 Parameterisation of the macropore geometery of the Andelst field site in the SWAP.

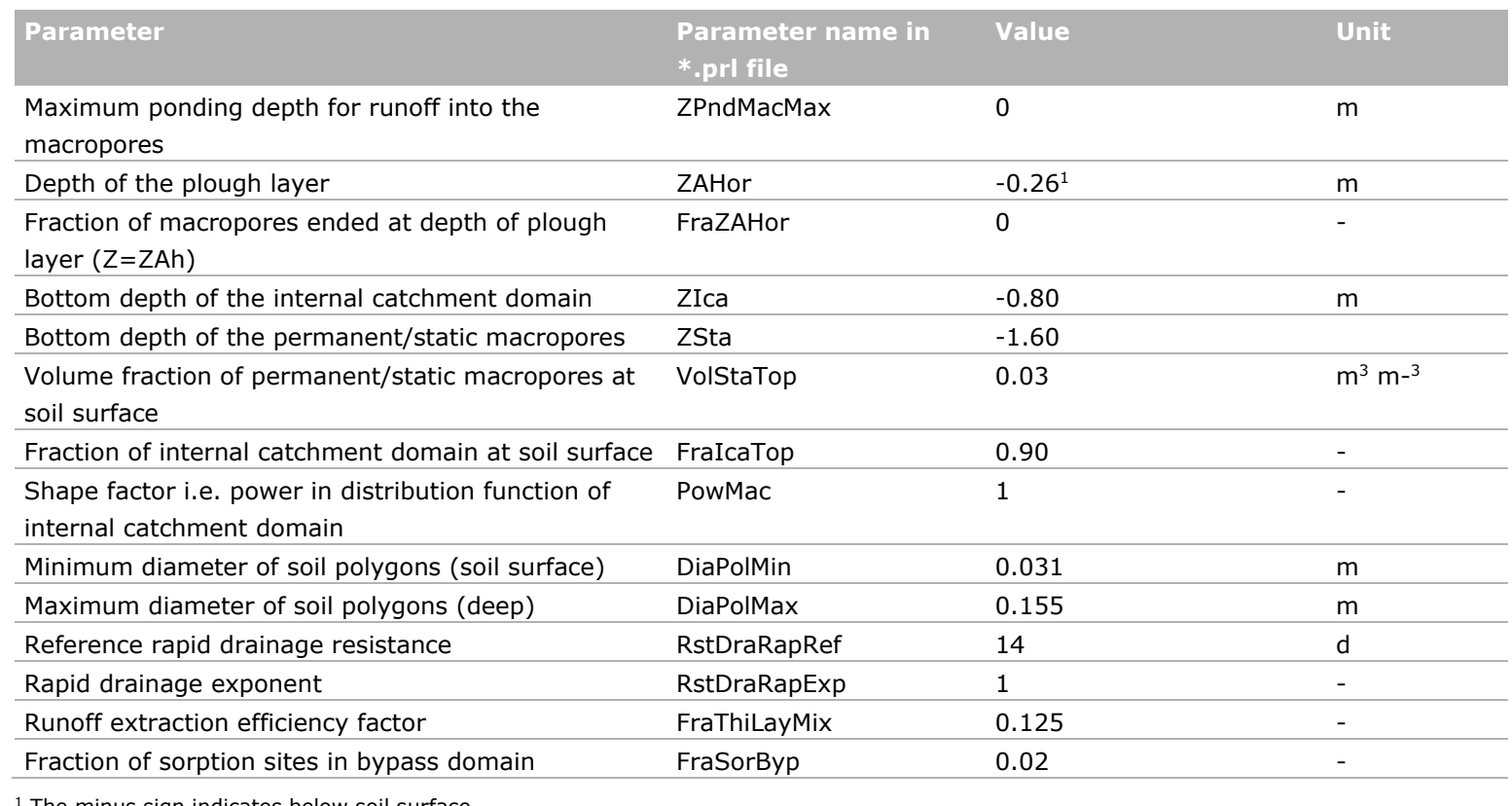

1 The minus sign indicates below soil surface

Tiktak et al. (2012c) give a mathematical description of the shrinkage characteristics used in SWAP. The two user-specified parameters (the void ratio at moisture ration zero and the moisture ratio at transition of residual to normal shrinkage are described by pedotransfer functions using the clay content and mass fraction of organic matter as input (functions are provided by Tiktak et al. (2012c). These pedostransfer functions are incorporated in the PEARL model. Hence, SWAP input values for these two parameters are generated automatically. 


\section{Drainage characteristics}

Ter Horst et al. (2006) determined the drainage base $(80 \mathrm{~cm}$ below soil surface) and the drainage resistance (14 days) from linear regression between measured drain fluxes and groundwater levels. At a later stage the drainage base (ZDra_1 in the *.prl file) was calibrated to $82 \mathrm{~cm}$ below the soil surface. The obtained drainage resistance was assigned to the rapid drainage system (RstDraRapRef in Table A2.3). A drainage resistance of 140 days (i.e. ten times the rapid drainage resistance) was assigned by Tiktak et al. (2012b) to the drainage resistance of soil system (i.e. macropores + matrix; RstDra_1 in the *.prl file). The distance between the drains was set to $10 \mathrm{~m}$.

Table A2.5 provides the parameterisation in SWAP of the drainage system for the fruit orchard scenario.

Table A2.5 Parameterisation of drainage system of the Andelst field site in the SWAP.

\begin{tabular}{llll} 
Parameter & Parameter name in & Value \\
Reference rapid drainage resistance & RstDraRapRef & 14 & $\mathrm{~d}$ \\
\hline Matrix drainage resistance & RstDra_1 & 140 & $\mathrm{~d}$ \\
\hline Drain depth & ZDra_1 & 0.82 & $\mathrm{~m}$ \\
\hline Distance between the drains & DistDra_1 & 10 & $\mathrm{~m}$ \\
\hline
\end{tabular}

\section{Lower boundary condition}

The lower boundary condition of the SWAP model is taken from bore hole B39H0311 in the DINO database (www.dinoloket. $\mathrm{nl}$ ). This borehole is situated at approximately $1 \mathrm{~km}$ from the field site and contains data for the period 1991 - 2005 (i.e. 15 years). Hydraulic heads were adjusted to account for the difference in altitude between the two sites (see Tiktak et al. (2012), page 51 for details).

The bottom boundary flux was calculated by SWAP using the hydraulic head difference between the phreatic groundwater and the groundwater in the underlying semi-confined aquifer (Cauchy condition).

Table A2.6 provides the parameterisation in SWAP of the lower boundary condition for the fruit orchard scenario.

Table A2.6 Parameterisation of lower boundary condition of the Andelst field site in the SWAP.

\begin{tabular}{lll} 
Parameter & $\begin{array}{l}\text { Parameter name in } \\
* \text { prl file }\end{array}$ & Value \\
$\begin{array}{l}\text { Option selected for bottom flux } \\
\text { (Sine/HeadOnly/HeadAndFlux) }\end{array}$ & OptBotFlux & HeadOnly \\
\hline Switch on or switch off vertical resistance (Yes/No) & OptNoResVert & No \\
\hline $\begin{array}{l}\text { Shape type of groundwater level } \\
\text { (Elliptic/Parabolic/Sinusoidal/NoDrains) }\end{array}$ & OptShapeGrwLev & NoDrains \\
\hline $\begin{array}{l}\text { Drainage base to correct the groundwater level } \\
\text { Resistance of the underlying aquitard }\end{array}$ & HeaDraBase & -0.82 \\
\hline $\begin{array}{l}\text { Name of file containing time series of hydraulic } \\
\text { heads }\end{array}$ & LowerBoundaryFile & BBW \\
\hline
\end{tabular}

\footnotetext{
${ }^{14}$ Containing data of DINO bore hole B39H0311, observations done fortnightly. Corrected for altitude differences (13 cm).
} 


\section{Annex 3 Template PEARL input files *.prl for the Dutch upwards and sideways spraying in fruit scenario}

\section{Parameterisation for the tree strip}

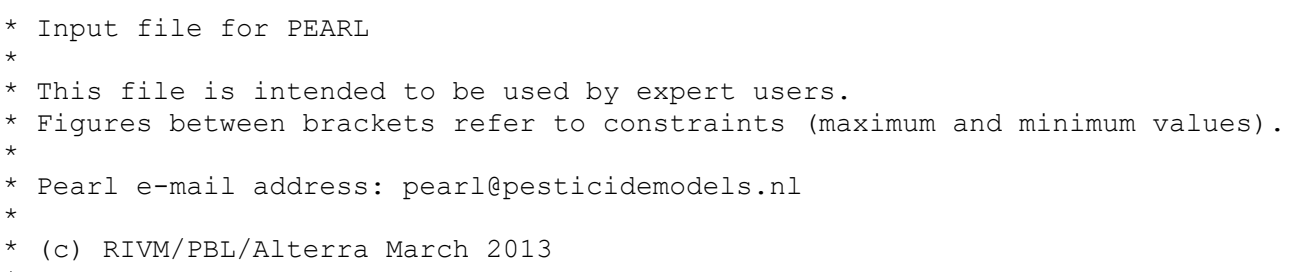

Andelst

Andelst_Soil

HAMB-APP $\bar{L} E S$

In

Examplescheme

No

Yes

Location
SoiltypeID
CropCalendar
SubstanceName
ApplicationScheme
DepositionScheme
Irrigationscheme

identification

Soil identification

Crop calendar

Substance name

Application scheme

Deposition scheme

Irrigation scheme

* Section 1: Control section

* Description

* Release type option CallingProgram

* Options can be: FOCUSPEARL, GEOPEARL, DRAINBOW, EFSAPEARL, BROWSEPEARL, CHINAPEARL

DRAINBOW

1.1.1

* Time domain

$01-J a n-1986$

31-Dec-2005

* SWAP control

No

* Options to run SWAP using OptHyd

* OnLine

* Offline

* Automatic

* Only

* Standard

* GenerateInput

Automatic

* If optHyd is 'standara

CallingProgram

CallingProgramVersion

Release type

Version numbers of model, interface and database

Timstart

TimEnd

RepeatHydrology

Runs SWAP and then PEARI

Assumes a pfo file with hydrological output from SWAP

Skip SWAP if SWAP run has already been done

Run SWAP only and process results in PEARL output format

Select the .pfo as specified by the user

Generate the input files for SWAP

Specify SWAPId to identify SWAP pfo file

tree_strip

summer

$1 \cdot d-5$

DelTimSwaMin

(d)
Dutch surface water standard scenario for crops

Minimum time step in $\operatorname{SWAP}[1 d-8 \mid 0.1]$ 


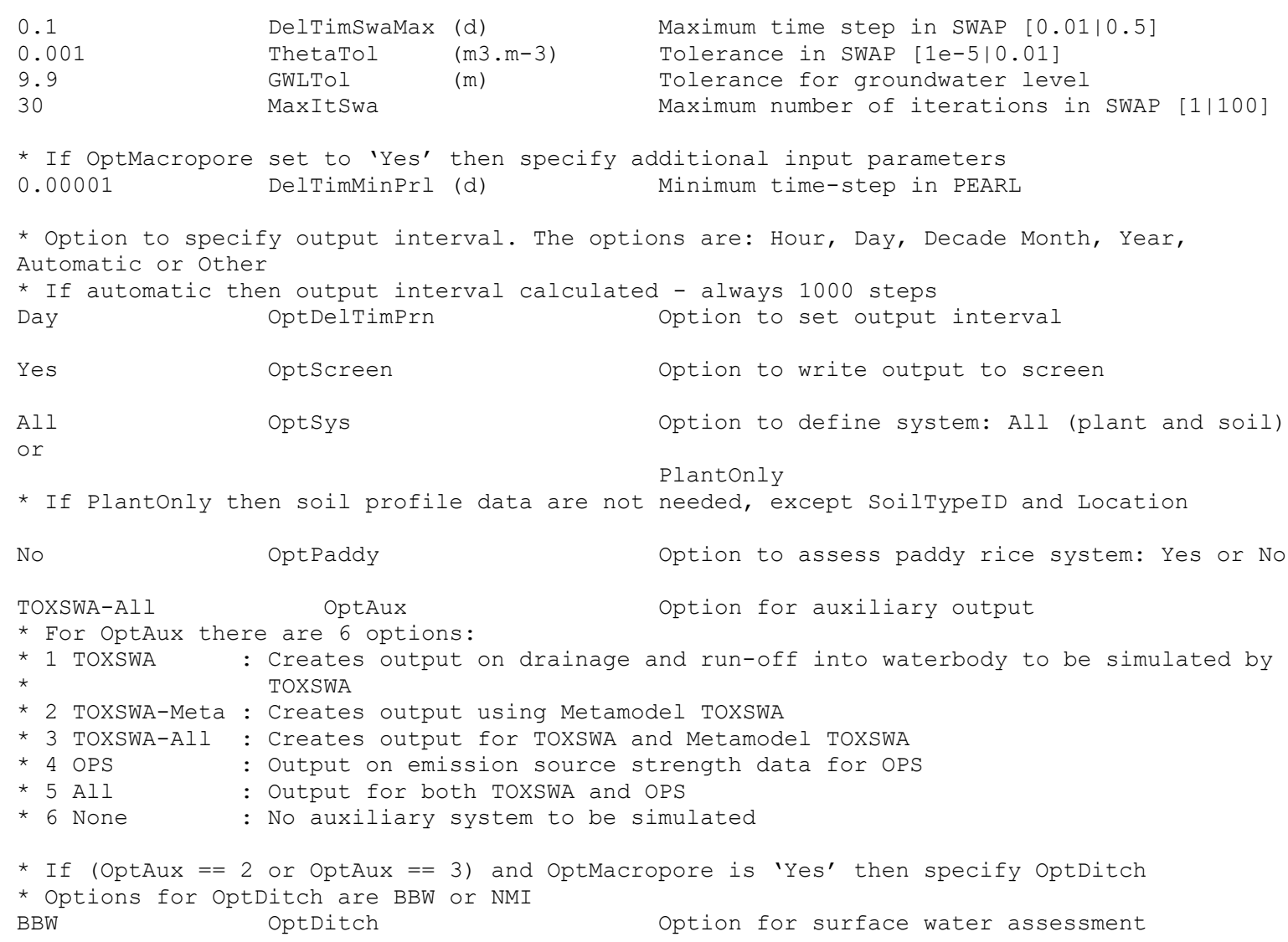


* Specify for each soil horizon:

* The saturated water content

$(\mathrm{m} 3 . \mathrm{m}-3) \quad[0 \mid 0.95]$

* The residual water content

$(\mathrm{m} 3 . \mathrm{m}-3) \quad[0 \mid 0.04]$

* Parameter AlphaDry

$(\mathrm{cm}-1) \quad[1 . \mathrm{d}-3 \mid 1]$

Parameter AlphaWet

* Parameter $\mathrm{n}$

* The saturated conductivity

* Parameter lambda (1)

$(\mathrm{cm}-1) \quad[1 \cdot d-3 \mid 1]$

$(-) \quad[1 \mid 5]$

$(\mathrm{m} . \mathrm{d}-1) \quad[1 . \mathrm{d}-4 \mid 10]$

* If OptMacropore 'Yes' then specify

* Entry pressure head PreHeaEnt

* Anisotropy coefficient

$$
(-) \quad[-25 \mid 25]
$$

$(-)$

* New Staring Series - not used for standard scenario

* table horizon VanGenuchtenPar

* Nr Thetasat ThetaRes AlphaDry AlphaWet n

* $(\mathrm{m} 3 \cdot \mathrm{m}-3) \quad(\mathrm{m} 3 \cdot \mathrm{m}-3) \quad(\mathrm{cm}-1) \quad(\mathrm{cm}-1)$

$\begin{array}{cccrr}* & (\mathrm{~m} 3 . \mathrm{m}-3) & (\mathrm{m} 3 . \mathrm{m}-3) & (\mathrm{cm}-1) & (\mathrm{cm}-1) \\ * & 0.391 & 0.036 & 0.0149 & 0.0298\end{array}$

* 2

0.0126

0.0298

(-)

1.468
1.565
1.598
1.606
1.606
1.606

KSat 1

* 3

0.351

0.029

0.0181

0.0252

$*$
$*$$\quad 0.31$

0.015

0.0281

0.0362

0.31

0.015

0.0281

0.0562

* $6 \quad 0.31$

0.015

0.0281

0.0562
0.0562

1.606

. $d-1)$

$(-)$

2.016

0.5

$\begin{array}{ll}2.448 & 0.5 \\ 2.448 & 0.5\end{array}$

* end table

* If OptMacropore 'Yes' then extended table VanGenuchtenPar

table horizon VanGenuchtenPar

\begin{tabular}{|c|c|c|c|c|c|c|c|c|c|}
\hline $\mathrm{Nr}$ & $\begin{array}{l}\text { Thetasat } \\
(\mathrm{m} 3 \cdot \mathrm{m}-3)\end{array}$ & $\begin{array}{l}\text { ThetaRes } \\
(\mathrm{m} 3 \cdot \mathrm{m}-3)\end{array}$ & $\begin{array}{l}\text { AlphaDry } \\
(\mathrm{cm}-1)\end{array}$ & $\begin{array}{l}\text { AlphaWet } \\
(\mathrm{cm}-1)\end{array}$ & $\begin{array}{l}\mathrm{n} \\
(-)\end{array}$ & $\begin{array}{l}\text { KSat } \\
(\mathrm{m} \cdot \mathrm{d}-1)\end{array}$ & $\begin{array}{l}1 \\
(-)\end{array}$ & $\begin{array}{r}\text { PreHeaEnt } \\
(\mathrm{cm})\end{array}$ & $\begin{array}{r}\text { CofAniso } \\
\text { (- }\end{array}$ \\
\hline 1 & 0.4050 & 0.050 & 0.0063 & 0.0063 & 1.1712 & 0.0100 & -4.80 & 0.0 & 1.0 \\
\hline 3 & 0.3930 & 0.100 & 0.0075 & 0.0075 & 1.1080 & 0.0017 & -14.45 & 0.0 & 1.0 \\
\hline 4 & 0.3950 & 0.010 & 0.0172 & 0.0172 & 1.0925 & 0.0163 & -5.80 & 0.0 & 1. \\
\hline 5 & 0.4440 & 0.000 & 0.0117 & 0.0117 & 1.0735 & 0.0251 & -0.25 & 0.0 & 1. \\
\hline 8 & 0.4600 & 0.010 & 0.0180 & 0.0180 & 1.0500 & 0.7100 & -11.00 & 0.0 & 1. \\
\hline
\end{tabular}

Input

OptRho

Option for bulk density: Calculate or Input

* If Rhoopt = Input then specify bulk density for each horizon:

table horizon Rho (kg.m-3) [100|2000]

11466.0

1508.0

1520.0

1520.0

1504.0

1620.0

1620.0

1620.0

end_table

* Eñd If

* Option to include hysteresis

No OptHysteresis

Hysteresis option: No, InitWetting InitDrying

* If No or InitDrying then specify minimum pressure head

$0.2 \quad$ PreHeaWetDryMin $(\mathrm{cm}) \quad$ Minimum pressure head to switch drying/wetting

* Maximum ponding depth and boundary air layer thickness (both location properties)

$0.01 \quad$ ZPndMax $\quad(\mathrm{m}) \quad$ Maximum ponding depth [0|1]

* If OptMacropore is 'Yes' then specify boundary pressure head that controls run-off

$0.0 \quad \mathrm{Hb} \quad(\mathrm{cm}) \quad$ Boundary pressure head

$0.001 \quad$ RstSurRunoff (d) Resistance for surface runoff

* End if

* Soil evaporation parameters

1.0 FacEvpsol "Crop factor" for bare soil [0.5/1.5]

* Option to select evaporation reduction method: Boesten or Black

optSolEvp

Evaporation reduction option

* If Boesten or Black specify soil evaporation parameters

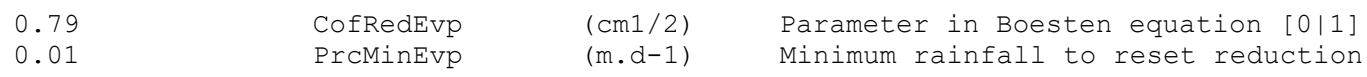

* Parameter values of the functions describing the relative diffusion coefficients MillingtonQuirk OptCofDifRel MillingtonQuirk, Troeh or Currie

* If MillingtonQuirk: 


$\begin{array}{llll}2.0 & \text { ExpDifLigMilNom } & (-) & \text { Exponent in nominator of equation }[0.1 \mid 5] \\ 0.6667 & \text { ExpDifLiqMilDen } & (-) & \text { Exponent in denominator of eqn }[0.1 \mid 2] \\ 2.0 & \text { ExpDifGasMilNom }(-) & \text { Exponent in nominator of equation }[0.1 \mid 5] \\ 0.6667 & \text { ExpDifGasMilDen }(-) & \text { Exponent in denominator of eqn }[0.1 \mid 2]\end{array}$

* End If

* Dispersion length of solute in liquid phase [0.5Delz|1]

Table horizon LenDistiq (m)

10.05

20.05

30.05

$4 \quad 0.05$

50.05

$6 \quad 0.05$

$7 \quad 0.05$

$8 \quad 0.05$

end_table

* Ponding of water on soil surface: Constant or TimeDependent

Constant OptPnd Option for pond

Fileid PondingDepthFile

* Section 2a: Macropore section

* Only required if OptMacropore set to 'Yes'

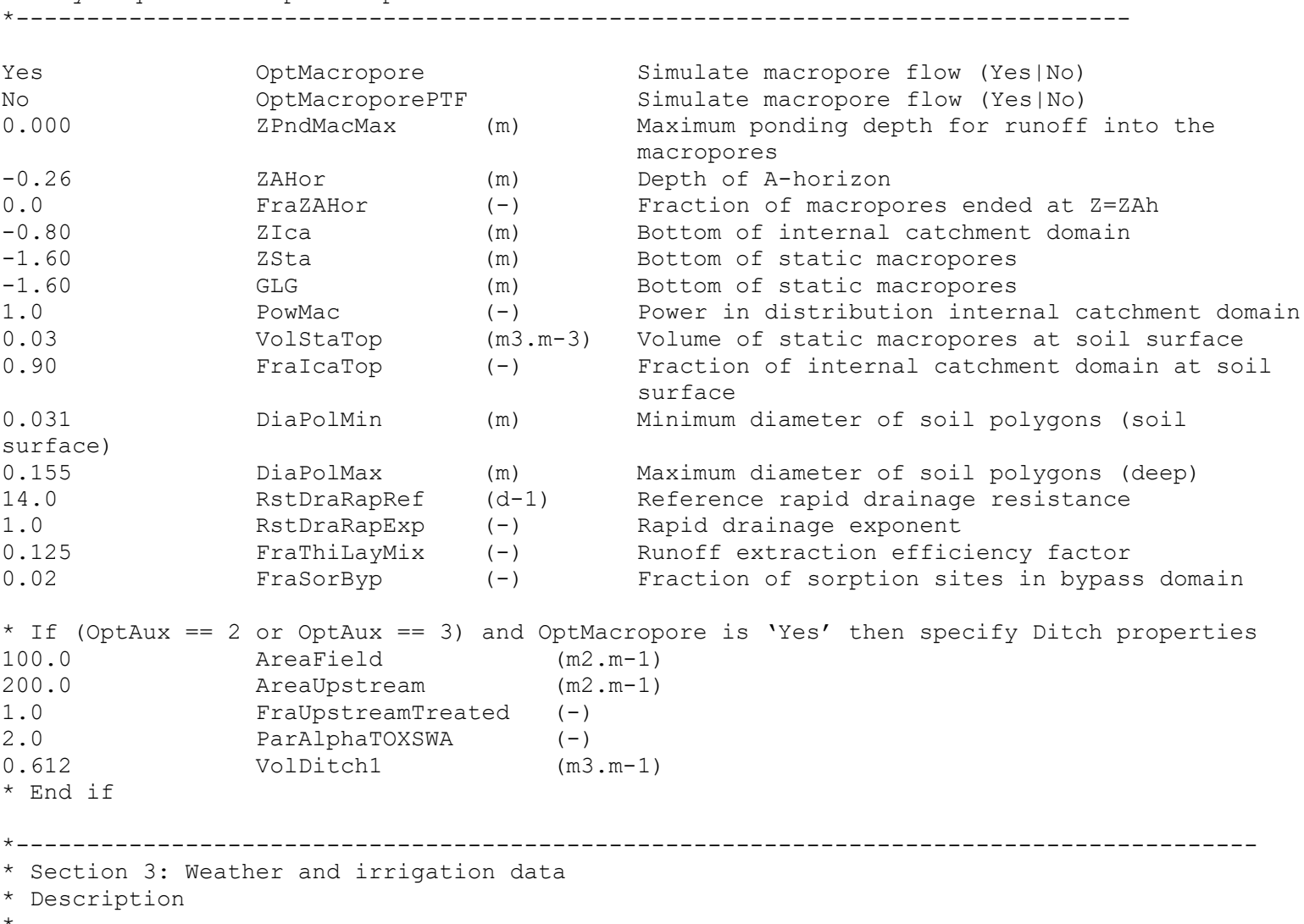

Herwijn Meteostation

Input OptEvp

$51.858 \quad$ Lat

$0.07 \quad$ Alt

* Initial lower boundary soil temperature [-20|40]

* Upper boundary temperature is read from meteo file

12.6

TemLbosta

(C)

* Irrigation section

Surface Auto

OptIrr

* Options for OptIrr are:

* No: no irrigation

* Surface: Surface irrigation, irrigation depth spec. by user

* Surface Auto: Surface irrigation, irrigation depth calc. by model

* Sprinkler: Sprinkler irrigation, irrigation depth spec. by user

* Sprinkler_Auto: Sprinkler irrigation, irrigation depth calc. by model

* Sprinkler_Weekly: Sprinkler irrigation, irrigation depth calc. by user 
* Irrigation data have to be provided in a file Station.irr (e.g. debilt.irr)

* Maximum number of characters in filename is 7.

* If RepeatHydrology is set to Yes, the first year is required only

* Format of the file should be as below:

* table IrrTab (mm)

* 01-Aug-1980 10.0

* end_table

1.0 FacPrC (-)

$0.0 \quad$ DifTem (C)

1.0 FacEvp (-)

Daily OptMetInp

Correction factor for precipitation

Correction for temperature

Correction factor for evapotranspiration

Daily

option for meteorological data: Hourly or

* Options for the calculation of the resistance of air to volatilisation; options are Laminar

* or Aerodynamic

* If set to 'Aerodynamic' then OptResBou is also required: options are Hicks or Wang

* If set to 'laminar' then ThiAirBoulay required

Laminar OptTraRes Option for resistance air set to Laminar

If set to 'Laminar' then specify thickness boundary air layer

$0.01 \quad$ ThiAirBoulay (m) Boundary air layer thickness [1e-6/1]

Yes OptRainfallEvents Option to consider rainfall events

EventDuration OptRainfallintensity

No OptSnow Option to consider snow in SWAP

* Section 4: Boundary and initial conditions of hydrological model

* Section 4a: Lower boundary flux conditions

* Description

$\star-$

* Initial condition

-80.9 ZGrwLevSta (cm) Initial groundwater level [-5000|0]

* Choose one of the following options for the bottom boundary:

* GrwLev Flux Cauchy FncGrwLev Dirichlet Zeroflux Freedrain Lysimeter

Cauchy opt tho

Lower boundary option selected

* If Lboopt = Cauchy then specify lower boundary option

* Options for bottom flux can be Sine, HeadOnly or HeadAndFlux

Headonly OptBotflux Option selected for bottom flux

No OptNoResVert Switch on or switch off vertical resistance

NoDrains OptShapeGrwLev Elliptic, Parabolic, Sinusoidal, NoDrains

$-0.8200 \quad$ HeaDraBase (m) Drainage base to correct GrwLev [-100/0]

$5.0 \quad$ RstAqt $\quad(d) \quad$ Resistance of aquitard [0|1e4]

* If OptBotflux HeadOnly or HeadAndFlux specify file with data

* Lower boundary conditions

BBW LowerBoundaryFile

* If HeadOnly then read data on Head from LowerBoundaryfile (FileId.bot)

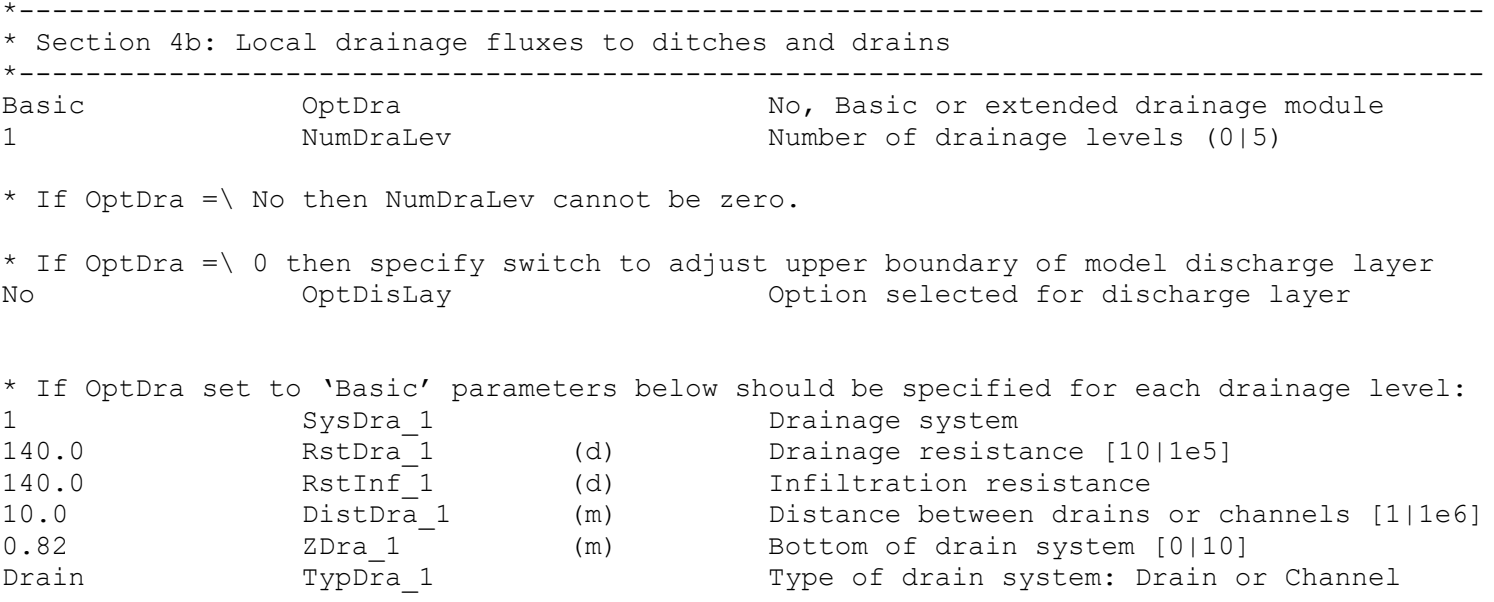

* Section 5: Compound section

* Description

table compounds

In

end_table 


\section{7 \\ MolMas_In $(g \cdot \operatorname{mol}-1)$ \\ Molar mass $[10 \mid 10000]$}

* Transformation table (parent-daughter relationships)

table FraprtDau (mol.mol-1)

end table

* Example for a pesticide with three metabolites, named "met1", "met2" and "met3":

* Reaction 1: In is transformed into met1 (25\%)

* Reaction 2: In is transformed into met2 (44\%)

* Reaction 3: met1 is transformed into met3 (63\%)

* table FraprtDau (mol.mol-1)

* 0.25 In $->$ met 1

$\star 0.44$ In $\rightarrow$ met2

* 0.63 met $1->\operatorname{met} 3$

* end_table

* Transformation rate parameters

EqlDom_Input OptDT50_In

Option for DT50: Input or Calculate in equilibrium domain (EqlDom) or in liquid phase only (LiqPhs)

$\begin{array}{lll}118.0 & \text { DT50Ref_In (d) } & \text { Half-life time [1|1e6] } \\ 20.0 & \text { TemRefTra_In (C) } & \text { Temperature at which DT50 is measured [5|30] } \\ 0.70 & \text { ExpLiqTra_In (-) } & \text { Exponent for the effect of liquid [0|5] } \\ \text { OptimumConditions } & \text { OptCntLiqTraRef_In } & \text { OptimumConditions or NonoptimumConditions } \\ 1.0 & \text { CntLiqTraRef_In (kg.kg-1) } & \text { Liq. content at which DT50 is measured [0|1] } \\ 65.4 & \text { MolEntTra_In (kJ.mol-1) } & \text { Molar activation energy [0|200] }\end{array}$

* Two options for input possible for FaczTra: interpolate or horizon

* If 'horizon' option selected then specify factor for each horizon

* If 'interpolate' option selected then specify factor and depth

table interpolate FaczTra

$(-)$

Factor for the effect of depth [0|1]

hor In

0.001 .00

0.301 .00

0.310 .50

0.600 .50

0.610 .30

$1.00 \quad 0.30$

1.010 .00

3.200 .00

end table

* Freundlich equilibrium sorption

pH-independent OptCoffre_In

$1.0 \quad$ ConLiqRef In

0.80 (mg.L-1)

pH-dependent, pH-independent, Coffre

(-) Freundich sorption exponent [0.111.3]

* If pH-independent (use the coefficient for sorption on organic matter):

131.0 KomEql In (L.kg-1) Coef. eql. sorption on org. matter [0|le9]

131.0 KomEqlMax_In (L.kg-1) Coef. eql. sorption on org. matter in dry soil $[0 \mid 1 e 9]$

* If pH-dependent (use pKa value and coefficient for sorption on organic matter):

374.7 KomEqlAcid In ( L.kg-1) Coef. for eql. sorption on om - acid [0/1e9]

7.46 KomEqlBase_In ( $\mathrm{L} . \mathrm{kg}-1)$ Coef. for eql. sorption on om - base [0/1e9]

$4.6 \quad$ pKa In - p

pHCorrection

* If Coffre (specify the depth dependence and the coefficient for equilibrium sorption):
131.0
KSorEql In (L.kg-1)
0.0 Molentsor In (kJ.mol-1)

20.0

TemRefSor In

(C)

* Two options for input possible for FaczSor: interpolate or horizon

* If 'horizon' option selected then specify factor for each horizon

* If 'interpolate' option selected then specify factor and depth

table horizon FaczSor

Factor for the effect of depth [0|1]

hor In

11.0

21.0

31.0

41.0

51.0

61.0

71.0

81.0

end_table

* End If 
* Gas/liquid partitioning

\begin{tabular}{|c|c|c|c|}
\hline 4. $E-10$ & PreVapRef_In & $(\mathrm{Pa})$ & Saturated vapour pressure [0|2e5] \\
\hline 20.0 & TemRefVap_In & (C) & .. measured at $[0 \mid 40]$ \\
\hline 95.0 & MolEntVap_In & $(\mathrm{kJ} \cdot \mathrm{mol}-1)$ & Molar enthalpy of vaporisation $[-200 \mid 200]$ \\
\hline 610.0 & SlbWatRef_In & $(m g \cdot L-1)$ & Solubility in water $[1 e-9 \mid 1 e 6]$ \\
\hline 20.0 & TemRefSlb_In & $(\mathrm{C})$ & .. measured at $[0 \mid 40]$ \\
\hline 27.0 & MolEntSlb_In & $(\mathrm{kJ} \cdot \mathrm{mol}-1)$ & Molar enthalpy of dissolution [-200|200] \\
\hline Non- & sor & & \\
\hline 75 & CofDesRat_In & $(d-1)$ & Desorption rate coefficient [0|0.5] \\
\hline & FacSorNeqĒql & In $(-)$ & CoffreNeq/CofFreEql [0|-] \\
\hline
\end{tabular}

* Uptake

$0.0 \quad$ FacUpt_In (-) Coefficient for uptake by plant [0|10]

* Canopy processes

Lumped OptDspCrp_In

Lumped, Specified or Calculated

* If Lumped:

10 .

DT50DspCrp_In (d)

Half-life at crop surface [1|1e6]

* If Specified:

1. d 6

1. $d 6$

DT50PenCrp_In (d)

DT50VolCrp_In (d)

DT50TraCrp_In (d)

$1 . d 6$

* If Calculated:

1. $d 6$

DT50PenCrp In DT50TraCrp_In

RadGloRef

(d)

$1 . d 6$

500.0

FraDepRex

(d)

(W. m-2)

0.0
0.2

FacTraDepRex

(-)

$(-)$

FacVolDepRex

$(-)$

0.2

FacPenDepRex

$(-)$

0.2

FacWasDepRex

$(-)$

0.2

* End If

100.0

FacWasCrp_In

$(m-1)$

Half-life due to penetration [1|le6]
Half-life due to volatilization [1|le6]

Half-life due to transformation [1|1e6]

Half-life due to penetration [1|1e6]

Half-life due to photo-transformation [1|1e6]

Global solar radiation for DT50TraCrp

Fraction of deposit with reduced exposure

Factor for the effect of restricted exposure of deposit on transformation

Factor for the effect of restricted exposure of deposit on volatilisation

Factor for the effect of restricted exposure of deposit on penetration

Factor for the effect of restricted exposure of deposit on wash-off

Wash-off factor $[1 e-6 \mid 0.1]$

* Diffusion of solute in liquid and gas phases

4.3d-5 CofDifWatRef In (m2.d-1) R

0.43 CofDifAirRef_In (m2.d-1) Reference diff. coeff. in air [0.1/3]

20.0 TemRefDif_In (C) Diff. coeff measured at temperature [10/30]

* Section 6: Management section

* Description

1.0 ZTgt (m) Depth of target layer [0.1|Z(N)-1]

$1 \quad$ DelTimevt (a) Repeat interval of events [NoRepeat|1|2|3]

* Event table:

* Column 1: Date* Column 2: Event type: AppSolSur, AppSolInj, AppSolTil, AppCrpUsr,

* AppCrplaI

* Appsolsur, Appsolinj, AppSoltil cannot be combined with optsys set to Plantonly

* If Event = Appsolsur (soil surface application):

* Column 3: Dosage (kg/ha) [0|-]

* If EventType = Appcrp (application to the crop canopy):

* Column 3: Dosage (kg/ha) [0|-]

* Column 4: Optional: Fraction of dosage applied to the crop canopy (-) [0/1]

* End If

table Applications

23-Apr AppCrpUsr 0.330 .726

end_table

* Tillage table - can be empty

* Specify date (dd-mmm-yyy) or day in year (dd-mmm) and tillage depth (m)

* Tillage cannot be combined with OptSys set to Plantonly

table TillageDates

end table

* Section 7: Initial and boundary conditions of pesticide fate model 
* Two options for input possible: interpolate or horizon

* If 'horizon' option selected then specify content for each horizon

* If 'interpolate' option selected then specify content and depth

* If metabolites are included then initial contents for these substances are set to zero.

table interpolate CntSysEql

$0.0000 \quad 0.000$

$3.2000 \quad 0.000$

end_table

$(\mathrm{mg} \cdot \mathrm{kg}-1)$

* Initial conditions

Concentration in non-equil. domain [0|-]

* If using metabolites, ConsysNeq should be specified for all metabolites

table interpolate CntSysNeq (mg.kg-1)

$0.0000 \quad 0.000$

$3.2000 \quad 0.000$

end_table

* Upper boundary flux

$[0 \mid-]$

table FlmDep

31-Dec-2005 0.0

end_table

* Section 8: Crop section

* Description

* Emergence and harvest date of crop.

* Note: Length of growing season must be constant for one crop

* If repeat crops: Specification of year not required

table Crops

01-Jan 31-Dec APPLESI

end_table

table IrrigationPeriods

01-May 31-oct

end_table

APPLES 1

* Crop cycle fixed or variable (calculated from temperature sum)

Fixed OptLenCrp Fixed or Variable

* Crop parameters as a function of development stage

* Column 1: Development stage: 0 = emergence; 1 = harvest (-) [0|1]

* Column 2: LAI: Leaf Area Index (m2.m-2) [0|12]

* Column 3: FacCrp: Crop factor [0|2]

* Column 4: ZRoot: Rooting depth (m) [0|10]

* Column 5: Heightcrp: Crop height [0|10]

* LAI FacCrp ZRoot HeightCrp

table CrpPar_APPLES1

$\begin{array}{lllll}0.0 & 0.0 & 1.0 & 0.8 & 0.0 \\ 0.249 & 0.0 & 1.0 & 0.8 & 0.0 \\ 0.496 & 6.9 & 1.66 & 0.8 & 0.0 \\ 0.833 & 6.9 & 1.66 & 0.8 & 0.0 \\ 1.0 & 0.0 & 1.0 & 0.8 & 0.0\end{array}$

end_table

* Root density table (first column is relative depth)

* Column 1: Relative depth 0 = soil surface; $1=$ DepRoot

* Column 2: Root density distribution

table RootDensity_APPLES1

$0.0 \quad 1.0$

1.01 .0

end_table

* Crop water use

$-10.0$

$-25.0$

$-500.0$

$-800.0$

$-16000.0$

HLIm1_APPLES1 (cm) HLim2_APPLES1 (cm) HLim3Ū APPLES1 (cm) HLim3L APPLES1 (cm) HLim4_ĀPPLES1 (cm)

70.0

0.46

1. 0
RstEvpCrp_APPLES1 (s.m-1)

CofExtDif APPLES1 (-)

CofExtDir_APPLES1 (-)
Anaerobiosis point [-100/0]

Wet reduction point $[-1000 / 0]$

Dry reduction point $[-10000 / 0]$

Dry reduction point $[-10000 / 0]$

Wilting point [-16000/0]

Min. canopy resistance [0|1000] 


$\begin{array}{lll}0.0 & \text { FraCovitm_APPLES1 }(-) \\ 0.3 & \text { ZTensiometer_APPLES } \quad(\mathrm{m}) \\ -300.0 & \text { PreHeaIrrSta_APPLES } & (\mathrm{cm}) \\ 0.25 & \text { CofIntCrp_APPLES1 } & (\mathrm{cm}) \\ 15.0 & \text { IrgThreshold_APPLES1 } & (\mathrm{mm}) \\ -100 & & \\ & \text { PreHeafldCapIrr } & (\mathrm{cm})\end{array}$

Constant in Braden eq for interception [0|1] Threshold of moisture deficit to allow Irrigation

Pressure head at field capacity for irrigation option $[-1000 \mid 0]$

\footnotetext{
* Section 9: Output control
}

* Description

*------------

* First, specify the time format in the output file:

* Daysfromsta : Print number of days since start of simulation

* Daysfrom1900 : Print number of days since 1900

* Years : Print years

Daysfromsta DateFormat

No OptDelOutFiles

Format of time column in output file

No PrintCumulatives

* Specify type of report required

* Leaching report is not relevant if only Plant compartment is considered

Yes DrainageReport

No AirReport

No SoilReport

Summary report for leaching assessment

Summary report for drainage assessment

Summary report for volatilisation assessment

* If OptReport set to SoilReport

0.2 Thilayper (m) Target depth for persistency

* End if

Summary report for soil persistence assessment

*If LeachingReport set to 'Yes' then specify target percentile *50.0 TargetPercentile (\%) Percentile for leaching assessment

*End if

* Specify warming-up period

5 Inityears (-) Length of warming-up period

* Specify dates for vertical profiles of main state variables, e.g. concentration in liquid

* phase; table can be empty

table Verticalprofiles

end_table

* Format of the ordinary output - use FORTRAN notation:

* $e$ is scientific notation, $g=$ general is general notation

* Then follow the number of positions

* Then the number of digits

g12.4 RealFormat Format of ordinary output

* If OptSys is set to 'All' (Soil and Plant) then specify the nodal heights for which output is requested

table OutputDepths (m)

end_table

All OutputDepths

* Finally, specify for all variables whether output is wanted (Yes or No)

* As PEARL can potentially generate large output files, it is recommended to minimise

* the number of output variables

* Section I : Output from the SWAP model, version 2.0.9e

* Meteorological data

No print_VelWnd wind speed

No print_TemAir air temperature

* General variables

$\begin{array}{ll}\text { No } & \text { print_GrwLev } \\ \text { No } & \text { print_LAI } \\ \text { No } & \text { print_ZRoot } \\ \text { No } & \text { print_FacCrpEvp } \\ \text { No } & \text { print_FraCovCrp } \\ \text { No } & \text { print_AvoLiqErr } \\ \text { No } & \text { print_StoCap } \\ \text { No } & \text { print_AvoLiqSol } \\ \text { No } & \text { print_ZPnd }\end{array}$

Groundwater level (m)

Leaf Area Index (m2.m-2)

Rooting depth (m)

Crop factor (-)

Soil cover (-)

Water balance error (m)

Phreatic storage capacity $(\mathrm{m} 3 \cdot \mathrm{m}-2)$

Amount of water in soil

* If OptMacropore set to 'Yes'

No print_AvoMacIca 


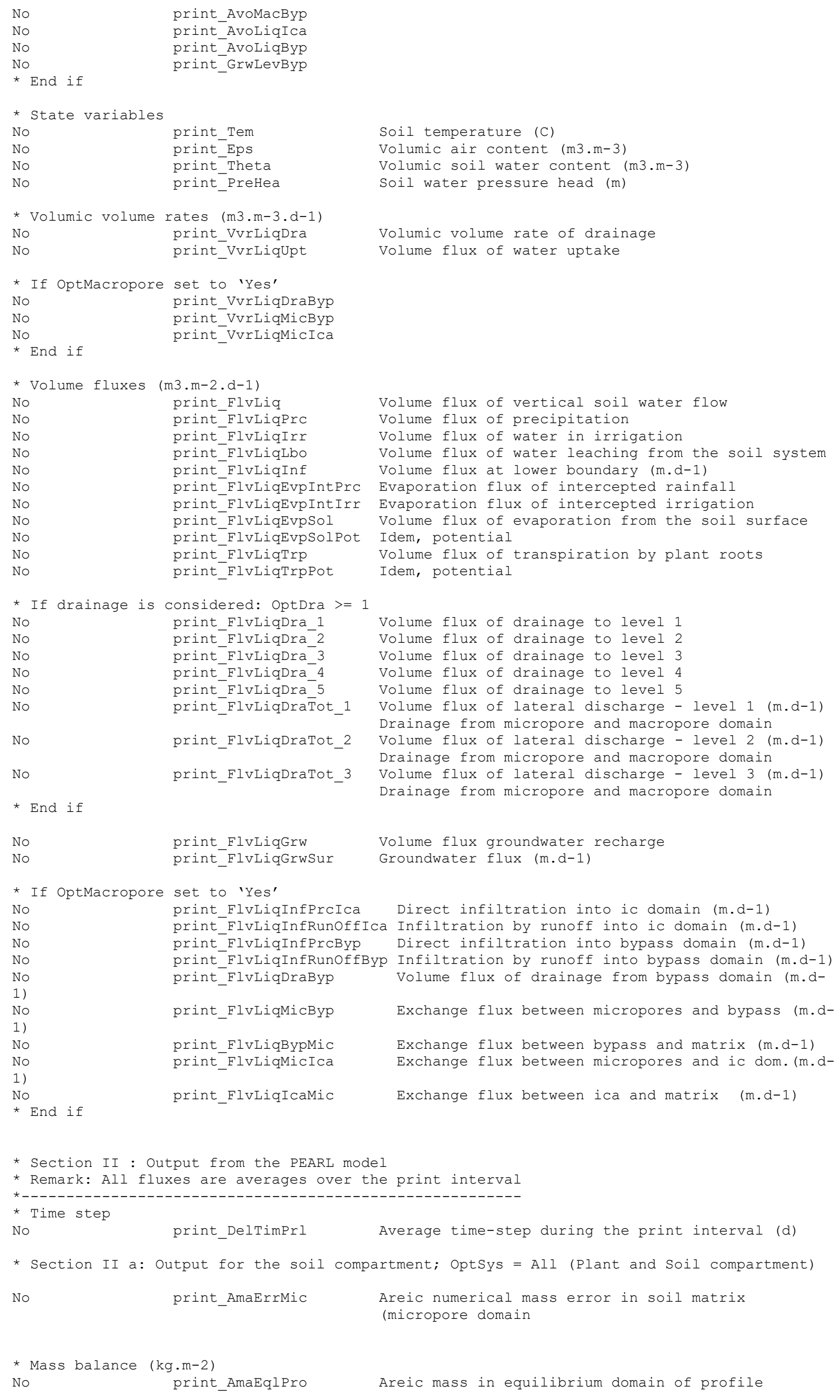




\section{*} No

No

No

No

No

No

No

No

No

No

* End if
print_AmaEqlTil print AmaEqlTgt print_AmaNeqPro print_AmaNeqTil print AmaNeqTgt print_AmaSysPro print AmaSysTil print_AmaSysTgt print_AmaAppSol print AmaForPro print_AmaTraPro print AmaUptPro print_AmaRunoff
Areic mass in equilibrium domain of tillage layer

Areic mass in equilibrium domain of target layer

Areic mass in non-eql. domain of profile

Areic mass in non-eql. domain of tillage layer

Areic mass in non-eql. domain of target layer

Areic mass of pesticide in the system

Areic mass of pesticide in the tillage layer

Areic mass of pesticide in the target layer

Areic mass applied to the soil system

Areic mass of formation

Areic mass of pesticide transformation

Areic mass of pesticide uptake

Areic mass of runoff from the field

$\begin{array}{ll}\text { * If drainage is considered: OptDra }>=1 \\ \text { No } & \text { print_AmaDra_1 } \\ \text { No } & \text { print_AmaDra_2 } \\ \text { No } & \text { print_AmaDra_3 } \\ \text { No } & \text { print_AmaDra_4 } \\ \text { No } & \text { print_AmaDra_5 } \\ \text { No } & \text { print_AmaDraPro } \\ \text { * End if } & \end{array}$

Areic mass of runoff infiltrating the bypass domain Areic mass of runoff infiltrating the ic domain Areic mass of drainage from the bypass domain Areic mass of drainage from the micropore domain Areic mass of exchange between ica and matrix Areic mass of exchange between bypass and matrix Areic mass of exchange between ica and matrix Areic mass of exchange between bypass and matrix Areic mass in the bypass domain Areic mass in the internal catchment domain

\begin{tabular}{|c|c|c|}
\hline No & print ConLiq & Concentration in liquid phase \\
\hline No & print_ConGas & Concentration in gas phase \\
\hline No & print_ConSysEql & Concentration in equilibrium domain \\
\hline No & print_ConSysNeq & Concentration in non-equilibrium domain \\
\hline No & print_Consys & Concentration in the soil system \\
\hline No & print ConLiqSatAvg & Avg. conc.in liq. phase between $1-2 \mathrm{~m}$ \\
\hline No & print_ConLiqLbo & Concentration in percolate \\
\hline & considered: OptDra & \\
\hline No & print_ConLiqDra & Concentration in drainage water \\
\hline No & print_ConLiqDra_1 & Concentration in drainage water, system \\
\hline No & print_ConLiqDra_2 & Concentration in drainage water, system \\
\hline No & print_ConLiqDra_3 & Concentration in drainage water, system \\
\hline No & print_ConLiqDra_4 & Concentration in drainage water, system \\
\hline No & print_ConLiqDra_5 & Concentration in drainage water, system \\
\hline
\end{tabular}

* End if

* If OptAux $=2$ or OptAux $=3$ then

$\begin{array}{ll}\text { No } & \text { print_ConLiqDitch_1 } \\ \text { No } & \text { print_ConLiqDitch_2 } \\ \text { No } & \text { print_ConLiqDitch_3 }\end{array}$

* End if

* If OptMacropore set to 'Yes'

No print_ConLiqByp

No print ConLiqIca

No print ConLiqTot

No print_ConLiqDraByp

* End if

* If paddy water layer is considered: OptPaddy set to 'Yes'

$\begin{array}{lll}\text { No } & \text { print_ConLiqWatLay } & \text { Concentration in the paddy water layer } \\ \text { No } & \text { print_ConLiqWatLayCur } & \text { Current concentration in the paddy water layer } \\ \text { No } & \text { print_ConLiqRunWatLay Concentration in run-off water }\end{array}$

* End if

* If OptReport set to SoilReport

$\begin{array}{ll}\text { No } & \text { print_ConLiqPer } \\ \text { No } & \text { print_CntSysPer }\end{array}$

* End if

* Pesticide mass fluxes (kg.m-2.d-1)

No print_FlmLiq
Concentration in surface water from level 1

Concentration in surface water from level 2

Concentration in surface water from level 3

Concentration in the bypass domain

Concentration in the internal catchment domain

Total concentration (mean of matrix and macropore)

Concentration in drainage water from bypass domain
Areic mass of drainage to level 1

Areic mass of drainage to level 2

Areic mass of drainage to level 3

Areic mass of drainage to level 4

Areic mass of drainage to level 5

Areic mass of lateral discharge 


$\begin{array}{ll}\text { No } & \text { print_FlmGas } \\ \text { No } & \text { print_FlmSys } \\ \text { No } & \text { print_FlmLiqLbo } \\ \text { No } & \text { print_FlmLiqInfSys } \\ \text { No } & \text { print_FlmGasVol }\end{array}$

*olatilisation concepts

* if OptTraRes $=1$, concept of laminar air boundary resistance

End if print_RstAirLam Resistand

* If OptTraRes $=2$, concept of aerodynamic resistance

No print_RstAer aerodynamic resistance

boundary resistance

* End if

print_VelfriLcl friction velocity

End of Section II a

* Section II b: Output for the plant compartment

* Remark: Optsys can be 'All' or 'Plantonly'

$\begin{array}{ll}\text { * General } & \\ \star & \\ \text { No } & \text { print_AmaCrp } \\ \text { No } & \text { print_AmaAp Crp } \\ \text { No } & \text { print_AmaDspCrp } \\ \text { No } & \text { print_AmaHarCrp } \\ \text { No } & \text { print_AmaWasCrp } \\ \text { No } & \text { print_FlmDepCrp }\end{array}$

Areic mass of pesticide at the canopy

Areic mass of pesticide applied to the canopy

Areic mass rate of pesticide dissipation

Areic mass rate of pesticide removal by harvest

Areic mass rate of pesticide wash-off

Areic mass rate of pesticide deposited on canopy

* Specific

If competing processes are considered: OptDspCrp > 1

No

canopy

print AmaPenCrp

No print AmaTracrp

Areic mass penetrated into the crop canopy

End if

Areic mass transformed on the crop canopy

If competing processes are considered and volatilisation dependent on meteorological conditions: OptDspCrp $=3$

No

No print AmaCrpRex

No print_AmaVolCrpFex

No print AmaVolCrpRex

with

No print AmaWasCrpFex

No print_AmaWasCrpRex

No print_AmaPenCrpFex

No print_AmaPenCrpRex

No print AmaTraCrpFex

on

No

print AmaTraCrpRex

End if

* End of Section II b

No print_FlvLiqCanDrp

No print_AmaSolsur
Areic mass fully exposed at the crop canopy

Areic mass with reduced exposure at the crop canopy

Areic mass of pesticide volatilised

Areic mass of pesticide volatilised from deposit

reduced exposure

Areic mass of wash-off from fully exposed deposit

Areic mass of wash-off from deposit with reduced exposure

Areic mass of fully exposed pesticide penetrated Into the plant

Areic mass of pesticide penetrated into the plant from deposit with reduced exposure

Areic mass of fully exposed pesticide transformed

the plant surface

Areic mass of restrictedly exposed pesticide

transformed on the plant surface

End of Pearl input file 


\section{Parameterisation for the grass strip}

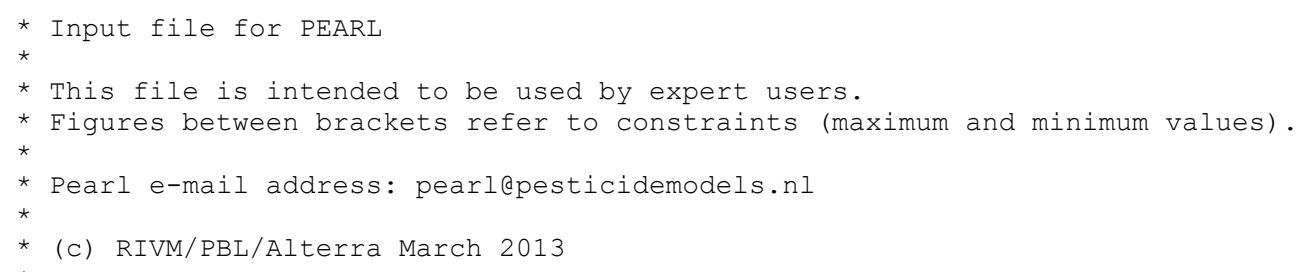

* Section 0: Run identification

Andelst

Andelst_soil

HERW_GRĀSS

In

Examplescheme

No

Yes

Location
SoiltypeID
CropCalendar
SubstanceName
Applicationscheme
DepositionScheme
IrrigationScheme

identification

Soil identification

Crop calendar

Substance name

Application scheme

Deposition scheme

Irrigation scheme

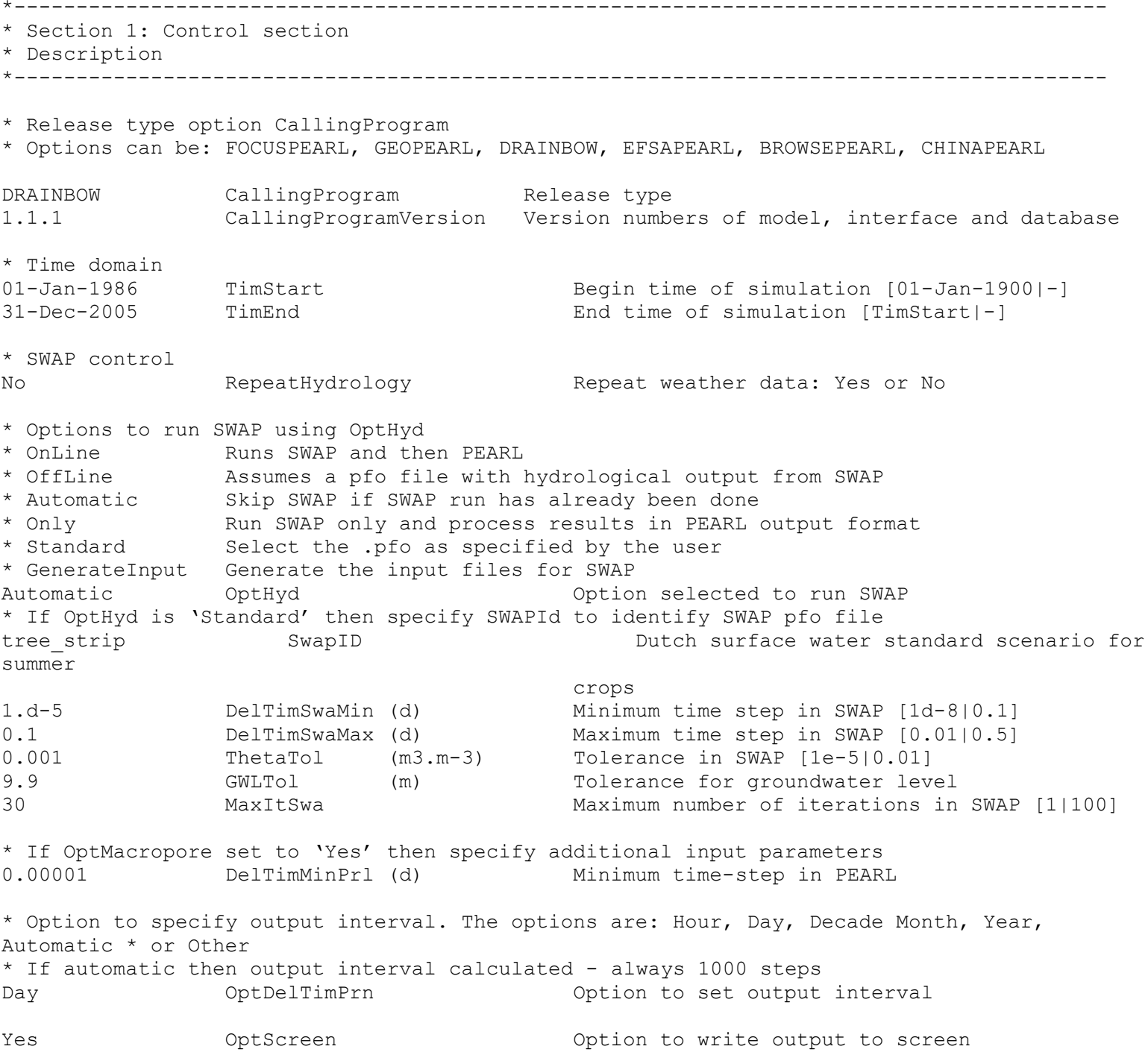


* If Plantonly then soil profile data are not needed, except SoiltypeID and Location

* For OptAux there are 6 options:

* 1 TOXSWA : Creates output on drainage and run-off into waterbody to be simulated by * TOXSWA

* 2 TOXSWA-Meta : Creates output using Metamodel ToxSWA

* 3 TOXSWA-All: Creates output for TOXSWA and Metamodel TOXSWA

* 4 OPS : Output on emission source strength data for OPS

* 5 All : Output for both TOXSWA and OPS

* 6 None : No auxiliary system to be simulated

* If (OptAux == 2 or OptAux == 3) and OptMacropore is 'Yes' then specify OptDitch * Options for OptDitch are BBW or NMI

BBW OptDitch Option for surface water assessment

* Section 2: Soil section

* Description

If OptSys set to Plantonly then only Location and SoilTypeID (section 0 ) are required. All parameters in section 2 can be omitted if this option has been selected..

* The soil profile

* Specify for each horizon:

* Horizon thickness (m)

* The number of soil compartments [1/500]

* Nodes are distributed evenly over each horizon table Soilprofile

ThiHor NumLay

$\begin{array}{ll}(\mathrm{m}) & \\ 0.01 & 1 \\ 0.25 & 25 \\ 0.08 & 8 \\ 0.16 & 8 \\ 0.20 & 10 \\ 0.50 & 20 \\ 1.00 & 20 \\ 1.00 & 20 \\ \text { end table }\end{array}$

end_table

* Basic soil parameters

* Specify for each soil horizon:

* Mass content of sand, expressed as a fraction of the mineral soil (kg.kg-1) [0/1]

* Mass content of silt, expressed as a fraction of the mineral soil (kg.kg-1) [0/1]

* Mass content of clay, expressed as a fraction of the mineral soil (kg.kg-1) [0/1]

* Organic matter mass content [0|1]

* pH. pH measured in $0.01 \mathrm{M} \mathrm{CaCl2}$ is preferred (see theory document) (-) [1/13] table horizon Soilproperties

$\begin{array}{llllll}\text { Nr } & \begin{array}{l}\text { FraSand } \\ (\mathrm{kg} . \mathrm{kg}-1)\end{array} & \begin{array}{l}\text { FraSilt } \\ (\mathrm{kg} \cdot \mathrm{kg}-1)\end{array} & \begin{array}{l}\text { FraClay } \\ (\mathrm{kg} \cdot \mathrm{kg}-1)\end{array} & \begin{array}{l}\text { Cntom } \\ (\mathrm{kg} \cdot \mathrm{kg}-1)\end{array} & \begin{array}{c}\mathrm{pH} \\ (-)\end{array} \\ 1 & 0.194 & 0.529 & 0.277 & 0.021 & -99 \\ 2 & 0.194 & 0.529 & 0.277 & 0.021 & -99 \\ 3 & 0.191 & 0.520 & 0.289 & 0.021 & -99 \\ 4 & 0.188 & 0.512 & 0.300 & 0.011 & -99 \\ 5 & 0.143 & 0.509 & 0.348 & 0.010 & -99 \\ 6 & 0.147 & 0.480 & 0.373 & 0.005 & -99 \\ 7 & 0.157 & 0.471 & 0.372 & 0.005 & -99 \\ 8 & 0.157 & 0.471 & 0.372 & 0.005 & -99 \\ \text { end_table } & & & & \end{array}$

* Parameters of the Van Genuchten-Mualem relationships

* Specify for each soil horizon:

* The saturated water content

* The residual water content

$(\mathrm{m} 3 \cdot \mathrm{m}-3) \quad[0 \mid 0.95]$

* Parameter AlphaDry

* Parameter AlphaWet

* Parameter $\mathrm{n}$

* The saturated conductivity

* Parameter lambda (1)

* If OptMacropore 'Yes' then specify

* Entry pressure head PreHeaEnt

* Anisotropy coefficient (-)

$(\mathrm{cm}-1) \quad[1 . \mathrm{d}-3 \mid 1]$

$(\mathrm{cm}-1) \quad[1 \cdot d-3 \mid 1]$

$(-) \quad[1 \mid 5]$

$(\mathrm{m} . \mathrm{d}-1) \quad[1 . \mathrm{d}-4 \mid 10]$

$(-) \quad[-25 \mid 25]$

* New Staring Series - not used for standard scenario

* table horizon VanGenuchtenPar 


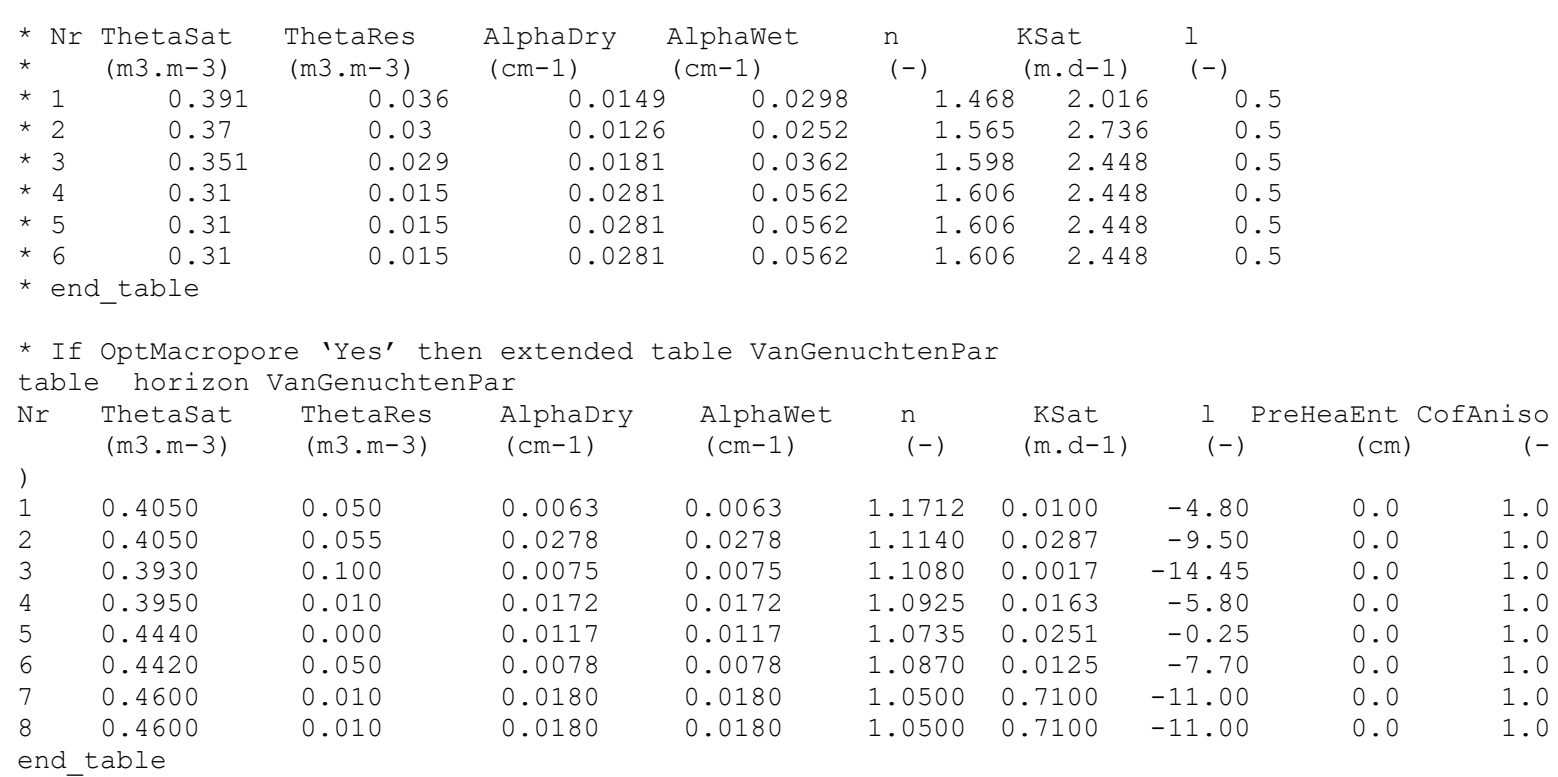

Input OptRho Option for bulk density: Calculate or Input * If Rhoopt = Input then specify bulk density for each horizon:

table horizon Rho (kg.m-3) [100|2000]

$\begin{array}{ll}1 & 1466.0 \\ 2 & 1508.0 \\ 3 & 1520.0 \\ 4 & 1520.0 \\ 5 & 1504.0 \\ 6 & 1620.0 \\ 7 & 1620.0 \\ 8 & 1620.0 \\ \text { end table } \\ \text { * Eñd If }\end{array}$

* Option to include hysteresis

No OptHysteresis Hysteresis option: No, InitWetting InitDrying

* If No or InitDrying then specify minimum pressure head

$0.2 \quad$ PreHeaWetDrymin ( $\mathrm{cm}$ ) Minimum pressure head to switch drying/wetting

* Maximum ponding depth and boundary air layer thickness (both location properties)

$0.01 \quad$ ZPndMax (m) Maximum ponding depth [0|1]

* If OptMacropore is 'Yes' then specify boundary pressure head that controls run-off

$0.0 \quad \mathrm{Hb} \quad(\mathrm{cm}) \quad$ Boundary pressure head

$0.001 \quad$ RstSurRunoff (d) Resistance for surface runoff

* End if

* Soil evaporation parameters

1.0 FacEvpsol (-) "Crop factor" for bare soil [0.5|1.5]

* Option to select evaporation reduction method: Boesten or Black

Boesten OptSolEvp Evaporation reduction option

* If Boesten or Black specify soil evaporation parameters

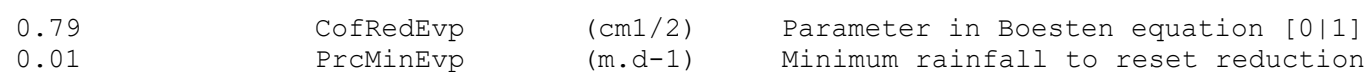

* Parameter values of the functions describing the relative diffusion coefficients

MillingtonQuirk OptCofDifRel MillingtonQuirk, Troeh or Currie

* If MillingtonQuirk:

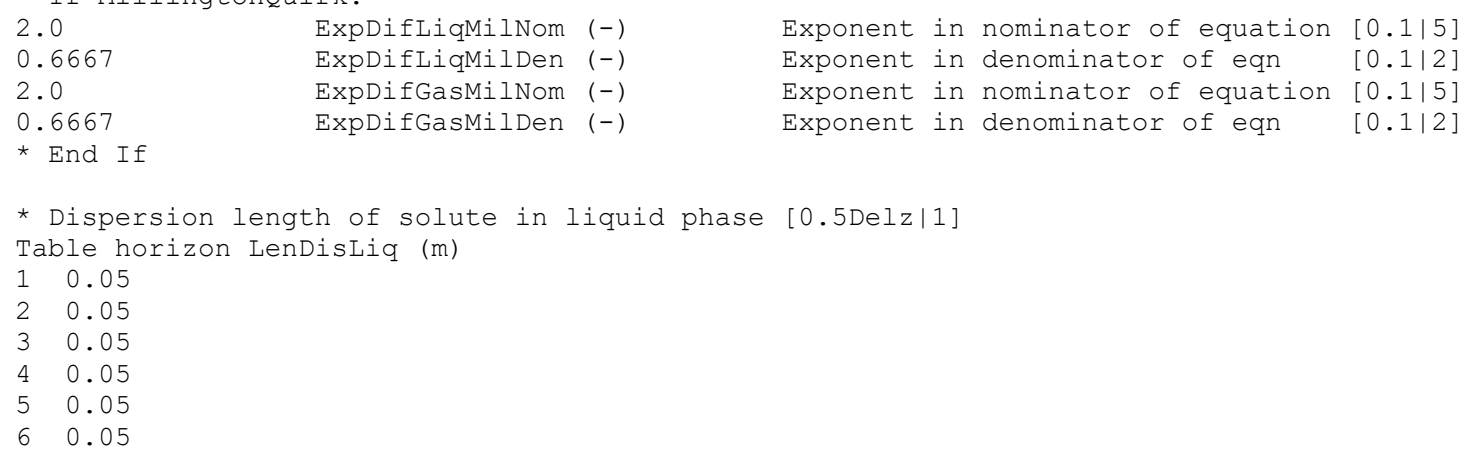


$7 \quad 0.05$

80.05

end_table

* Ponding of water on soil surface: Constant or TimeDependent

Constant OptPnd Option for ponding of water

* If TimeDependent specify file with data on ponding depth

FileId PondingDepthFile

* Section 2a: Macropore section

* Only required if OptMacropore set to 'Yes'

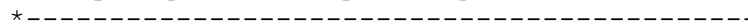

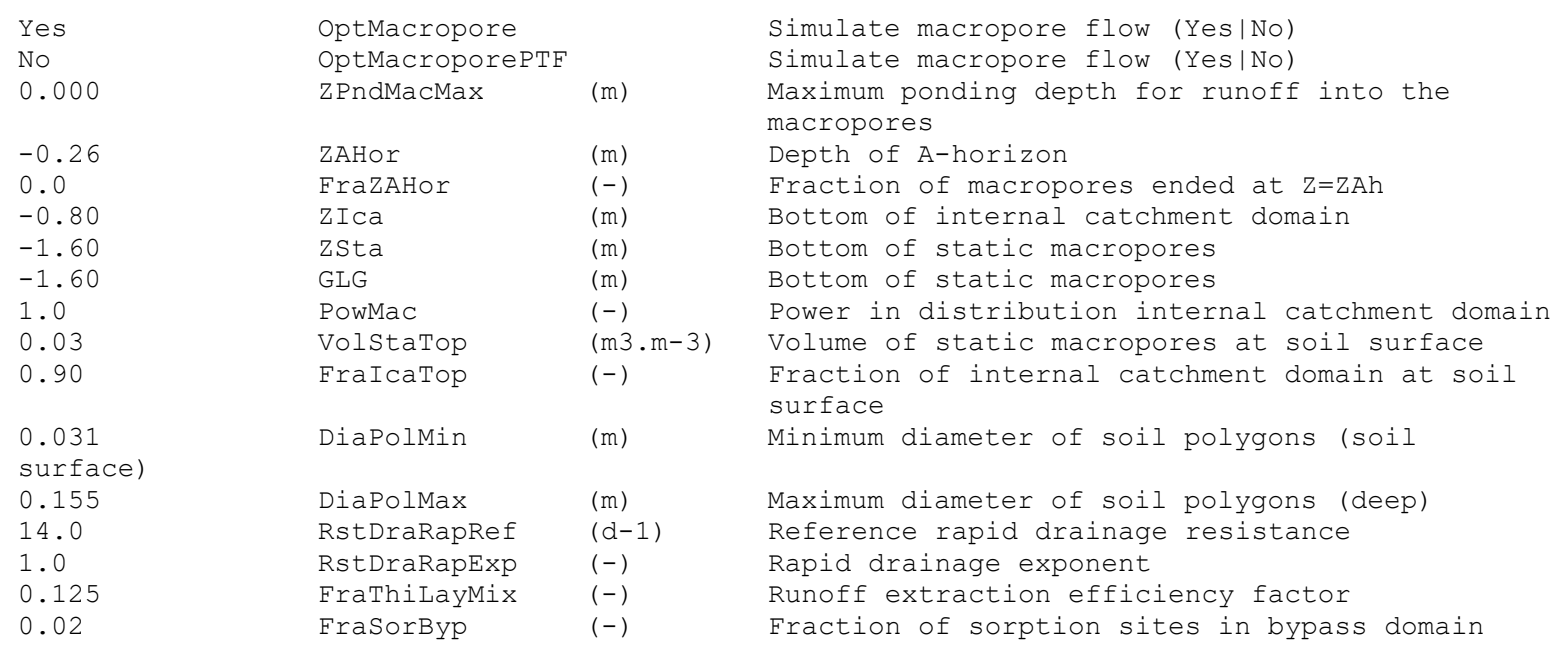

* If (OptAux == 2 or OptAux == 3) and OptMacropore is 'Yes' then specify Ditch properties

$100.0 \quad$ Areafield (m2.m-1)

$200.0 \quad$ AreaUpstream (m2.m-1)

1.0 FraUpstreamTreated (-)

2.0 ParAlphaTOXSWA (-)

0.612 VolDitch1 (m3.m-1)

* End if

* Section 3: Weather and irrigation data

* Description

Herwijn Meteostation

Input OptEvp

Evapotranspiration: Input, Penman,

OptEvp

PenmanMonteith or Makkink

51.858 Lat Latitude of meteo station [-60/60]

0.07 Alt (m) Altitude of meteo station [-400|3000]

* Initial lower boundary soil temperature [-20|40]

* Upper boundary temperature is read from meteo file

$\begin{array}{lll}12.6 & \text { TemLbosta } & \text { (C) }\end{array}$

* Irrigation section

No OptIrr

* Options for OptIrr are:

* No: no irrigation

* Surface: Surface irrigation, irrigation depth spec. by user

* Surface_Auto: Surface irrigation, irrigation depth calc. by model

* Sprinklèr: Sprinkler irrigation, irrigation depth spec. by user

* Sprinkler_Auto: Sprinkler irrigation, irrigation depth calc. by model

* Sprinkler_Weekly: Sprinkler irrigation, irrigation depth calc. by user

FileName IrrigationData Name of file with irrigation data

* Irrigation data have to be provided in a file Station.irr (e.g. debilt.irr);

* Maximum number of characters in filename is 7.

* If RepeatHydrology is set to Yes, the first year is required only

* Format of the file should be as below:

* table IrrTab (mm)

* 01-Aug-1980 10.0

* end table

$\begin{array}{lll}1.0 & \text { FacPrc }(-) & \text { Correction factor for precipitation } \\ 0.0 & \text { DifTem (C) } & \text { Correction for temperature } \\ 1.0 & \text { FacEvp (-) } & \text { Correction factor for evapotranspiration } \\ \text { Daily } & \text { OptMetinp } & \text { option for meteorological data: Hourly or }\end{array}$ 
* Options for the calculation of the resistance of air to volatilisation; options are Laminar

* or Aerodynamic

* If set to 'Aerodynamic' then OptResBou is also required: options are Hicks or Wang

* If set to 'laminar' then ThiAirBoulay required

Laminar OptrraRes Option for resistance air set to Laminar

If set to 'Laminar' then specify thickness boundary air layer

$0.01 \quad$ ThiAirBoulay (m) Boundary air layer thickness [1e-6|1]

Yes OptRainfallevents Option to consider rainfall events

EventDuration OptRainfallintensity

No OptSnow Option to consider snow in SWAP

* Section 4: Boundary and initial conditions of hydrological model

* Section 4a: Lower boundary flux conditions

* Description

* Initial condition

-80.9 ZGrwLevsta (cm) Initial groundwater level [-5000|0]

* Choose one of the following options for the bottom boundary:

* GrwLev Flux Cauchy FncGrwLev Dirichlet Zeroflux FreeDrain Lysimeter

$\begin{array}{lll}\text { Cauchy OptLbo } & \text { Lower boundary option selected }\end{array}$

* If Lboopt = Cauchy then specify lower boundary option

* Options for bottom flux can be Sine, Headonly or HeadAndFlux

Headonly OptBotflux Option selected for bottom flux

No OptNoResVert

NoDrains OptShapeGrwLev

$-0.8200 \quad$ HeaDraBase

(m)

5. 0 RstAqt

Switch on or switch off vertical resistance Elliptic, Parabolic, Sinusoidal, NoDrains

* If OptBotflux HeadOnly or HeadAndFlux specify file with data

* Lower boundary conditions

BBW LowerBoundaryFile

* If Headonly then read data on Head from LowerBoundaryfile (FileId.bot)

* Section 4b: Local drainage fluxes to ditches and drains

$\begin{array}{lll}\star & \text { OptDra } & \text { No, Basic or extended drainage module }\end{array}$

$1 \quad$ NumDraLev Number of drainage levels (0/5)

* If OptDra $=\backslash$ No then NumDraLev cannot be zero.

* If OptDra $=\backslash 0$ then specify switch to adjust upper boundary of model discharge layer

No OptDislay option selected for discharge layer

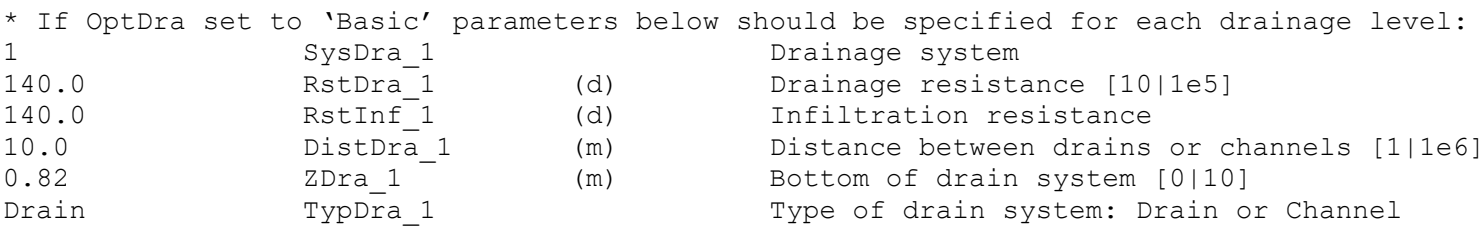

* Section 5: Compound section

* Description

* Compounds. First compound is the parent pesticide, the others are metabolites.

table compounds

In

end table

255.7 MolMas_In (g.mol-1) Molar mass [10|10000]

* Transformation table (parent-daughter relationships)

table FraprtDau (mol.mol-1)

end_table

* Example for a pesticide with three metabolites, named "met1", "met2" and "met3":

* Reaction 1: In is transformed into met1 (25\%)

* Reaction 2: In is transformed into met2 (44\%)

* Reaction 3: met1 is transformed into met3 (63\%)

* table FraPrtDau (mol.mol-1)

* 0.25 In $\rightarrow$ met 1

* 0.44 In $\rightarrow$ met 2

$\star 0.63$ met $1->$ met 3 


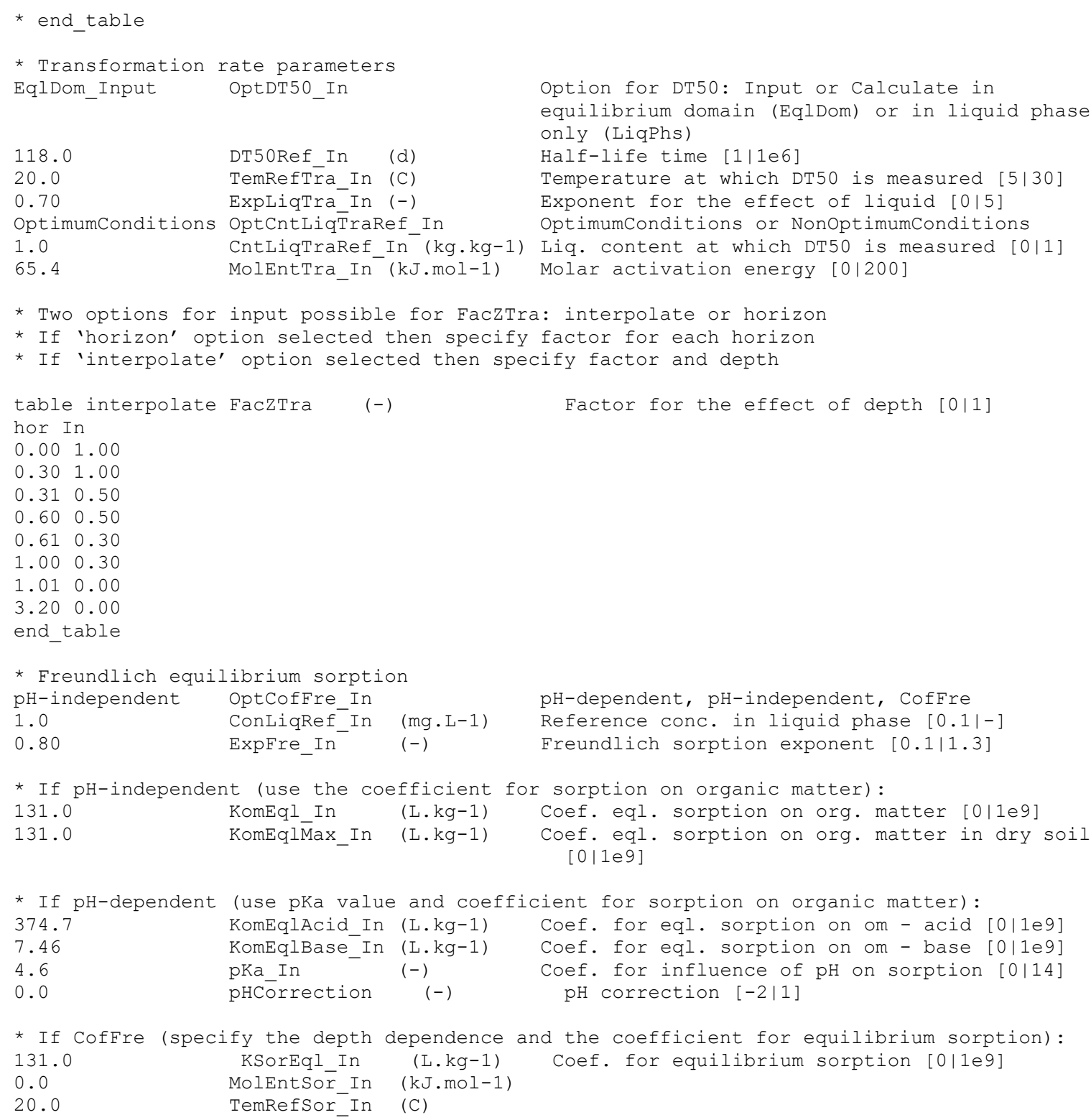

1.0

21.0

31.0

41.0

51.0

61.0

71.0

81.0

end table

* End If

* Gas/liquid partitioning

4.E-10 PreVapRef In (Pa) Saturated vapour pressure [0|2e5]

20.0 TemRefVap_In (C) . . measured at [0|40]

95.0 MolentVap In

$610.0 \quad$ SlbWatRef In

20.0 TemRefSlb_In

(kJ.mol-1) Molar enthalpy of vaporisation [-200|200]

27.0

MolEntSlb In

$(\mathrm{mg} \cdot \mathrm{L}-1)$

Solubility in water [1e-9|1e6]

(C) $\quad$. measured at [0|40]

* Non-equilibrium sorption

$0.075 \quad$ CofDesRat In $(d-1)$

0.18 FacSorNeqEql_In (-)

* Uptake 


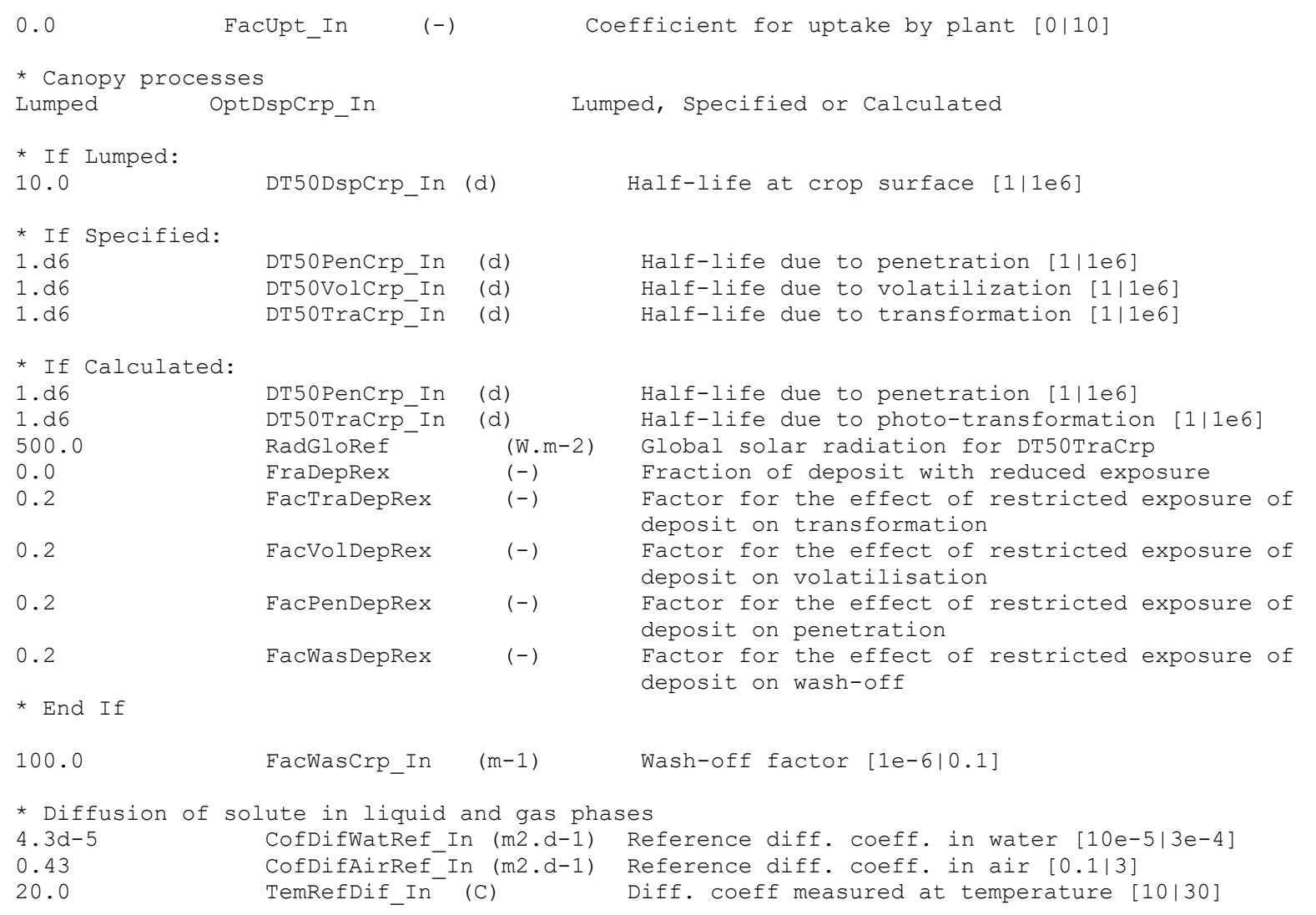

$*$ Section 6: Management section
* Description

$1.0 \quad$ ZTgt $(\mathrm{m}) \quad$ Depth of target layer [0.1|Z(N)-1]

1 DelTimEvt (a) Repeat interval of events [NoRepeat|1|2|3]

* Event table:

* Column 1: Date* Column 2: Event type: AppSolSur, AppSolInj, AppSolTil, AppCrpUsr, AppCrplAI

* AppSolsur, AppsolInj, Appsoltil cannot be combined with Optsys set to Plantonly

* If Event = Appsolsur (soil surface application):

* Column 3: Dosage (kg/ha) [0|-]

* If EventType = AppCrp (application to the crop canopy):

* Column 3: Dosage (kg/ha) [0|-]

* Column 4: Optional: Fraction of dosage applied to the crop canopy (-) [0/1]

* End If

table Applications

23-Apr AppCrpUsr $0.06 \quad 0.9$

end_table

* Tillage table - can be empty

* Specify date (dd-mmm-yyy) or day in year (dd-mmm) and tillage depth (m)

* Tillage cannot be combined with Optsys set to Plantonly

table TillageDates

end_table

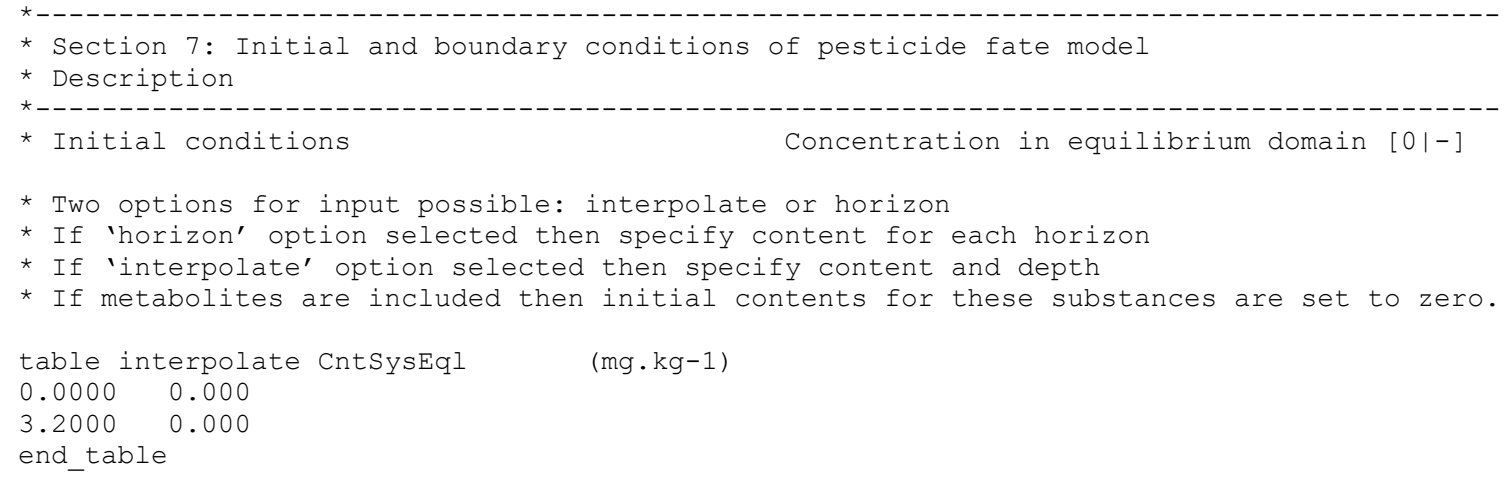


* Initial conditions

Concentration in non-equil. domain [0|-]

* If using metabolites, ConsysNeq should be specified for all metabolites

table interpolate CntSysNeq (mg.kg-1)

$0.0000 \quad 0.000$

$3.2000 \quad 0.000$

end_table

* Upper boundary flux

$[0 \mid-]$

table FlmDep

$01-J a n-1986 \quad 0.0$

31-Dec-2005 0.0

end_table

* Section 8: Crop section

* Description

Yes RepeatCrops Repeat crop table: Yes or No

* Emergence and harvest date of crop.

* Note: Length of growing season must be constant for one crop

* If repeat crops: Specification of year not required

table Crops

01-Jan 31-Dec GRASS

end_table

table IrrigationPeriods

end_table

* Crop cycle fixed or variable (calculated from temperature sum)

Fixed OptLencrp Fixed or Variable

* Crop parameters as a function of development stage

* Column 1: Development stage: 0 = emergence; 1 =harvest (-) [0|1]

* Column 2: LAI: Leaf Area Index (m2.m-2) [0|12]

* Column 3: FacCrp: Crop factor (-) [0|2]

* Column 4: ZRoot: Rooting depth (m) [0|10]

* Column 5: HeightCrp: Crop height (m) [0|10]

* LAI FaCCrp ZRoot HeightCrp

table crppar GRASS

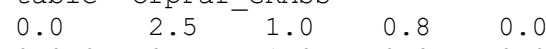

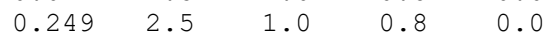

$\begin{array}{lllll}0.496 & 2.5 & 0.75 & 0.8 & 0.0\end{array}$

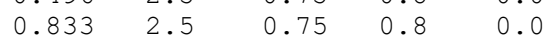

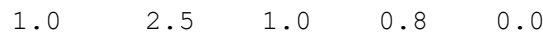

end_table

* Root density table (first column is relative depth)

* Column 1: Relative depth 0 = soil surface; 1 = DepRoot

* Column 2: Root density distribution

table RootDensity_GRASS

0.01 .0

$1.0 \quad 1.0$

end_table

* Crop water use

$-10.0$

$-25.0$

$-500.0$

$-800.0$

$-16000.0$

HLim1_GRASS ( $\mathrm{cm})$

HLim2 GRASS ( $\mathrm{cm}$ )

HLim3 $\bar{U}$ GRASS (cm)

HLim3L-GRASS (cm)

HLim4_ḠGASS (cm)

$(-)$

[0 01$]$

$(-)$

[0 1 ]

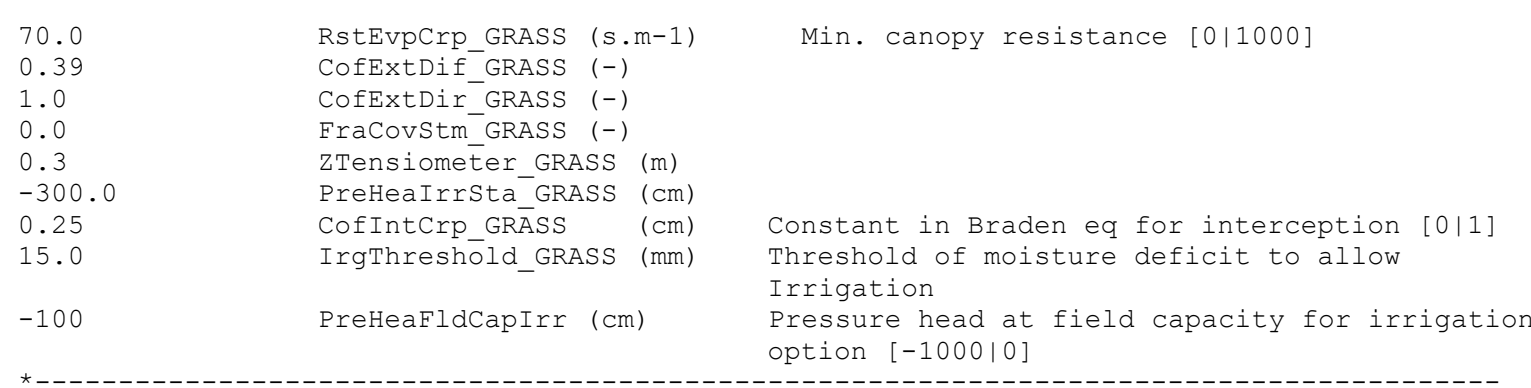

* Section 9: Output control

* Description

* First, specify the time format in the output file:

* Daysfromsta : Print number of days since start of simulation 


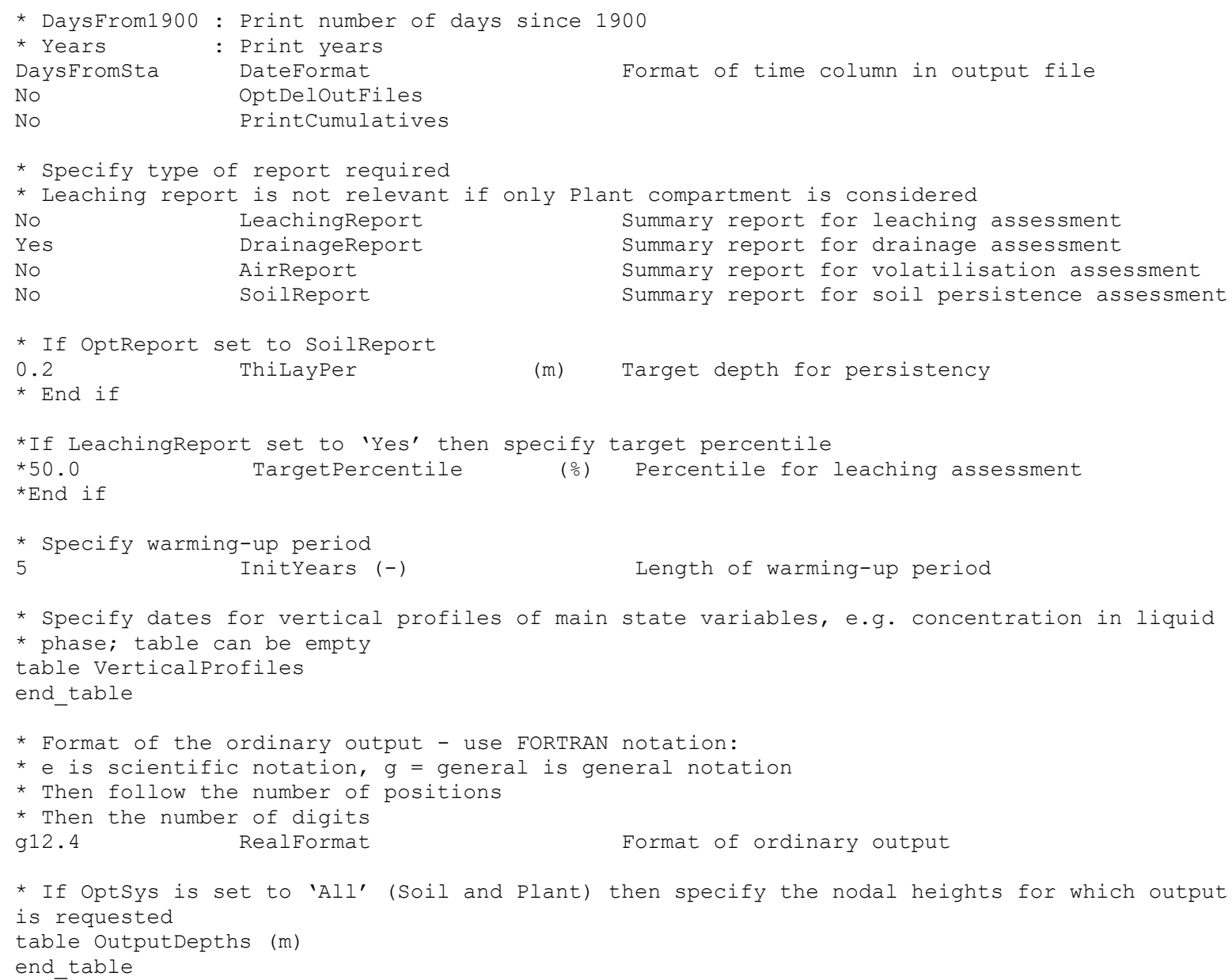




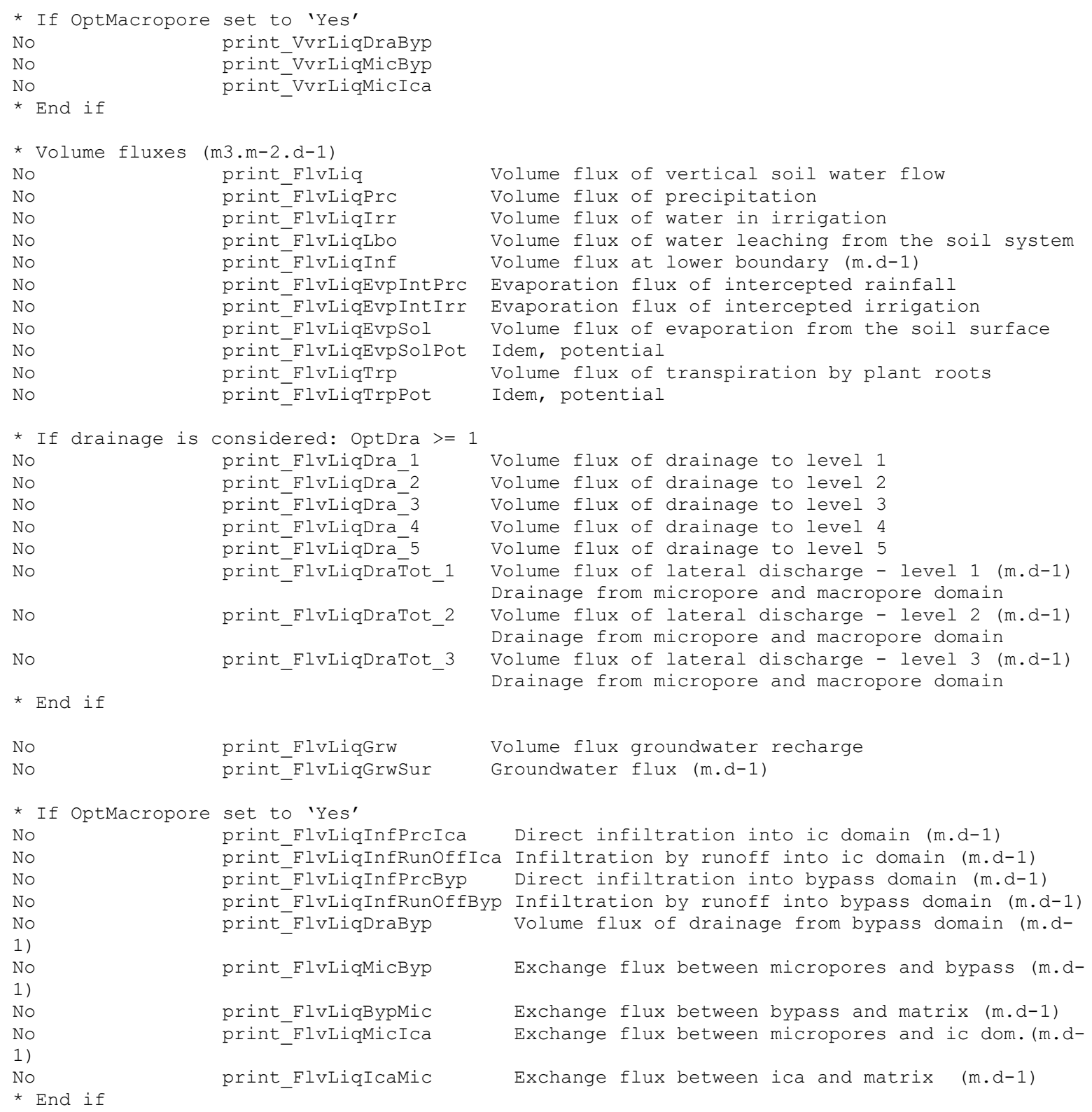

* End if

* Section II : Output from the PEARL model

* Remark: All fluxes are averages over the print interval

* Time step print_DelTimPrl Average time-step during the print interval

* Section II a: Output for the soil compartment; Optsys = All (Plant and soil compartment)

No

print_AmaErrMic
Areic numerical mass error in soil matrix (micropore domain

$\begin{array}{lr}\text { * Mass balance } & (\mathrm{kg} \cdot \mathrm{m}-2) \\ \text { No } & \text { print_AmaEqlPro } \\ \text { No } & \text { print_AmaEqlTil } \\ \text { No } & \text { print_AmaEqlTgt } \\ \text { No } & \text { print_AmaNeqPro } \\ \text { No } & \text { print_AmaNeqTil } \\ \text { No } & \text { print_AmaNeqTgt } \\ \text { No } & \text { print_AmaSysPro } \\ \text { No } & \text { print_AmaSysTil } \\ \text { No } & \text { print_AmaSysTgt } \\ \text { No } & \text { print_AmaAppSol } \\ \text { No } & \text { print_AmaForPro } \\ \text { No } & \text { print_AmaTraPro } \\ \text { No } & \text { print_AmaUptPro } \\ \text { No } & \text { print_AmaRunoff }\end{array}$

* If OptMacropore set to 'Yes'
Areic mass in equilibrium domain of profile Areic mass in equilibrium domain of tillage layer Areic mass in equilibrium domain of target layer Areic mass in non-eql. domain of profile Areic mass in non-eql. domain of tillage layer Areic mass in non-eql. domain of target layer Areic mass of pesticide in the system Areic mass of pesticide in the tillage layer Areic mass of pesticide in the target layer Areic mass applied to the soil system

Areic mass of formation

Areic mass of pesticide transformation

Areic mass of pesticide uptake

Areic mass of runoff from the field 
No

No

No

No

No

No

No

No

No

* End if
print_AmaInfRunoffIca print AmaDraByp print_AmaDraPro print AmaMicIca print AmaMicByp print_AmaIcaMic print AmaBypMic print_AmaByp print AmaIca
Areic mass of runoff infiltrating the ic domain Areic mass of drainage from the bypass domain Areic mass of drainage from the micropore domain Areic mass of exchange between ica and matrix Areic mass of exchange between bypass and matrix Areic mass of exchange between ica and matrix Areic mass of exchange between bypass and matrix Areic mass in the bypass domain Areic mass in the internal catchment domain

$\begin{array}{ll}\text { * If drainage is considered: OptDra }>=1 \\ \text { No } & \text { print_AmaDra_1 } \\ \text { No } & \text { print_AmaDra_2 } \\ \text { No } & \text { print_AmaDra_3 } \\ \text { No } & \text { print_AmaDra_4 } \\ \text { No } & \text { print_AmaDra_5 } \\ \text { No } & \text { print_AmaDraPro } \\ \text { * End if } & \end{array}$

Areic mass of drainage to level 1

Areic mass of drainage to level 2

Areic mass of drainage to level 3

Areic mass of drainage to level 4

Areic mass of drainage to level 5

Areic mass of lateral discharge

\begin{tabular}{|c|c|c|}
\hline No & print_ConLiq & Concentration in liquid phase \\
\hline No & print_ConGas & Concentration in gas phase \\
\hline No & print_ConSysEql & Concentration in equilibrium domain \\
\hline No & print_ConSysNeq & Concentration in non-equilibrium domain \\
\hline No & print_Consys & Concentration in the soil system \\
\hline No & print_ConLiqSatAvg & Avg. conc.in liq. phase between 1-2 m \\
\hline No & print_ConLiqLbo & Concentration in percolate \\
\hline & red: OptDra & \\
\hline No & t_ConLiqDra & Concentration in drainage water \\
\hline No & print_ConLiqDra_1 & Concentration in drainage water, system \\
\hline No & print_ConLiqDra_2 & Concentration in drainage water, system \\
\hline No & print_ConLiqDra_3 & Concentration in drainage water, system \\
\hline No & print_ConLiqDra_4 & Concentration in drainage water, system \\
\hline No & print_ConLiqDra_5 & Concentration in drainage water, system \\
\hline
\end{tabular}

* End if print ConLiqDra-

* If OptAux $=2$ or OptAux $=3$ then

$\begin{array}{ll}\text { No } & \text { print_ConLiqDitch_1 } \\ \text { No } & \text { print_ConLiqDitch_2 } \\ \text { No } & \text { print_ConLiqDitch_3 }\end{array}$

Concentration in surface water from level 1

Concentration in surface water from level 2

Concentration in surface water from level 3

* End if print contigDitch-3

$\begin{array}{ll}\text { * If OptMacropore } & \text { set to 'Yes' } \\ \text { No } & \text { print_ConLiqByp } \\ \text { No } & \text { print_ConLiqIca } \\ \text { No } & \text { print_ConLiqTot } \\ \text { No } & \text { print_ConLiqDraByp } \\ \text { * End if } & \end{array}$

Concentration in the bypass domain

Concentration in the internal catchment domain

Total concentration (mean of matrix and macropore)

concentration in drainage water from bypass domain

* If paddy water layer is considered: OptPaddy set to 'Yes'

$\begin{array}{lll}\text { No } & \text { print_ConLiqWatLay } & \text { Concentration in the paddy water layer } \\ \text { No } & \text { print_ConLiqWatLayCur } & \text { Current concentration in the paddy water layer } \\ \text { No } & \text { print_ConLiqRunWatLay Concentration in run-off water }\end{array}$

* End if print_ConLiqRunWatlay Concentration in run-off water

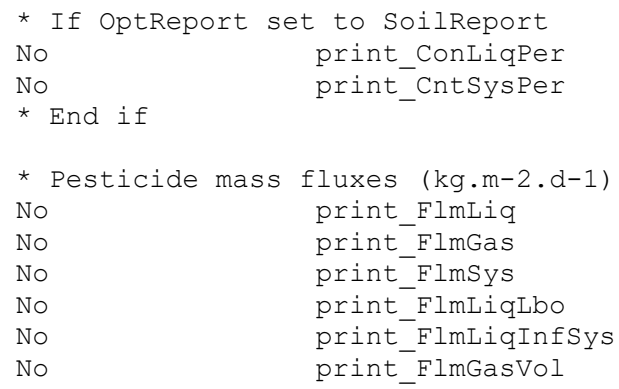

Liquid concentration in persistency layer Content in persistency layer

Pesticide mass flux in liquid phase Pesticide mass flux in gas phase Total pesticide mass flux (FlmLig+FlmGas) Accumulated mass flux at the lower boundary Accumulated mass flux of pesticide infiltration Accumulated mass flux of pesticide volatilisation

* Volatilisation concepts

* if OptTraRes $=1$, concept of laminar air boundary resistance

No print_RstAirLam Resistance to transport through laminar air layer

* End if $(\mathrm{s} \cdot \mathrm{m}-1)$

* If OptTraRes $=2$, concept of aerodynamic resistance

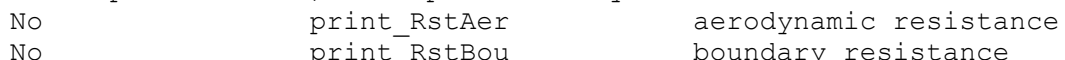

$\begin{array}{ll}\text { No } & \text { print Roundary resistance } \\ \text { print VelFriLcl } & \text { friction velocity }\end{array}$ 


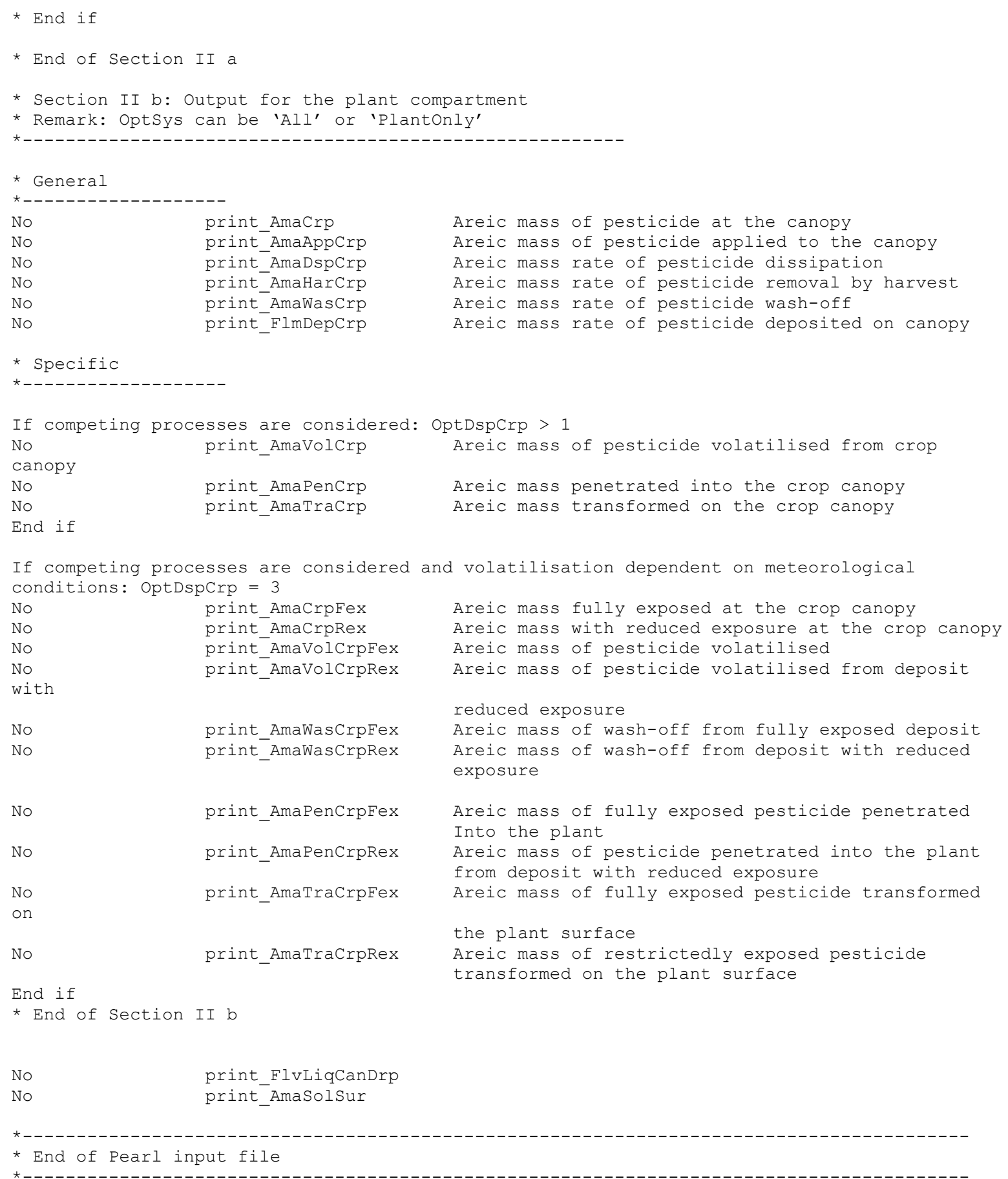




\section{Annex 4 Background information SWQN parameterisation}

This annex is added as technical description and for reference and transparency. It consists of two parts. Part 1 provides details of the SWQN parameterisation and Part 2 is dedicated to the conversion of water depths and discharges in SWQN output to water depths and discharges in TOXSWA input.

The SWQN version used was SWQN Version 3.03.0 (Revision: 102).

\section{A4.1 Details SWQN parameterisation}

\section{Reference level}

In SWQN, a reference level needs to be defined at the nodes. We used a reference level of $10 \mathrm{~m}$, which is an arbitrary value (see Table A4.1 - column: Bottom level).

\section{Definition of the nodes for the SWQN simulation}

Table A4.1 gives the definition of the nodes as used for the SWQN simulation of the ditch of the upwards and sideways directed spraying scenario. Precipitation and/or evaporation was not taken into account (PrecEvapID =0). The maximum water level was $11.08 \mathrm{~m}$ (i.e. 11.08 minus $10 \mathrm{~m}$ reference level results in 1.08 maximum water depth, which is equal to the soil surface (Figure 3.1). The initial water depth is $30 \mathrm{~cm}$, except for the boundary nodes that have a lower water depth.

\section{Definition of the sections for the SWQN simulation}

Table A4.2 gives the definition of the sections, as used for the SWQN parameterisation. For each section, the begin- and end nodes are specified, as well as its length $(10 \mathrm{~m})$ and bottom width of the begin and end nodes $(1.74 \mathrm{~m}$ ). The simplified St. Venant Equations using in SWQN (Smit et al., 2009) require either the Manning or Chezy friction coefficient as input. We decided to use the Manning coefficient in for all nodes and in all situations (i.e. discharging and inlet situation), and to use the same value as for the ditch of the EU FOCUS Surface Water scenarios: 25 m1/3 s-1 (FOCUS, 2001). 
Table A4.1 The SWQN_NodesDefinition.csv file as used for the SWQN simulation of the ditch of the upwards and sideways directed spraying scenario. The water levels are given in metres. The bottom level is an arbitrary chosen level.

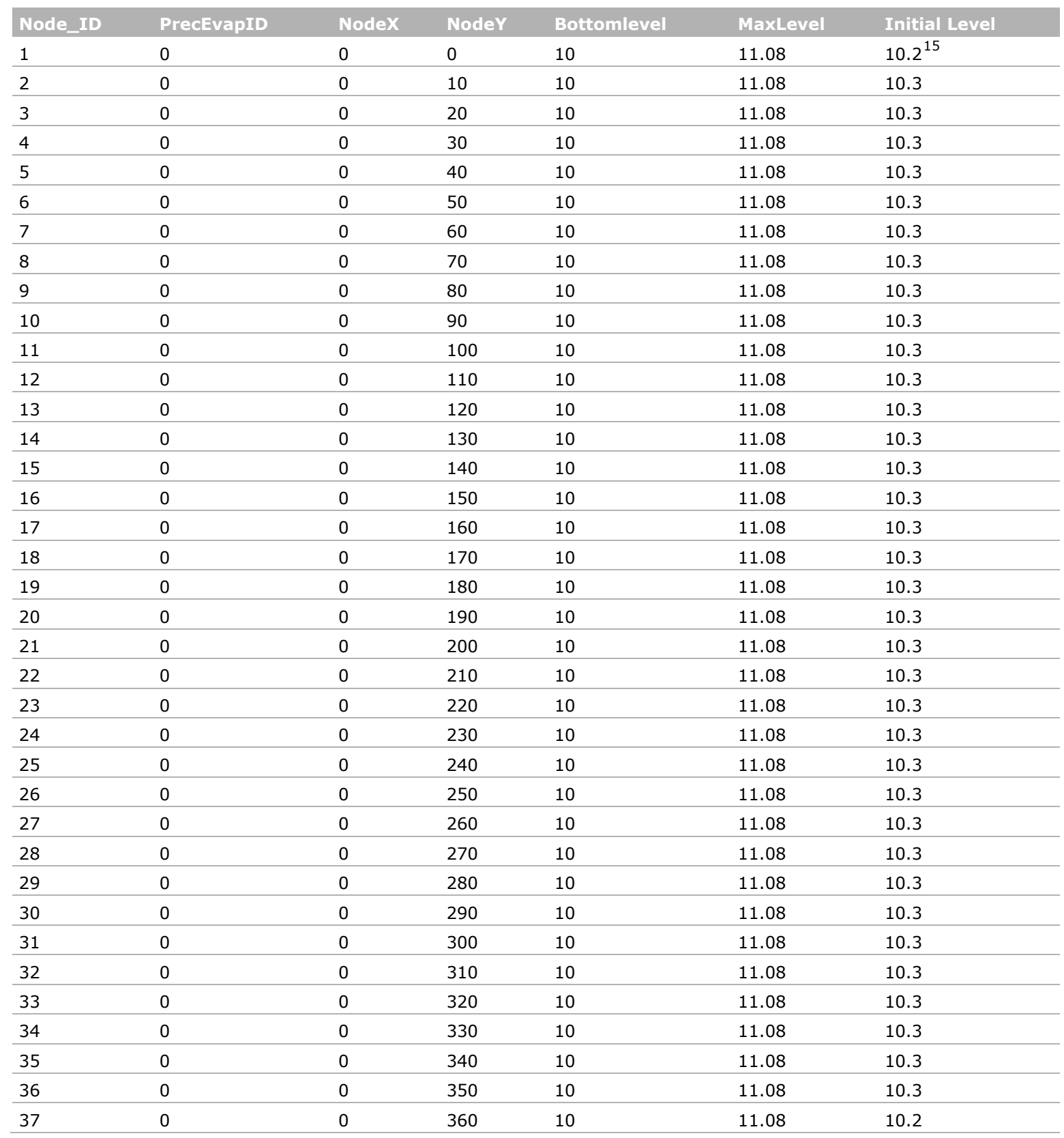

\footnotetext{
${ }^{15}$ This value was arbitrary chosen and is overruled by the boundary level values as given in Table A4.5.
} 


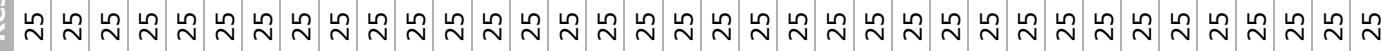

is

$\stackrel{5}{\frac{1}{2}}$

3

5

$\frac{1}{9}$

ذ্

$\delta$

T

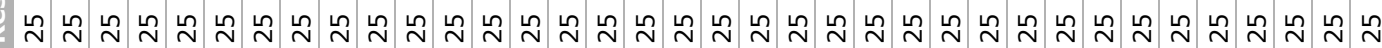

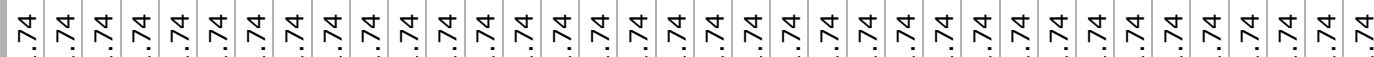

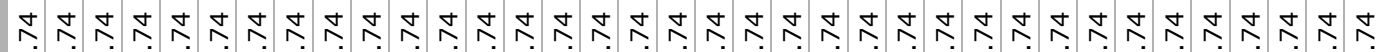

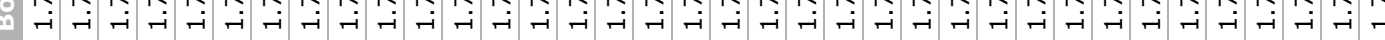

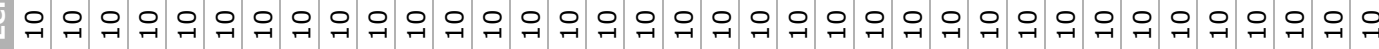
○

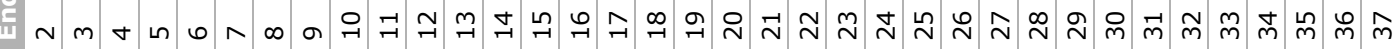
을 음

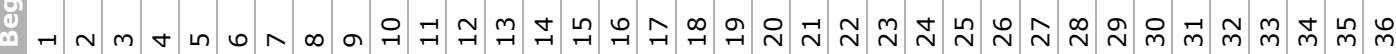
近 


\section{Weirs}

In SWQN, the weirs are defined by two input files: SWQN_WeirsDefinition.csv (Table A4.3) and SWQN_WeirsControl.csv (Table A4.4). The characteristics of the weir are specified in SWQN_WeirsDefinition.csv.

The sections were the weirs are located are defined, the crest width $(50 \mathrm{~cm})$, the initial crest width (note that this value defines the actual crest width in case the option SelectControlWeir is set to 2 in SWQN_WeirsControl.csv), minimal and maximal crest levels and the weir coefficients $\left(\mu_{\text {weir }}=1.5 \mathrm{~m}^{0.5} \mathrm{~s}^{-1}\right.$ ) are defined.

Table A4.3 The SWQN_WeirsDefinition.csv file as used for the SWQN simulation of the ditch of the upwards and sideways directed spraying scenario.

\begin{tabular}{lllllll} 
Weir_ID & Section & MaxCrestWidth & InitialCrestWidth & MaxCrestLevel & MinCrestLevel \\
1 & 2 & 3.9 & 0.5 & & 11.08 & 10.26 \\
\hline 2 & 35 & 3.9 & 0.5 & & 11.08 & 10.26 \\
\hline & & & & & \\
Weir_ID & Section & InitialCrestl_evel & MuPosFree & MuNegFree & MuPosSub & MuPosSub \\
1 & 2 & 10.26 & 1.5 & 1.5 & 1.5 & 1.5 \\
\hline 2 & 35 & 11.08 & 1.5 & 1.5 & 1.5 & 1.5 \\
\hline
\end{tabular}

The control settings of the weir are specified in SWQN_WeirsControl.csv (Table A2.4). For level control, we used the fixed crest level option (SelectControlWeir $=2$ ). For each weirID and date the level control (CrestLevel in $\mathrm{m}$ from reference level) is fixed. In SWQN_WeirsControl.csv crest level values are sustained in time until a new value is given. In case SelectControlWeir is set to 2, the CrestWidth, the Target level of the begin node and the Target level of the end node which are input of SWQN_WeirsControl.csv are dummy values.

Table A4.4 Part of the SWQN_WeirsControl.csv file as used for the SWQN simulation of the ditch of the upwards and sideways directed spraying scenario.

\begin{tabular}{|c|c|c|c|c|c|c|}
\hline Date & WeirID & SelectControl Weir & CrestWidth* & CrestLevel & $\begin{array}{l}\text { Targetlevel } \\
\text { Begin* }\end{array}$ & $\begin{array}{l}\text { Targetlevel } \\
\text { End* }\end{array}$ \\
\hline 01-01-1986 & 1 & 2 & 1.74 & 10.26 & \multirow{6}{*}{\multicolumn{2}{|c|}{$\begin{array}{l}\text { On Jan. } 1^{\text {st }} 1986 \text {, Weir } 2 \text { in section } \\
2 \text { acts as a barrier forcing flow } \\
\text { towards Weir } 1 \text { (Section } 35 \text { ), with } \\
\text { crest height set to the Winter level } \\
\text { of } 26 \mathrm{~cm} \text {. }\end{array}$}} \\
\hline 01-01-1986 & 2 & 2 & 1.74 & 11.08 & & \\
\hline 09-01-1986 & 1 & 2 & 1.74 & 11.08 & & \\
\hline 09-01-1986 & 2 & 2 & 1.74 & 10.26 & & \\
\hline 01-04-1986 & 1 & 2 & 1.74 & 11.08 & & \\
\hline 01-04-1986 & 2 & 2 & 1.74 & 10.275 & & \\
\hline $11-06-1986$ & 1 & 2 & 1.74 & 10.275 & \multirow{8}{*}{\multicolumn{2}{|c|}{$\begin{array}{l}\text { On Jan. } 9^{\text {th }} 1986 \text {, there is a shift } \\
\text { in flow direction. Weir } 1 \text { in Section } \\
35 \text { acts as a barrier forcing flow } \\
\text { towards Weir } 2 \text { (Section 2), with } \\
\text { crest height set to the Winter level } \\
\text { of } 26 \mathrm{~cm} \text {. }\end{array}$}} \\
\hline $11-06-1986$ & 2 & 2 & 1.74 & 11.08 & & \\
\hline $12-06-1986$ & 1 & 2 & 1.74 & 11.08 & & \\
\hline $12-06-1986$ & 2 & 2 & 1.74 & 10.275 & & \\
\hline $13-06-1986$ & 1 & 2 & 1.74 & 10.275 & & \\
\hline $13-06-1986$ & 2 & 2 & 1.74 & 11.08 & & \\
\hline $19-07-1986$ & 1 & 2 & 1.74 & 11.08 & & \\
\hline $19-07-1986$ & 2 & 2 & 1.74 & 10.275 & & \\
\hline
\end{tabular}

* Dummy values; not used in case SelectControlWeir is set to 2 .

\section{Boundary levels of the begin and end nodes of the $360 \mathrm{~m}$ long ditch (Node 1 and Node 37)} Level boundaries are specified in the SWQN input file: SWQN_LevelBoundary.csv (Table A4.5). They were set to $10.05 \mathrm{~m}(5 \mathrm{~cm})$ on Nodes 1 and 37 , and are needed to make sure that the water can leave the ditch. Only the levels on the start date need to be given in SWQN_LevelBoundary.csv as values are sustained in time until a new value is given. 
Table A4.5 The SWQN_LevelBoundary.cSv file as used for the SWQN simulation of the ditch of the upwards and sideways directed spraying scenario.

\begin{tabular}{lll} 
Date & ExtCompNumber & Level \\
$01 / 01 / 1986$ & 1 & 10.05 \\
\hline $01 / 01 / 1986$ & 37 & 10.05 \\
\hline
\end{tabular}

Boundary fluxes of the begin- and end nodes of the $\underline{\mathbf{3 0 0}} \mathbf{m}$ long ditch (Node $\mathbf{4}$ and Node 34) Flow boundaries in Nodes 4 and 34 are specified in the SWQN input file: SWQN_FlowBoundary.cSV (Table A4.6). This discharge is given in $\mathrm{m}^{3} / \mathrm{s}$.

Table A4.6 Part of the SWQN_FlowBoundary.CSV file as used for the SWQN simulation of the ditch of the upwards and sideways directed spraying scenario. Discharge is given in $m^{3} s^{-1}$. ExtCompNumber refers to nodeID.

\begin{tabular}{|c|c|c|c|}
\hline Date & ExtCompNumber & Discharge & \multirow{8}{*}{$\begin{array}{l}\text { Note: discharge in } \mathrm{m}^{3} / \mathrm{s} \\
\text { On Jan. } 1^{\text {st }} 1986, \text { Node } 34 \text { receives incoming } \\
\text { discharge and Node } 4 \text { does not. This indicates } \\
\text { that there is a water-inlet situation. On Jan. } 1^{\text {st }} \\
1986 \text { for all nodes between Nodes } 4 \text { and } 34 \text { the } \\
\text { incoming discharge is set to zero. The values are } \\
\text { sustained in time. }\end{array}$} \\
\hline 01/01/1986 & 4 & 0 & \\
\hline $01 / 01 / 1986$ & 34 & 0.000499595 & \\
\hline & & & \\
\hline $02 / 01 / 1986$ & 4 & 0 & \\
\hline 02/01/1986 & 34 & 0.000550985 & \\
\hline . & . & . & \\
\hline 08/01/1986 & 34 & $7.652942 e-05$ & \\
\hline 09/01/1986 & 4 & 0.000288533 & \multirow{7}{*}{$\begin{array}{l}\text { Varying incoming discharge in Node } 34 \text { until Jan. } \\
9^{\text {th }} \text {. There is a change to an inlet situation. This is } \\
\text { indicated by setting the discharge in Node } 34 \text { to } \\
\text { zero and specifying a discharge }>0 \text { for Node } 4 \text {. }\end{array}$} \\
\hline 09/01/1986 & 34 & 0 & \\
\hline $10 / 01 / 1986$ & 4 & 0.000763183 & \\
\hline . & . & . & \\
\hline $10 / 06 / 1986$ & 4 & $2.385436 \mathrm{e}-05$ & \\
\hline $11 / 06 / 1986$ & 4 & 0 & \\
\hline $11 / 06 / 1986$ & 34 & $2.605046 \mathrm{e}-06$ & \\
\hline $12 / 06 / 1986$ & 4 & 0.000121572 & \\
\hline $12 / 06 / 1986$ & 34 & 0 & \\
\hline $13 / 06 / 1986$ & 4 & 0 & \\
\hline $13 / 06 / 1986$ & 34 & $1.300021 \mathrm{e}-05$ & \\
\hline . & . & . & \\
\hline $18 / 07 / 1986$ & 34 & $9.181654 \mathrm{e}-06$ & \\
\hline $19 / 07 / 1986$ & 4 & 0.000370351 & \\
\hline $19 / 07 / 1986$ & 34 & 0 & \\
\hline
\end{tabular}

The dates are following the period used for the simulation of the extended Andelst dataset in SWAP/PEARL. For the relation between the year numbers of the synthetic velocity time-series and those used the SWAP-PEARL, SWQN and TOXSWA simulations, see Annex 8.

\section{Boundary fluxes representing drainage of the nodes intervening the begin- and end nodes of the $\underline{\mathbf{3 0 0}} \mathbf{m}$ long ditch}

Lateral water fluxes as a function of time and calculated with the SWAP-PEARL model are imposed as follows: i) in case of discharging situation lateral water fluxes are imposed to node 4 up to and including node $33, \mathrm{ii}$ ) in case of a water-inlet situation lateral water fluxes are imposed to node 5 up to and including node 34 . 
For each node, the imposed lateral discharges were calculated by multiplying the drainage water flux from SWAP-PEARL (sum of FLvLiqDraMic and FlvLiqDraByp in the *.e2t file ${ }^{16}$ ) with the length of the section $(10 \mathrm{~m})$ and the depth of the field (i.e. depth perpendicular to the evaluation ditch: $140 \mathrm{~m}$ ).

Flow boundaries representing drainage in Nodes 4 to 34 are specified in the SWQN input file:

SWQN_FlowBoundary1.csv (Table A4.7). This discharge is given in $\mathrm{m}^{3} / \mathrm{s}$.

Table A4.7 Part of the SWQN_FlowBoundary1.csv file as used for the SWQN simulation of the ditch of the upwards and sideways directed spraying scenario. Discharge representing drainage is given in $m^{3} s^{-1}$. ExtCompNumber refers to nodeID.

\begin{tabular}{|c|c|c|c|}
\hline Date & ExtCompNumber & Discharge & \multirow{8}{*}{$\begin{array}{l}\text { Note: discharge representing drainage in } \\
\mathrm{m}^{3} / \mathrm{s} \\
\text { Until Jan. } 5^{\text {th }} 1986 \text {, there is no incoming } \\
\text { lateral discharge representing drainage in } \\
\text { to the ditch. On Jan. } 5^{\text {th }} 1986 \text { SWAP/PEARL } \\
\text { calculates a drainage event and the lateral } \\
\text { discharge is imposed on Nodes } 5 \text { to } 34 ; \\
\text { the nodes that should receive lateral } \\
\text { discharge in case of a water-inlet situation. }\end{array}$} \\
\hline 01/01/1986 & 4 & 0 & \\
\hline 01/01/1986 & 34 & 0 & \\
\hline 05/01/1986 & 5 & $9.462963 e-06$ & \\
\hline 05/01/1986 & 34 & $9.462963 e-06$ & \\
\hline 06/01/1986 & 5 & $1.134259 \mathrm{e}-07$ & \\
\hline 06/01/1986 & 34 & $1.134259 \mathrm{e}-07$ & \\
\hline 07/01/1986 & 5 & 0 & \\
\hline 07/01/1986 & 34 & 0 & \\
\hline . & . & . & \\
\hline $16 / 01 / 1986$ & 4 & $2.657407 e-06$ & \\
\hline $16 / 01 / 1986$ & 33 & $2.657407 e-06$ & $\begin{array}{l}\text { On Jan. } 16^{\text {th }} 1986 \text { SWAP/PEARL calculates } \\
\text { a drainage event and the lateral discharge } \\
\text { is imposed on Nodes } 4 \text { to } 33 \text {; the nodes } \\
\text { that should receive lateral discharge in } \\
\text { case of a discharging situation. }\end{array}$ \\
\hline
\end{tabular}

\footnotetext{
${ }^{16}$ Note that the e2t file used, is the file resulting from summing up the fluxes on an hourly basis of two separate SWAPPEARL simulations for the grass and tree strips (area weighted: $1 / 3$ tree strip, $2 / 3$ grass strip).
} 


\section{Runtime options}

In the file SWQN_Runtimeoptions.in the calculation period, the numerical and output time steps and the input and output types are given.

Below the content of the SWQN_Runtimeoptions.in file as used for the SWQN simulation of the ditch of the upwards and sideways directed spraying scenario is given.

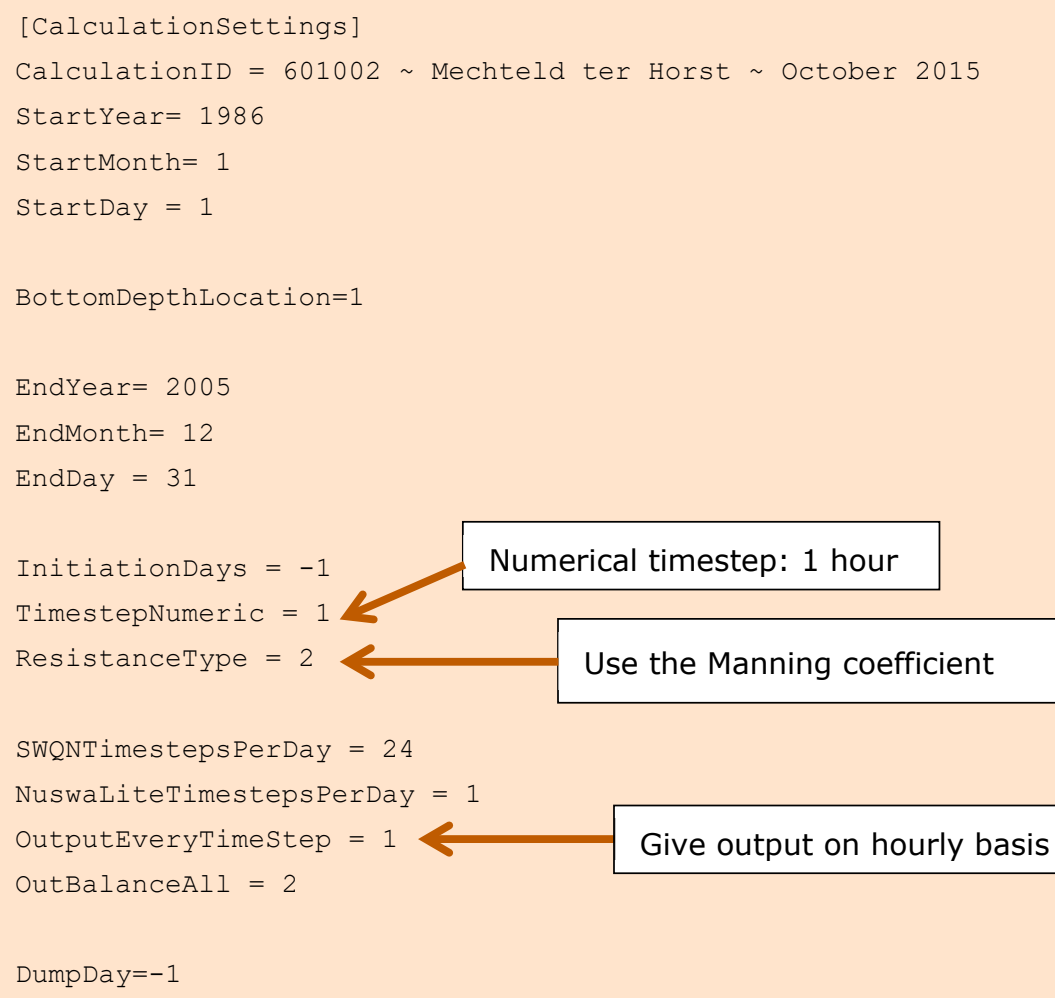




\section{A4.2 Method for converting the output of SWQN to input for TOXSWA}

In the SWQN output file, SWQN_OutDepths_TStep.csv water depths (in $\mathrm{m}$ ) are given for each node and each hour. In the SWQN output file, SWQN_OutDischarges_TStep.csv discharges (in m3/s) are given for each section. The discharge is a positive value if flow is from begin node to end node.

In SWQN, a section is found between two nodes as shown in Figure A4.1; $\mathrm{n} 1$ is the begin node of Section $\mathrm{s} 1$ and $\mathrm{n} 2$ is the end node of Section s1. Discharge in section s1 equals the discharge in node $\mathrm{n} 1$. This is valid for both flow directions.

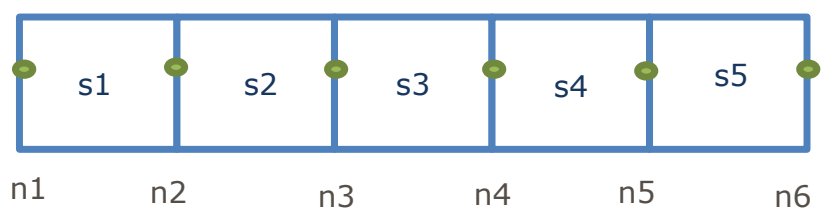

Figure A4.1 System of sections and nodes as used in SWQN.

TOXSWA uses a system of segments and nodes to describe a watercourse. A node is found in the centre of a segment, as shown in Figure A4.2; Node $n 1$ is found in the centre of Segment s1.

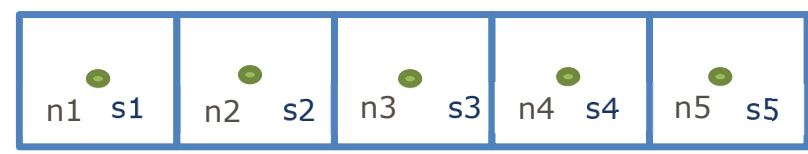

Figure A4.2 System of segments and nodes as used in TOXSWA.

In TOXSWA, water depths (called DepWat in TOXSWA) are defined in a node, and discharges (called QBou in TOXSWA) are defined on the boundaries of a segment. This implies that, for instance, DepWat(1) gives the water depth in Node 1. QBou(0) gives the discharge over the upper boundary of Segment 1 and QBou(1) gives the discharge on the boundary of Segment 1 and Segment 2.

Note that SWQN sections and TOXSWA segments have matching positions that assume equal lengths of segments and sections. SWQN nodes are, however, found on another location in a section/segment than TOXSWA nodes (Figure A4.3). Water depths in SWQN nodes and discharges in SWQN sections are translated to water depths in TOXSWA nodes and discharges over TOXSWA segment boundaries are as follows:

$\mathrm{h}_{\text {TOXSWAni }}=0.5 *\left(\mathrm{~h}_{\text {SWQNni }}+\mathrm{h}_{\text {SWQNni+1 }}\right)$

$\mathrm{QBou}_{\mathrm{si}}=\mathrm{Q}_{\mathrm{swQNsi}}$

Where $\mathrm{h}_{\text {TOxSWAni }}$ is the water depth in TOXSWA Node $\mathrm{i}, \mathrm{h}_{\text {SwQNni }}$ is the water depth in SWQN Node $\mathrm{i}$, QBou $_{\mathrm{si1}}$ is the discharge over the upper boundary of TOXWA Segment $i$ and $Q_{s w Q N s i}$ is the discharge in SWQN Segment i. Equations A4.1 and A4.2 are only valid in case the length of the SWQN sections equals the length of the corresponding TOXSWA segment. 


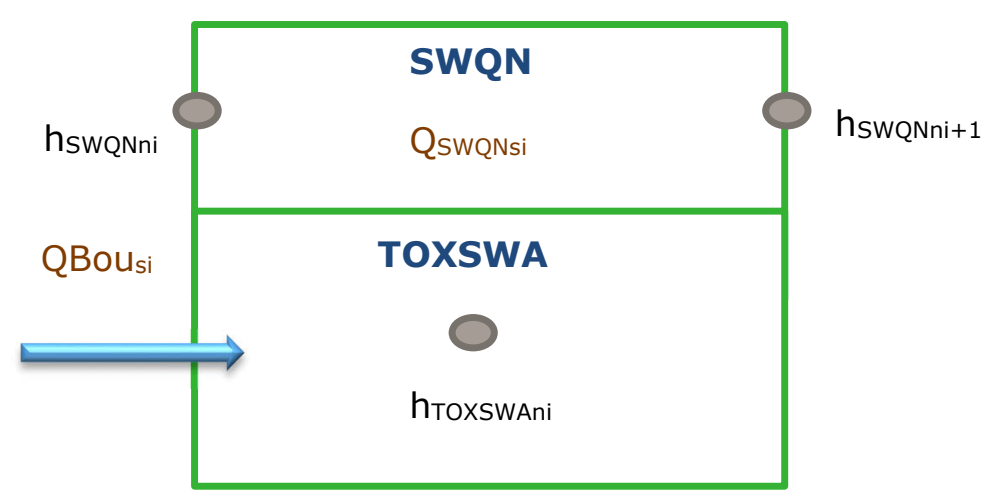

Figure A4.3 Up: System of sections and nodes as used in SWQN; depicting the description of discharge and water depth. Below: System of segments and nodes as used in TOXSWA; depicting the description of discharge and water depth.

When projecting the $300 \mathrm{~m}$ ditch to be simulated with TOXSWA on the $360 \mathrm{~m}$ ditch simulated with SWQN, TOXSWA Segment 1 will correspond to SWQN Section 4, and following this system, TOXSWA Segment 30 will correspond to SWQN Section 34. Table A4.1 shows the results of this projection considering the translation of SWQN output of water depths and discharges in to TOXSWA input of water depths and discharges.

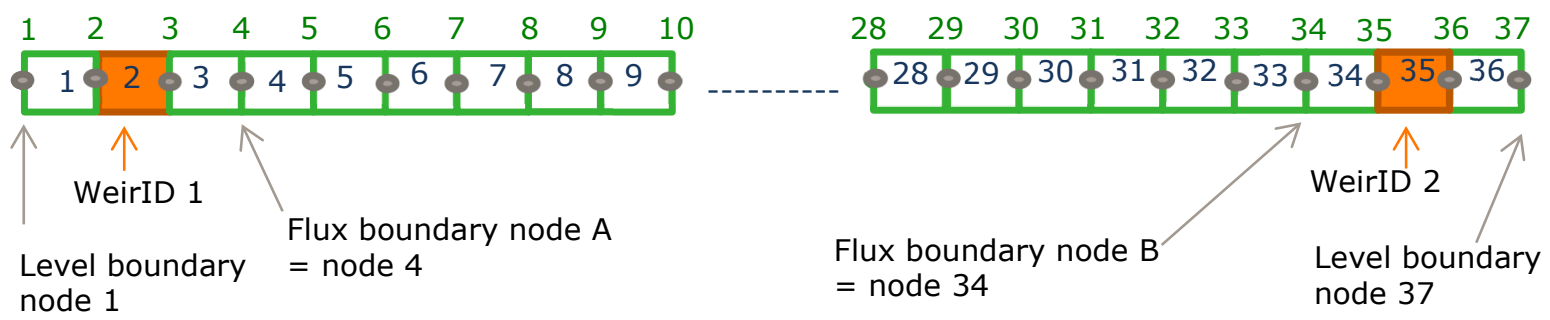

Figure A4.4 Schematisation of the ditch of the upwards and sideways directed spraying scenario in nodes and sections in SWQN (360 m). The grey dots represent the nodes (starting with Node ID 1 on the left-hand side and ending with Node ID 37 on the right-hand side). The green boxes represent the sections (starting with ID 1 on the left-hand side and ending with ID 36 on the right-hand side). 
Table A4.8 Translating discharges in SWQN sections to discharges over the upper boundary of TOXSWA segments and translating water depths in SWQN nodes to water depths in TOXSWA nodes.

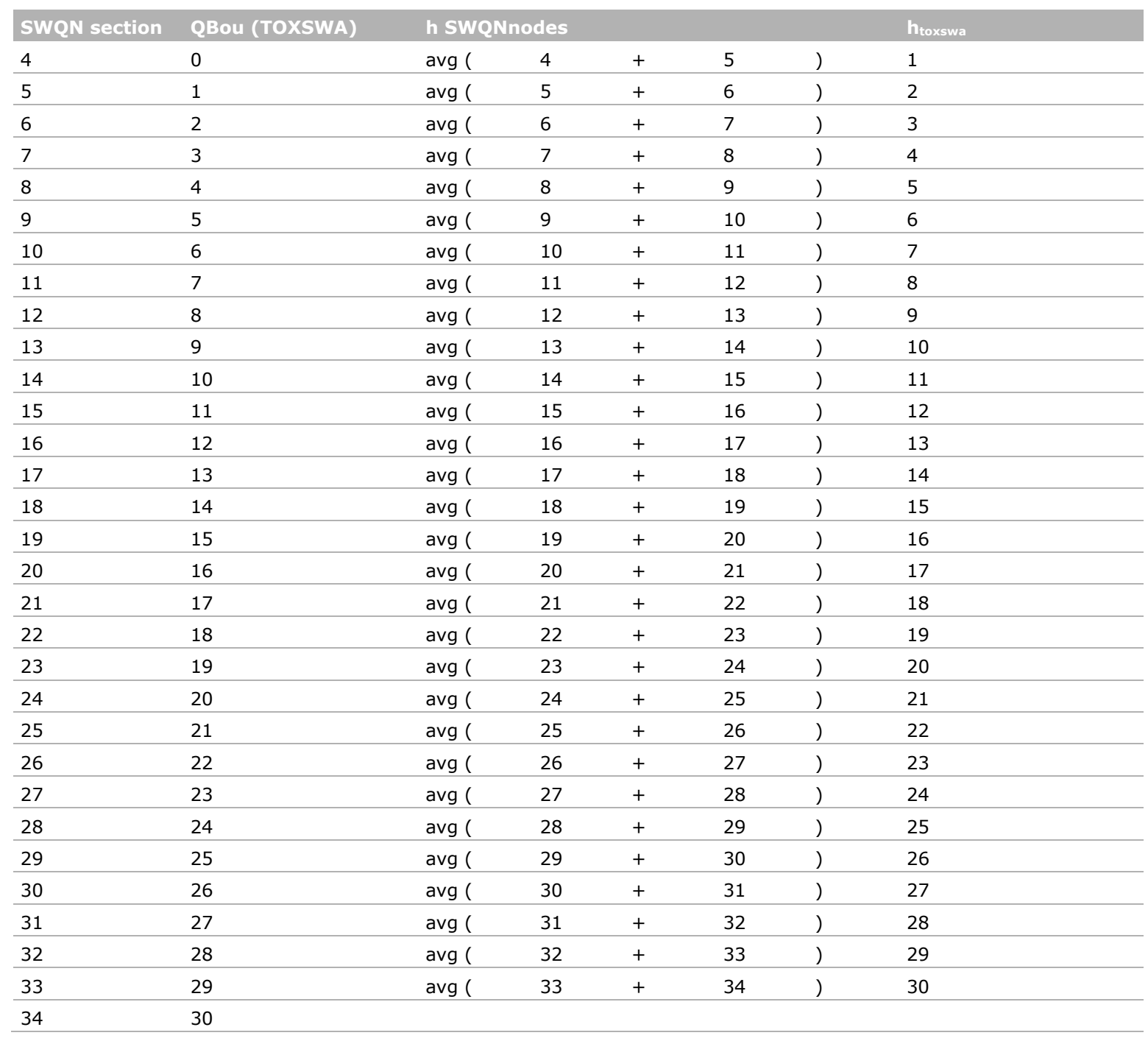




\section{Annex 5 Artefacts in discharges and water depths calculated with SWQN}

As demonstrated in Figures A5.1 and A5.2, sudden increases or decreases in both the water depth and discharge calculated by the SWQN model were found occasionally. These sudden increases and decreases lasted for one to a few hours. They often occur on the day of a switch in the flow direction of the water or a few days after this switch. We suspect that they are the result of artefacts of the numerical solution. However, analysis showed that they do not provoke water balance errors (Figure A5.3). Given the limited number of these sudden increases or decreases, their short duration (one to several hours) and limited size (around one order of magnitude for the discharge and several millimetres for the water depth), we expect that the sudden increases or decreases in both the water depth and discharge will have a limited effect on the Predicted Environmental Concentration in the ditch. This must be assessed with example calculations (which are not part of this report).

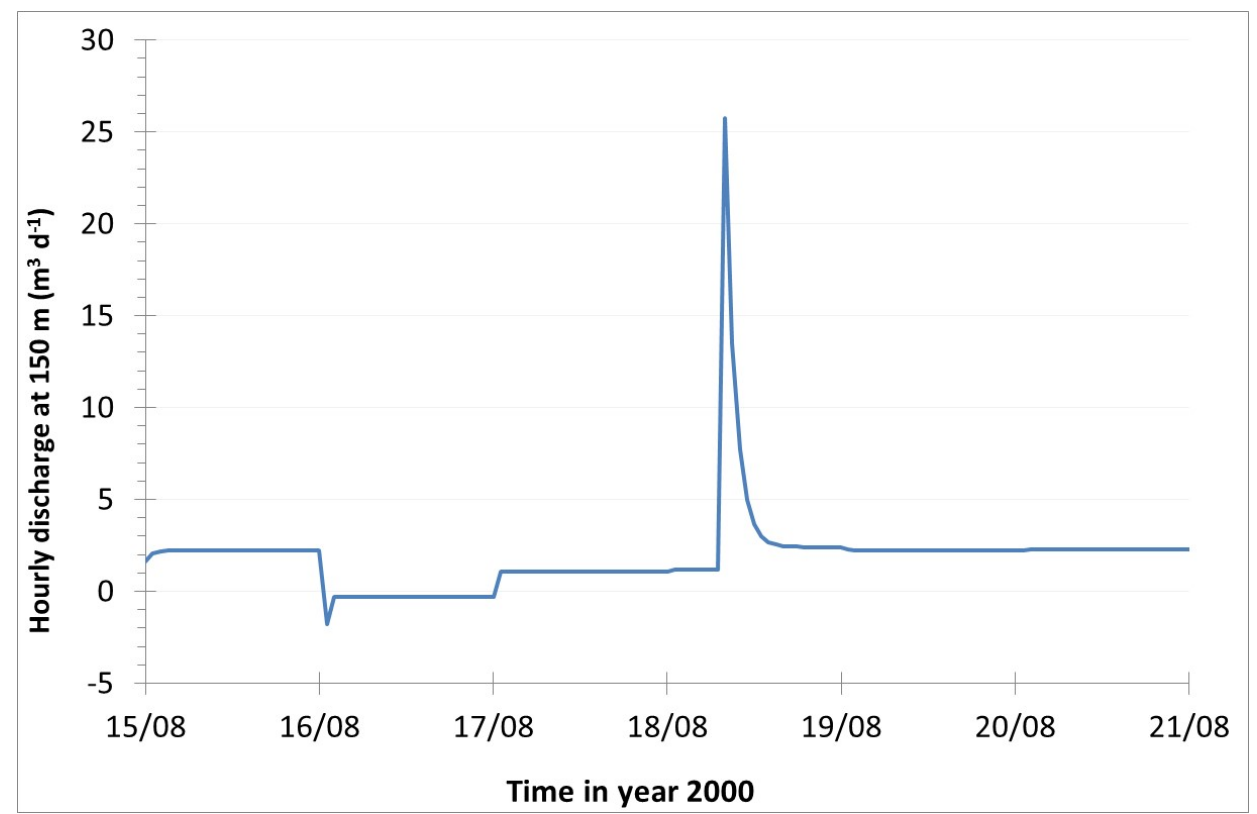

Figure A5.1 Hourly values of discharge in the centre of the 100m evaluation ditch as function of time for a few selected days in year 2000 and as result of the calibration of the model for the selected case (Case 2 in Table 4.1). The discharge set as boundary condition changes per day. The simulated discharge at $150 \mathrm{~m}$ responds generally within 2 hrs. A peak occurs only after a switch in flow direction (positive to negative and vice versa). 


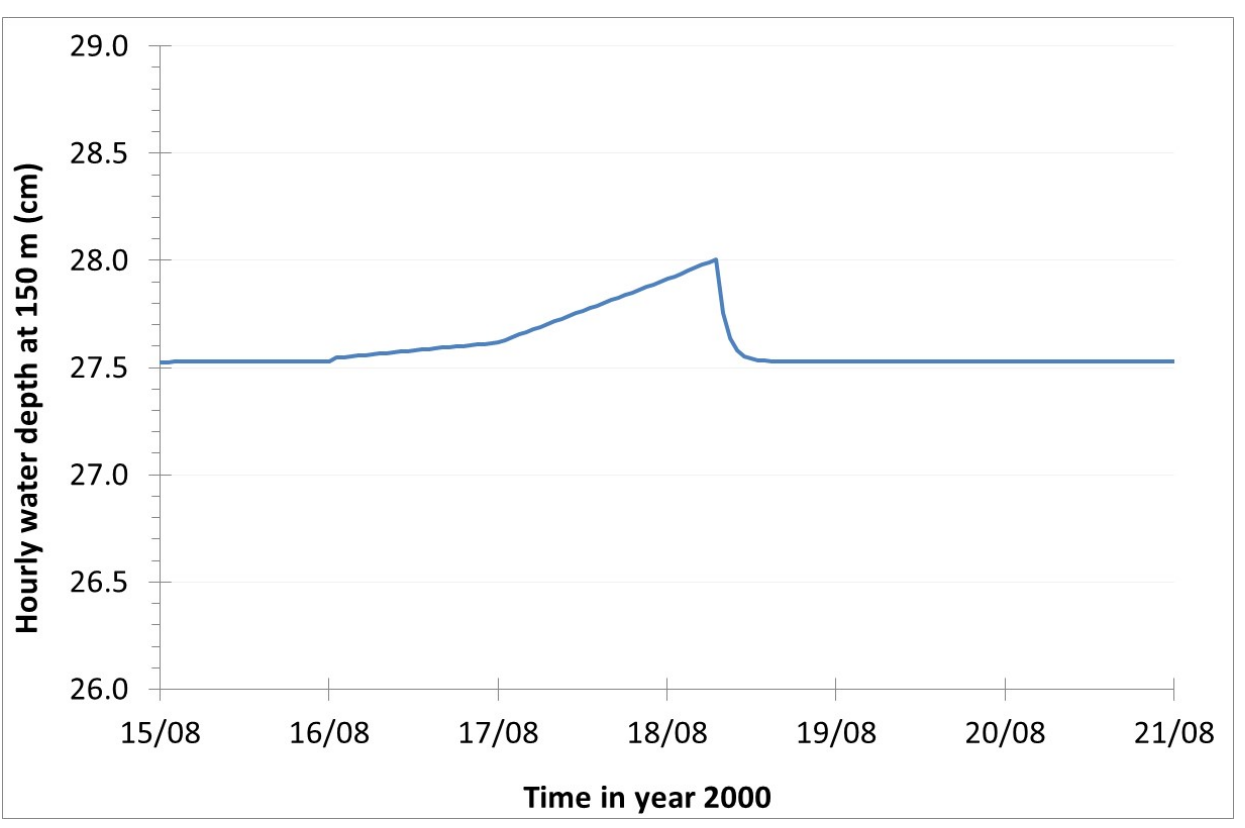

Figure A5.2 Hourly values of water depth in the centre of the $100 \mathrm{~m}$ evaluation ditch as function of time for year 2000 and as result of the calibration of the model for the selected case (Case 2 in Table 4.1). This figure corresponds to the water fluxes in Figure A5.1.

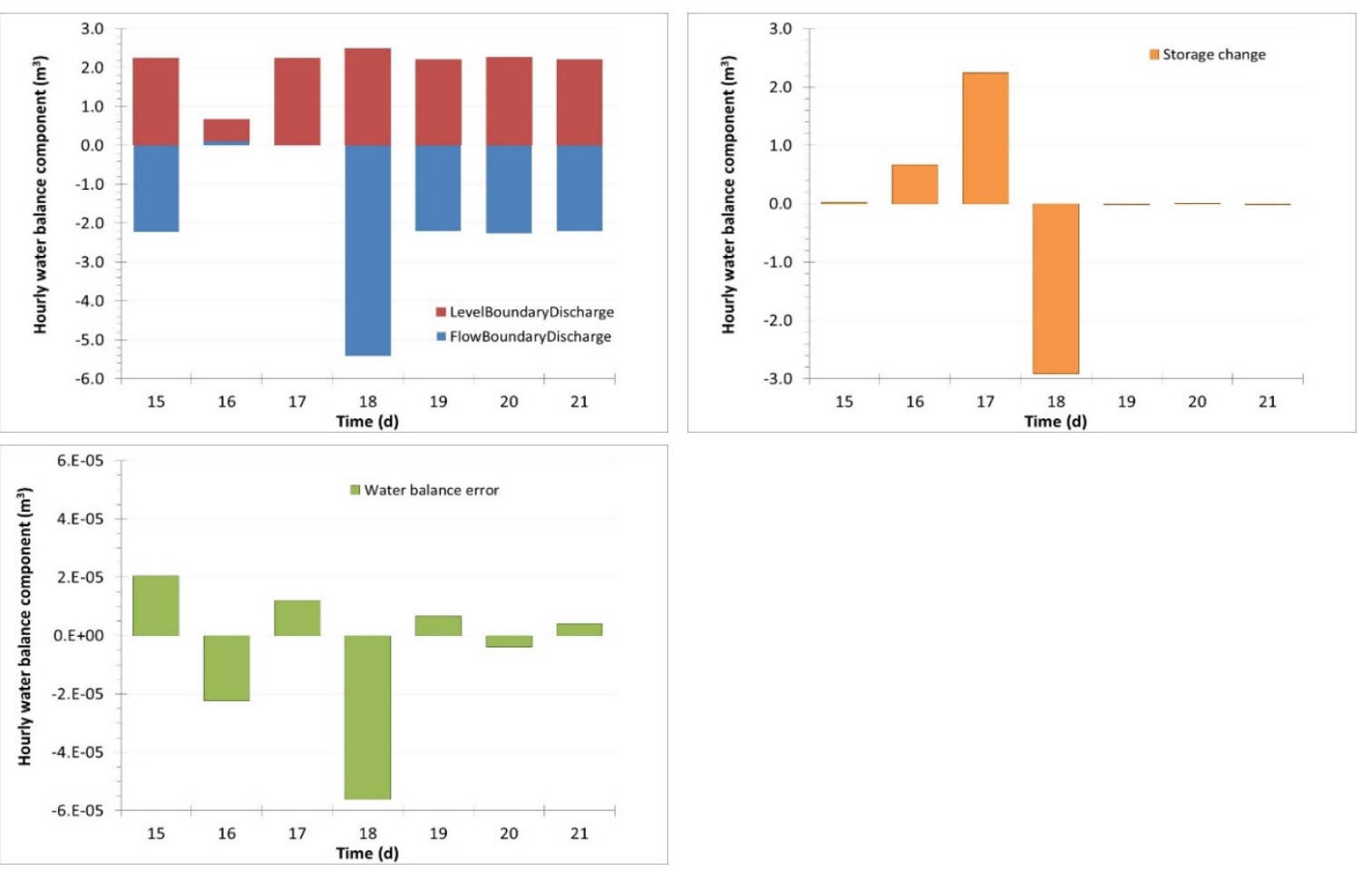

Figure A5.3 Hourly water balance for a seven-day period in the year 2000, corresponding to the period of Figures A5.1 and A5.2 A. Major water balance components: Flow boundary discharge (imposed discharges) and level boundary discharge (discharges leaving the ditch; a positive value indicates incoming flow, a negative value indicates outgoing flow). B. Change in storage in the ditch as calculated by the model; a positive value indicates an increase in water storage. C. Water balance error. Note the different scales of the $y$-axis.

The water balance error is calculated as the difference in the hourly change in storage minus the sum of the hourly inflow (flow boundary discharge) and the hourly outflow (level boundary discharge).

The water volume in the $300 \mathrm{~m}$ long ditch is about $167 \mathrm{~m}^{3}$ for the seven-day period in the year 2000 shown in Figures A5.1 - A5.3. The maximum water balance error for this period is around $5.6 \cdot 10^{-5} \mathrm{~m}^{3}$. The error relative to the water volume in the ditch is around $3.410^{-5} \%$. 


\section{Annex 6 Sediment properties of selected ditches measured by Adriaanse et al.}

Values are based on five measurements per ditch over $100 \mathrm{~m}$ of ditch. Tables are taken from Adriaanse et al. (2015) Chapter 6.

Table A6.1 Sediment properties of the watercourse near Emmeloord in July and September 2013 (Zuiderzeeland Water Board).

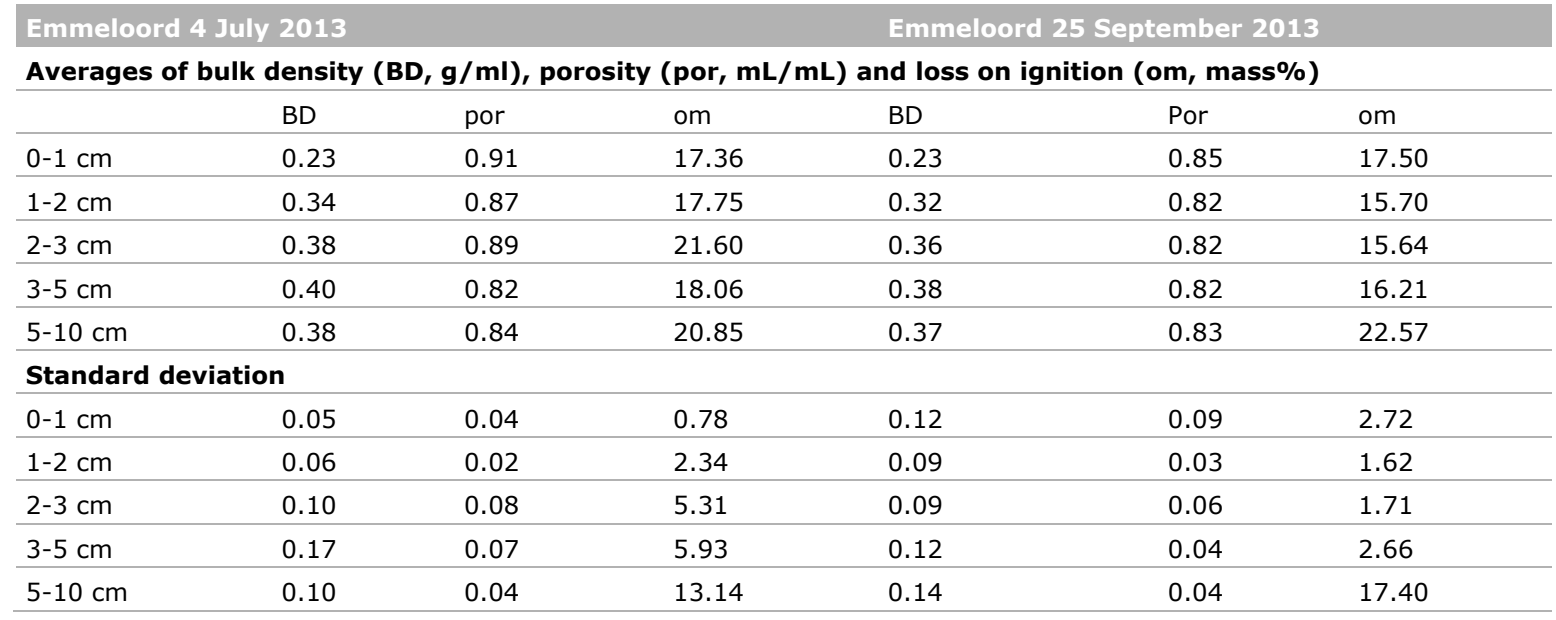

Table A6.2 Sediment properties of the watercourse near Nieuwolda in July and September 2013 (Hunze en Aas Water Board).

\begin{tabular}{|c|c|c|c|c|c|c|}
\hline \multicolumn{4}{|c|}{ Nieuwolda 25 July 2013} & \multicolumn{3}{|c|}{ Nieuwolda 25 September 2013} \\
\hline & BD & Por & om & $\mathrm{BD}$ & por & om \\
\hline $1-2 \mathrm{~cm}$ & 0.54 & 0.80 & 8.52 & 0.43 & 0.72 & 9.91 \\
\hline $2-3 \mathrm{~cm}$ & 0.58 & 0.80 & 8.36 & 0.45 & 0.68 & 9.77 \\
\hline $5-10 \mathrm{~cm}$ & 0.66 & 0.75 & 6.45 & 0.57 & 0.75 & 8.32 \\
\hline \multicolumn{7}{|c|}{ Standard deviation } \\
\hline $0-1 \mathrm{~cm}$ & 0.10 & 0.21 & 0.48 & 0.09 & 0.04 & 1.63 \\
\hline $1-2 \mathrm{~cm}$ & 0.10 & 0.04 & 0.60 & 0.10 & 0.05 & 1.29 \\
\hline
\end{tabular}


Table A6.3 Sediment properties of the watercourse near Uden, Brabant in June and September 2013 (Aa en Maas Water Board).

\section{Uden 12 June $2013 \quad$ Uden 24 September 2013}

Averages of bulk density (BD, $\mathrm{g} / \mathrm{ml})$, porosity (por, $\mathrm{mL} / \mathrm{mL}$ ) and loss on ignition (om, mass\%)

\begin{tabular}{|c|c|c|c|c|c|c|}
\hline & BD & Por & om & $B D$ & por & om \\
\hline $0-1 \mathrm{~cm}$ & 0.19 & 0.93 & 22.18 & 0.09 & 0.84 & 30.23 \\
\hline $1-2 \mathrm{~cm}$ & 0.31 & 0.87 & 19.51 & 0.14 & 0.83 & 29.21 \\
\hline $3-5 \mathrm{~cm}$ & 0.44 & 0.85 & 14.82 & 0.34 & 0.87 & 15.10 \\
\hline $5-10 \mathrm{~cm}$ & 0.56 & 0.81 & 12.35 & 0.46 & 0.81 & 10.46 \\
\hline $0-1 \mathrm{~cm}$ & 0.06 & 0.05 & 3.80 & 0.03 & 0.04 & 3.60 \\
\hline $1-2 \mathrm{~cm}$ & 0.04 & 0.06 & 1.82 & 0.03 & 0.06 & 4.78 \\
\hline $2-3 \mathrm{~cm}$ & 0.07 & 0.06 & 2.25 & 0.04 & 0.06 & 6.22 \\
\hline $3-5 \mathrm{~cm}$ & 0.12 & 0.05 & 4.18 & 0.18 & 0.09 & 6.46 \\
\hline
\end{tabular}

Table A6.4 Sediment properties of the watercourse near Willemstad, Noord-Brabant in July and September 2013 (Brabantse Delta Water Board).

\section{Willemstad24 July $2013 \quad$ Willemstad 24 September 2013}

Averages of bulk density $(B D, \mathrm{~g} / \mathrm{ml})$, porosity (por, $\mathrm{mL} / \mathrm{mL}$ ) and loss on ignition (om, mass\%)

\begin{tabular}{|c|c|c|c|c|c|c|}
\hline & $B D$ & por & om & $\mathrm{BD}$ & por & om \\
\hline $0-1 \mathrm{~cm}$ & 0.38 & 0.81 & 10.74 & 0.25 & 0.85 & 14.05 \\
\hline $1-2 \mathrm{~cm}$ & 0.54 & 0.79 & 9.66 & 0.44 & 0.79 & 10.19 \\
\hline $3-5 \mathrm{~cm}$ & 0.50 & 0.78 & 9.50 & 0.46 & 0.79 & 10.40 \\
\hline $5-10 \mathrm{~cm}$ & 0.50 & 0.78 & 9.49 & 0.54 & 0.75 & 9.73 \\
\hline $0-1 \mathrm{~cm}$ & 0.08 & 0.04 & 1.08 & 0.11 & 0.08 & 5.10 \\
\hline $1-2 \mathrm{~cm}$ & 0.05 & 0.04 & 0.91 & 0.08 & 0.02 & 1.40 \\
\hline $2-3 \mathrm{~cm}$ & 0.03 & 0.03 & 0.88 & 0.09 & 0.02 & 1.63 \\
\hline $3-5 \mathrm{~cm}$ & 0.04 & 0.02 & 0.72 & 0.08 & 0.03 & 1.06 \\
\hline
\end{tabular}




\section{Annex 7 Hydrological responses}

This Annex provides graphical information of several hydrological parameters for each year in the last 15 years of the 20-year-period, for which the hydrology is simulated with SWQN i.e.

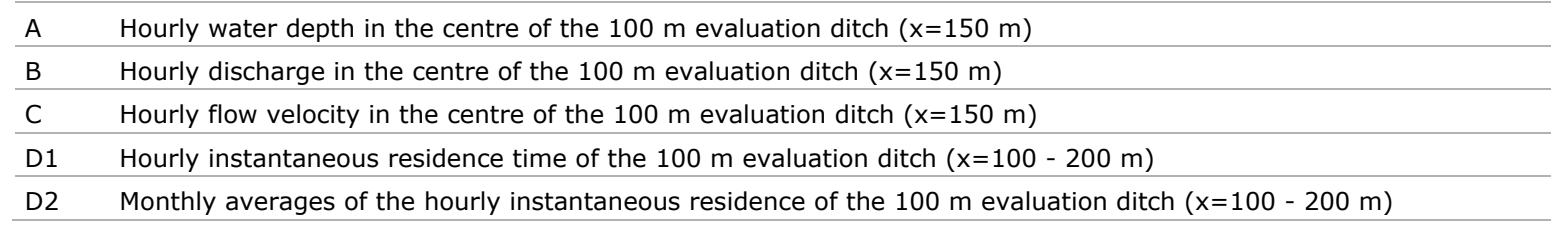

These 15 years are the years over which the Predicted Environmental Concentrations are simulated in the TOXSWA fate model and cover the period 1991 - 2005. Note the hydrological responses presented here are based upon 1) imposed discharge at the upper boundary of the ditch calculated from synthetic velocity time-series and 2) lateral discharges from drainage events calculated with SWAP/PEARL using real weather data. Although the hydrological responses presented here are largely based upon synthetic data (i.e. not referring to real weather years) we do refer to real weather years to demonstrate the linkage to the lateral discharges and PECs which are both calculated using real weather data.

The instantaneous hourly residence time of the selected stretch of the waterbody is calculated as follows:

$\tau_{j}=\sum_{i=1}^{i=n} \frac{V_{i}}{\left(Q_{i-1 / 2}+Q_{i+1 / 2}\right)}$

$\tau_{j}=\quad$ instantaneous residence time of the selected stretch of the waterbody calculated for hour $\mathrm{j}$ (d)

$\mathrm{Q}_{\mathrm{x}}=$ discharge at the boundary of the segment $\left(\mathrm{m}^{3} / \mathrm{d}\right)$

$V_{x}=\quad$ volume of the segment of the waterbody $\left(\mathrm{m}^{3}\right)$

$\mathrm{n}=$ number of segments in selected stretch of the watercourse

$\mathrm{i}=$ segment number $(-)$

$\mathrm{j}=$ hour number $(-)$

Monthly averaged instantaneous residence time based upon hourly values are calculated as follows:

$\tau_{\text {month }}=\frac{1}{m} \sum_{j=1}^{j=m} \tau_{j}$

where

$\mathrm{m}=$ number of hours in the month (-) 


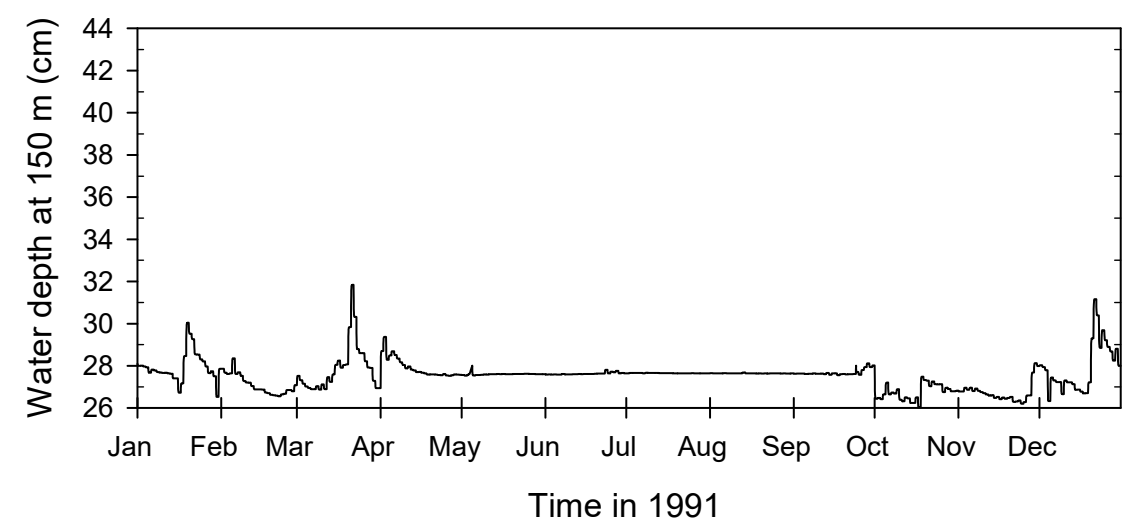

A

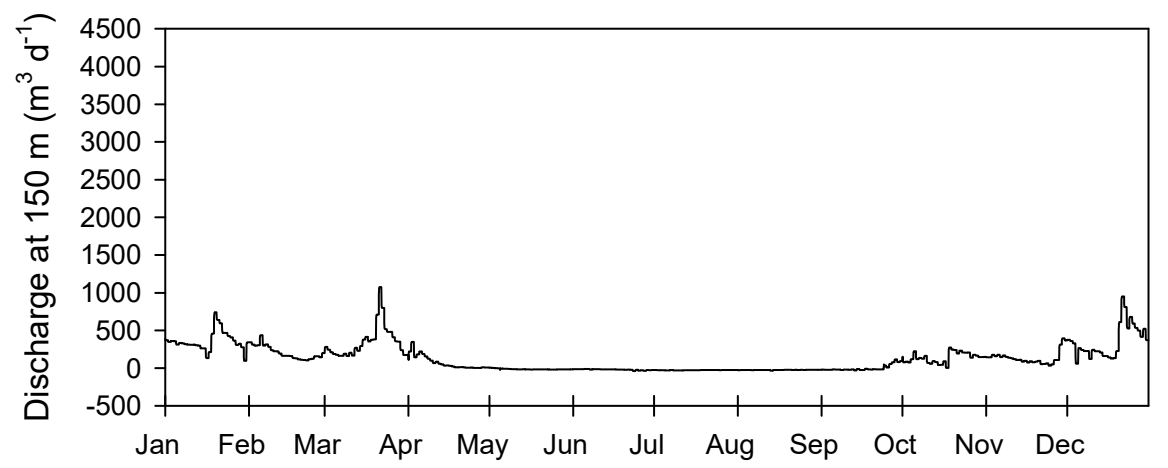

B

Time in 1991

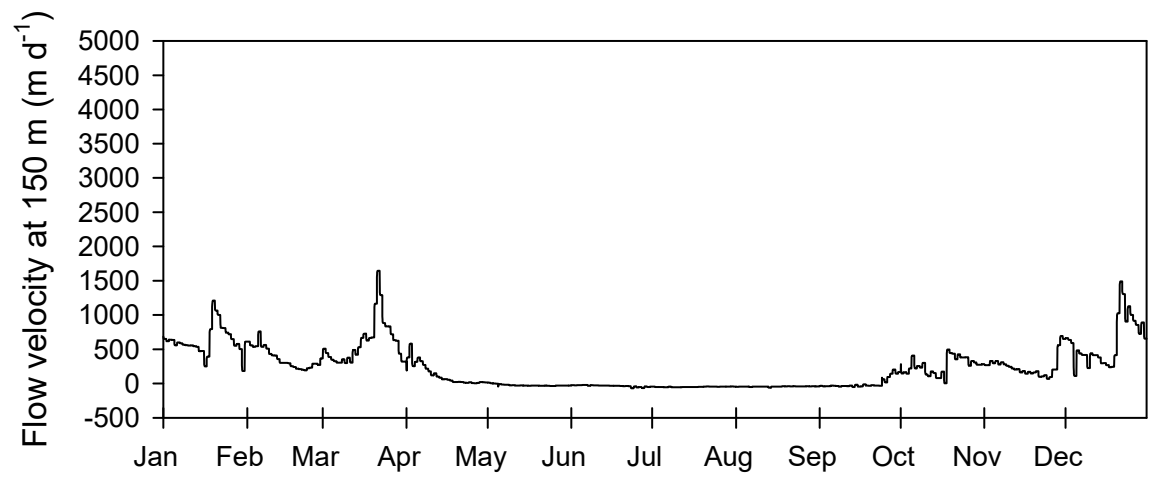

Time in 1991

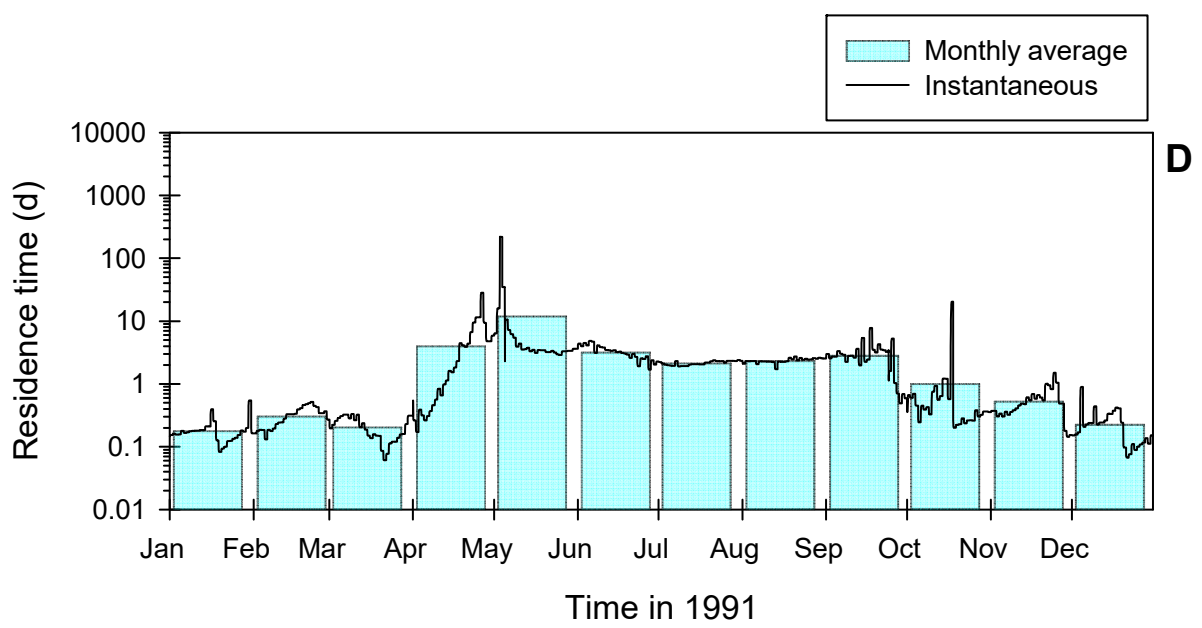

Figure A7.1 (A) Hourly water depth in the centre of the $100 \mathrm{~m}$ evaluation ditch $(x=150 \mathrm{~m})$ in year 1991. (B) Hourly discharge in the centre of the $100 \mathrm{~m}$ evaluation ditch $(x=150 \mathrm{~m})$ in year 1991. (C) Hourly flow velocity in the centre of the $100 \mathrm{~m}$ evaluation ditch $(x=150 \mathrm{~m})$ in year 1991. (D) Hourly instantaneous residence time of the $100 \mathrm{~m}$ evaluation ditch $(x=100-200 \mathrm{~m})$ in year 1991 (solid line) and monthly average residence time of the $100 \mathrm{~m}$ evaluation ditch $(x=100-200 \mathrm{~m})$ in year 1991 . 


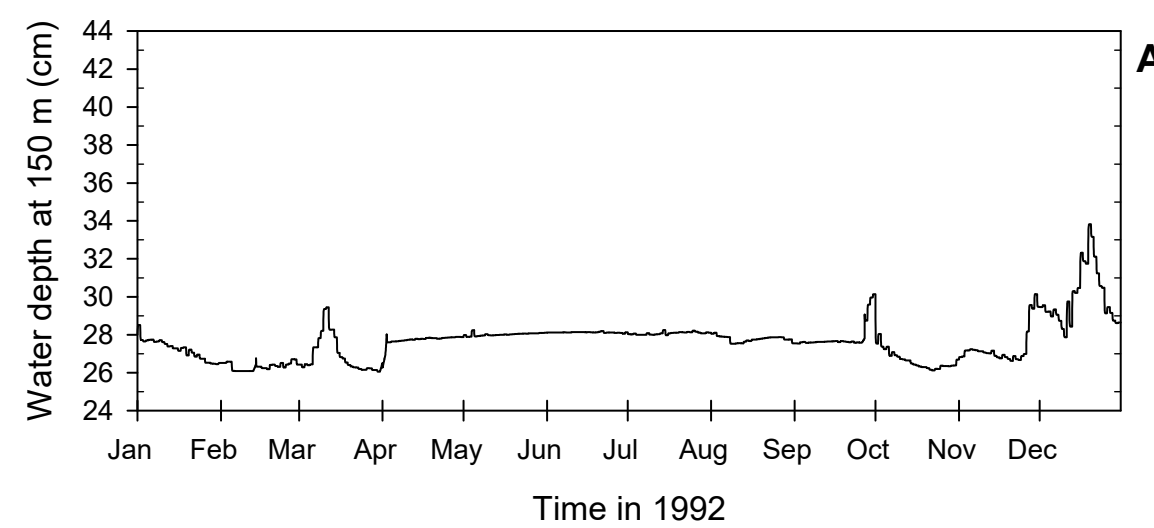

A
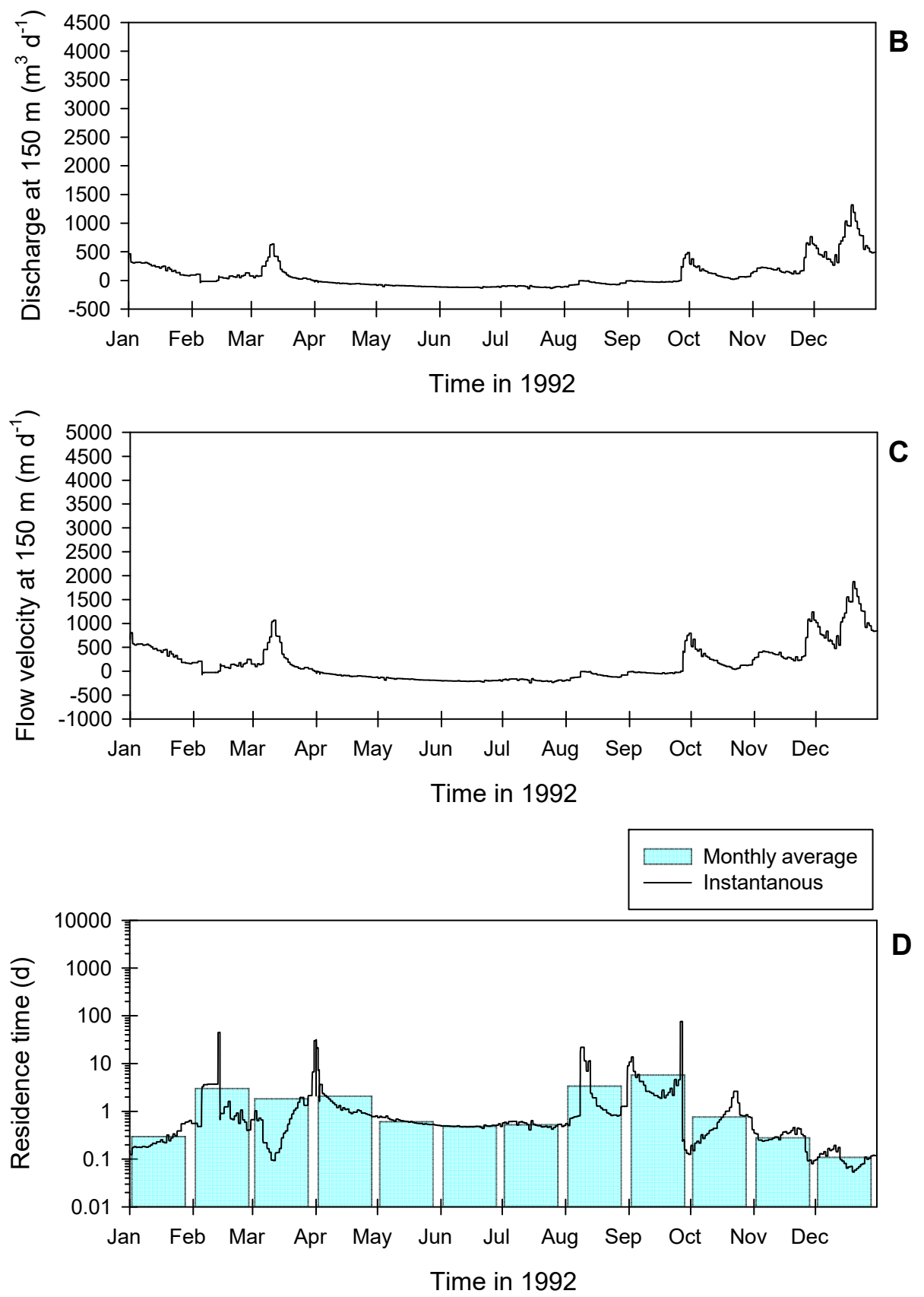

Figure A7.2 (A) Hourly water depth in the centre of the $100 \mathrm{~m}$ evaluation ditch $(x=150 \mathrm{~m})$ in year 1992. (B) Hourly discharge in the centre of the $100 \mathrm{~m}$ evaluation ditch $(x=150 \mathrm{~m})$ in year 1992. (C) Hourly flow velocity in the centre of the $100 \mathrm{~m}$ evaluation ditch $(x=150 \mathrm{~m})$ in year 19929. (D) Hourly instantaneous residence time of the $100 \mathrm{~m}$ evaluation ditch $(x=100-200 \mathrm{~m})$ in year 1992 (solid line) and monthly average residence time of the $100 \mathrm{~m}$ evaluation ditch ( $x=100-200 \mathrm{~m}$ ) in year 1992. 

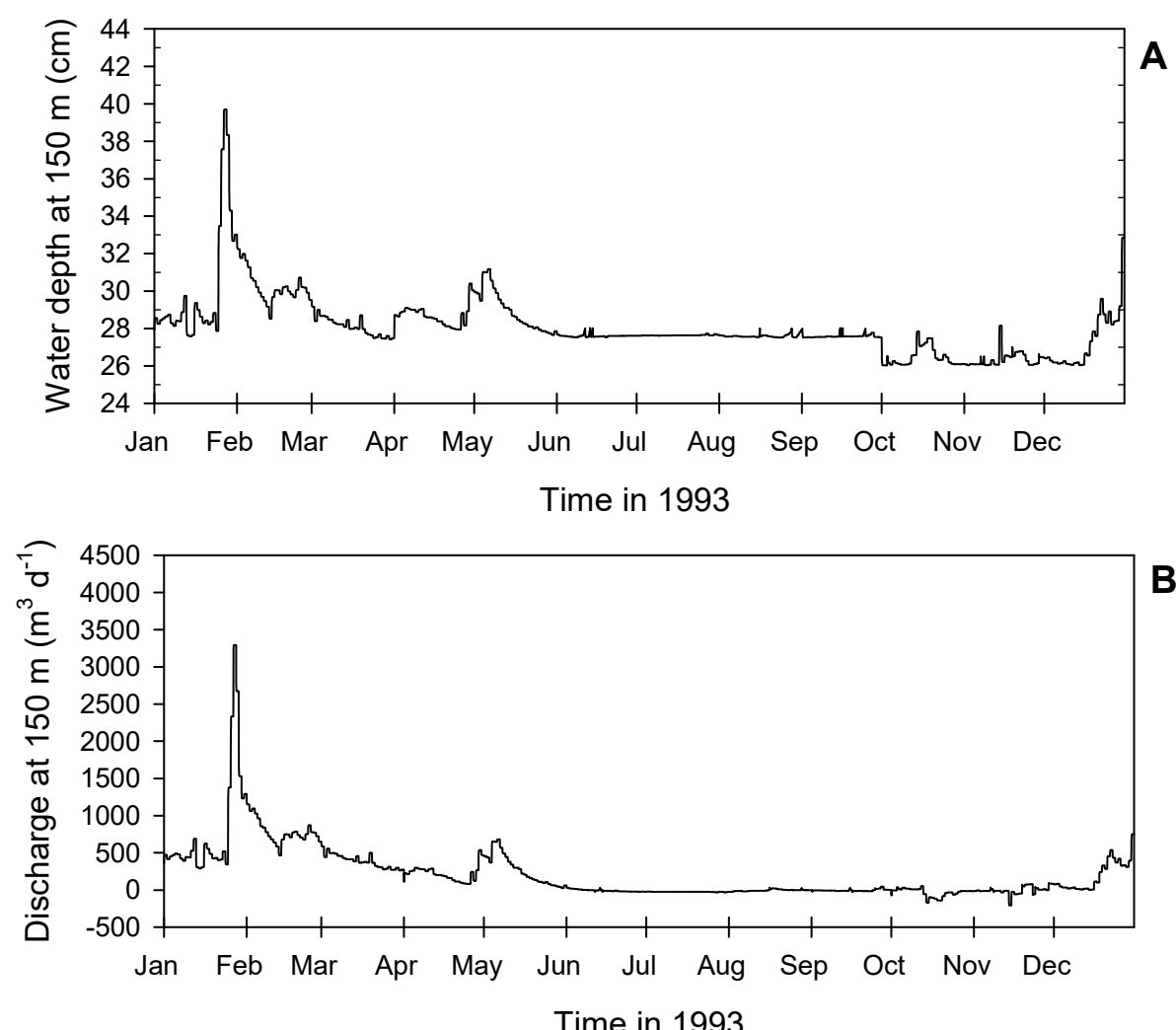

B

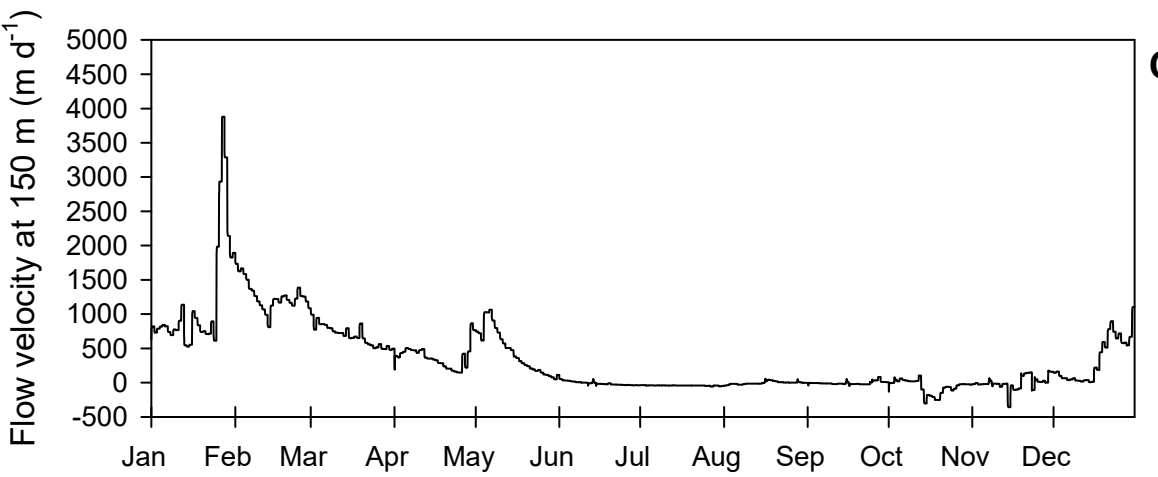

Time in 1993

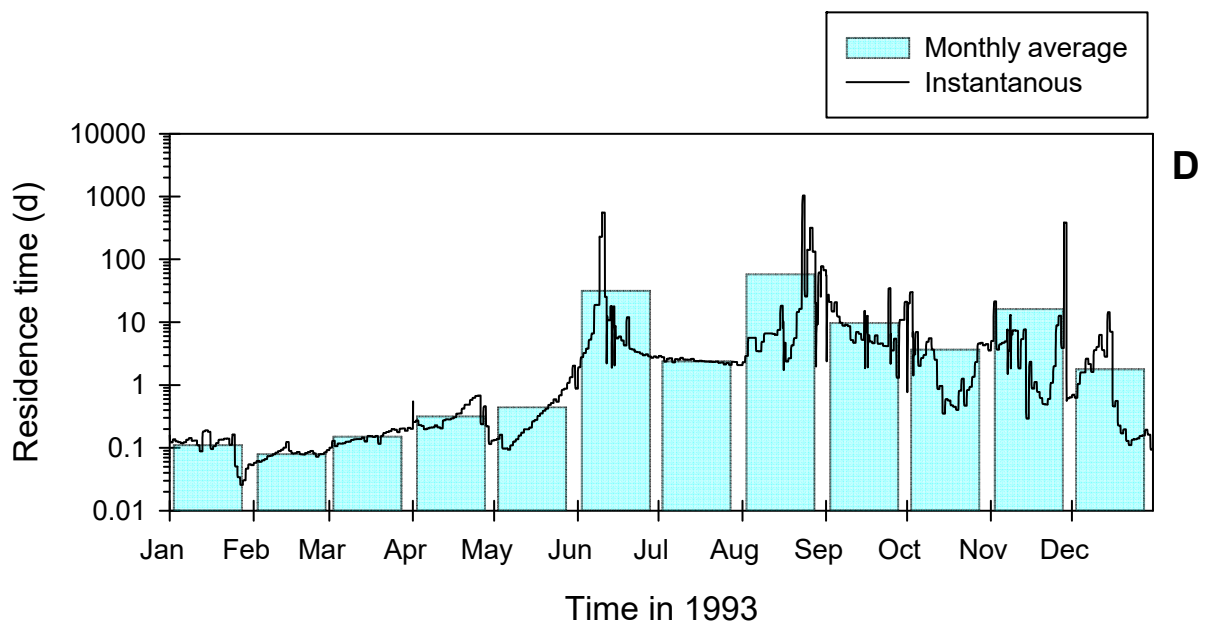

Figure A7.3 (A) Hourly water depth in the centre of the $100 \mathrm{~m}$ evaluation ditch $(x=150 \mathrm{~m})$ in year 1993. (B) Hourly discharge in the centre of the $100 \mathrm{~m}$ evaluation ditch $(x=150 \mathrm{~m})$ in year 1993. (C) Hourly flow velocity in the centre of the $100 \mathrm{~m}$ evaluation ditch $(x=150 \mathrm{~m})$ in year 1993. (D) Hourly instantaneous residence time of the $100 \mathrm{~m}$ evaluation ditch $(x=100-200 \mathrm{~m})$ in year 1993 (solid line) and monthly average residence time of the $100 \mathrm{~m}$ evaluation ditch ( $x=100-200 \mathrm{~m}$ ) in year 1993. 

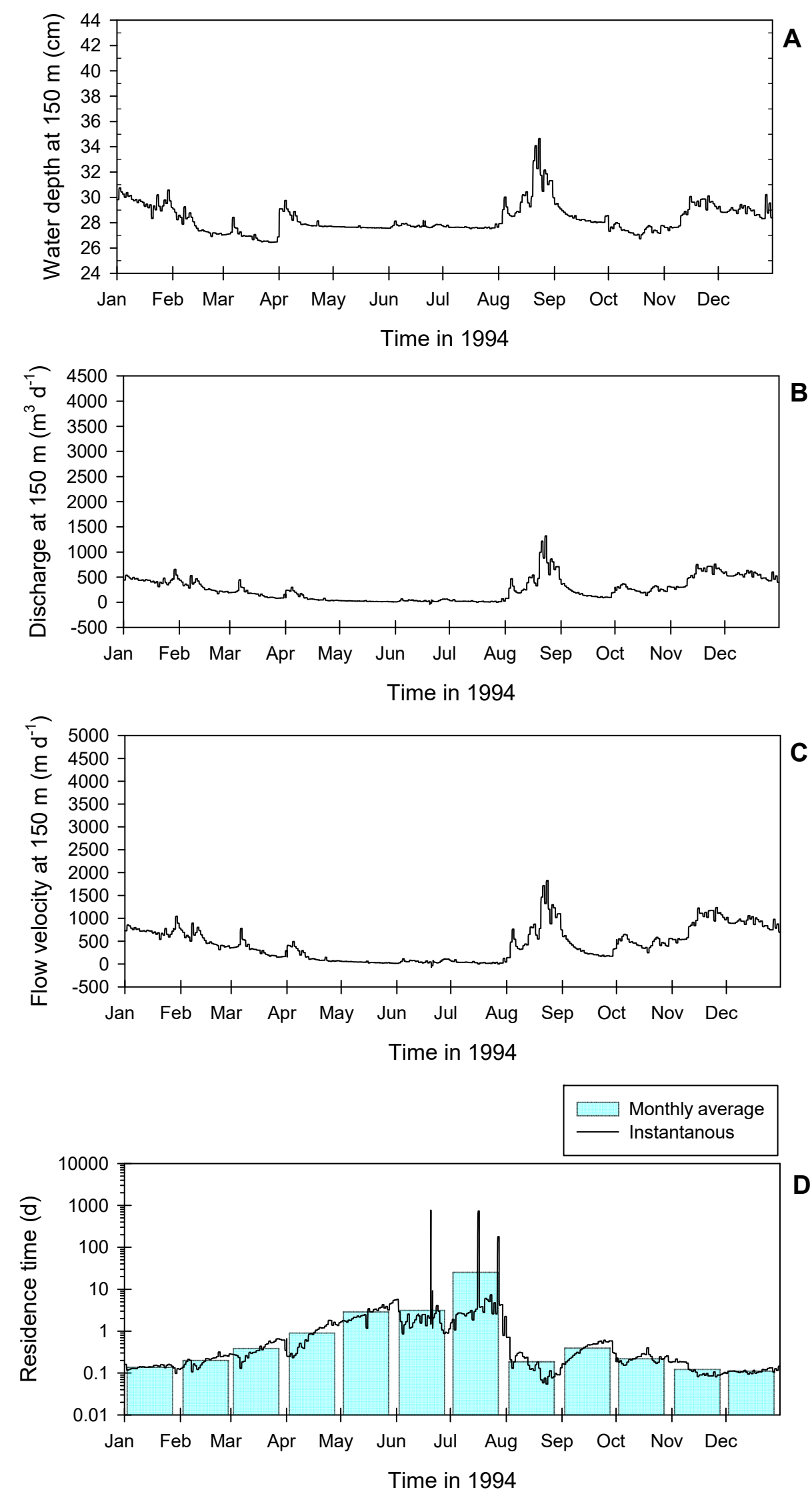

Figure A7.4 (A) Hourly water depth in the centre of the $100 \mathrm{~m}$ evaluation ditch $(x=150 \mathrm{~m})$ in year 1994. (B) Hourly discharge in the centre of the $100 \mathrm{~m}$ evaluation ditch $(x=150 \mathrm{~m})$ in year 1994. (C) Hourly flow velocity in the centre of the $100 \mathrm{~m}$ evaluation ditch $(x=150 \mathrm{~m})$ in year 1994. (D) Hourly instantaneous residence time of the $100 \mathrm{~m}$ evaluation ditch $(x=100-200 \mathrm{~m})$ in year 1994 (solid line) and monthly average residence time of the $100 \mathrm{~m}$ evaluation ditch ( $x=100-200 \mathrm{~m}$ ) in year 1994. 

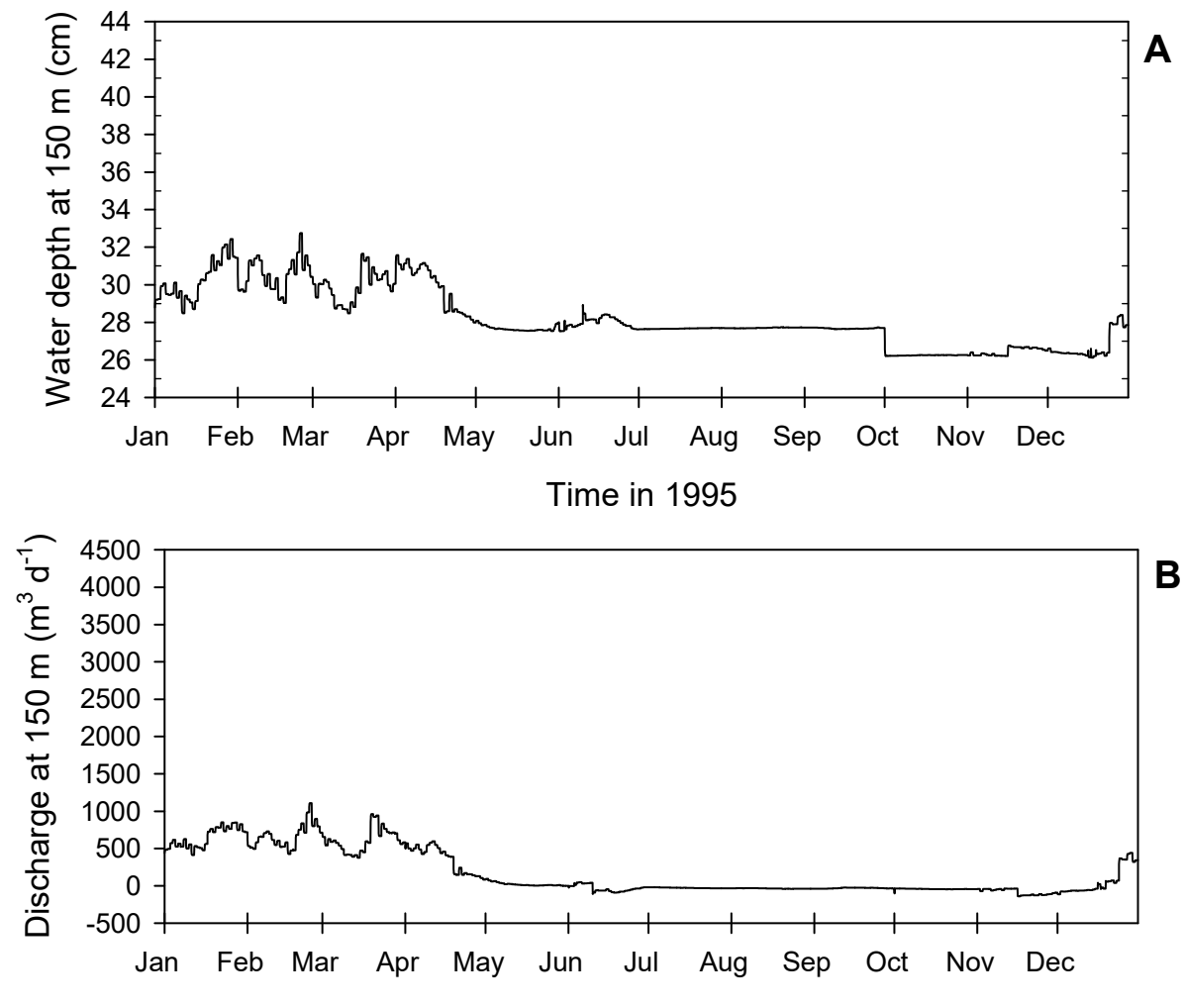

B

Time in 1995
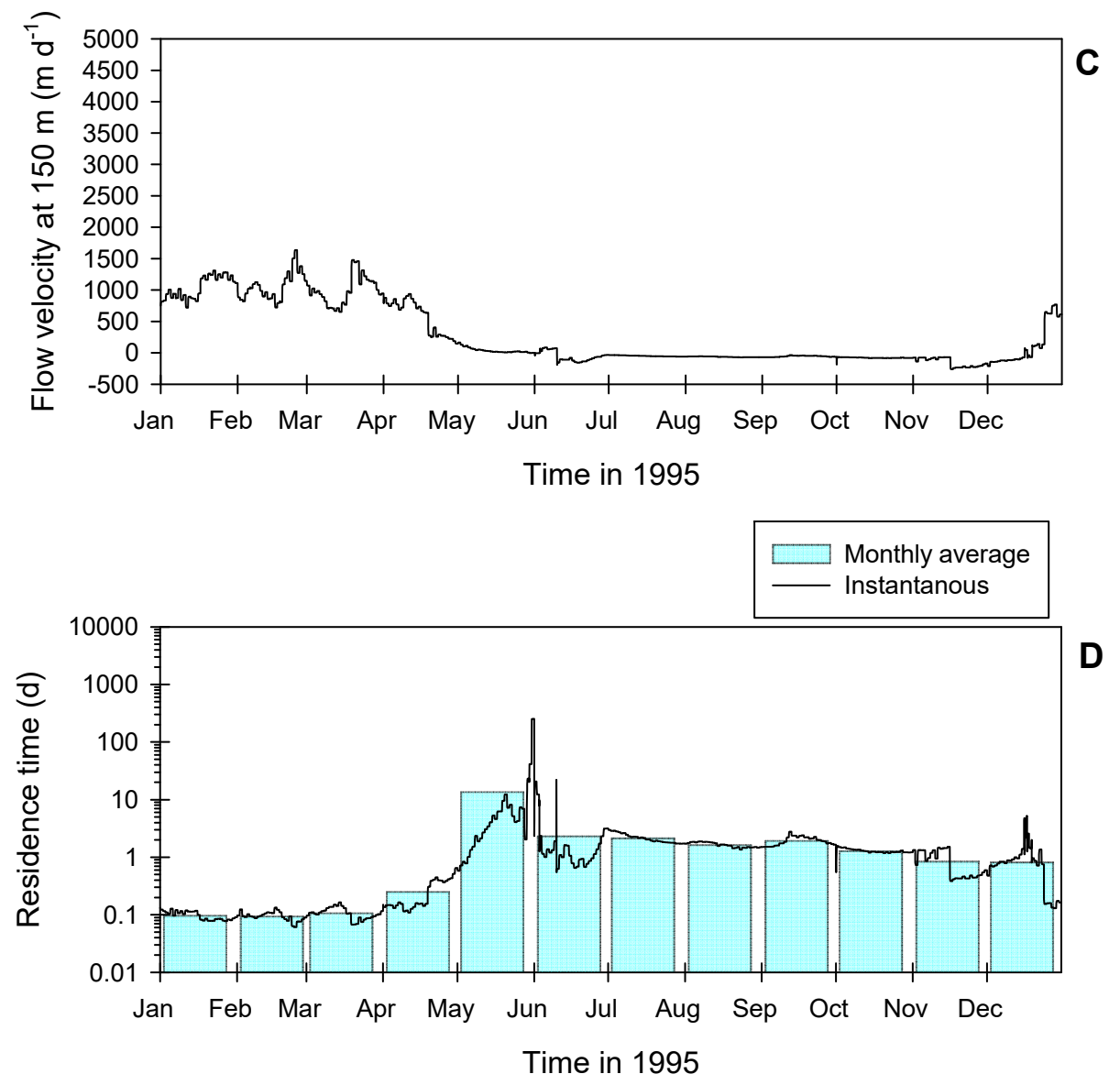

Figure A7.5 (A) Hourly water depth in the centre of the $100 \mathrm{~m}$ evaluation ditch $(x=150 \mathrm{~m})$ in year 1995. (B) Hourly discharge in the centre of the $100 \mathrm{~m}$ evaluation ditch $(x=150 \mathrm{~m})$ in year 1995 . (C) Hourly flow velocity in the centre of the $100 \mathrm{~m}$ evaluation ditch $(x=150 \mathrm{~m})$ in year 1995 . (D) Hourly instantaneous residence time of the $100 \mathrm{~m}$ evaluation ditch $(x=100-200 \mathrm{~m})$ in year 1995 (solid line) and monthly average residence time of the $100 \mathrm{~m}$ evaluation ditch ( $x=100-200 \mathrm{~m}$ ) in year 1995. 

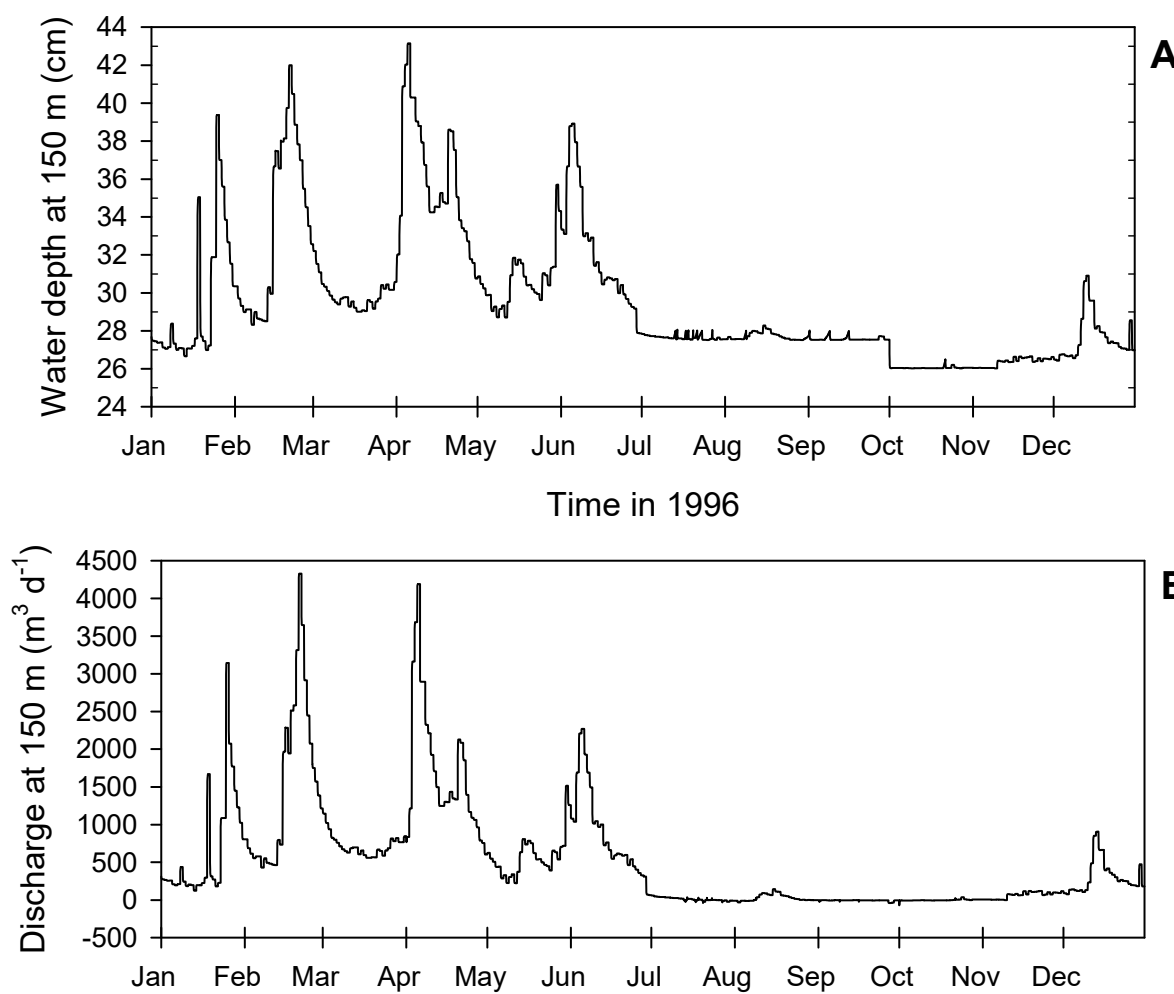

B

Time in year 1996
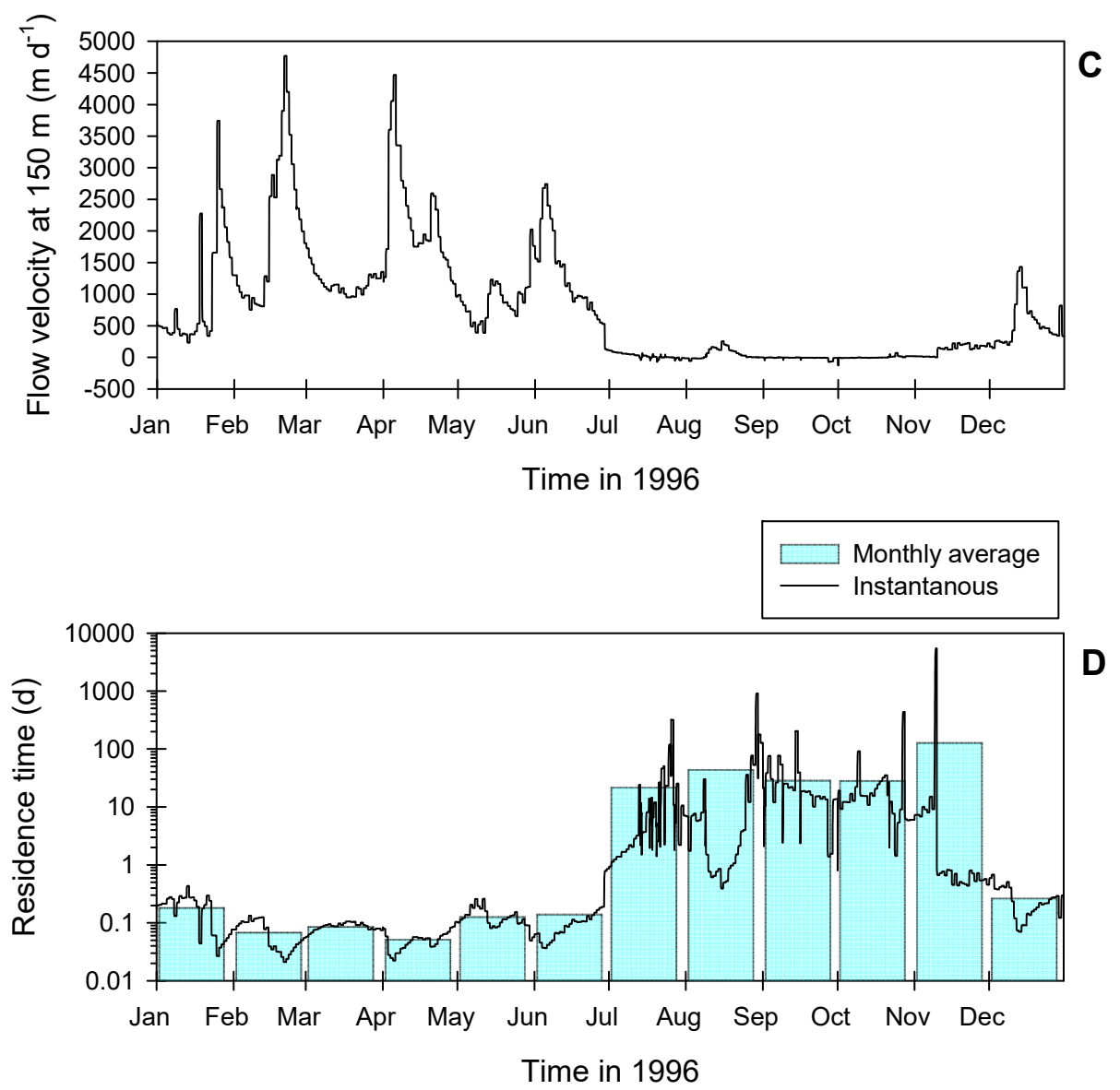

Figure A7.6 (A) Hourly water depth in the centre of the $100 \mathrm{~m}$ evaluation ditch $(x=150 \mathrm{~m})$ in year 1996. (B) Hourly discharge in the centre of the $100 \mathrm{~m}$ evaluation ditch $(x=150 \mathrm{~m})$ in year 1996. (C) Hourly flow velocity in the centre of the $100 \mathrm{~m}$ evaluation ditch $(x=150 \mathrm{~m})$ in year 1996 . (D) Hourly instantaneous residence time of the $100 \mathrm{~m}$ evaluation ditch $(x=100-200 \mathrm{~m})$ in year 1996 (solid line) and monthly average residence time of the $100 \mathrm{~m}$ evaluation ditch ( $x=100-200 \mathrm{~m}$ ) in year 1996. 

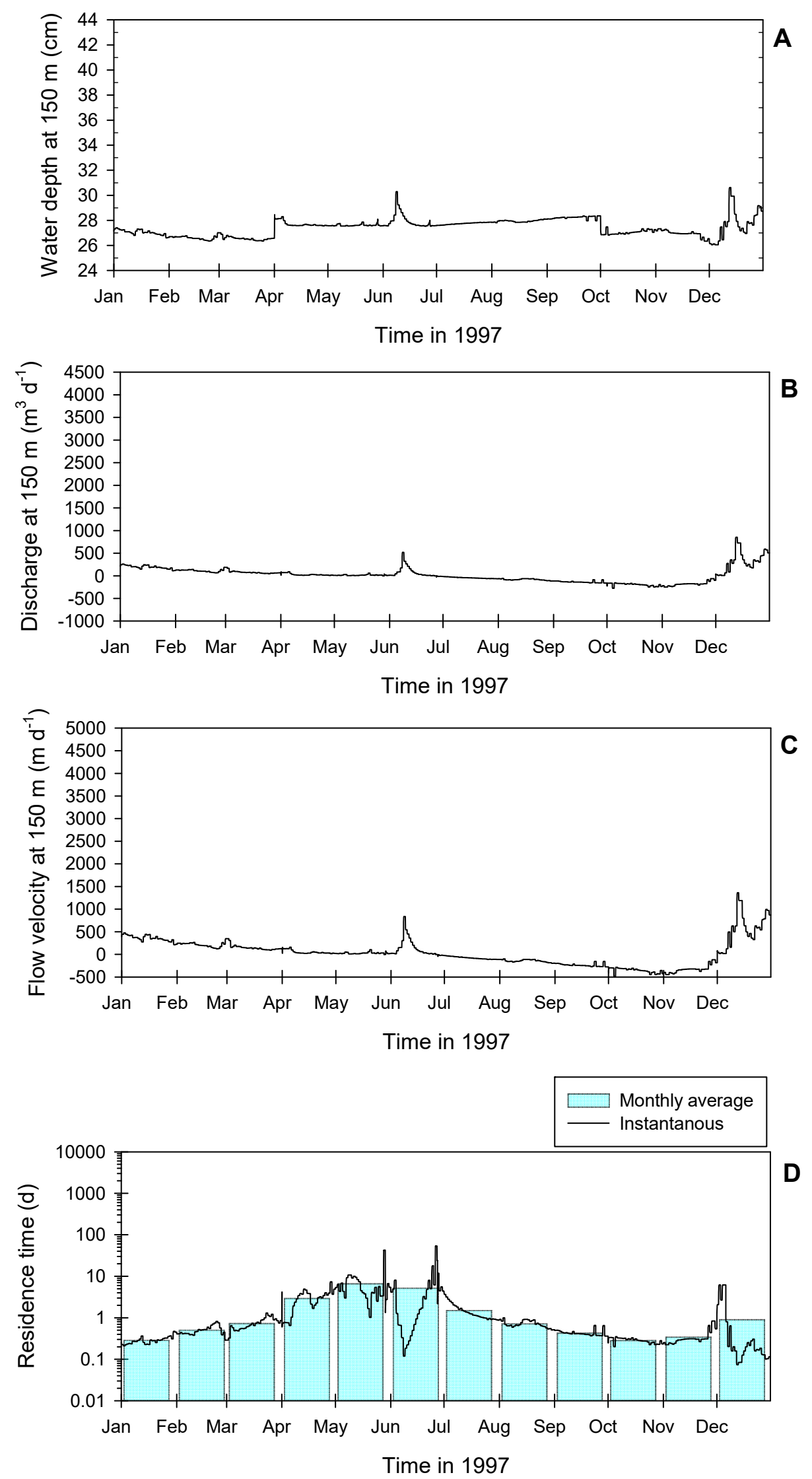

Figure A7.7 (A) Hourly water depth in the centre of the $100 \mathrm{~m}$ evaluation ditch $(x=150 \mathrm{~m})$ in year 1997. (B) Hourly discharge in the centre of the $100 \mathrm{~m}$ evaluation ditch $(x=150 \mathrm{~m})$ in year 1997. (C) Hourly flow velocity in the centre of the $100 \mathrm{~m}$ evaluation ditch $(x=150 \mathrm{~m})$ in year 1997. (D) Hourly instantaneous residence time of the $100 \mathrm{~m}$ evaluation ditch $(x=100-200 \mathrm{~m})$ in year 1997 (solid line) and monthly average residence time of the $100 \mathrm{~m}$ evaluation ditch ( $x=100-200 \mathrm{~m}$ ) in year 1997. 

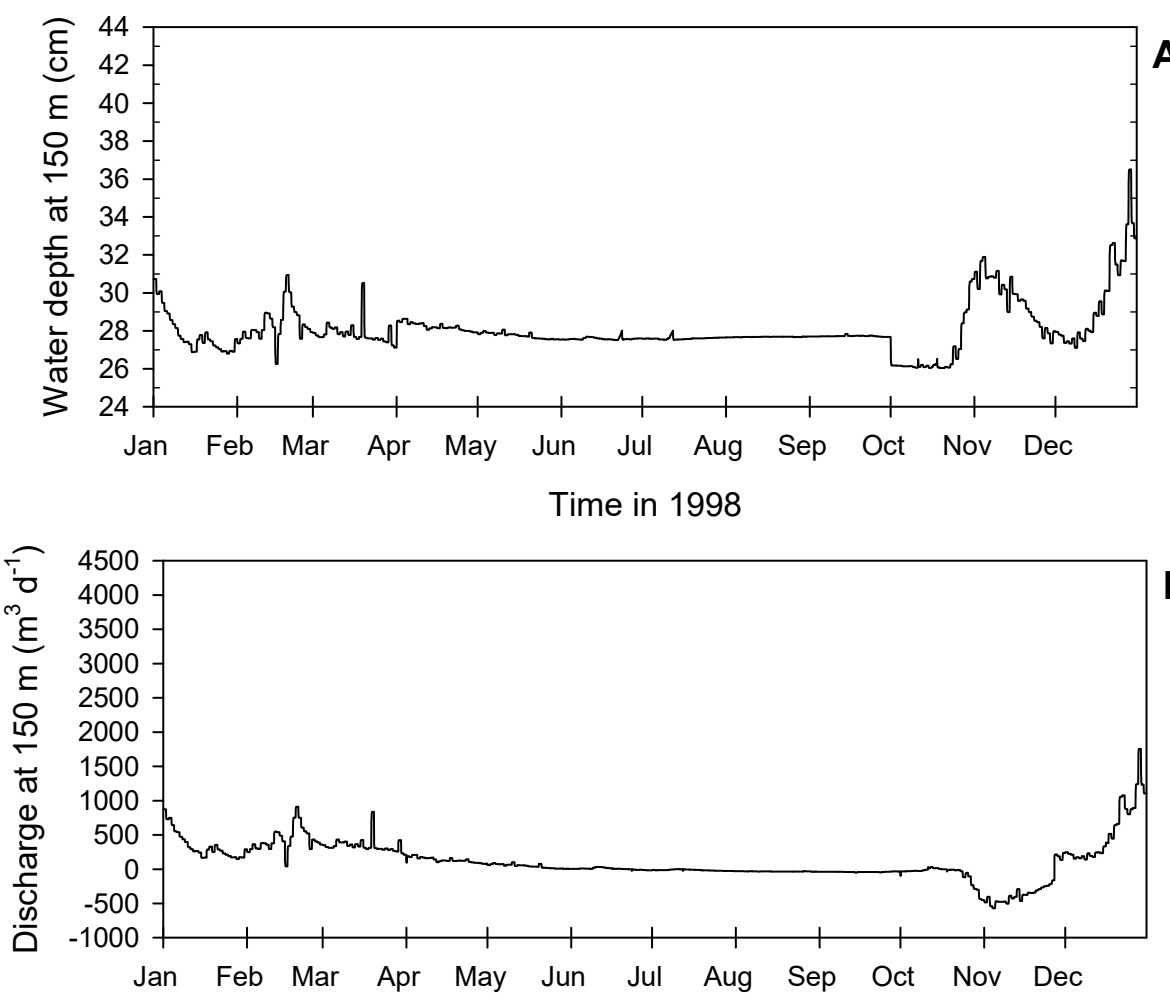

B

Time in 1998
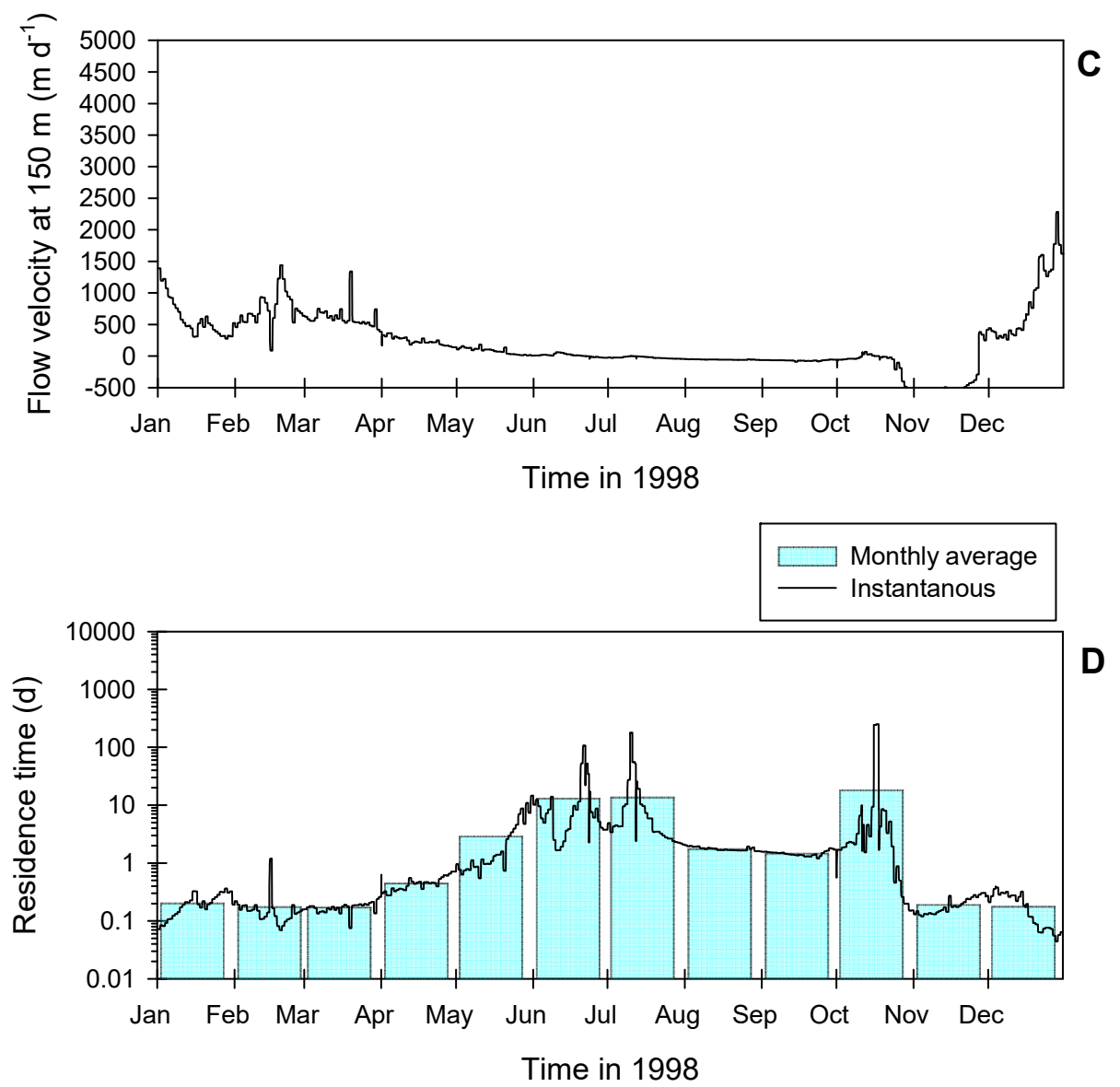

Figure A7.8 (A) Hourly water depth in the centre of the $100 \mathrm{~m}$ evaluation ditch $(x=150 \mathrm{~m})$ in year 1998. (B) Hourly discharge in the centre of the $100 \mathrm{~m}$ evaluation ditch $(x=150 \mathrm{~m})$ in year 1998. (C) Hourly flow velocity in the centre of the $100 \mathrm{~m}$ evaluation ditch $(x=150 \mathrm{~m})$ in year 1998 . (D) Hourly instantaneous residence time of the $100 \mathrm{~m}$ evaluation ditch $(x=100-200 \mathrm{~m})$ in year 1998 (solid line) and monthly average residence time of the $100 \mathrm{~m}$ evaluation ditch ( $x=100-200 \mathrm{~m}$ ) in year 1998. 

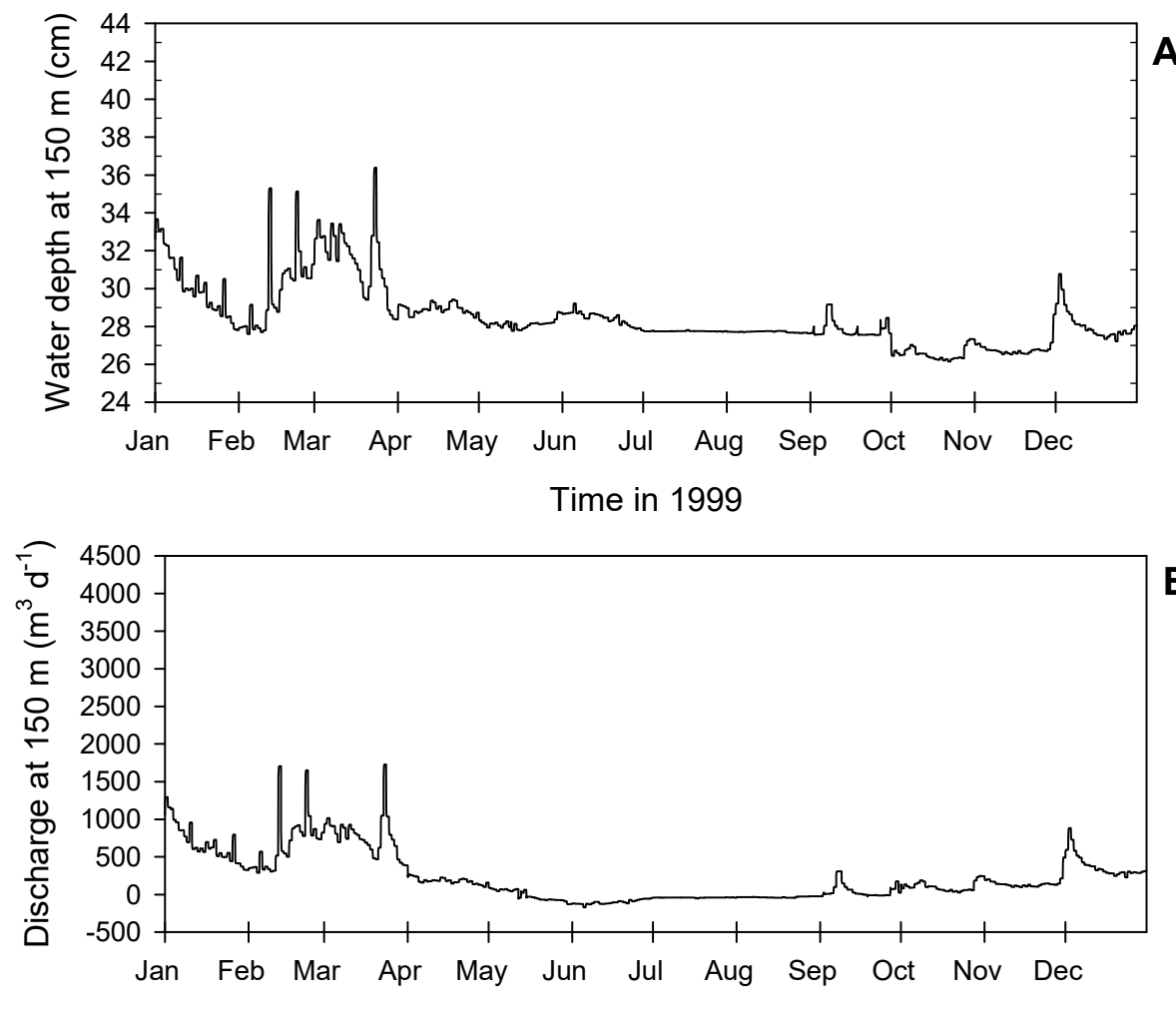

Time in 1999
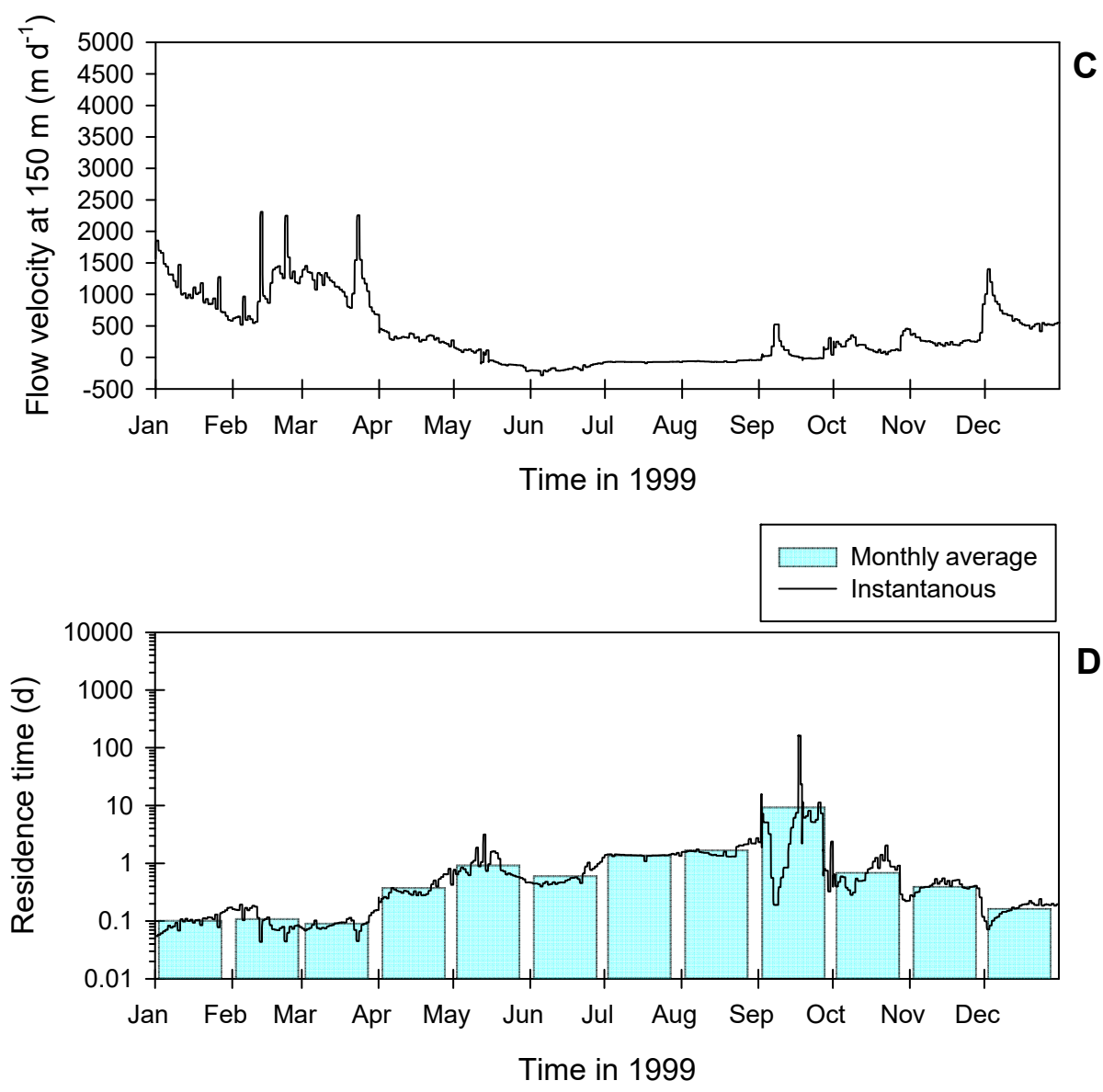

Figure A7.9 (A) Hourly water depth in the centre of the $100 \mathrm{~m}$ evaluation ditch $(x=150 \mathrm{~m})$ in year 1999. (B) Hourly discharge in the centre of the $100 \mathrm{~m}$ evaluation ditch $(x=150 \mathrm{~m})$ in year 1999 . (C) Hourly flow velocity in the centre of the $100 \mathrm{~m}$ evaluation ditch $(x=150 \mathrm{~m})$ in year 1999. (D) Hourly instantaneous residence time of the $100 \mathrm{~m}$ evaluation ditch $(x=100-200 \mathrm{~m})$ in year 1999 (solid line) and monthly average residence time of the $100 \mathrm{~m}$ evaluation ditch ( $x=100-200 \mathrm{~m}$ ) in year 1999. 

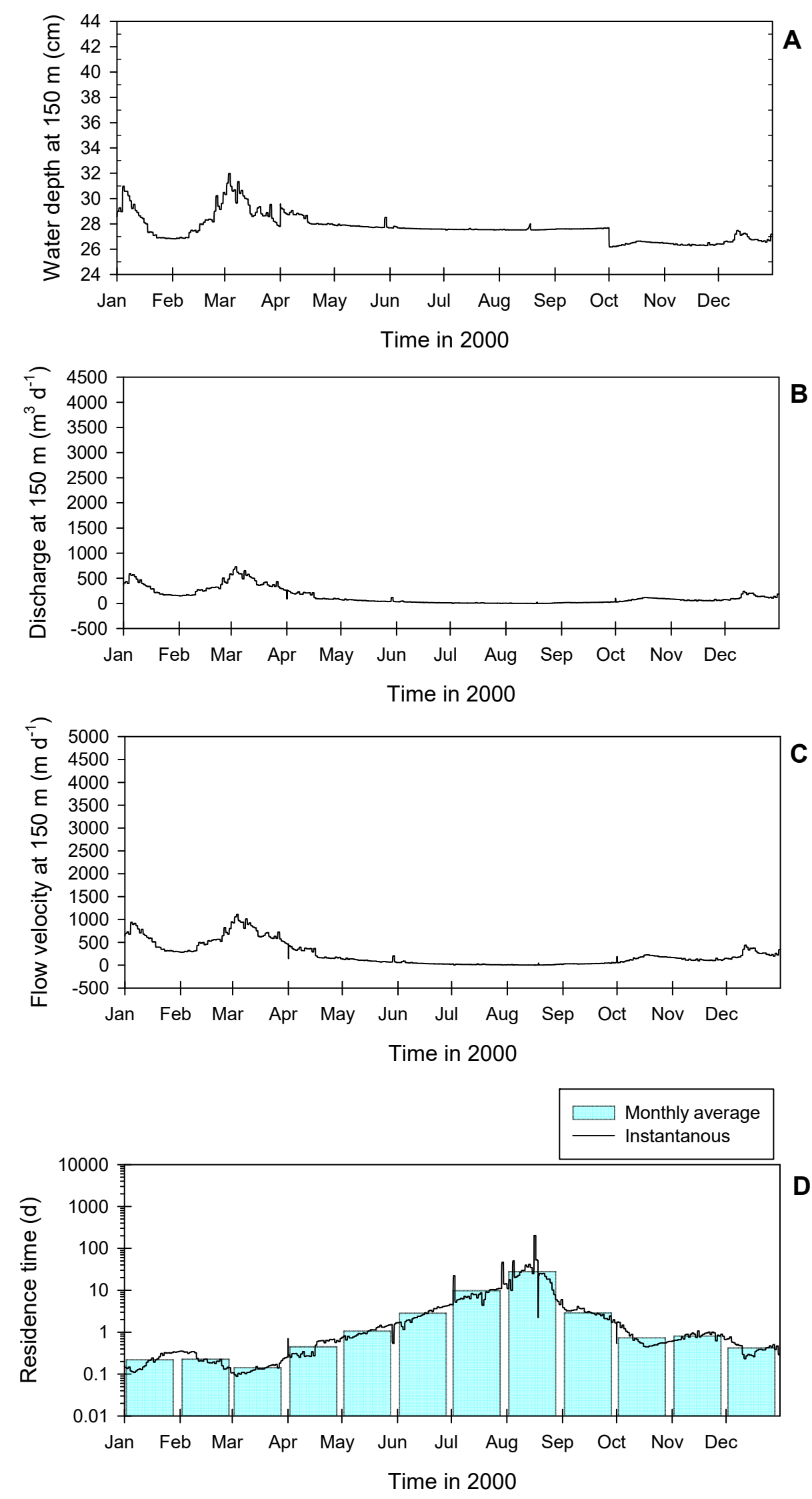

Figure A7.10 (A) Hourly water depth in the centre of the $100 \mathrm{~m}$ evaluation ditch $(x=150 \mathrm{~m})$ in year 2000. (B) Hourly discharge in the centre of the $100 \mathrm{~m}$ evaluation ditch $(x=150 \mathrm{~m}$ ) in year 2000. (C) Hourly flow velocity in the centre of the $100 \mathrm{~m}$ evaluation ditch $(x=150 \mathrm{~m})$ in year 2000. (D) Hourly instantaneous residence time of the $100 \mathrm{~m}$ evaluation ditch $(x=100-200 \mathrm{~m})$ in year 2000 (solid line) and monthly average residence time of the $100 \mathrm{~m}$ evaluation ditch ( $x=100-200 \mathrm{~m}$ ) in year 2000. 


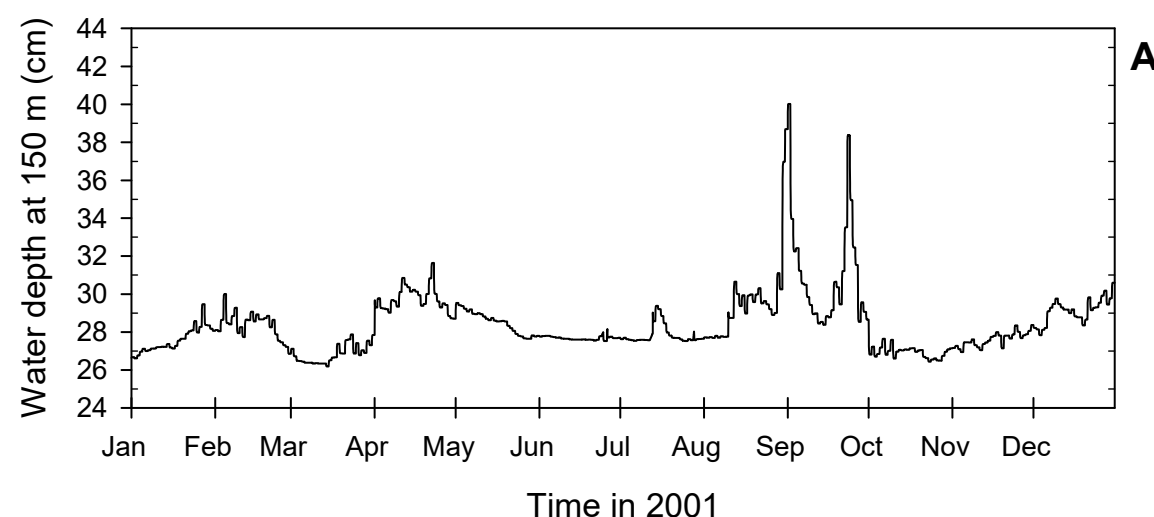

A

Time in 2001

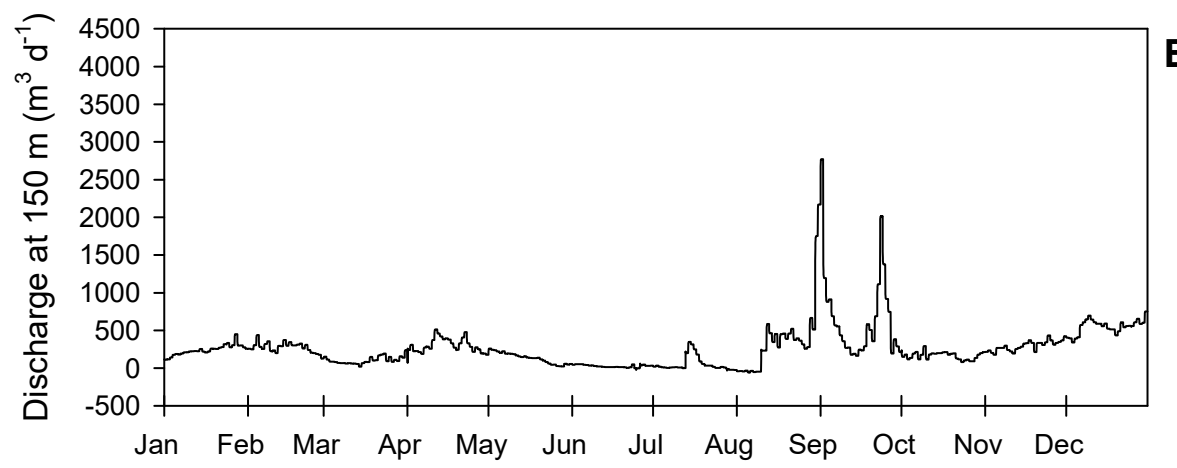

Time in 2001

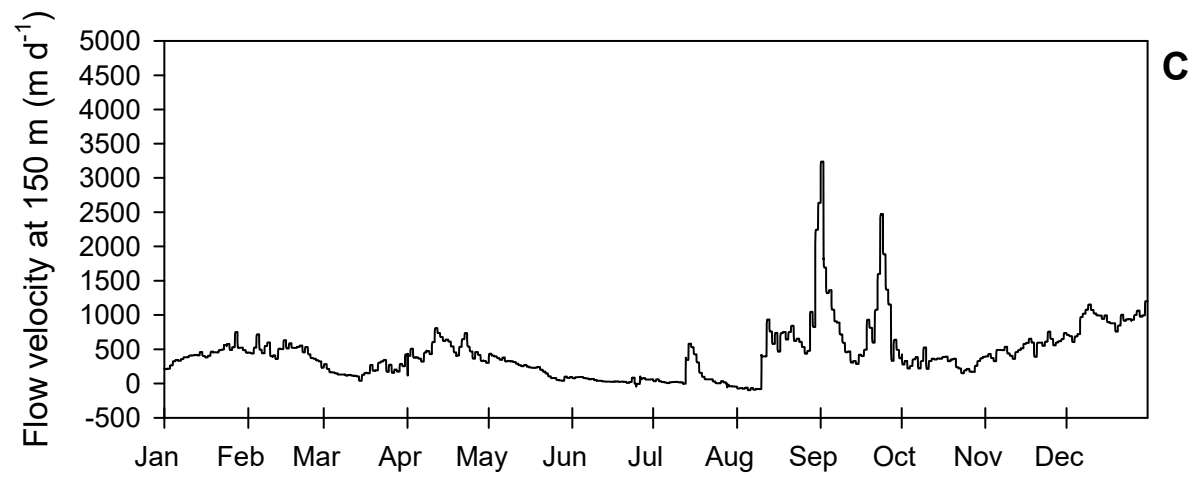

Time in 2001

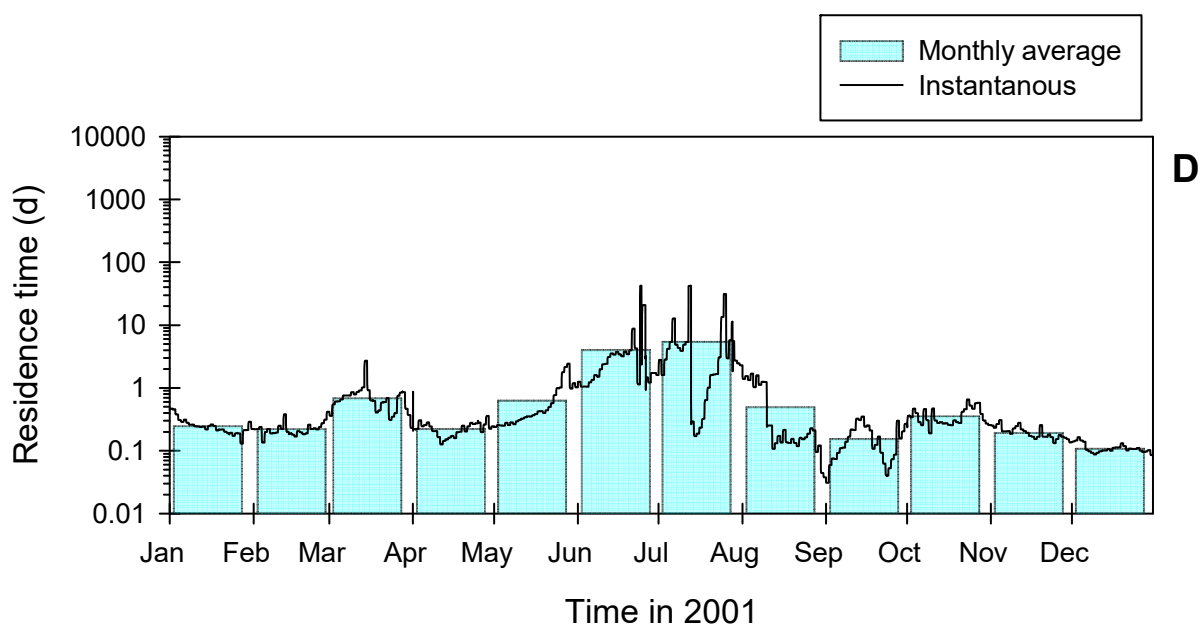

Figure A7.11 (A) Hourly water depth in the centre of the $100 \mathrm{~m}$ evaluation ditch $(x=150 \mathrm{~m})$ in year 2001. (B) Hourly discharge in the centre of the $100 \mathrm{~m}$ evaluation ditch $(x=150 \mathrm{~m})$ in year 2001. (C) Hourly flow velocity in the centre of the $100 \mathrm{~m}$ evaluation ditch $(x=150 \mathrm{~m})$ in year 2001. (D) Hourly instantaneous residence time of the $100 \mathrm{~m}$ evaluation ditch $(x=100-200 \mathrm{~m})$ in year 2001 (solid line) and monthly average residence time of the $100 \mathrm{~m}$ evaluation ditch $(x=100-200 \mathrm{~m})$ in year 2001. 


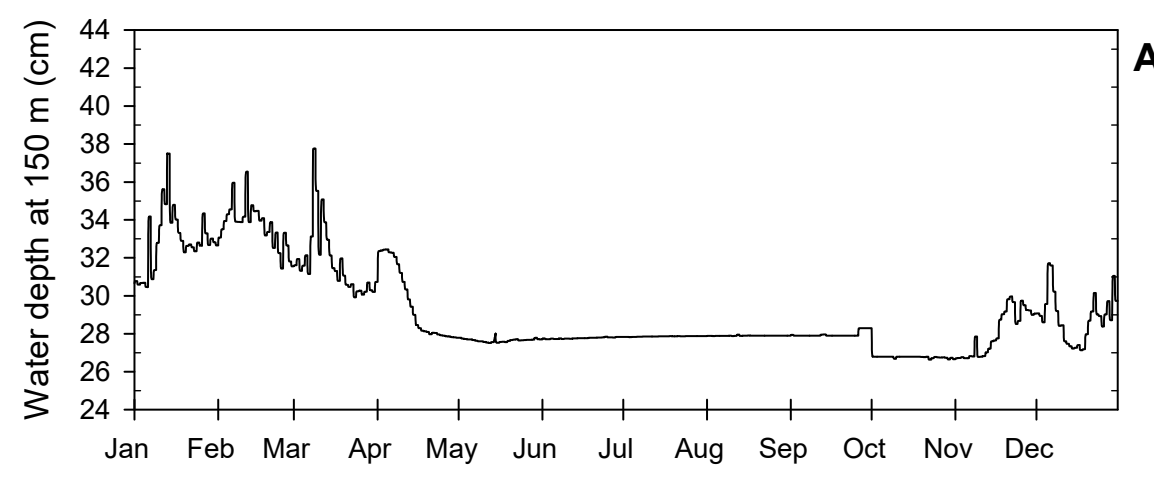

Time in 2002
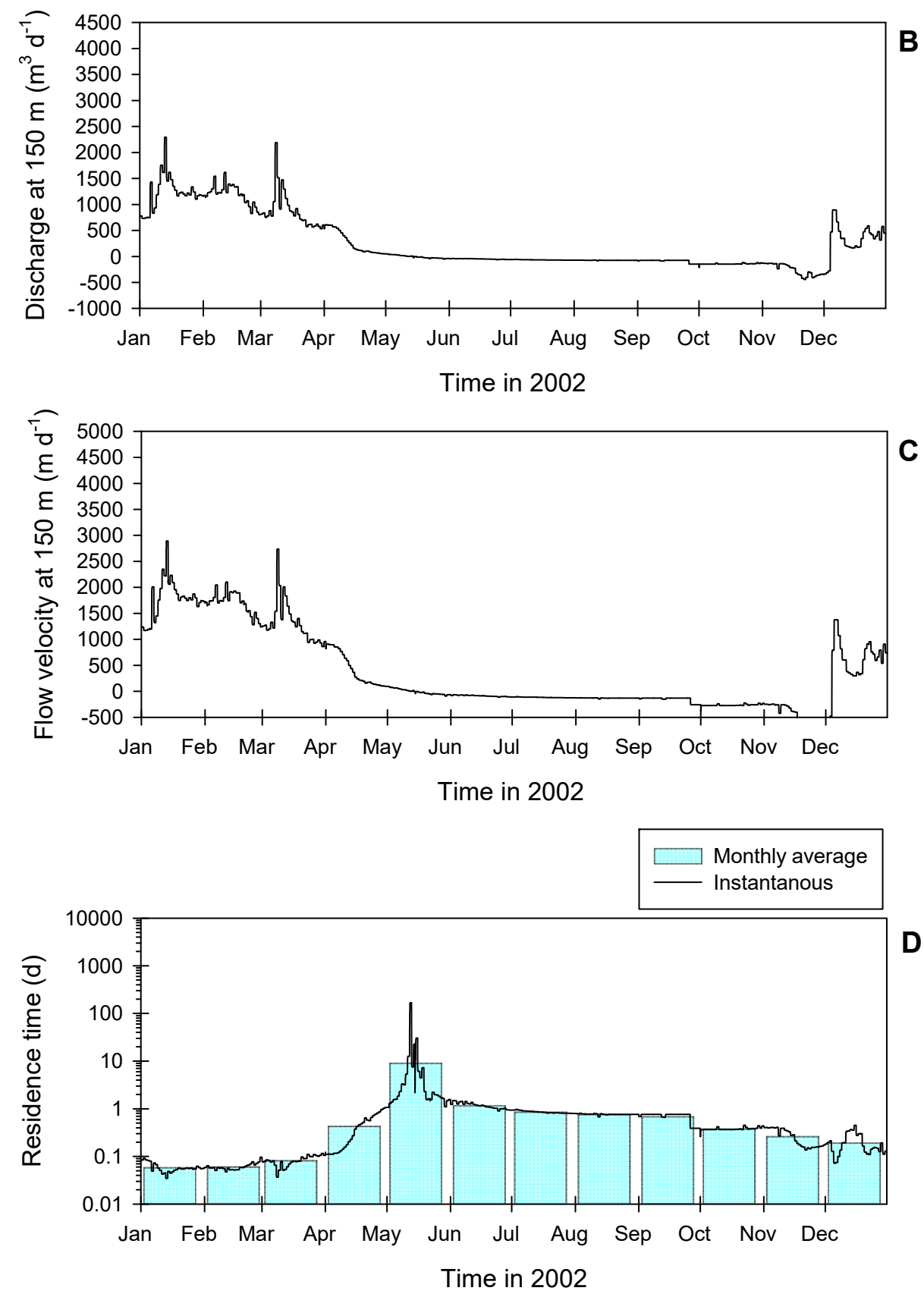

Figure A7.12 (A) Hourly water depth in the centre of the $100 \mathrm{~m}$ evaluation ditch $(x=150 \mathrm{~m})$ in year 2002. (B) Hourly discharge in the centre of the $100 \mathrm{~m}$ evaluation ditch $(x=150 \mathrm{~m})$ in year 2002. (C) Hourly flow velocity in the centre of the $100 \mathrm{~m}$ evaluation ditch $(x=150 \mathrm{~m})$ in year 2002. (D) Hourly instantaneous residence time of the $100 \mathrm{~m}$ evaluation ditch $(x=100-200 \mathrm{~m})$ in year 2002 (solid line) and monthly average residence time of the $100 \mathrm{~m}$ evaluation ditch $(x=100-200 \mathrm{~m})$ in year 2002 . 


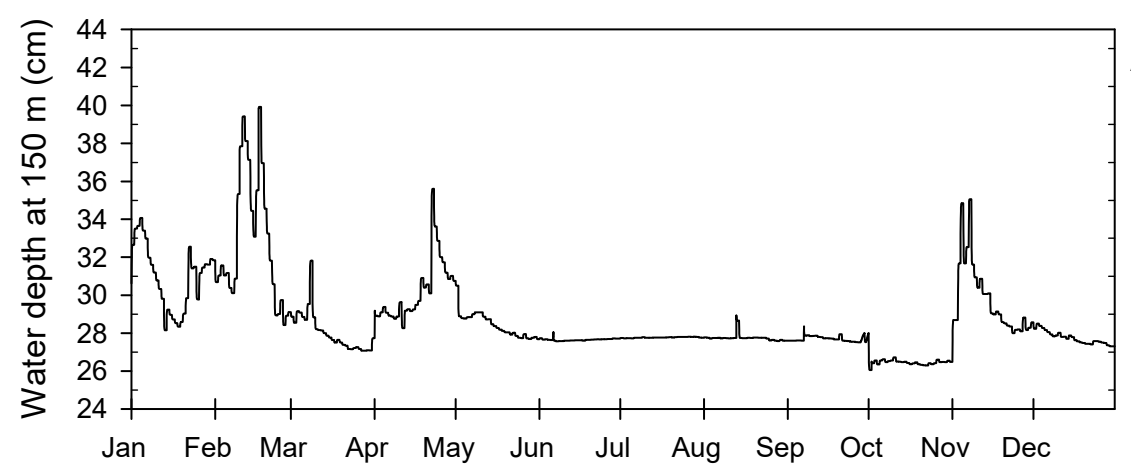

A

Time in 2003

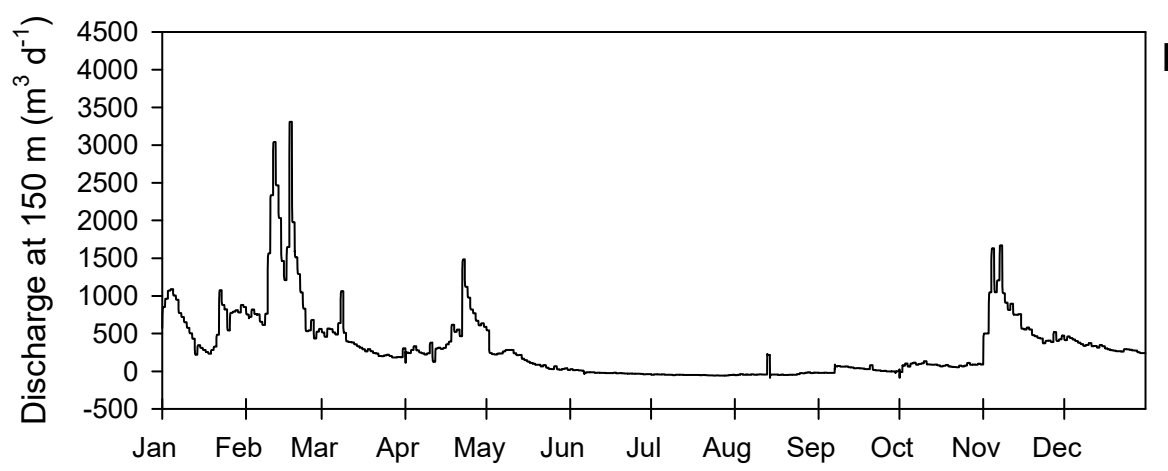

B

Time in 2003

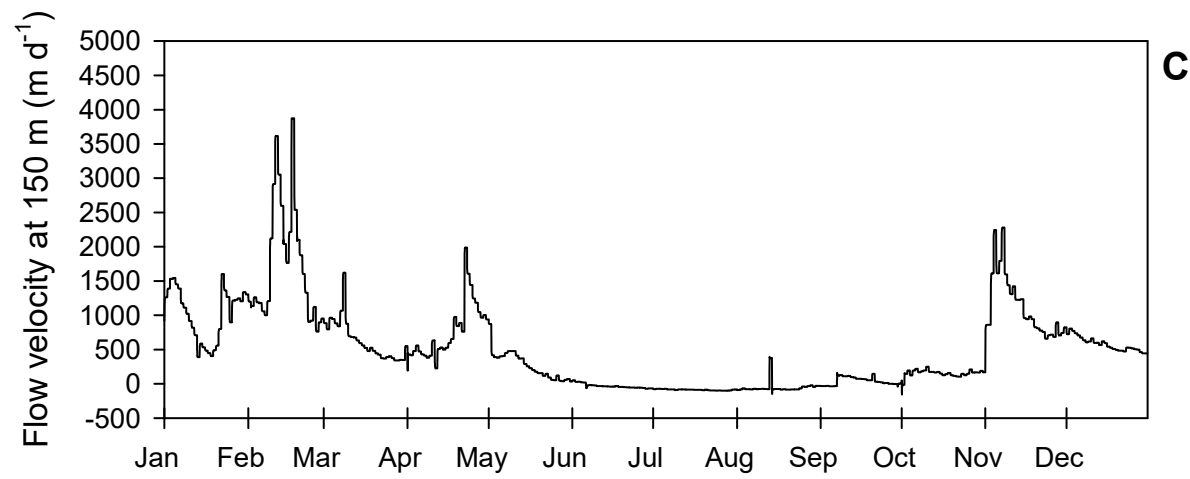

Time in 2003

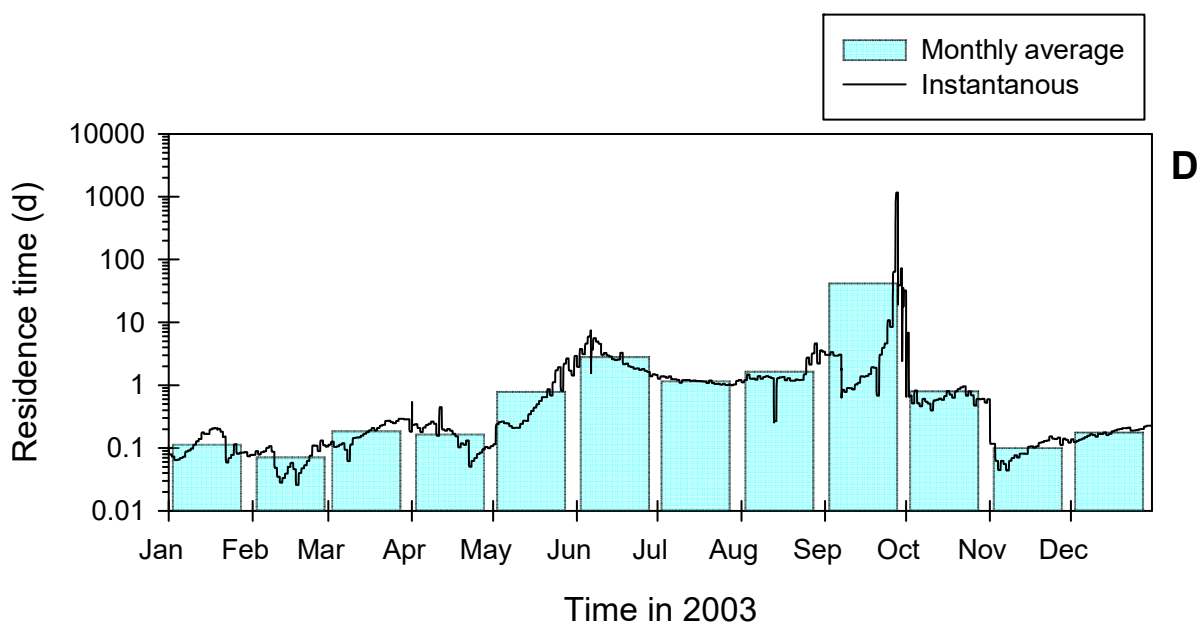

Figure A7.13 (A) Hourly water depth in the centre of the $100 \mathrm{~m}$ evaluation ditch $(x=150 \mathrm{~m})$ in year 2003. (B) Hourly discharge in the centre of the $100 \mathrm{~m}$ evaluation ditch $(x=150 \mathrm{~m})$ in year 2030. (C) Hourly flow velocity in the centre of the $100 \mathrm{~m}$ evaluation ditch $(x=150 \mathrm{~m})$ in year 2003. (D) Hourly instantaneous residence time of the $100 \mathrm{~m}$ evaluation ditch $(x=100-200 \mathrm{~m})$ in year 2003 (solid line) and monthly average residence time of the $100 \mathrm{~m}$ evaluation ditch $(x=100-200 \mathrm{~m})$ in year 2003. 


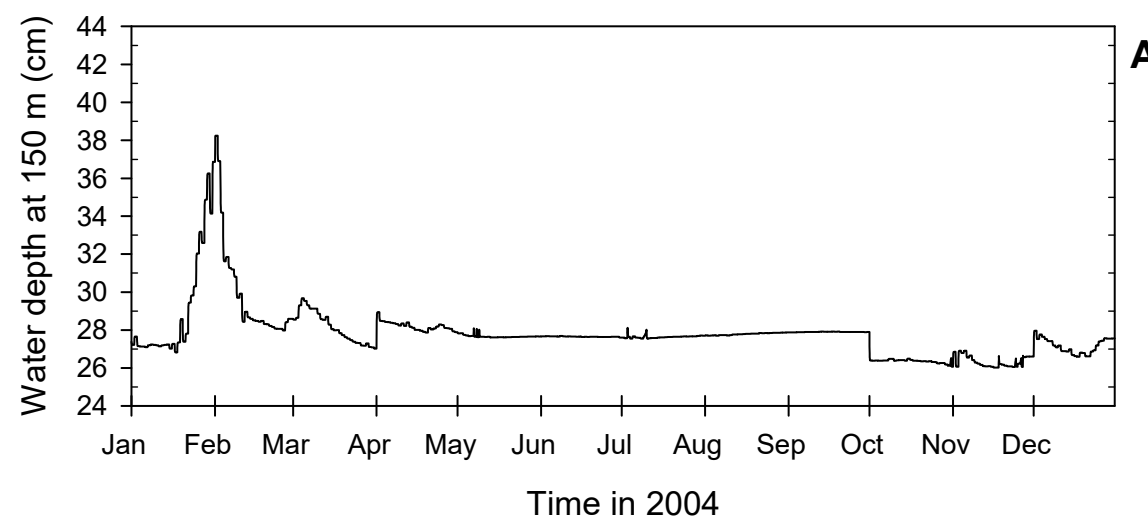

A

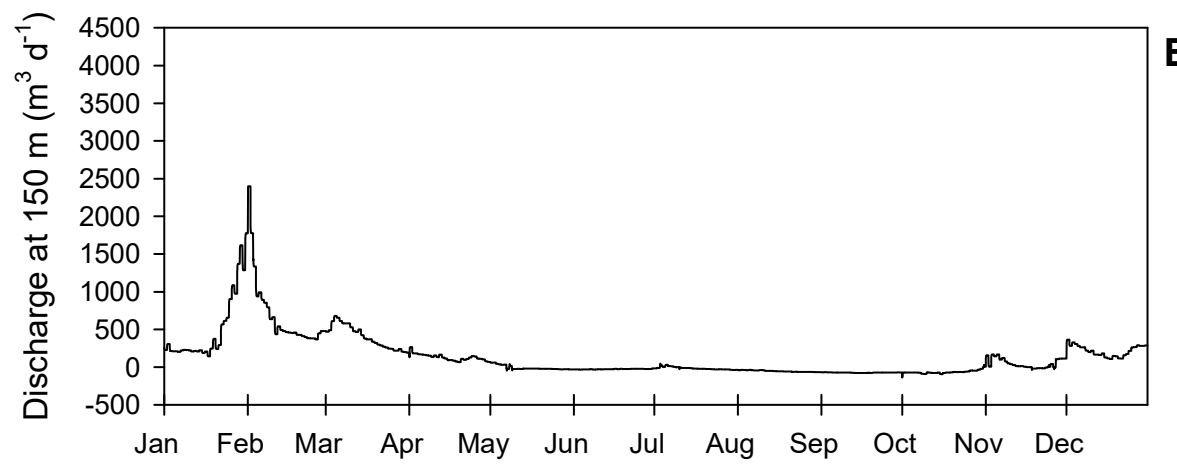

B

Time in 2004

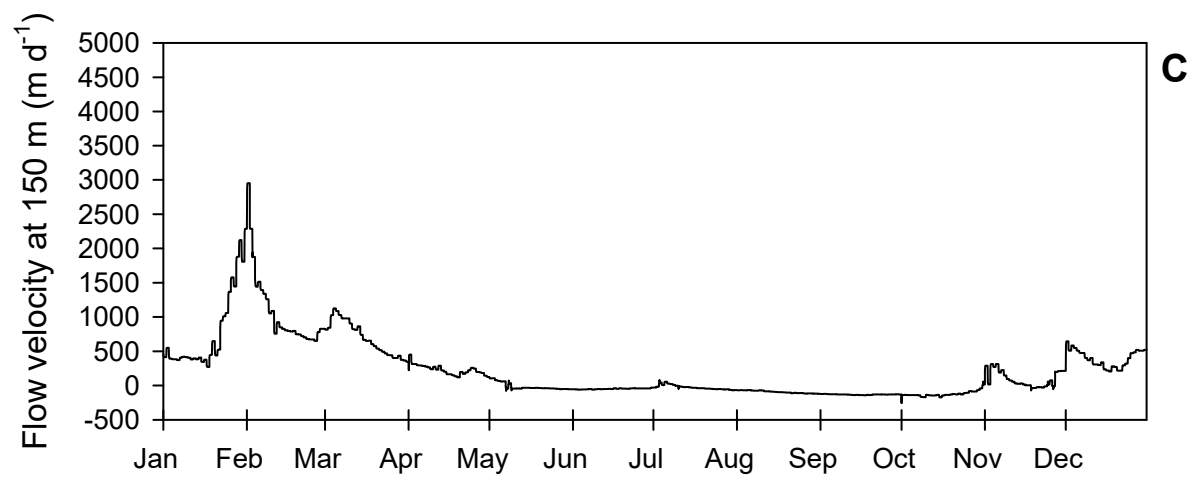

Time in 2004

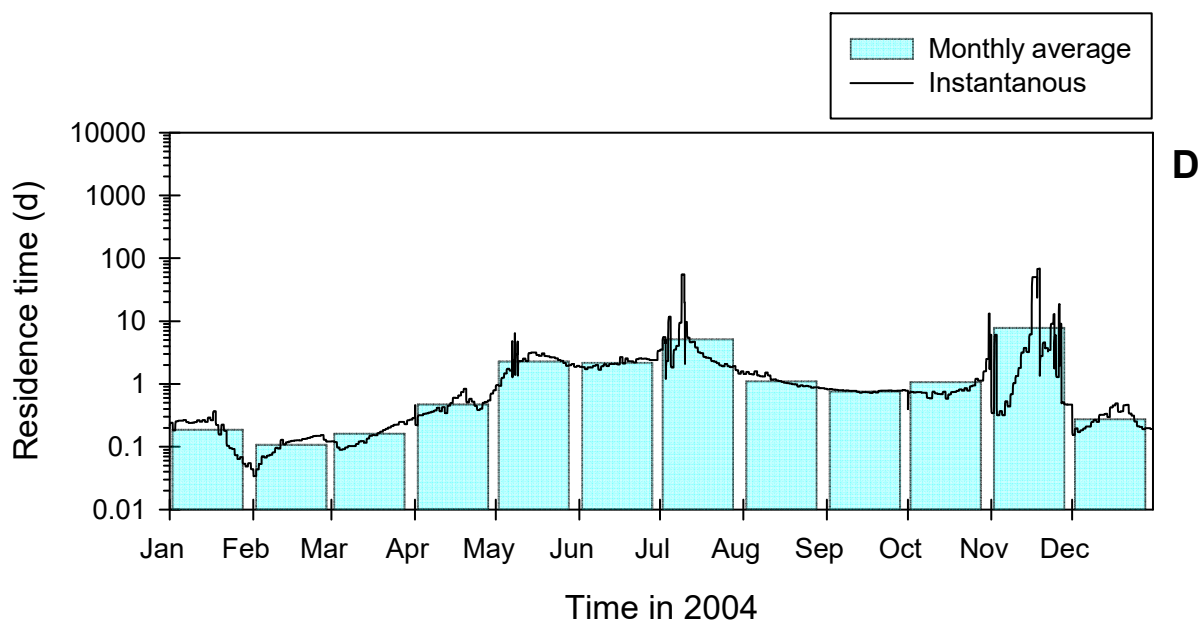

Figure A7.14 (A) Hourly water depth in the centre of the $100 \mathrm{~m}$ evaluation ditch $(x=150 \mathrm{~m})$ in year 2004. (B) Hourly discharge in the centre of the $100 \mathrm{~m}$ evaluation ditch $(x=150 \mathrm{~m})$ in year 2004. (C) Hourly flow velocity in the centre of the $100 \mathrm{~m}$ evaluation ditch $(x=150 \mathrm{~m})$ in year 2004. (D) Hourly instantaneous residence time of the $100 \mathrm{~m}$ evaluation ditch $(x=100-200 \mathrm{~m})$ in year 2004 (solid line) and monthly average residence time of the $100 \mathrm{~m}$ evaluation ditch ( $x=100-200 \mathrm{~m}$ ) in year 2004. 


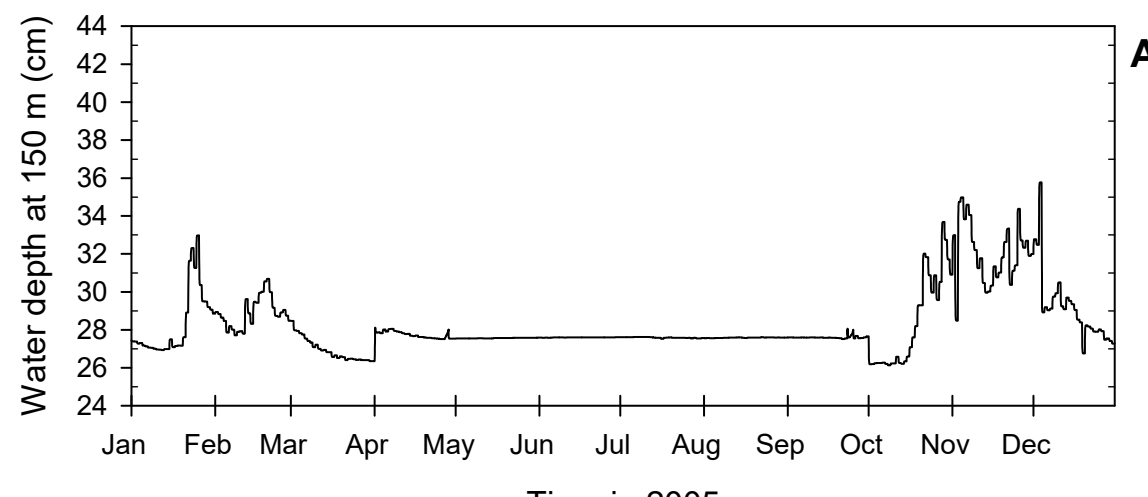

A

Time in 2005

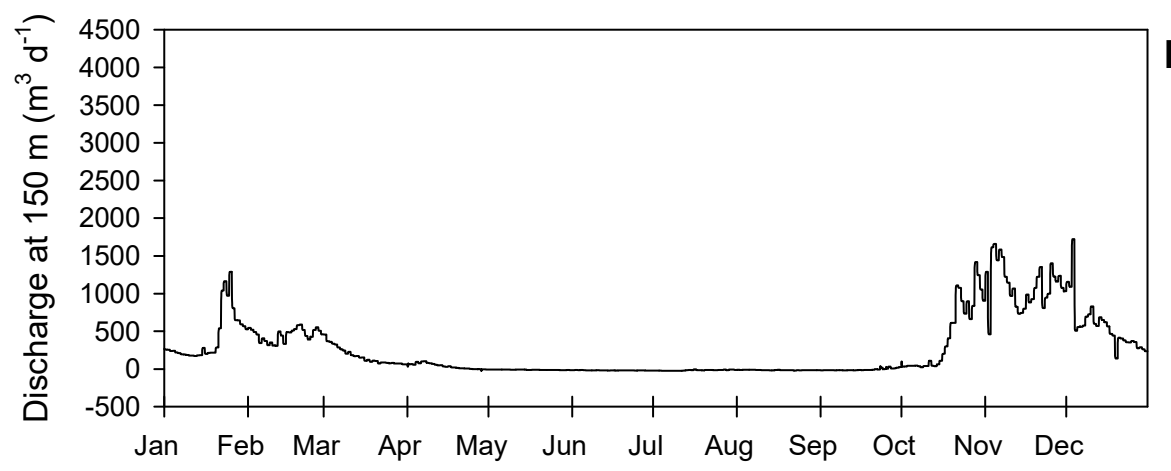

B

Time in 2005

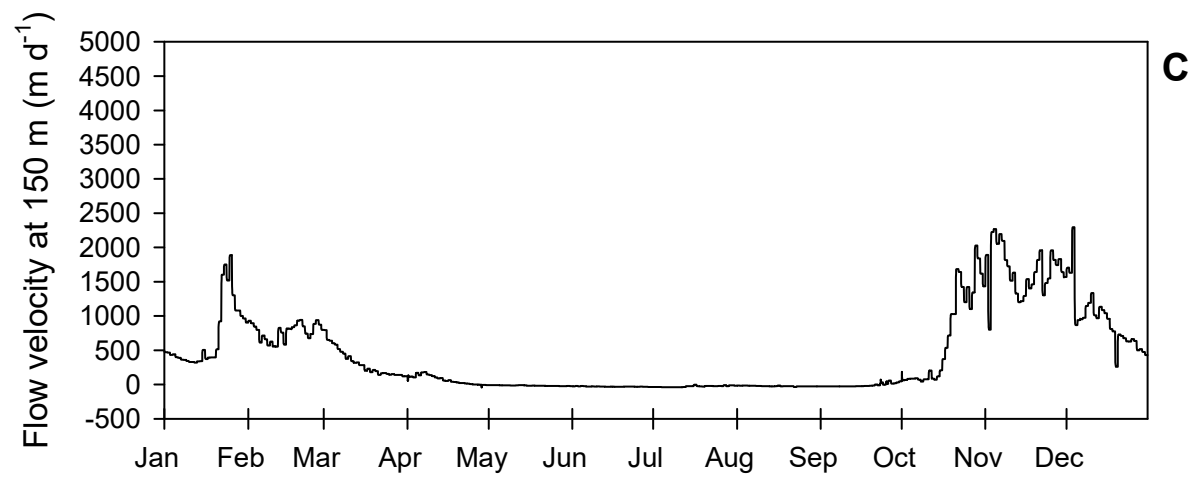

Time in 2005

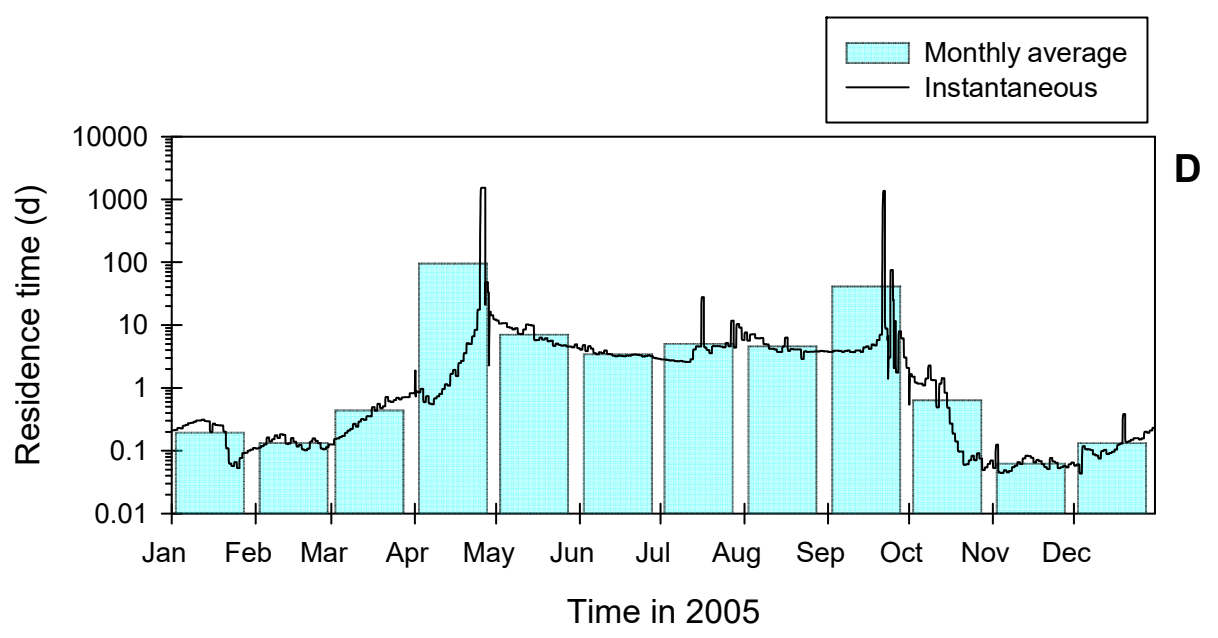

Figure A7.15 (A) Hourly water depth in the centre of the $100 \mathrm{~m}$ evaluation ditch $(x=150 \mathrm{~m})$ in year 2005. (B) Hourly discharge in the centre of the $100 \mathrm{~m}$ evaluation ditch $(x=150 \mathrm{~m})$ in year 2005. (C) Hourly flow velocity in the centre of the $100 \mathrm{~m}$ evaluation ditch $(x=150 \mathrm{~m})$ in year 2005. (D) Hourly instantaneous residence of the $100 \mathrm{~m}$ evaluation ditch $(x=100-200 \mathrm{~m})$ in year 2005 (solid line) and monthly average residence time of the $100 \mathrm{~m}$ evaluation ditch $(x=100-200 \mathrm{~m})$ in year 2005 . 


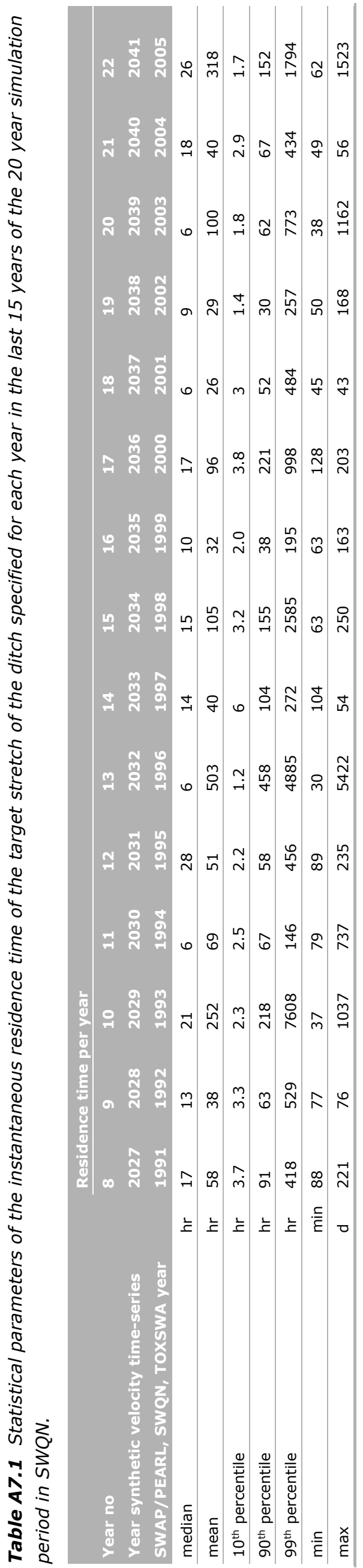

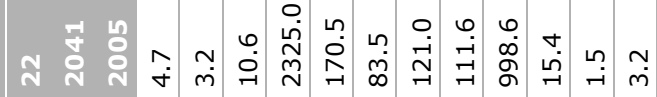

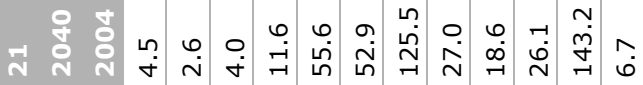

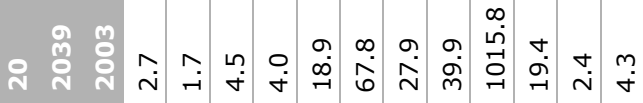

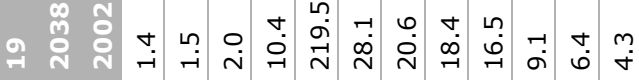

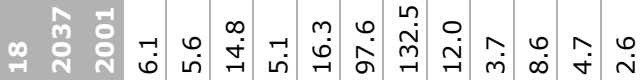

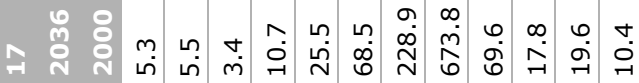

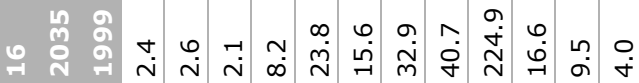

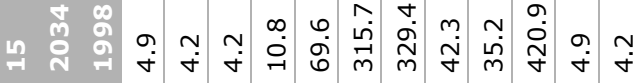

मेन

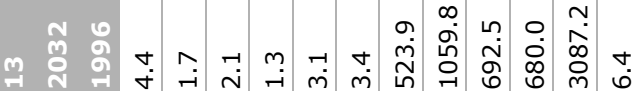

อ

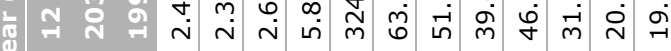

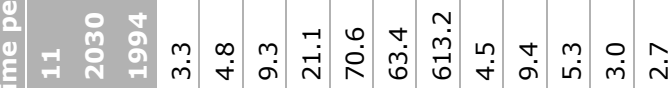

紊

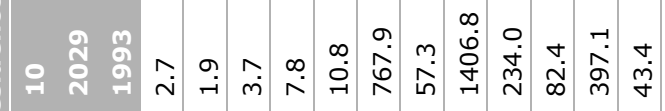

ঠ

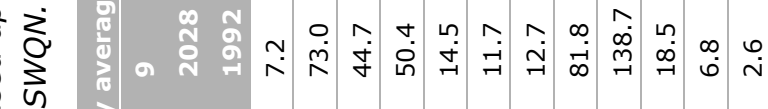
贾

है

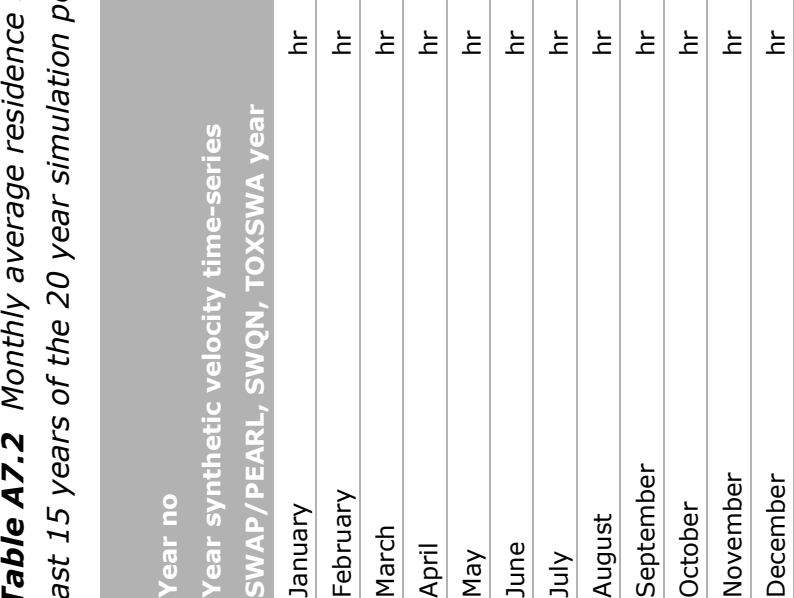




\section{Annex 8 Relation between the year numbers of the synthetic velocity time-series and those used the SWAP, PEARL, SWQN and TOXSWA simulations}

\begin{tabular}{|c|c|c|}
\hline Year number & $\begin{array}{l}\text { Years as used in for establishing the } \\
\text { synthetic velocity time-series } 27\end{array}$ & $\begin{array}{l}\text { Years as used in the SWAP/PEARL, SWQN } \\
\text { and TOXSWA simulations }\end{array}$ \\
\hline 1 & 2020 & NA \\
\hline 3 & 2022 & 1986 \\
\hline 4 & 2023 & 1987 \\
\hline 6 & 2025 & 1989 \\
\hline 7 & 2026 & 1990 \\
\hline 8 & 2027 & 1991 \\
\hline 9 & 2028 & 1992 \\
\hline 13 & 2032 & 1996 \\
\hline 14 & 2033 & 1997 \\
\hline 15 & 2034 & 1998 \\
\hline 16 & 2035 & 1999 \\
\hline 17 & 2036 & 2000 \\
\hline 18 & 2037 & 2001 \\
\hline 19 & 2038 & 2002 \\
\hline 20 & 2039 & 2003 \\
\hline 21 & 2040 & 2004 \\
\hline 27 & 2046 & NA \\
\hline
\end{tabular}




\section{Annex 9 Meteorological data as input in the TOXSWA model}

Table A9.1 shows which parameters are needed in this *.meth input file.

Table A9.1 Description of the data in the TOXSWA meteo file, *.meth.

\begin{tabular}{|c|c|c|}
\hline Description & Unit & $\begin{array}{l}\text { Parameter in } \\
\text { 'meth' ffle }\end{array}$ \\
\hline name of meteo station & - & MSTAT \\
\hline month & - & MM \\
\hline day & - & DD \\
\hline shortwave radiation, sum in hour & $\mathrm{kJ} / \mathrm{m}^{2}$ & RAD \\
\hline temperature at reference level & ${ }^{\circ} \mathrm{C}$ & $\mathrm{T}$ \\
\hline relative atmospheric humidity at reference level (relative to $1(=100 \%)$ ) & - & HUM \\
\hline cloud cover, ( $9=$ sky invisible) & octants & CLD \\
\hline evapotranspiration reference (ETref $=-99.9$ is a dummy value) & $\mathrm{mm}$ & ETref \\
\hline
\end{tabular}

For use in TOXSWA several parameters in the KNMI meteo files were converted. The conversions required are specified below.

The shortwave radiation (in $\mathrm{kJ} \mathrm{m}^{-2}$ ) needed for TOXSWA is derived from the global radiation (in $\mathrm{J} / \mathrm{cm}^{2}$ ) during the hourly division given in the KNMI file by multiplying its values by 10 .

At Herwijnen, atmospheric temperature ( $T$ ) and relative humidity (HUM) are measured at a height of $1.50 \mathrm{~m}$ (note that in TOXSWA this is the reference level $z_{r}$ to be entered in the *.txw file; see Section 3.2.1 in Beltman et al., 2017). Atmospheric temperature is given in $0.1^{\circ} \mathrm{C}$ in the KNMI file and converted to ${ }^{\circ} \mathrm{C}$ by dividing its values by 10 . The humidity data is given in percent in the KNMI file and for use in the TOXSWA *.meth converted to a fraction by dividing its values by 100 .

The covering of the sky by clouds is determined and is recorded in octants. The values given are the hourly observations in a natural day. 0,1 and 2 represent blue sky, 3, 4 and 5 partly cloudy, 6, 7 and 8 cloudy and 9 sky invisible. The octant number is translated in the meteo file to values ranging from zero (octant value is 0 ) with steps of 0.125 to 1 (octant value is 9 ).

The wind speed (WIND) was measured at a height of $10 \mathrm{~m}$ (note that in TOXSWA this is the observation level $z_{\text {obs }}$ to be entered in the *.txw file; see Section 3.2.1 of Beltman et al., 2017). Wind speed is given in $0.1 \mathrm{~m} . \mathrm{s}^{-1}$ in the KNMI file and converted to $\mathrm{ms}^{-1}$ by dividing its values by 10 .

The air pressure reduced to mean sea level, at the time of observation values in the KNMI file are given in $0.1 \mathrm{hPa}$ and are for use in TOXSWA converted to kPa by dividing its value by 100 .

Rain is given in $0.1 \mathrm{~mm}$ in the KNMI file and converted to mm by dividing its values by 10 . The so-called reference evaporation (ETref) is not used by TOXSWA at present. 
Wageningen Environmental Research P.O. Box 47

6700 AA Wageningen

The Netherlands

T +31 (0)317480700

www.wur.nl/environmental-research

Wageningen Environmental Research Report 3017

ISSN 1566-7197
The mission of Wageningen University \& Research is "To explore the potential of nature to improve the quality of life". Under the banner Wageningen University \& Research, Wageningen University and the specialised research institutes of the Wageningen Research Foundation have joined forces in contributing to finding solutions to important questions in the domain of healthy food and living environment. With its roughly 30 branches, 5,000 employees and 12,000 students, Wageningen University \& Research is one of the leading organisations in its domain. The unique Wageningen approach lies in its integrated approach to issues and the collaboration between different disciplines.

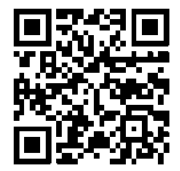




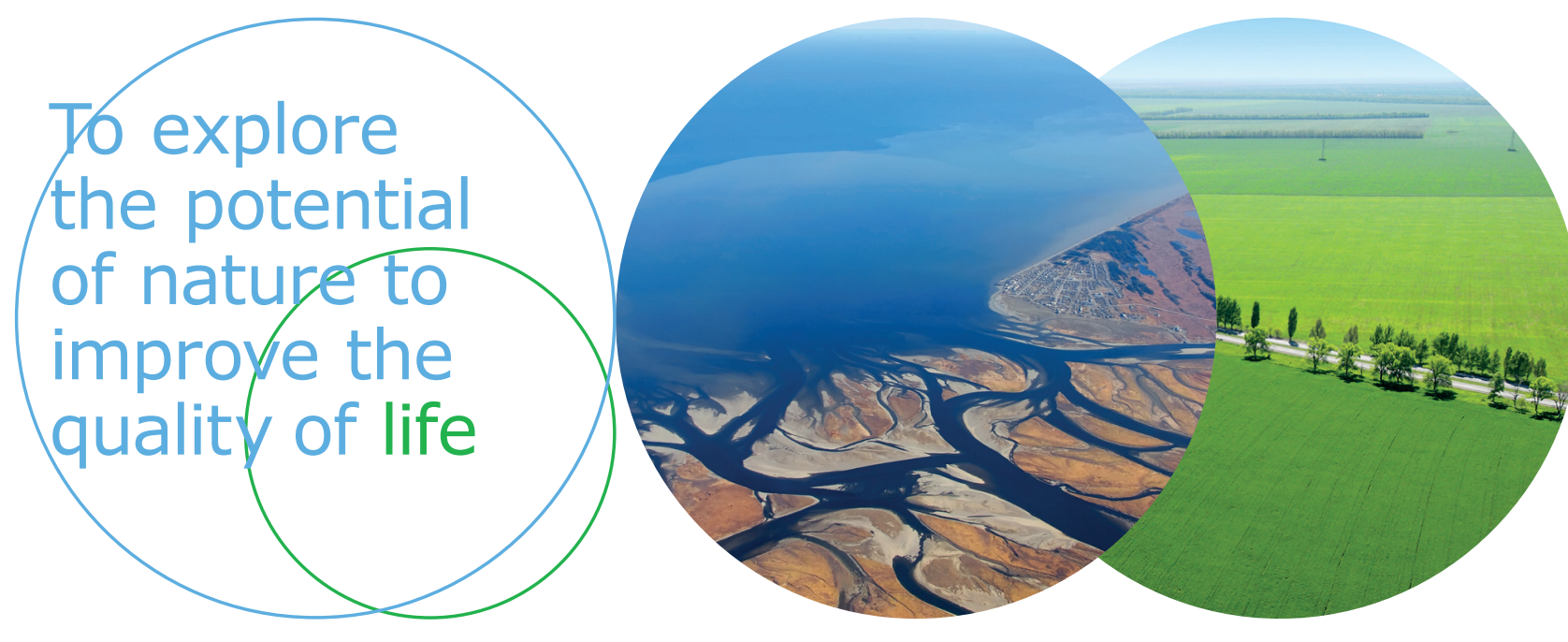

Wageningen Environmental Research P.O. Box 47

$6700 \mathrm{AB}$ Wageningen

The Netherlands

$T+31(0) 317480700$

www.wur.eu/environmental-research

Report 3017

ISSN 1566-7197

ISBN 978-94-6395-430-3
The mission of Wageningen University \& Research is "To explore the potential of nature to improve the quality of life". Under the banner Wageningen University \& Research, Wageningen University and the specialised research institutes of the Wageningen Research Foundation have joined forces in contributing to inding solutions to important questions in the domain of healthy food and living environment. With its roughly 30 branches, 5,000 employees and 12,000 students, Wageningen University \& Research is one of the leading organisations in its domain. The unique Wageningen approach lies in its integrated approach to issues and the collaboration between different disciplines. 